\title{
Atlas of new and revised high-resolution spectroscopy of six CO isotopologues in the $101-115 \mathrm{~nm}$ range
}

\section{Transition energies of the $v^{\prime}=0,1,2$, and 3 to $v^{\prime \prime}=0$ bands of the $B^{1} \Sigma^{+}, C^{1} \Sigma^{+}$, and $E^{1} \Pi$ to $X^{1} \Sigma^{+}$states, related term values, and molecular constants}

\author{
J. L. Lemaire ${ }^{1, \star}$, A. N. Heays ${ }^{2}$, M. Eidelsberg ${ }^{2}$, L. Gavilan ${ }^{3}$, G. Stark ${ }^{4}$, S. R. Federman ${ }^{5}$, \\ J. R. Lyons ${ }^{6}$, and N. de Oliveira ${ }^{7}$ \\ ${ }^{1}$ Institut des Sciences Moléculaires d'Orsay (ISMO), CNRS - Université Paris-Sud (UMR 8214), 91405 Orsay, France \\ 2 Observatoire de Paris, LERMA, UMR 8112 du CNRS, Meudon, France \\ ${ }^{3}$ Université Versailles St-Quentin, Sorbonne Universités, UPMC Paris 06, CNRS/INSU, LATMOS-IPSL, 78280 Guyancourt, France \\ ${ }^{4}$ Department of Physics, Wellesley College, Wellesley, MA 02481, USA \\ ${ }^{5}$ Department of Physics and Astronomy, University of Toledo, Toledo, OH 43606, USA \\ ${ }^{6}$ School of Earth and Space Exploration, Arizona State University, Tempe, AZ 85281, USA \\ ${ }^{7}$ DESIRS Beam Line, Synchrotron SOLEIL, Saint Aubin, France
}

e-mail: jean-louis.lemaire@u-psud.fr

Received 17 October 2017 / Accepted 15 November 2017

\begin{abstract}
Our knowledge of astronomical environments containing CO depends on accurate molecular data to reproduce and interpret observed spectra. The recent and future improvements of ultraviolet space instrumentation, both in sensitivity and resolution, require increasingly detailed laboratory molecular spectroscopy as a reference. As part of a long-term experimental campaign at the SOLEIL Synchrotron facility, we have acquired gas-phase absorption spectra of six CO isotopologues in the vacuum ultraviolet. These spectra are recorded using the Fourier-transform spectrometer installed on the DESIRS beamline, providing a unique resolving power up to $10^{6}$ in the 8-13 eV range. We have used resolutions in the 300 000-450 000 range for this campaign, which enable the analysis of individual line positions. We report new measurements on neighboring Rydberg states in the $101-115 \mathrm{~nm}$ range that could also be used as $f$-value calibrators, namely $B^{1} \Sigma^{+}, C^{1} \Sigma^{+}$, and $E^{1} \Pi$, for six CO isotopologues. This range encompasses the absorption transitions $B\left(v^{\prime}=0,1\right.$, and 2), $C\left(v^{\prime}=0,1,2\right.$, and 3), and $E\left(v^{\prime}=0,1,2\right.$, and 3$)$ from $X^{1} \Sigma^{+}\left(v^{\prime \prime}=0\right)$. Higher resolution laser-based measurements of CO isotopologues from the literature are used to improve the absolute calibration and accuracy of our data. The overall uncertainty of the great majority of the line positions presented in this atlas is estimated to be $0.01 \mathrm{~cm}^{-1}$. In addition, some of the data derived from transition energies measurements, such as term values and molecular constants, are obtained for the first time, and others are improvements on previous sparser or lower spectral resolution datasets.
\end{abstract}

Key words. molecular data - methods: laboratory: molecular - techniques: spectroscopic - techniques: interferometric

\section{Introduction}

This work is part of a larger effort to catalog, interpret, and model the photoabsorption spectrum of $\mathrm{CO}$ in the 90 $155 \mathrm{~nm}$ wavelength region. These measurements are performed at the third-generation SOLEIL synchrotron facility in SaintAubin, France. We employ the Fourier-transform spectrometer (FTS) installed on the DESIRS beam line, a unique instrument that combines high spectral resolution and a high signal-tonoise ratio $(\mathrm{S} / \mathrm{N})$ in the vacuum ultraviolet (VUV) wavelength range.

In the course of our earlier work (2008-2015) on CO photoabsorption spectroscopy in the $90-155 \mathrm{~nm}$ region, we were mainly interested in oscillator strengths and perturbations for several CO isotopologues. A large part of this work concerned the Rydberg $W-X$ bands and Rydberg complexes in the 92.5$97.5 \mathrm{~nm}$ range: Eidelsberg et al. $(2012,2014,2017)$ for ${ }^{12} \mathrm{C}^{16} \mathrm{O}$, ${ }^{13} \mathrm{C}^{16} \mathrm{O}$, ${ }^{12} \mathrm{C}^{18} \mathrm{O}$, and ${ }^{13} \mathrm{C}^{18} \mathrm{O}$, respectively, and perturbations

^ Previously at Observatoire de Paris (LERMA), France. in the $W-X$ bands (Heays et al. 2014) and the $f$-value measurements of the lowest VUV states (Stark et al. 2014), while another part dealt with the $A-X$ bands for ${ }^{13} \mathrm{C}^{16} \mathrm{O}$ (Gavilan et al. 2013) and ${ }^{13} \mathrm{C}^{18} \mathrm{O}$ (Lemaire et al. 2016). The common goal of these studies was the accurate determination of oscillator strengths, with an absolute calibration made by reference to the unperturbed $B^{1} \Sigma^{+}\left(v^{\prime}=0\right)-X^{1} \Sigma^{+}\left(v^{\prime \prime}=0\right)$ band that was previously well characterized by high-resolution $\left(0.14 \mathrm{~cm}^{-1}\right)$ laser-based measurements (Stark et al. 1999) and by synchrotron-based measurements (Federman et al. 2001). The $B^{1} \Sigma^{+}-X^{1} \Sigma^{+}$bands were already extensively investigated for four isotopologues $\left({ }^{12} \mathrm{C}^{16} \mathrm{O}\right.$, ${ }^{13} \mathrm{C}^{16} \mathrm{O},{ }^{12} \mathrm{C}^{18} \mathrm{O}$, and ${ }^{13} \mathrm{C}^{18} \mathrm{O}$ ) in both absorption and emission (Eidelsberg et al. 1987) using the Observatoire de Paris (Meudon, France) $10 \mathrm{~m}$ VUV grating spectrograph. In that work, term values were derived for the B00, B10, and B20 absorption bands. The uncertainty on the absolute wavenumbers was estimated to be $\pm 0.1 \mathrm{~cm}^{-1}$.

Throughout this paper, the notation is simplified as follows: states are designed by their symmetry (e.g., $X^{1} \Sigma^{+}$or $E^{1} \Pi$ ), while a band is denoted $E^{1} \Pi\left(v^{\prime}\right)-X^{1} \Sigma^{+}\left(v^{\prime \prime}\right)$ or for brevity $E X v^{\prime} v^{\prime \prime}$, for 
example, EX20 for $v^{\prime}=2$ and $v^{\prime \prime}=0$, or shorter: E20. The notation indicating the isotopologues is also simplified in tables and figures, where we write, for example, 1216 for ${ }^{12} \mathrm{C}^{16} \mathrm{O}$, etc.

The current investigation describes our high-resolution measurements of the $B^{1} \Sigma^{+}, C^{1} \Sigma^{+}$, and $E^{1} \Pi$ states for six $\mathrm{CO}$ isotopologues in the $101-115 \mathrm{~nm}$ range. This range encompasses the following absorption transitions: $B\left(v^{\prime}=0,1\right.$ and 2$), C\left(v^{\prime}=0\right.$, $1,2$ and 3$)$, and $E\left(v^{\prime}=0,1,2\right.$ and 3$)$ from the fundamental electronic state $X\left(v^{\prime \prime}=0\right)$.

This work revisits and completes, $25 \mathrm{yr}$ later, part of the $\mathrm{CO}$ atlas of transition frequencies started by the Paris-Meudon Observatory team (Eidelsberg et al. 1991; Le Floch 1992), and initiated by the work of Letzelter et al. (1987) and Viala et al. (1988) on the photoabsorption and photodissociation cross sections, either measured or calculated for the four isotopologues ${ }^{12} \mathrm{C}^{16} \mathrm{O},{ }^{12} \mathrm{C}^{18} \mathrm{O},{ }^{13} \mathrm{C}^{16} \mathrm{O}$, and ${ }^{13} \mathrm{C}^{18} \mathrm{O}$. It improves and completes calculations derived from the combination of earlier low-resolution measurements of term values and molecular constants of $\mathrm{B} 00$ and $\mathrm{B} 10$ for ${ }^{12} \mathrm{C}^{16} \mathrm{O}$ (Le Floch \& Amiot 1985), of $\mathrm{C} 00$ and $\mathrm{E} 00$ for ${ }^{12} \mathrm{C}^{16} \mathrm{O}$ (Le Floch 1992), and of B00, B10, C00 and E00 for ${ }^{12} \mathrm{C}^{18} \mathrm{O}$ and ${ }^{13} \mathrm{C}^{18} \mathrm{O}$ (Haridass et al. 1994). Line positions of $\mathrm{B} 20$ for ${ }^{12} \mathrm{C}^{16} \mathrm{O}$ have been studied by Baker \& Launay (1994).

This work also revisits and completes earlier experimental work at low resolution on E00 and E10 (Baker et al. 1993, 1994). Higher resolution work (Cacciani et al. 1995, 2001; Cacciani \& Ubachs 2004; Drabbels et al. 1993a,b; Ubachs et al. 1995, 2000) is discussed in detail in Sect. 2.1 as these data are used in this work for the absolute calibration of our data.

It is also worth mentioning the extensive work of Morton \& Noreau (1994), which provides a compilation of electronic transitions (including $\mathrm{BX} 00$ to $\mathrm{BX} 20, \mathrm{CX} 00$ to $\mathrm{CX} 30$, and EX00 to EX20) in the CO molecule $\left({ }^{12} \mathrm{C}^{16} \mathrm{O},{ }^{12} \mathrm{C}^{18} \mathrm{O},{ }^{13} \mathrm{C}^{16} \mathrm{O}\right.$, and ${ }^{13} \mathrm{C}^{18} \mathrm{O}$ ). Line positions are limited in this work to $J^{\prime \prime} \leq 6$. This paper includes all experimental data published up to 1994.

A first detailed model of $\mathrm{CO}$ photodissociation, based on laboratory data, including depth-dependent attenuation and isotopeselective self-shielding of photodissociation rates, was developed by van Dishoeck \& Black (1988) to model in detail, coupled with a chemical network, the structure and chemistry of a variety of interstellar clouds. This work, updated by measurements produced in the subsequent $20 \mathrm{yr}$, was revisited by Visser et al. (2009), including self- and mutual-shielding of all isotopologues (in particular, for the first time, ${ }^{12} \mathrm{C}^{17} \mathrm{O}$ and ${ }^{13} \mathrm{C}^{17} \mathrm{O}$ ) as well as shielding by atomic and molecular hydrogen.

All term values are referenced to the $X^{1} \Sigma^{+}\left(v^{\prime \prime}=0, J^{\prime \prime}=0\right)$ ground state of the respective isotopologues, according to the ground-state energy levels determined by Guelachvili et al. (1983) and Farrenq et al. (1991).

This work only reports and is based on lines that are observed and clearly identified in spectra, with the exception of the extremely congested $Q$-branches of the $E$ state (at low $J$ ) for which we report in our tables literature values obtained at very high resolution (for E00 and E10) or estimated (for E20) for the sake of completeness.

This article is organized as follows. Section 2 briefly describes the experimental setup and the analysis procedure. Section 3 presents our results: line assignments, term values, and molecular constants for each state $(B, C$, and $E)$ and bands observed. The last section presents our concluding remarks.

\section{Experimental setup and data analysis}

$\mathrm{CO}$ spectra are recorded at high resolution using the vacuumultraviolet Fourier-transform spectrometer (VUV-FTS) available on beamline DESIRS (Dichroïsme Et Spectroscopie par Interaction avec le Rayonnement Synchrotron) of the SOLEIL synchrotron. The beamline and spectrometer have been described in detail in previous publications (de Oliveira et al. 2009, 2011, 2016; Nahon et al. 2012, 2013).

Four bottles of isotopically purified gases, namely ${ }^{12} \mathrm{C}^{16} \mathrm{O}$ (Alphagaz, 99.997\%), ${ }^{12} \mathrm{C}^{18} \mathrm{O}$ (ICON Isotopes, ${ }^{18} \mathrm{O} 99 \%$ ), ${ }^{13} \mathrm{C}^{16} \mathrm{O}$ (Messer, $\left.{ }^{13} \mathrm{C} 99.1 \% ;{ }^{16} \mathrm{O} 99.95 \%\right),{ }^{13} \mathrm{C}^{18} \mathrm{O}$ (Cambridge Isotopes, $\left.{ }^{13} \mathrm{C} 99 \%,{ }^{18} \mathrm{O} 95 \%\right)$, and one bottle containing a ${ }^{12} \mathrm{C}^{16} \mathrm{O} /{ }^{12} \mathrm{C}^{17} \mathrm{O} /{ }^{12} \mathrm{C}^{18} \mathrm{O}$ mixture (ICON Isotopes, $41.5 \%, 48.5 \%$, and $9.9 \%$ respectively), are used to obtain data for five isotopologues. The presence of a sixth isotopologue, the rarely studied ${ }^{13} \mathrm{C}^{17} \mathrm{O}$, is detected as an impurity in the ${ }^{13} \mathrm{C}^{16} \mathrm{O}$ and ${ }^{13} \mathrm{C}^{18} \mathrm{O}$ bottles, and serves to complete this analysis, which provides a consistent dataset on six natural isotopologues.

Sample gases continuously flow through a $10 \mathrm{~cm}$ long windowless absorption cell that is open on both sides through capillary tubes. Most spectra are recorded at room temperature $(295 \mathrm{~K})$, but a few are obtained with the central part of the cell cooled by liquid nitrogen; this results in a gas temperature of $90 \pm 5 \mathrm{~K}$. In some cases, these cooled spectra are useful for improved line assignations by reducing the number of lines in a spectrum and their Doppler broadening.

A total of 69 spectra, recorded at different pressures and spectral resolutions, were analyzed for this work (amounting to 3327 individual lines). The analysis was performed line by line, determining the line positions by modeling them as Gaussian or Voigt functions (for $\sim 97 \%$ of the cases), and at times extracting them from simulations of the spectra of blended lines. In order to improve the accuracy, the present results rely on up to four different records for a given band and a given isotopologue. The bands observed in this work are reported in Table 1.

A key element of this work is the need for absolute wavelength calibration. The first step in the calibration procedure is provided by the FTS team. In summary, the raw FTS interferogram data based on the accurate measurement of the mirror displacement are first phase-corrected and then Fourier-transformed into a frequency spectrum. The resulting spectra are frequencycalibrated using atomic lines from different origins that appear in the spectra (de Oliveira et al. 2011, 2016). The accuracy of individual rovibrational lines is not only dependent on the accuracy of the absolute frequency calibration atomic lines, but also on the spectral resolution and on the strength and blendedness of each measured line. The parameters involved are the number, $N$, of independent scanning steps for a given line, which depends itself on the width, $W$, (mainly Doppler) of the measured line, and on the $\mathrm{S} / \mathrm{N}$ compared to the background continuum signal. The final accuracy of line positions, $\sigma$ in wavenumbers, reported by de Oliveira et al. (2011), is based on the empirical expression $\Delta(\sigma) \sim W /(S / N \times \sqrt{N})$ (see also their reference 20 ).

Lemaire et al. (2016) reported line positions determined from VUV-FTS spectra with a relative accuracy better than $\sim \pm 0.008 \mathrm{~cm}^{-1}$ at $87000 \mathrm{~cm}^{-1}$ (or $\sim \pm 0.01 \mathrm{pm}$ at $115 \mathrm{~nm}$ ). A comparison of wavenumber measurements of common sets of lines from multiple independent spectra is consistent with this estimated accuracy.

Two methods were used to place all spectra on a unique wavelength scale. First, more than 30 atomic lines (mainly Xe $\mathrm{I}, \mathrm{Kr} \mathrm{I}$, and sometimes $\mathrm{O}$ I) present in the studied range were 
Table 1. Summary of bands measured at high resolution.

\begin{tabular}{cccccccccccccc}
\hline \hline State & $X^{1} \Sigma^{+}$ & \multicolumn{3}{c}{$B^{1} \Sigma^{+}$} & \multicolumn{1}{c}{$C^{1} \Sigma^{+}$} & \multicolumn{1}{c}{$E^{1} \Pi$} \\
\hline Band & $X$ & & $B X$ & \multicolumn{1}{c}{$C X$} & \multicolumn{1}{c}{$E X$} \\
\hline$v^{\prime}-v^{\prime \prime}$ & $v=0$ & 00 & 10 & 20 & 00 & 10 & 20 & 30 & 00 & 10 & 20 & 30 \\
\hline Isotopologue & & & & & & & & & & & & \\
\hline${ }^{12} \mathrm{C}^{16} \mathrm{O}$ & $*$ & $\checkmark$ & $\checkmark$ & $\checkmark$ & $\checkmark$ & $\checkmark$ & $\checkmark$ & $\checkmark$ & $\checkmark$ & $\checkmark$ & $\checkmark$ & $\checkmark$ \\
${ }^{12} \mathrm{C}^{17} \mathrm{O}$ & $*$ & $\checkmark$ & $\checkmark$ & no & $\checkmark$ & $\checkmark$ & no & $\checkmark$ & $\checkmark$ & $\checkmark$ & $\checkmark$ & $\checkmark$ \\
${ }^{12} \mathrm{C}^{18} \mathrm{O}$ & $*$ & $\checkmark$ & $\checkmark$ & $\checkmark$ & $\checkmark$ & $\checkmark$ & $\checkmark$ & $\checkmark$ & $\checkmark$ & $\checkmark$ & $\checkmark$ & $\checkmark$ \\
${ }^{13} \mathrm{C}^{16} \mathrm{O}$ & $*$ & $\checkmark$ & $\checkmark$ & $\checkmark$ & $\checkmark$ & $\checkmark$ & $\checkmark$ & $\checkmark$ & $\checkmark$ & $\checkmark$ & $\checkmark$ & $\checkmark$ \\
${ }^{13} \mathrm{C}^{17} \mathrm{O}$ & $*$ & $\checkmark$ & $\checkmark$ & no & $\checkmark$ & $\checkmark$ & no & no & $\checkmark$ & $\checkmark$ & no & no \\
${ }^{13} \mathrm{C}^{18} \mathrm{O}$ & $*$ & $\checkmark$ & $\checkmark$ & $\checkmark$ & $\checkmark$ & $\checkmark$ & $\checkmark$ & $\checkmark$ & $\checkmark$ & $\checkmark$ & $\checkmark$ & $\checkmark$ \\
\hline
\end{tabular}

Notes. $\checkmark$ : observed, no: not observed. * are data calculated from Farrenq et al. (1991).

Table 2. References to the high-resolution calibration band or lines used (reference labels sorted by publication dates are given at the bottom of the table).

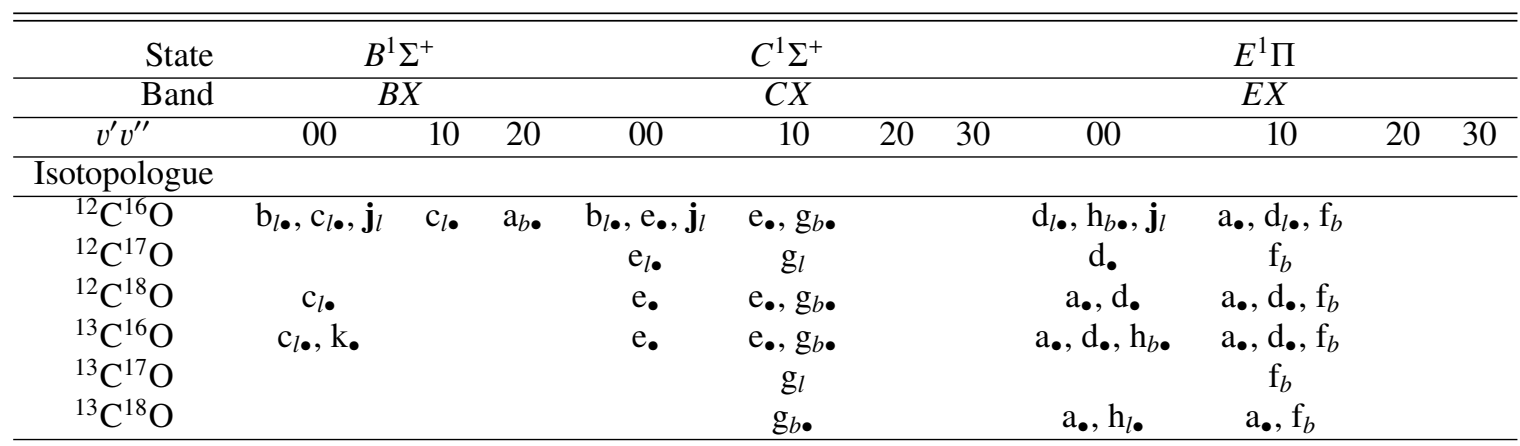

Notes. References providing data for bands with fewer than about ten lines are indexed with $l$ and for more than ten lines with $b$. References providing term values and/or molecular constants are indexed with a filled blue dot.

References. a: Baker et al. (1993, 1994); Baker (1994). b: Drabbels et al. (1993a). c: Drabbels et al. (1993b). d: Cacciani et al. (1995). e: Ubachs et al. (1995). f: Ubachs et al. (2000). g: Cacciani et al. (2001). h: Cacciani \& Ubachs (2004). j: Daprà et al. (2016). k: Niu et al. (2016).

used with reference frequencies taken from the NIST atomic lines database ${ }^{1}$. The presence of these gases is due to unintentional minor contamination or to a column of rare gas introduced on the beamline intended to filter out high-frequency harmonics generated in the undulator. Most of these lines have been measured with an accuracy of $10^{-3} \mathrm{~nm}$ and some with an accuracy of up to $10^{-6} \mathrm{~nm}$. These latter are O I: $115.21512 \mathrm{~nm}$ (Kaufman \& Edlén 1974), Xe I: 106.125564 nm, 105.612829 nm, 104.383497 nm (Yoshino \& Freeman 1985; Brandi et al. 2001), and Kr I: $100.1060639 \mathrm{~nm}$ (Brandi et al. 2002). The positions of these lines are shown in Fig. 1.

Second, the random error associated with calibrating the wavenumber scale via a small number of atomic transitions can sometimes be improved upon by including reference data for molecular lines. For this aim, high-resolution laser measurements of some CO lines (and isotopologues) available in the literature were employed (Cacciani et al. 1995, 2001; Cacciani \& Ubachs 2004; Drabbels et al. 1993a,b; Ivanov et al. 2008; Philip et al. 2004; Ubachs et al. 1994, 1995, 2000, and recently Daprà et al. 2016). Most of these measurements, obtained by narrowband laser spectroscopy in one- or two-photon experiments, rely on the $I_{2}$ - or $\mathrm{Te}_{2}$-saturation spectrum as primary absolute calibrators, associated with the marks of an actively stabilized Fabry-Pérot étalon. They are summarized in the next subsection (in alphabetical order) and are cited in the corresponding sections.

\footnotetext{
1 http://physics.nist.gov/PhysRefData/ASD/lines_form. html
}

To overcome the lack of calibration data for some bands, we considered the overlapping regions of contiguous scans. A given setting of the undulator delivers a quasi-Gaussian beam profile of width $\sim 5 \mathrm{~nm}$ at $1 / e$ of the peak signal. An absorption scan encompasses about 3-5 bands, as can be seen in Fig. 1. With the right choice of undulator settings, we were able to measure at least three bands in a single scan. In this way, a band with no calibration reference can be surrounded by two bands subject to accurate calibration, for instance, the B20 band surrounded by the $\mathrm{B} 10$ and $\mathrm{C} 00$ bands.

The final accuracy of our measurements also relied upon isotopologue cross calibrations. These were obtained through mixed isotopologue samples (as is the case for the available ${ }^{12} \mathrm{C}^{16} \mathrm{O}-{ }^{12} \mathrm{C}^{17} \mathrm{O}$ bottle, which contains some small amount of ${ }^{12} \mathrm{C}^{18} \mathrm{O}$, and as in the case of ${ }^{13} \mathrm{C}^{17} \mathrm{O}$, which was present as an impurity in ${ }^{13} \mathrm{C}^{16} \mathrm{O}$ and ${ }^{13} \mathrm{C}^{18} \mathrm{O}$ bottles). Even with pure gas samples, isotopologue impurities may show up in spectra that were recorded at high pressures. We also prepared and used on purpose mixed isotopologue samples allowing for such cross calibrations.

It is worth noting that more data were collected for this work than are included in papers dedicated to oscillator strength measurements. Those are restricted in pressure range and consequently in number of lines observed, in order to keep optical depths $<1.5$, or absorption lower than $78 \%$, for the accurate determination of oscillator strengths. For this study we used higher pressures in order to observe high $J^{\prime}$ levels and isotopologues present in small amounts. As described above, we also use cooled gases to remove possible ambiguities. 


\subsection{Laser calibration benchmarks and associated data}

An absolute calibration of lines requires the availability of accurately determined standards, either atomic or molecular, as close as possible to the lines under study. There are many reported laser-based measurements of CO VUV transitions with accurate absolute calibrations based on primary standards. Some previous work has been limited to a few lines of each vibrational band, while others offer almost complete bands for use as comparisons for calibration purposes. Data like this exist for most $\mathrm{CO}$ isotopologues. They are summarized in detail in this section.

Reports of laser-based measurements that were used to accurately calibrate our spectra often also presented an analysis of the rotational structure of the bands under study, providing associated data such as term values, reduced term values, and molecular constants. These results are also mentioned in detail in this section as they are compared later to our own results.

Depending on the data available, laser calibrated benchmarks could in some cases be derived from transitions other than the one-photon $P, R$, and $Q$ transitions of this study. When two-photon $O, S$, or $Q$ transitions were available, the corresponding one-photon transitions for the $R$ - and $P$-branches were recalculated by way of term values, taking into account that common- $J^{\prime}$ term values (TVs) of the excited state calculated from various one- and two-photon transition frequencies, that is, $\operatorname{TV}\left(O_{J^{\prime}=i \leftarrow J^{\prime \prime}=i+2}\right), \operatorname{TV}\left(P_{J^{\prime}=i \leftarrow J^{\prime \prime}=i+1}\right), \operatorname{TV}\left(Q_{J^{\prime}=i \leftarrow J^{\prime \prime}=i}\right)$, $\operatorname{TV}\left(R_{J^{\prime}=i \leftarrow J^{\prime \prime}=i-1}\right)$, and $\operatorname{TV}\left(S_{J^{\prime}=i \leftarrow J^{\prime \prime}=i-2}\right)$, have to be equal.

We summarize below all references providing laser calibration benchmarks that were used for this work, as well as the associated data mentioned above. They are sorted by alphabetical order of authors. With the exception of the first laser high-resolution measurements (Baker et al. at Paris-Meudon Observatory and Drabbels et al. at Nijmegen University), the majority of $\mathrm{CO}$ molecular calibration lines used here were measured using ultra-high resolution lasers at VU University Amsterdam (Cacciani et al., Daprà et al., Ivanov et al., Niu et al., and Ubachs et al.).

Baker (1994)

This paper reports some perturbations observed in the B20 state of ${ }^{12} \mathrm{C}^{16} \mathrm{O}$ that are due to the interaction with the ${ }^{3} \Pi(\mathrm{F} 1)$ spinorbit component of the $k^{3} \Pi(0)-X^{1} \Sigma^{+}(0)$ band. Line positions and term values are given for $\mathrm{B} 20$ and $\mathrm{kX} 00$.

Baker \& Launay (1994)

This paper analyzes the $k^{3} \Pi\left(v^{\prime}=2,3\right.$ and 5$)-X^{1} \Sigma^{+}(0)$ bands, the first one perturbing the E00 band, and the last one the E10 band. Line positions and term values are given for $\mathrm{kX} 20, \mathrm{kX} 30$, and kX50.

Baker et al. (1993, 1994)

These papers provide a study of the E00 and E10 bands for four isotopologues, ${ }^{12} \mathrm{C}^{16} \mathrm{O},{ }^{13} \mathrm{C}^{16} \mathrm{O},{ }^{12} \mathrm{C}^{18} \mathrm{O}$, and ${ }^{13} \mathrm{C}^{18} \mathrm{O}$. Spectra were recorded using $2+1$ resonantly enhanced multiphoton excitation showing the five rotational branches $O, P, Q, R$, and $S$ at a resolution of $\sim 0.1 \mathrm{~cm}^{-1}$. Spectra were acquired either separately for each isotopologue or with mixtures of several, and were then separated by time of flight mass spectrometry, in order to obtain an accurate relative calibration between isotopologues. Perturbations of E10 were analyzed. Term values (for three isotopologues of E00 and four of E10) and molecular constants (for E10) are also given for the four isotopologues.

Cacciani \& Ubachs (2004)

This paper gives $Q$-branch transition frequencies of E00 [ $Q$ : $\left.J^{\prime}=1-8\right]$ for ${ }^{12} \mathrm{C}^{16} \mathrm{O}$ and $\left[Q: J^{\prime}=1-7\right]$ for ${ }^{13} \mathrm{C}^{16} \mathrm{O}$ and ${ }^{13} \mathrm{C}^{18} \mathrm{O}$. Measured and calculated transition frequencies for $\mathrm{E} 00$ of ${ }^{12} \mathrm{C}^{16} \mathrm{O}$ [up to $J^{\prime}=34$ with gaps] and ${ }^{13} \mathrm{C}^{16} \mathrm{O}$ [up to $J^{\prime}=42$ with gaps], obtained by three different experimental methods, are accessible as supplementary data.

Cacciani et al. (1995)

This paper provides a few term values for ${ }^{12} \mathrm{C}^{16} \mathrm{O}$ (the E00 band $\left[J^{\prime}=31,41\right.$, and 44] and E10 band $\left.\left[J^{\prime}=5-13\right]\right)$, focused in both cases around perturbations. Molecular constants are also determined for ${ }^{12} \mathrm{C}^{16} \mathrm{O}$ (E00 and E10), ${ }^{13} \mathrm{C}^{16} \mathrm{O}$ (E00 and E10), ${ }^{12} \mathrm{C}^{18} \mathrm{O}$ (E00 and E10), and ${ }^{12} \mathrm{C}^{17} \mathrm{O}$ (E00). Transition frequencies were tabulated in a later paper (Cacciani \& Ubachs 2004).

Cacciani et al. (2001)

This paper provides transition frequencies for $R$ - and $P$-branch lines of the $\mathrm{C} 10$ band for ${ }^{12} \mathrm{C}^{16} \mathrm{O}\left[R: J^{\prime}=0-27 ; P: J^{\prime}=1-31\right]$, ${ }^{12} \mathrm{C}^{18} \mathrm{O}\left[R: J^{\prime}=0-13 ; P: J^{\prime}=1-8,10\right],{ }^{13} \mathrm{C}^{16} \mathrm{O}\left[R: J^{\prime}=0-15 ;\right.$ $\left.P: J^{\prime}=1-5,9-20\right],{ }^{13} \mathrm{C}^{18} \mathrm{O}\left[R=J^{\prime}=0-5,8-12 ; P: J^{\prime}=1,3,5-8\right]$, and a few for ${ }^{12} \mathrm{C}^{17} \mathrm{O}\left[R: J^{\prime}=0-2 ; P: J^{\prime}=1\right]$ and ${ }^{13} \mathrm{C}^{17} \mathrm{O}[R$ : $\left.J^{\prime}=0-1,3-5 ; P: J^{\prime}=1-3\right]$. Molecular constants are also calculated for the six isotopologues, although at lower accuracy for ${ }^{12} \mathrm{C}^{17} \mathrm{O}$ and ${ }^{13} \mathrm{C}^{17} \mathrm{O}$.

Daprà et al. (2016)

This paper is mainly based on data for ${ }^{12} \mathrm{C}^{16} \mathrm{O}$ published by the Amsterdam team over several years and gives measured wavelengths (Tables 6-8; called molecular parameters) for the $R$ and $P$ (and $Q$ for E00) $J^{\prime}=0-5$ transitions of the B00, C00, and E00 bands. Their results are expressed with an accuracy of up to the sixth digit (in nanometers) and an error bar of between 3 and 13 in units of this digit. The restriction to the lowest rotational states $\left(J^{\prime} \leq 5\right)$ is due to the fact that this paper is aimed at the comparison with quasar observations. These data are the most accurate to date. They result from measurements and not from calculations, as can be deduced from the fact that term values for a given level, determined through the $R$ - and $P$-branches, are not strictly equal.

Drabbels et al. (1993a)

This paper reports observed transition frequencies for ${ }^{12} \mathrm{C}^{16} \mathrm{O}$ of the $Q$ - and $S$-branch lines of B00 [ $J^{\prime}=0-14$ for $Q$ and $0-1$ for $S$ ] and of C00 [ $J^{\prime}=0-6$ for $Q$ and $0-1$ for $\left.S\right]$. Corresponding molecular constants are also calculated from these data.

Drabbels et al. (1993b) This paper completes the previous paper with additional measurements of $Q$ lines for B10 $\left[J^{\prime}=0\right.$ $2]$, for ${ }^{13} \mathrm{C}^{16} \mathrm{O} \mathrm{B} 00\left[J^{\prime}=0-2\right]$, and for ${ }^{12} \mathrm{C}^{18} \mathrm{O}$ B00 $\left[J^{\prime}=0-1\right]$. There is also a slight revision of ${ }^{12} \mathrm{C}^{16} \mathrm{O}$ B00 $\left[J^{\prime}=0-4\right.$ for $Q$ and $0-1$ for $S$ ], but as this paper was submitted earlier than the previous paper, it is not clear which should be considered as the more accurate.

Molecular constants are calculated for these four bands.

Ivanov et al. (2008)

This paper reports "extreme-ultraviolet laser metrology of O I transitions" (about 20 lines in the 94.86-102.82 nm range) that are used for absolute calibration purposes, when oxygen is present, for E20 and higher energy states.

Niu et al. (2016)

While focused on the spectroscopy and perturbation analysis of the $A^{1} \Pi(v=0)$ state of ${ }^{13} \mathrm{C}^{16} \mathrm{O}$, this paper provides deperturbed molecular constants for $\mathrm{B} 00$.

Ubachs et al. (1994)

This paper summarizes the work performed in the 91.2-115 nm range by the Amsterdam and Nijmegen teams over several years, reporting molecular constants for many states of four isotopologues and, of relevance to the present work, for ${ }^{12} \mathrm{C}^{16} \mathrm{O}(\mathrm{B} 00$, $\mathrm{B} 10, \mathrm{C} 00),{ }^{13} \mathrm{C}^{16} \mathrm{O}$ (B00), and ${ }^{12} \mathrm{C}^{18} \mathrm{O}$ (B00).

Ubachs et al. (1995)

This is a laser spectroscopic study of ${ }^{12} \mathrm{C}^{17} \mathrm{O}$ (observed here for the first time) $R$ - and $P$-branch lines of C00 $\left[J^{\prime}=10-17\right.$ for $R$ and $10-15$ for $P$ ] and derived molecular constants. The latter are also 
given for $\mathrm{C} 00$ and $\mathrm{C} 10$ for ${ }^{12} \mathrm{C}^{16} \mathrm{O},{ }^{13} \mathrm{C}^{16} \mathrm{O}$, and ${ }^{12} \mathrm{C}^{18} \mathrm{O}$, but no transition frequencies are available.

Ubachs et al. (2000)

This paper reports the transition frequencies of E10 for six isotopologues. For ${ }^{12} \mathrm{C}^{16} \mathrm{O}\left[R: J^{\prime}=0-26\right.$ with three gaps; $Q$ : $J^{\prime}=8-21$ with two gaps; $P: J^{\prime}=5-28$ with three gaps], ${ }^{12} \mathrm{C}^{18} \mathrm{O}$ $\left[R: J^{\prime}=0-11 ; Q: J^{\prime}=8-13\right.$ with one gap; $P: J^{\prime}=2-13$ with three gaps $],{ }^{13} \mathrm{C}^{16} \mathrm{O}\left[R: J^{\prime}=0-20\right.$ with five gaps; $Q: J^{\prime}=7-23 ; P$ : $\left.J^{\prime}=2-20\right],{ }^{13} \mathrm{C}^{18} \mathrm{O}\left[R: J^{\prime}=0-20\right.$ with two gaps; $Q: J^{\prime}=1,18$; no $P]$, a few for ${ }^{12} \mathrm{C}^{17} \mathrm{O}\left[R: J^{\prime}=0-1 ; Q: J^{\prime}=1-2\right.$; no $\left.P\right]$ and for ${ }^{13} \mathrm{C}^{17} \mathrm{O}$ [R: $J^{\prime}=0-12$ with six gaps; $\left.Q: J^{\prime}=1-12 ; P: J^{\prime}=3\right]$. The very high resolution (up to $\sim 3 \times 10^{6}$ ) achieved by a narrowband laser source allowed assigning the $Q$-branch lines with an absolute accuracy of $0.003 \mathrm{~cm}^{-1}$ for all six natural CO isotopologues. Molecular constants are also derived for the ground-state $X\left(v^{\prime \prime}=0\right)$, E10 and the perturbing k60 bands.

References to the available absolute high-resolution calibration band or lines we used are summarized in Table 2 for each band and for each isotopologue. The availability of term values and/or molecular constants derived from the laser-based measurements is also noted in the table.

We also mention the mainly theoretical work of LefèbvreBrion \& Eidelsberg (2012), which presents molecular constants $\left(T_{v}\right.$ and $\left.B_{v}\right)$ for E00, E10, E20, and E30 derived from our VUVFTS high-resolution CO datasets, extracted before the absolute wavelength calibration of this work.

\subsection{Data analysis}

\subsubsection{Atlas of measured wavelengths and wavenumbers}

In order to place the atlas on an absolute wavelength scale, we compared our measured data with the entire set of calibration references from Table 2 (including all isotopologues when available). The average of their differences provides the value of a shift that was applied to correct the raw experimental wavelengths. As proof of the accuracy of the data delivered by the VUV-FTS team, this correction was usually very small $\left(<3.4 \times 10^{-5} \mathrm{~nm}\right.$ or $\left.0.03 \mathrm{~cm}^{-1}\right)$. Two sets of measured transition energies (including calibration shift corrections from the wavelength standards), $R_{m s}$ and $P_{m s}$, corresponding to the $R$ - and $P$-branches (and additionally $Q_{m s}$ for ${ }^{1} \Pi$ states), were the result from this procedure.

In order to check the quality of our transition energy determinations, we compared for each $J^{\prime}$ the values of

$$
\begin{aligned}
& A=R_{\left(J^{\prime}=i+1 \leftarrow J^{\prime \prime}=i\right)}-P_{\left(J^{\prime}=i+1 \leftarrow J^{\prime \prime}=i+2\right)} \text { to those of } \\
& B=X_{J^{\prime \prime}=i+2}-X_{J^{\prime \prime}=i},
\end{aligned}
$$

according to the method of combination differences (Herzberg et al. 1950). For each band and for each $J^{\prime}$, we calculated the difference $A-B$ between these two quantities, which we defined as $2 \times \delta_{P}$.

These differences lead to uncertainties in the term values $\mathrm{TV}_{R}$ and $\mathrm{TV}_{P}$. Some publications interested in precise term values shared equally for each $J^{\prime}$ the difference between $\mathrm{TV}_{R}$ and $\mathrm{TV}_{P}$ (or between $R$ and $P$, in order to calculate corrected transition energies $R_{\text {corr }}=\left(R_{m s}-\delta_{P}\right)$ and $P_{\text {corr }}=\left(P_{m s}+\delta_{P}\right)$, which produces a single best-term value based on both lines. We did not follow this procedure here, but kept the measured values.

\subsubsection{Atlas of term values and molecular constants}

For each measured band, we used the line positions of $R$ - and $P$-branch lines that terminate on the same upper rotational levels to calculate common upper-level term values with uncertainties.
The agreement of the term values calculated from independently measured $P$ - and $R$-branch transitions with a common upper $J$-level, $\mathrm{TV}_{R}$, and $\mathrm{TV}_{P}$, is never perfect because of experimental noise and in some cases line broadening. However, as we described above, the excellent reproducibility of the measurements obtained with the VUV-FTS for a given band and a given isotopologue from spectra recorded at different times suggests that when the discrepancy is larger than the random fitting errors, it reveals the possible presence of a local perturbation that modifies the shape of one of the lines involved. For each $J^{\prime}=i+1$ level, the final term value was obtained by averaging the term values $\mathrm{TV}_{R}=R_{J^{\prime}=i+1 \leftarrow J^{\prime \prime}=i}+X_{J^{\prime \prime}=i}$ and $\mathrm{TV}_{P}=P_{J^{\prime}=i+1 \leftarrow J^{\prime \prime}=i+2}+X_{J^{\prime \prime}=i+2}$ that were calculated from measured line positions of each rotational branch, $R_{m s}$ and $P_{m s}$. The relative difference is again $2 \times \delta_{P}$. As a final result, $R_{m s}, P_{m s}$ and $\delta_{P}$ values are tabulated for each band and isotopologue. Both $R_{m s}$ and $P_{m s}$ are given in wavelengths and wavenumbers (and $\delta_{P}$ in wavenumbers), and are presented in separate tables for ${ }^{12} \mathrm{C}$ - and ${ }^{13} \mathrm{C}$-bearing $\mathrm{CO}$ species.

Term values of the upper levels for all six isotopologues were derived from these two independent measurements. They are presented in separate tables for each band. while reduced term values are shown with graphs for better visualization. We must be careful for high $J^{\prime}$ term values in two specific cases: (a) a high value of $\delta_{P}$ (we adopted in this work a limit of $0.125 \mathrm{~cm}^{-1}$ ) might mean that one of the lines is less well identified than the other (or does not belong to the studied band), even if the two $R$ and $P$ lines are both clearly observed, and (b) no $\delta_{P}$ value indicates that only one transition is present, either $R$ or $P$. In the first case, we kept the TV derived from a single level, while in the second case, erratic TV values had to be rejected. All these tables and graphs are introduced for each state in the following sections.

For each band and isotopologue, the statistical uncertainty on term values was obtained by calculating over all $J^{\prime}$, when both $R$ and $P$ levels were measured, the average and standard deviation (at $2 \sigma$ ) of $2 \times \delta_{P} / 2$. The division by a factor of two takes into account that each term value results from two independent measurements $\left(R_{m s}\right.$ and $\left.P_{m s}\right)$ and that at least two different records (up to four in some cases, as described above) provide the same line position results. Each average is displayed in statistical tables, alongside its standard deviation (at $2 \sigma$ ), showing the dispersion in our measurements. An average closer to zero means that the $\delta_{P}$ values are randomly distributed, ensuring no bias in our measurements. A standard deviation closer to zero signifies a high probability of the absence of perturbation(s).

The molecular constants $T_{v}, B_{v}$, and $D_{v}$ were least-squares fitted to the experimental term values using a second-order polynomial. Following the above remarks, only a subset of term values was considered at times, particularly for high $J^{\prime}$ term values. Reduced term values were finally calculated for each vibrational level by subtracting a model defined by

$\operatorname{TV}(J)=T_{v}+B_{v} \times J(J+1)-D_{v} \times J^{2}(J+1)^{2}$

for the $e$-parity levels of the $B^{1} \Sigma^{+}$and $C^{1} \Sigma^{+}$sates and the $f$-parity levels of the $E^{1} \Pi$ state, while for the $e$-parity levels of $E^{1} \Pi$, the additional term

$q \times J(J+1)-q_{D} \times J^{2}(J+1)^{2}$

takes the $\Lambda$-doubling of this state into account (so that $q=B_{e}-$ $B_{f}$ and $q_{D}=D_{e}-D_{f}$, where the $e$ and $f$ subscripts refer to the parity of the considered levels). For the $E^{1} \Pi$ state, the $\Lambda$-doubling 
components can be either calculated by subtracting the molecular constants deduced from the $e$ - and $f$-parity levels, or they can be directly obtained by fitting the $\mathrm{TV}_{e}-\mathrm{TV}_{f}$ differences for each level to a second-order polynomial. The results of both methods are presented in Sect. 3.5. Their values were graphically compared according to their oxygen isotopic content to check for anomalies that are due to perturbations. In almost every case, our molecular constants were generated by much larger datasets than those referenced in Sect. 2.1 (see also Table 2).

It is worth noting that the lines in the $R$ - and $P$-branches are in general not observed up to the same $J^{\prime}$. It is also possible, in the case of high-pressure spectra, that some lines observed at high $J^{\prime}$ values belong to a weak unidentified underlying band. As a consequence, some reduced term value graphs could present a break or jump for the last higher $J^{\prime}$ values. This break, however, could correspond in some cases to a real perturbation.

\section{Results and discussion}

The results presented here constitute the first part of an atlas of the Rydberg states at wavelengths below $115 \mathrm{~nm}$ for six isotopologues of CO. They update and complete the previous CO atlas at the higher resolution provided by the VUV-FTS coupled to the SOLEIL synchrotron (Eidelsberg et al. 1991; for revised band origin wavenumbers, see Eidelsberg et al. 1992). They also fill some gaps and provide higher $J^{\prime}$ lines that were previously not observed with high-resolution laser methods.

In addition to the atlas of absolute wavelengths and wavenumbers for the $B, C$, and $E$ states of the six $C O$ isotopologues, we provide for the derived term value atlas for each observed band. As a further step, we calculate reduced term values and molecular parameters. The latter are compared according to their oxygen isotopic content, and when possible, with previous determinations.

Figure 1 shows the bandhead wavelengths of the states and bands studied in this work. Table 1 summarizes the measured bands for each isotopologue. Some isotopologue bands are not recorded because of the combination of low oscillator strengths and low available pressures or partial pressures. Low partial pressure is particularly a problem in the case of ${ }^{13} \mathrm{C}^{17} \mathrm{O}$, which is observed as a minor contaminant in high-pressure spectra of both ${ }^{13} \mathrm{C}^{16} \mathrm{O}$ and ${ }^{13} \mathrm{C}^{18} \mathrm{O}$.

For all ${ }^{12} \mathrm{C}$ (or ${ }^{13} \mathrm{C}$ )-bearing isotopologues, the isotope shift spacing between bandheads increases almost linearly with $v^{\prime}$ vibrational number, allowing for an easier differentiation of the lines pertaining to a given isotopologue for increasing $v^{\prime}$ and $J^{\prime}$.

\subsection{Specific cases of ${ }^{12} \mathrm{C}^{17} \mathrm{O}$ and ${ }^{13} \mathrm{C}^{17} \mathrm{O}$}

\subsection{1. ${ }^{12} \mathrm{C}^{17} \mathrm{O}$}

As ${ }^{12} \mathrm{C}^{17} \mathrm{O}$ is mixed in almost equal proportions with ${ }^{12} \mathrm{C}^{16} \mathrm{O}$ in our sample, the absolute calibration of ${ }^{12} \mathrm{C}^{17} \mathrm{O}$ transitions benefits from the absolute calibration of ${ }^{12} \mathrm{C}^{16} \mathrm{O}$ (as well as ${ }^{12} \mathrm{C}^{18} \mathrm{O}$, which is also present in a small amount).

\subsection{2. ${ }^{13} \mathrm{C}^{17} \mathrm{O}$}

The case of ${ }^{13} \mathrm{C}^{17} \mathrm{O}$ is specific because it is observed in the high-pressure spectra of either ${ }^{13} \mathrm{C}^{16} \mathrm{O}$ or ${ }^{13} \mathrm{C}^{18} \mathrm{O}$. The occurrence of the ${ }^{13} \mathrm{C}^{17} \mathrm{O}$ bands is due to isotopic contamination of the ${ }^{13} \mathrm{C}^{16} \mathrm{O}$ and ${ }^{13} \mathrm{C}^{18} \mathrm{O}$ bottles. Based on the relative strengths of identical absorption features, the ratio of the isotopologues

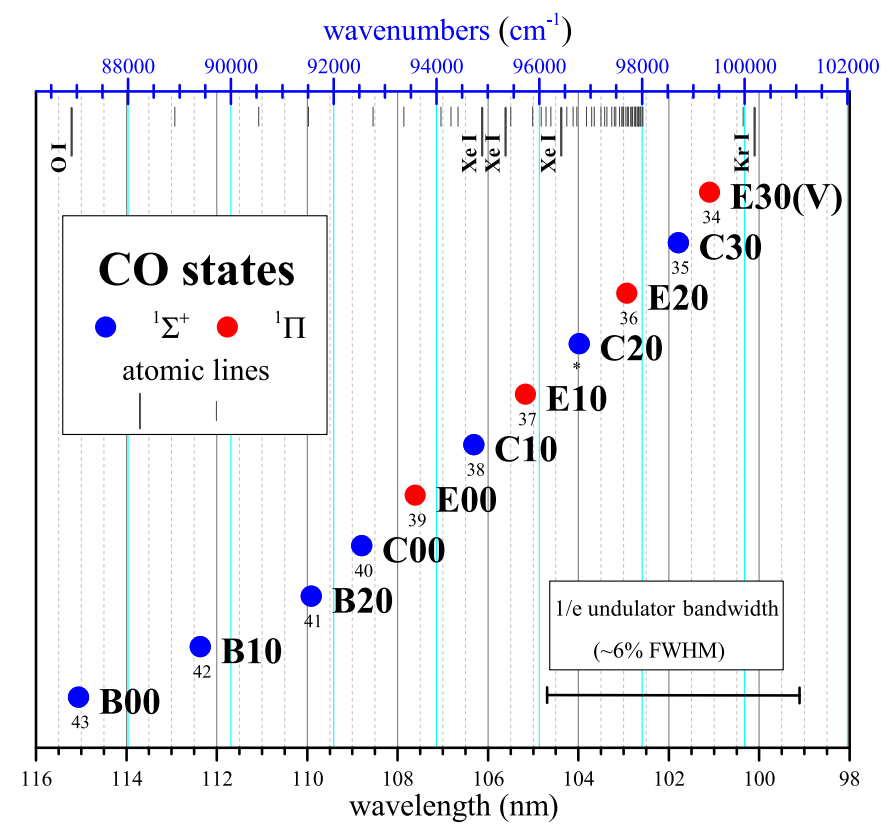

Fig. 1. Bandhead wavelengths of ${ }^{12} \mathrm{C}^{16} \mathrm{O}$ states and bands studied in this work. We also include the previously used numerical index notation (34-43) (Letzelter et al. 1987; Eidelsberg \& Rostas 1990, etc.). Atomic line calibrators are indicated with $\mid$ : for primary lines at high accuracy ( $1 \mathrm{fm}$ or better) and with $\mathrm{I}$ : for secondary lines at medium accuracy $(0.1 \mathrm{pm})$ (for the latter, mostly Xe I and a few Ar I and Kr I, see the NIST atomic line tables for identification), and the 1/e undulator bandwidth are shown as well.

in the ${ }^{13} \mathrm{C}^{16} \mathrm{O}$ gas sample, sorted by concentration, is found to be ${ }^{13} \mathrm{C}^{16} \mathrm{O}:{ }^{13} \mathrm{C}^{18} \mathrm{O}:{ }^{13} \mathrm{C}^{17} \mathrm{O}:{ }^{12} \mathrm{C}^{16} \mathrm{O}=1: 0.041: 0.073: 0: 0045$. The high $\mathrm{CO}$ pressure needed to observe the minor ${ }^{13} \mathrm{C}^{17} \mathrm{O}$ species leads to strong absorption and saturation of the main species spectrum. Combined with the fact that the isotopic shifts of $v^{\prime}=0$ bands are very small $\left(\leq 1 \mathrm{~cm}^{-1}\right.$ for $\mathrm{B} 00$ and $\mathrm{C} 00$ and $\leq 3 \mathrm{~cm}^{-1}$ for E00), ${ }^{13} \mathrm{C}^{17} \mathrm{O}$ lines for low $J^{\prime}$ are difficult to extract because of blending with saturated (broadened) lines. This effect is weaker for increasing $J^{\prime}$ because of the difference between molecular constants of the different isotopologues. ${ }^{13} \mathrm{C}^{17} \mathrm{O}$ lines of $\mathrm{B} 00$ with $J^{\prime}>2$ are measured nearly as accurately $\left(\sim 0.04 \mathrm{~cm}^{-1}\right)$ as for the main isotopologue (either ${ }^{13} \mathrm{C}^{16} \mathrm{O}$ or ${ }^{13} \mathrm{C}^{18} \mathrm{O}$ ), similarly for C00 lines with $J^{\prime}>6$. The search for low $J^{\prime}$ line positions is facilitated by considering the values extrapolated from the clearly observed high $J^{\prime}$ line levels (up to $J^{\prime}=23$ for B00, $J^{\prime}=21$ for B10, $J^{\prime}=39$ for $\mathrm{C} 10$, and $J^{\prime}=26$ for E00), which leads to an accuracy better than $0.08 \mathrm{~cm}^{-1}$ for the low $J^{\prime}$. This effect is less noticeable for $v^{\prime} \geq 1$ as the spacing of spectra bandheads of the different isotopologues increases with $v^{\prime}$.

All this concerns $R$ - and $P$-branches, but there is an additional difficulty for $Q$-branches that we consider in the $E$-state subsection.

\section{2. $X^{1} \Sigma^{+}$state}

In order to calculate the term values of all the bands presented here, high-accuracy data provided by Guelachvili et al. (1983) and Farrenq et al. (1991) were used. From their set of Dunham coefficients, rotational levels of the $v^{\prime \prime}=0 X^{1} \Sigma^{+}$ground state were calculated up to $J^{\prime \prime}=48$ with an uncertainty of $10^{-3} \mathrm{~cm}^{-1}$, which is at least as good as our own high-resolution measurements. Table 9 lists the ground-state rotational levels of the six 
J. L. Lemaire et al.: Atlas of new and revised high-resolution spectroscopy of six CO isotopologues in the 101-115 nm range

Table 3. References to table and figure numbers for the $B^{1} \Sigma^{+}$state.

\begin{tabular}{|c|c|c|c|c|}
\hline \multirow[t]{3}{*}{ Band } & \multicolumn{2}{|c|}{$\begin{array}{c}\text { Transition } \\
\text { wavelengths }\end{array}$} & \multirow{3}{*}{$\begin{array}{c}\begin{array}{c}\text { Term } \\
\text { values }\end{array} \\
\text { Table } \\
\end{array}$} & \multirow{2}{*}{$\begin{array}{c}\text { Reduced } \\
\text { TV } \\
\text { Figure }\end{array}$} \\
\hline & Tables & Figure & & \\
\hline & ${ }^{12} \mathrm{C} \quad{ }^{13} \mathrm{C}$ & & & \\
\hline $\mathrm{B} 00$ & A.1 & 2 & A.3 & 4 \\
\hline B 10 & A. 4 & 3 & A. 6 & 5 \\
\hline B20 & A. 7 & A.1 & A. 8 & A. 2 \\
\hline
\end{tabular}

isotopologues studied here, ${ }^{12} \mathrm{C}^{16} \mathrm{O},{ }^{12} \mathrm{C}^{17} \mathrm{O},{ }^{12} \mathrm{C}^{18} \mathrm{O},{ }^{13} \mathrm{C}^{16} \mathrm{O}$, ${ }^{13} \mathrm{C}^{17} \mathrm{O}$, and ${ }^{13} \mathrm{C}^{18} \mathrm{O}$. For each isotopologue, these $J^{\prime \prime}$ levels are adjusted to a ninth-order polynomial to obtain their molecular constants. They are reported in Table A.31.

For the sake of consistency between all isotopologues, we did not use the data on the ${ }^{12} \mathrm{C}^{16} \mathrm{O}$ ground state by Varberg \& Evenson (February 1992), which were published a few months after Farrenq et al. (October 1991). The latter provide data for six isotopologues, and a check on ${ }^{12} \mathrm{C}^{16} \mathrm{O} \mathrm{B} 00$ revealed a better agreement at high $J^{\prime}$ between the term values $\mathrm{TV}_{R}$ and $\mathrm{TV}_{P}$ derived for the $R$ - and $P$-branches.

\section{3. $B^{1} \Sigma^{+}$state}

The B00 and B10 bands were observed for all isotopologues, while B20 was observed for all bands except for ${ }^{12} \mathrm{C}^{17} \mathrm{O}$ and ${ }^{13} \mathrm{C}^{17} \mathrm{O}$. The lack of the $\mathrm{B} 20$ band in the ${ }^{12} \mathrm{C}^{17} \mathrm{O}$ spectra is explained by the low pressure used in scans of this isotopologue. For ${ }^{13} \mathrm{C}^{17} \mathrm{O}$, the absence is due to the combination of a very low partial pressure and the decreasing oscillator strength with $v^{\prime}$.

A total of $19 \mathrm{CO}$ laser-calibrated lines ( 14 for ${ }^{12} \mathrm{C}^{16} \mathrm{O}, 2$ for ${ }^{12} \mathrm{C}^{18} \mathrm{O}$, and 3 for ${ }^{13} \mathrm{C}^{16} \mathrm{O}$ ) were used to determine a shift correction of $-7.5 \times 10^{-6} \mathrm{~nm}\left(0.006 \mathrm{~cm}^{-1}\right)$ for B00 and 3 lines for B10, resulting in a shift correction of $-1.2 \times 10^{-5} \mathrm{~nm}\left(0.0095 \mathrm{~cm}^{-1}\right)$. These low values attest to the accuracy of our measurements. These corrections were applied to all isotopologues as their spectra are placed, as mentioned above, on a unique scale. Our term values are consistent within the uncertainty with those calculated by Le Floch \& Amiot (1985) and Haridass et al. (1994), the latter resulting from the combination of $B-A$ data with highresolution $A-X$ data obtained with the former Ottawa $10.6 \mathrm{~m}$ vacuum-grating spectrograph. For ${ }^{12} \mathrm{C}^{16} \mathrm{O} \mathrm{B} 00$, the average difference between our values and the Daprà et al. (2016) values is $5.0 \times 10^{-6} \mathrm{~nm}$.

For ${ }^{12} \mathrm{C}^{17} \mathrm{O}$, the present results complete a preliminary version of our B00 data that was incorporated in Hakalla et al. (2016) in order to perform the deperturbation analysis of the $A^{1} \Pi$ state of ${ }^{12} \mathrm{C}^{17} \mathrm{O}$, for which earlier optical measurements of $B-A$ and $C-A$ transitions were combined with our vacuum ultraviolet $B-X$ results. Similarly, for ${ }^{13} \mathrm{C}^{17} \mathrm{O}$, our results of $\mathrm{B} 00$ and $\mathrm{B} 10$ were used in Hakalla et al. (2017) to perform the deperturbation analysis of the $A^{1} \Pi$ state of ${ }^{13} \mathrm{C}^{17} \mathrm{O}$.

The data for ${ }^{13} \mathrm{C}^{18} \mathrm{O}$ are slightly better calibrated than in our recent paper (Lemaire et al. 2016) for B00 and B10. In addition, they are extended to higher $J^{\prime}$ levels for B 10 .

As indicated above, the B20 band was calibrated using the surrounding $\mathrm{B} 10$ and $\mathrm{C} 00$ bands, leading to a common shift correction of $+1.0 \times 10^{-5} \mathrm{~nm}\left(-0.0083 \mathrm{~cm}^{-1}\right)$ that was applied to all isotopologues. Figure A.3 illustrates for the four observed isotopologues the perturbations observed in B20 (also studied in ${ }^{12} \mathrm{C}^{16} \mathrm{O}$ and ${ }^{13} \mathrm{C}^{16} \mathrm{O}$ by Baker 1994$)$.
Table 4. Statistical uncertainty on the measured term values: $\delta_{P}$ average and std. dev. (at $2 \sigma$ ) (see Sect. 2.2.2) for the $B^{1} \Sigma^{+}$state.

\begin{tabular}{ccccc}
\hline \hline Band & Species & $N$ & $\overline{\delta_{P}}\left(\mathrm{~cm}^{-1}\right)$ & Std. dev. $\left(\mathrm{cm}^{-1}\right)$ \\
\hline B00 & 1216 & 62 & 0.000 & 0.007 \\
& 1217 & 44 & 0.007 & 0.023 \\
& 1218 & 60 & 0.003 & 0.022 \\
& 1316 & 60 & 0.011 & 0.026 \\
& 1317 & 36 & 0.001 & 0.026 \\
& 1318 & 54 & 0.002 & 0.006 \\
\hline B10 & 1216 & 60 & 0.00 & 0.02 \\
& 1217 & 30 & -0.010 & 0.033 \\
& 1218 & 52 & -0.001 & 0.009 \\
& 1316 & 54 & -0.001 & 0.013 \\
& 1317 & 40 & -0.011 & 0.027 \\
& 1318 & 38 & 0.007 & 0.010 \\
\hline B20 & 1216 & 22 & -0.003 & 0.034 \\
& 1217 & & & \\
& 1218 & 22 & 0.019 & 0.038 \\
& 1316 & 30 & -0.006 & 0.021 \\
& 1317 & & & \\
& 1318 & 30 & -0.005 & 0.032
\end{tabular}

Notes. $N$ : number of rotational transitions $(R$ and $P)$ involved in the statistics.

For ${ }^{12} \mathrm{C}^{16} \mathrm{O},{ }^{12} \mathrm{C}^{18} \mathrm{O},{ }^{13} \mathrm{C}^{16} \mathrm{O}$, and ${ }^{13} \mathrm{C}^{18} \mathrm{O}$, our absolutely calibrated data provide transition frequencies and term values for $\mathrm{B} 00, \mathrm{~B} 10$, and B20 that are consistent at slightly higher accuracy with those measured by Eidelsberg et al. (1987), which were obtained with the Observatoire de Paris (Meudon, France) $10 \mathrm{~m}$ VUV grating spectrograph. The same remark applies to the line positions obtained by Baker (1994) for B20 of ${ }^{12} \mathrm{C}^{16} \mathrm{O}$ with the same instrument.

Table 3 lists table and figure numbers associated with the BX bands. Table 4 gives the statistical uncertainty on the term values for the BX bands (see text in Sect. 2.2.2).

\section{4. $C^{1} \Sigma^{+}$state}

$\mathrm{C} 00, \mathrm{C} 10, \mathrm{C} 20$, and $\mathrm{C} 30$ were observed for ${ }^{12} \mathrm{C}^{16} \mathrm{O},{ }^{12} \mathrm{C}^{18} \mathrm{O}$, ${ }^{13} \mathrm{C}^{16} \mathrm{O}$, and ${ }^{13} \mathrm{C}^{18} \mathrm{O}$. For ${ }^{12} \mathrm{C}^{17} \mathrm{O}$, all bands were observed except for $\mathrm{C} 20$, for the same reason as for $\mathrm{B} 20$. For ${ }^{13} \mathrm{C}^{17} \mathrm{O}$, only $\mathrm{C} 00$ and $\mathrm{C} 10$ were observed; $\mathrm{C} 20$ and $\mathrm{C} 30$ are not observed for the same reason as for B20.

It is worth noting that for ${ }^{12} \mathrm{C}^{18} \mathrm{O}$, the $\mathrm{C} 30$ band does not appear in the same room-temperature spectra obtained at pressures where $\mathrm{C} 20$ is observed. It is only observed in a lowtemperature spectrum recorded at $90 \pm 5 \mathrm{~K}$, showing a limited number of $J^{\prime}$ levels.

Sixteen CO laser-calibrated lines were used to determine a shift correction of $1.3 \times 10^{-5} \mathrm{~nm}\left(-0.011 \mathrm{~cm}^{-1}\right)$ for C00. Seventytwo laser-calibrated lines were considered (not including ${ }^{12} \mathrm{C}^{17} \mathrm{O}$ and ${ }^{13} \mathrm{C}^{17} \mathrm{O}$, for which the number of lines in Cacciani et al. 2001 is limited) to determine the shift correction of $3.4 \times 10^{-5} \mathrm{~nm}$ $\left(-0.031 \mathrm{~cm}^{-1}\right)$ for $\mathrm{C} 10$.

Our term values are consistent with those calculated by Haridass et al. (1994), which were obtained from the combination of $C-A$ data with high-resolution $A-X$ data obtained with the former Ottawa spectrograph. For ${ }^{12} \mathrm{C}^{16} \mathrm{O} \mathrm{C} 00$, the average difference between our values and the values of Daprà et al. (2016) is $4.4 \times 10^{-5} \mathrm{~nm}\left(-0.037 \mathrm{~cm}^{-1}\right)$.

For $\mathrm{C} 00$, the present results complete a preliminary version of our ${ }^{12} \mathrm{C}^{17} \mathrm{O}$ data (as for $\mathrm{B} 00$ ) and provide new data on ${ }^{13} \mathrm{C}^{17} \mathrm{O}$. 


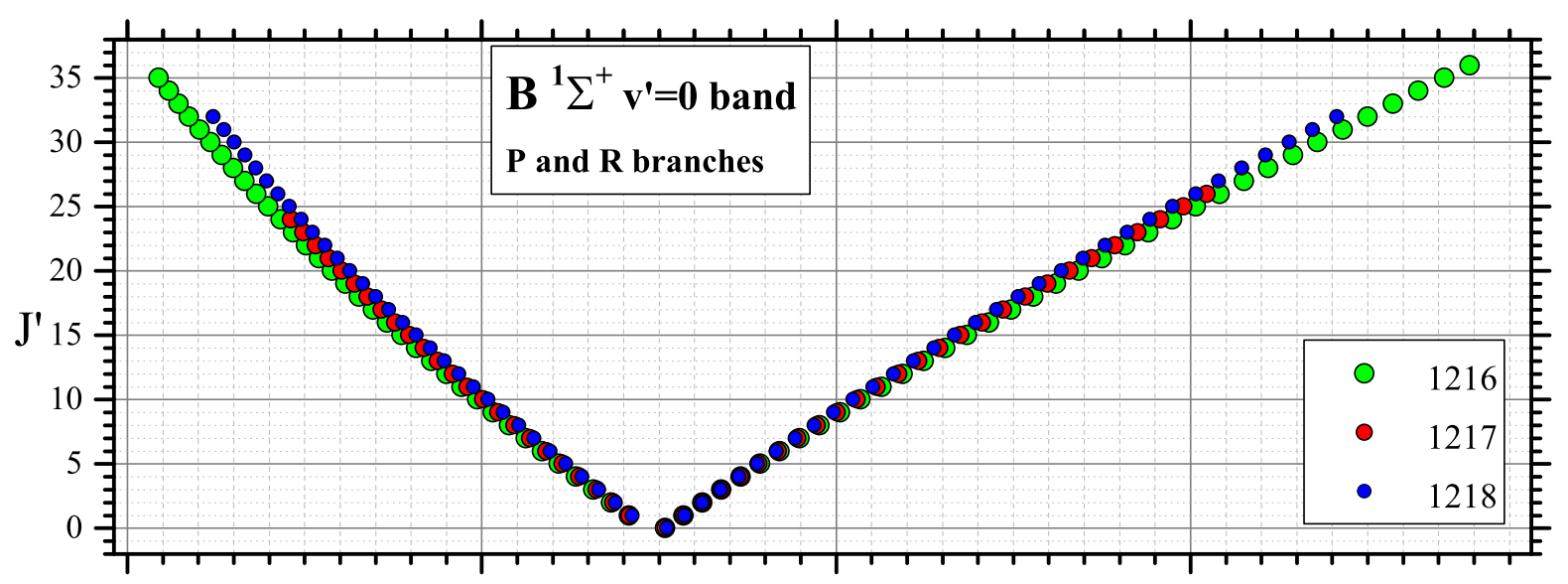
115.2
115.1
$\mathrm{nm}$
115.0
114.9

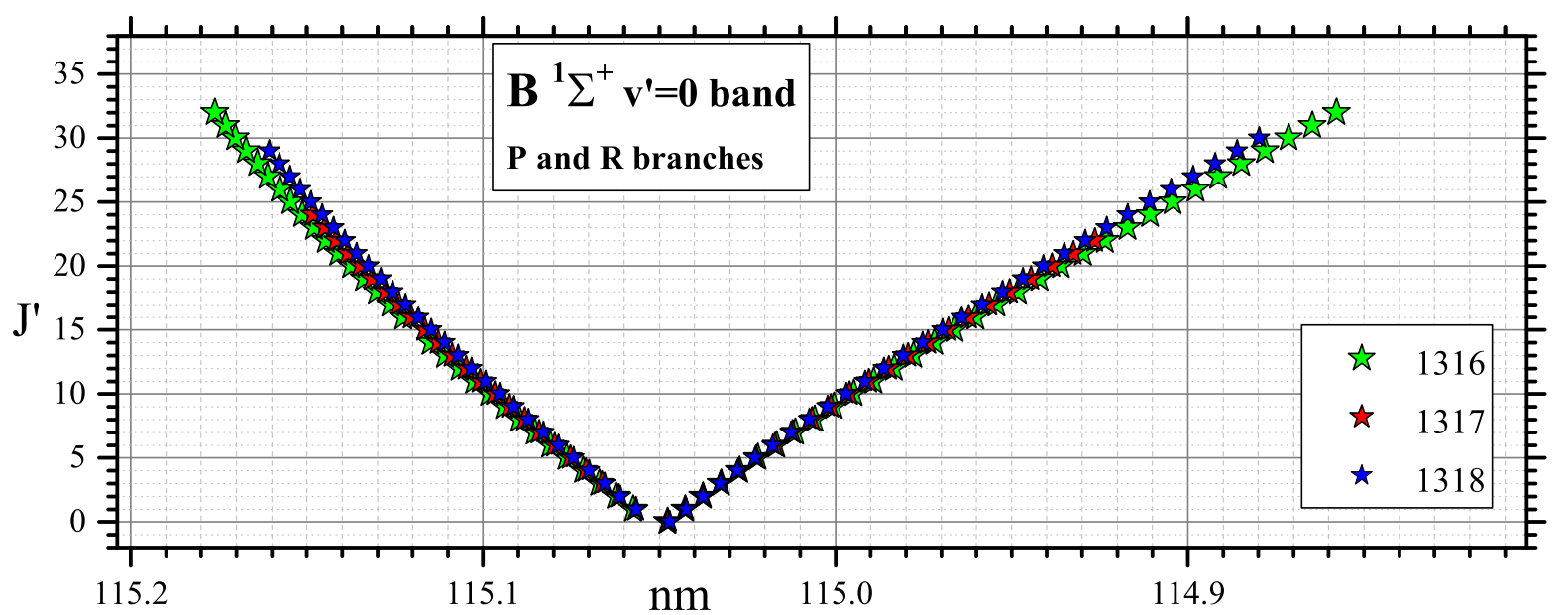

Fig. 2. Transition wavelengths of the $B^{1} \Sigma^{+}\left(v^{\prime}=0\right)-X^{1} \Sigma^{+}\left(v^{\prime \prime}=0\right)$ band for six CO isotopologues.

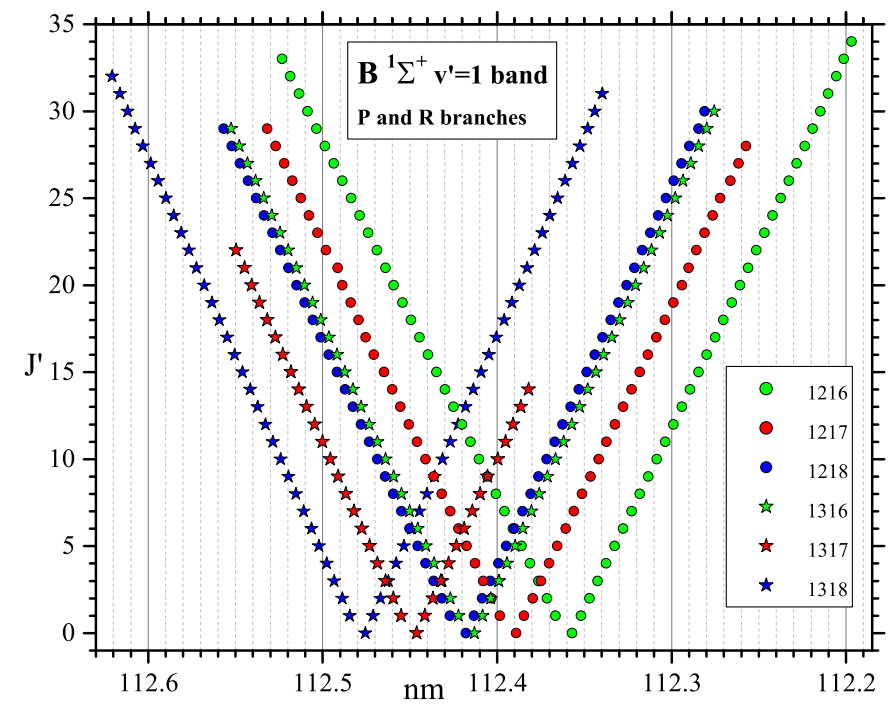

Fig. 3. Transition wavelengths of the $B^{1} \Sigma^{+}\left(v^{\prime}=1\right)-X^{1} \Sigma^{+}\left(v^{\prime \prime}=0\right)$ band for six $\mathrm{CO}$ isotopologues.

Both were used in order to perform the deperturbation analysis of the $A^{1} \Pi$ state of ${ }^{12} \mathrm{C}^{17} \mathrm{O}$ (Hakalla et al. 2016) and of ${ }^{13} \mathrm{C}^{17} \mathrm{O}$ (Hakalla et al. 2017).

As for $\mathrm{B} 00$ and $\mathrm{B} 10$, the present data for ${ }^{13} \mathrm{C}^{18} \mathrm{O}$ are slightly better calibrated and extend to higher $J^{\prime}$ levels than in our recent paper (Lemaire et al. 2016) for C00.
Table 5. References to table and figure numbers for the $C^{1} \Sigma^{+}$state.

\begin{tabular}{|c|c|c|c|c|c|}
\hline \multirow[t]{3}{*}{ Band } & \multicolumn{3}{|c|}{$\begin{array}{c}\text { Transition } \\
\text { wavelengths }\end{array}$} & \multirow{3}{*}{$\begin{array}{c}\begin{array}{c}\text { Term } \\
\text { values }\end{array} \\
\text { Table } \\
\end{array}$} & \multirow{2}{*}{$\begin{array}{c}\text { Reduced } \\
\text { TV } \\
\text { Figure }\end{array}$} \\
\hline & & & Figure & & \\
\hline & ${ }^{12} \mathrm{C}$ & ${ }^{13} \mathrm{C}$ & & & \\
\hline $\mathrm{C} 00$ & A.9 & A.10 & A.4 & A.11 & A.6 \\
\hline $\mathrm{C} 10$ & A. 12 & A.13 & A. 5 & A.14 & A.7 \\
\hline $\mathrm{C} 20$ & A. 15 & A. 15 & A. 8 & A. 16 & A. 9 \\
\hline $\mathrm{C} 30$ & A.17 & A. 17 & A.10 & A.18 & A.11 \\
\hline
\end{tabular}

The absolute calibration for $\mathrm{C} 20$ and $\mathrm{C} 30$ was obtained using the two surrounding primary atomic standards as calibrators (the Xe I line at $104.383497 \mathrm{~nm}$ for C20, and the Kr I line at $100.1060639 \mathrm{~nm}$ for C30, see Fig. 1) and checking that the numerous secondary standards (in the case of C20) are in agreement with each other (at an accuracy higher than $0.01 \mathrm{pm}$ ) for the five isotopologues.

Table 5 lists table and figure numbers associated with the $C X$ bands. Table 6 gives the statistical uncertainty on the term values for the $C X$ bands (see text in Sect. 2.2.2).

\section{5. $E^{1} \Pi$ state}

E00, E10, E20, and E30 [the latter formerly labeled as the $\mathbf{V}\left(\mathbf{A}^{2} \Pi\right){ }^{3} \Pi$ state by Eidelsberg \& Rostas (1990), with the present assignment confirmed by Lefèbvre-Brion \& Eidelsberg (2012)] were observed for all isotopologues, with the exception 
J. L. Lemaire et al.: Atlas of new and revised high-resolution spectroscopy of six CO isotopologues in the 101-115 nm range
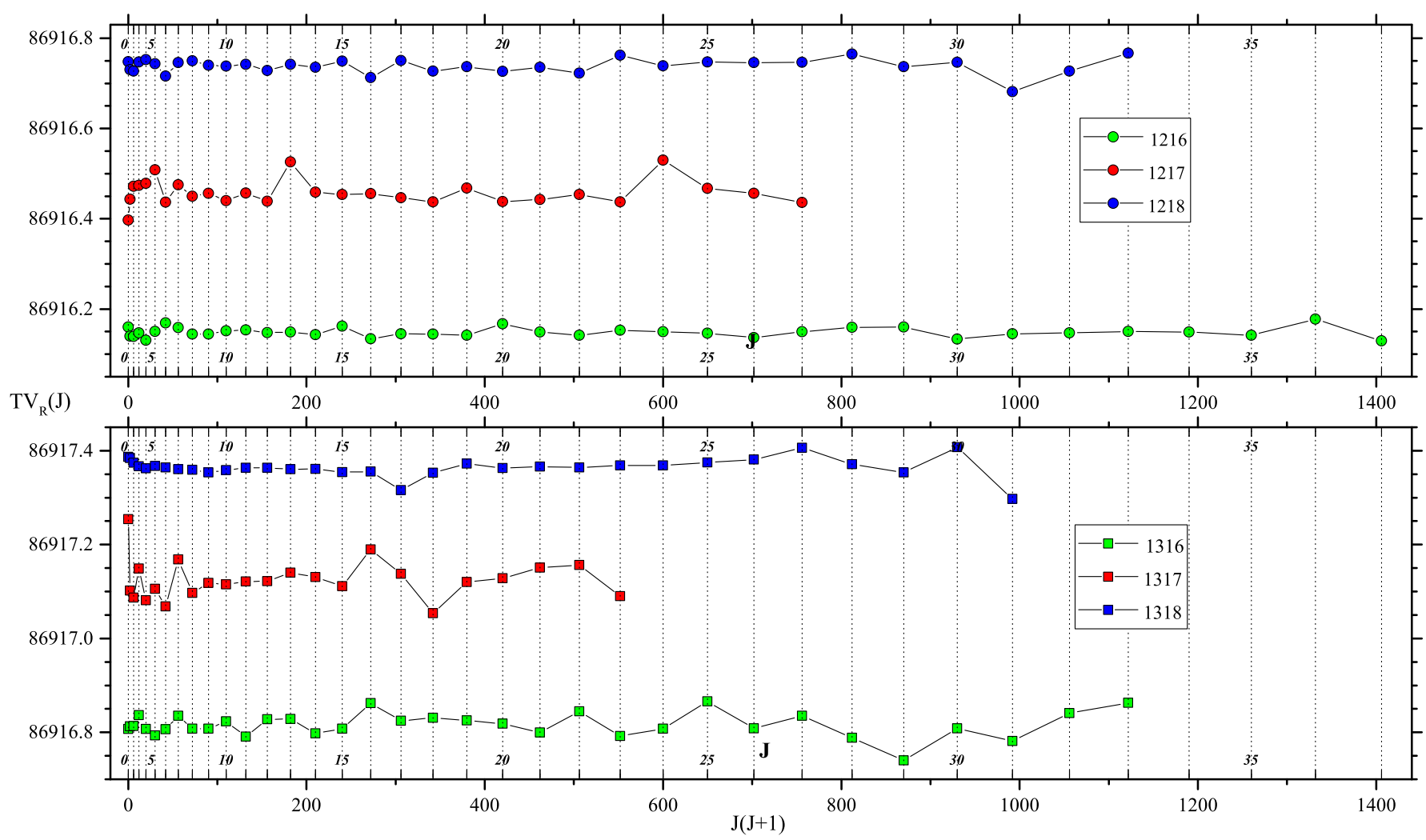

Fig. 4. Reduced term values $\left(\mathrm{cm}^{-1}\right)$ of the $B^{1} \Sigma^{+}\left(v^{\prime}=0\right)$ levels for six CO isotopologues.

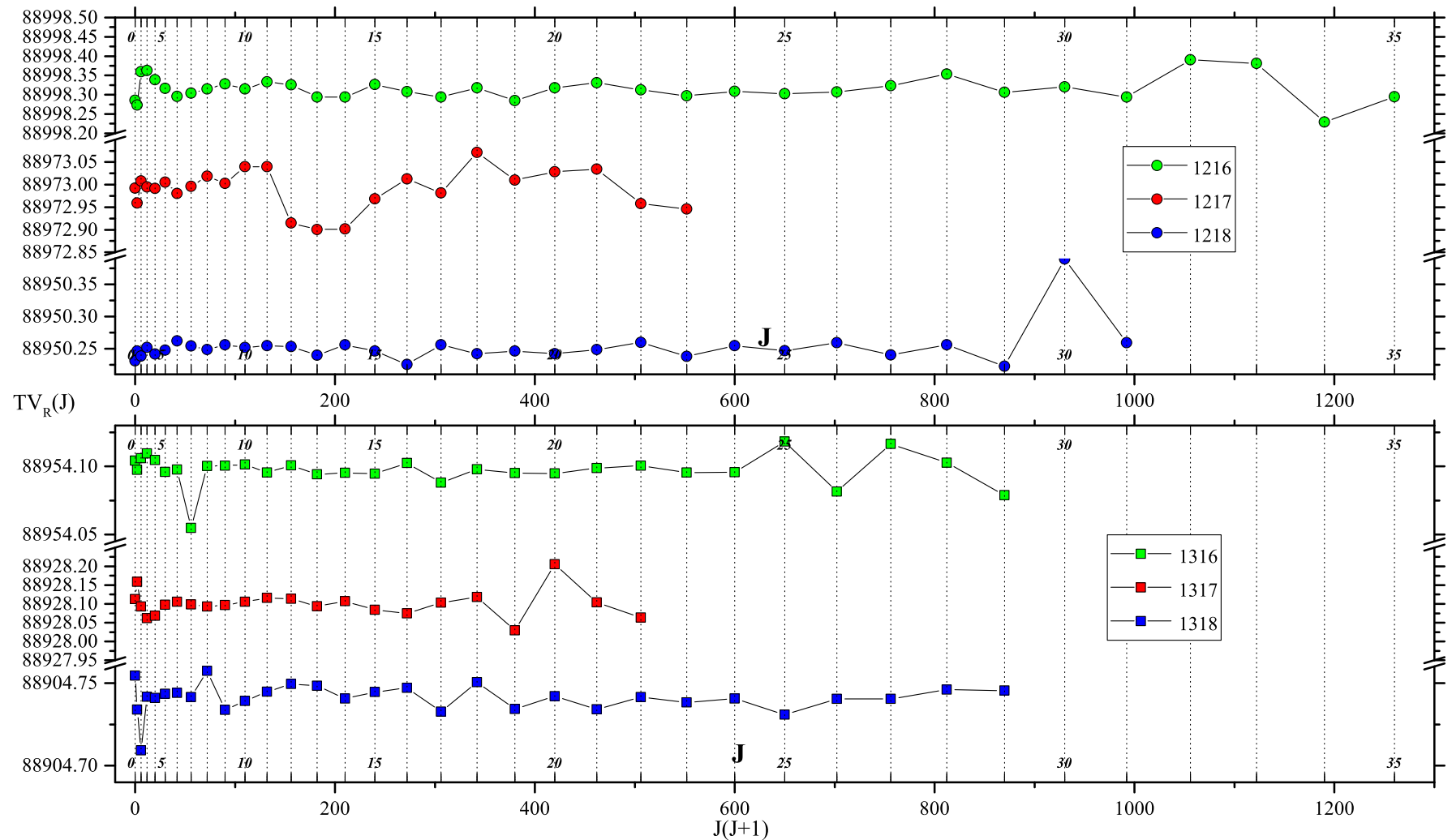

Fig. 5. Reduced term values $\left(\mathrm{cm}^{-1}\right)$ of the $B^{1} \Sigma^{+}\left(v^{\prime}=1\right)$ levels for six CO isotopologues. 
of $\mathrm{E} 20$ and $\mathrm{E} 30$ for ${ }^{13} \mathrm{C}^{17} \mathrm{O}$ (as for $\mathrm{B} 20$ because of the combination of a very low partial pressure and decreasing oscillator strength with $v^{\prime}$ ).

For E20 and E30 of ${ }^{12} \mathrm{C}^{18} \mathrm{O}$, the same remark holds as for C30. These two bands do not appear in spectra taken at room-temperature at pressures where E10 is observed. It is only observed in low-temperature spectra recorded at $90 \pm 5 \mathrm{~K}$, showing a limited number of $J^{\prime}$.

For all isotopologues, the rotational spacing is extremely small for the $Q$-branch of E00, E10, and E20, giving rise to congested spectra that require better resolution than available with the VUV-FTS and smaller Doppler broadening. This is particularly noticeable for the $Q$-branch of E10, where the lines are very slightly blueshifted with $J^{\prime}$ compared to the $Q$-branch of E00, which is slightly blueshifted, and the $Q$-branch of E20, which is slightly redshifted. Only with the use of a very narrow-band laser were Cacciani \& Ubachs (2004) able to separate the $Q$-branch of E00, and Ubachs et al. (2000) did this in combination with a deperturbation analysis for E10. The $Q$-branch of E30 has a very different aspect (similar to $A-X$ transitions) with a redshifted $Q$-branch and a returning limb for the $R$-branch with increasing $J^{\prime}$ (see for comparison Figs. A.12, A.17, and A.25 vs. A.28, and also Figs. A.15, A.16, A.24, and A.27 vs. Figs. A.30-A.36).

A careful analysis is required to distinguish the lines in the E00 bands of the different isotopologues. Spectra recorded at different pressures were used for this purpose. Figure A.16 illustrates the difficulty of this task for E00 with three spectra for ${ }^{13} \mathrm{C}^{18} \mathrm{O}$ and 2 for ${ }^{13} \mathrm{C}^{16} \mathrm{O}$. Figure A.27 shows the easier example of E20 for ${ }^{13} \mathrm{C}^{16} \mathrm{O}$ and ${ }^{13} \mathrm{C}^{18} \mathrm{O}$, and Figs. A.30-A.36 show the example of $\mathrm{E} 30$ for ${ }^{13} \mathrm{C}^{18} \mathrm{O}$.

There is very good agreement for the $R$ - and $P$-branch line positions between our present results and other high-resolution measurements (Cacciani et al. 1995; Cacciani \& Ubachs 2004 for E00 and Ubachs et al. 2000 for E10).

E00 was calibrated using a few levels observed by Cacciani et al. (1995) for ${ }^{12} \mathrm{C}^{16} \mathrm{O}$ [3 lines] and a large set of $R$ and $P$ levels (Cacciani \& Ubachs 2004) for ${ }^{12} \mathrm{C}^{16} \mathrm{O}$ [60 lines] and ${ }^{13} \mathrm{C}^{16} \mathrm{O}$ [32 lines] obtained by their methods labeled 1 and 0 (these data have to be calculated from the supplementary data, but no data are available for $\left.{ }^{13} \mathrm{C}^{18} \mathrm{O}\right)$. The resulting shift correction is estimated as $2.3 \times 10^{-5} \mathrm{~nm}\left(-0.020 \mathrm{~cm}^{-1}\right)$. Comparison to Daprà et al. (2016) shows an average difference of $3.8 \times 10^{-5} \mathrm{~nm}$ for $\mathrm{E} 00$. For ${ }^{12} \mathrm{C}^{18} \mathrm{O}$ and ${ }^{13} \mathrm{C}^{18} \mathrm{O}$, our term values for $\mathrm{E} 00$ ( $e$ - and $f$-parity) match those calculated by Haridass et al. (1994) well, which were obtained from the combination of $E-A$ data with high-resolution $A-X$ data collected with the former Ottawa spectrograph. For the $Q$-branch of ${ }^{12} \mathrm{C}^{16} \mathrm{O},{ }^{13} \mathrm{C}^{16} \mathrm{O}$, and ${ }^{13} \mathrm{C}^{18} \mathrm{O}$, which we cannot separate, we report the Cacciani \& Ubachs (2004) observed transition frequencies (see their Table 1). We merged the Cacciani et al. data with our higher- $J^{\prime}$ measurements. For the other isotopologues, ${ }^{12} \mathrm{C}^{17} \mathrm{O}$ and ${ }^{12} \mathrm{C}^{18} \mathrm{O}$, the $Q$ bandhead up to $J^{\prime} \approx 9$ was simulated to reproduce the observed spectra. These calculated data were merged with our measured data at higher $J^{\prime}$. For the last isotopologue, ${ }^{13} \mathrm{C}^{17} \mathrm{O}$, the $Q$-branch was simulated by interpolation of the ${ }^{13} \mathrm{C}^{16} \mathrm{O}$ and ${ }^{13} \mathrm{C}^{18} \mathrm{O}$ transitions (but these data are not reported in the table) in order to assign the few observed high $J^{\prime} Q$-lines.

E10 was calibrated by a few lines observed by Cacciani et al. (1995) for ${ }^{12} \mathrm{C}^{16} \mathrm{O}$ [9 lines] and a large set by Ubachs et al. (2000) of $R$ and $P$ lines for ${ }^{12} \mathrm{C}^{16} \mathrm{O}$ [42 $R$ and $P$ lines], for ${ }^{12} \mathrm{C}^{17} \mathrm{O}\left[2 R\right.$ lines], ${ }^{12} \mathrm{C}^{18} \mathrm{O}[24 P$ and $R$ lines $],{ }^{13} \mathrm{C}^{16} \mathrm{O}[25 P$ and $R$ lines], and ${ }^{13} \mathrm{C}^{18} \mathrm{O}$ [18 $R$ lines]. The absolute calibration for E10 obtained with the $R$ and $P$ levels is also confirmed by the presence of closely surrounding Xe I atomic lines (see Fig. 1).
Table 6. Statistical uncertainty on the measured term values: $\delta_{P}$ average and std. dev. (at $2 \sigma$ ) (see Sect. 2.2.2) for the $C^{1} \Sigma^{+}$state.

\begin{tabular}{|c|c|c|c|c|}
\hline Band & Species & $N$ & $\overline{\delta_{P}}\left(\mathrm{~cm}^{-1}\right)$ & Std. dev. $\left(\mathrm{cm}^{-1}\right)$ \\
\hline \multirow[t]{6}{*}{$\mathrm{COO}$} & 1216 & 72 & 0.010 & 0.027 \\
\hline & 1217 & 66 & -0.011 & 0.034 \\
\hline & 1218 & 70 & 0.000 & 0.010 \\
\hline & 1316 & 72 & 0.000 & 0.013 \\
\hline & 1317 & 70 & 0.004 & 0.021 \\
\hline & 1318 & 78 & -0.001 & 0.007 \\
\hline \multirow[t]{6}{*}{ C10 } & 1216 & 62 & 0.001 & 0.013 \\
\hline & 1217 & 42 & 0.001 & 0.010 \\
\hline & 1218 & 52 & -0.008 & 0.022 \\
\hline & 1316 & 54 & 0.008 & 0.045 \\
\hline & 1317 & 44 & 0.006 & 0.043 \\
\hline & 1318 & 56 & -0.003 & 0.017 \\
\hline \multirow[t]{6}{*}{$\mathrm{C} 20$} & 1216 & 28 & 0.003 & 0.012 \\
\hline & 1217 & & & \\
\hline & 1218 & 14 & 0.007 & 0.044 \\
\hline & 1316 & 16 & 0.004 & 0.043 \\
\hline & 1317 & & & \\
\hline & 1318 & 14 & -0.015 & 0.019 \\
\hline \multirow[t]{6}{*}{$\mathrm{C} 30$} & 1216 & 32 & 0.025 & 0.038 \\
\hline & 1217 & 6 & -0.007 & 0.048 \\
\hline & 1218 & 16 & -0.002 & 0.053 \\
\hline & 1316 & 16 & -0.004 & 0.056 \\
\hline & 1317 & & & \\
\hline & 1318 & 26 & 0.016 & 0.044 \\
\hline
\end{tabular}

Notes. $N$ : number of rotational transitions $(R$ and $P)$ involved in the statistics.

The resulting shift correction is estimated to be $5.0 \times 10^{-6} \mathrm{~nm}$. As it is not possible to distinguish the $Q$-branch of E10 for all isotopologues, we report in the tables the values obtained by Ubachs et al. (2000), merged with our measured data at higher $J^{\prime}$. Our dataset for $R$ - and $P$-branches extends those of Ubachs et al. (2000) to high $J^{\prime}$ values. Sample spectra are shown for ${ }^{12} \mathrm{C}^{16} \mathrm{O}$ in Fig. A.20, ${ }^{12} \mathrm{C}^{17} \mathrm{O}$ in Fig. A.21, ${ }^{12} \mathrm{C}^{18} \mathrm{O}$ in Fig. A.22, ${ }^{13} \mathrm{C}^{16} \mathrm{O}$ in Fig. A.23, and ${ }^{13} \mathrm{C}^{18} \mathrm{O}$ in Fig. A.24. All of them show additional lines, and among them, lines that belong to the perturbing state $k^{3} \Pi\left(v^{\prime}=5\right.$ and 6$)-X^{1} \Sigma^{+}\left(v^{\prime}=0\right)$ (Baker \& Launay 1994; Ubachs et al. 2000). The lower panel of Fig. A.21 shows the simulated absorption spectrum of ${ }^{12} \mathrm{C}^{17} \mathrm{O}$ at room temperature.

For E20 and E30, only low-resolution spectra without absolute calibration are available (Ogawa \& Ogawa 1974 for ${ }^{12} \mathrm{C}^{16} \mathrm{O}$ E20) and the Eidelsberg et al. (1991) atlas for ${ }^{12} \mathrm{C}^{16} \mathrm{O},{ }^{12} \mathrm{C}^{18} \mathrm{O}$, ${ }^{13} \mathrm{C}^{16} \mathrm{O}$, and ${ }^{13} \mathrm{C}^{18} \mathrm{O}$ for both E20 and E30, with either measured or extrapolated or calculated line positions. Consequently, the absolute calibration of E20 and E30, for which there are no previous high-resolution measurements, was obtained in the same way as for $\mathrm{C} 20$ and $\mathrm{C} 30$, using the two surrounding primary atomic standards as calibrators and checking that the numerous secondary standards (in the case of E20) are in agreement with each other (at an accuracy higher than $0.01 \mathrm{pm}$ ) for five isotopologues (with the exception of ${ }^{13} \mathrm{C}^{17} \mathrm{O}$ ). For E20, the $Q$-branch up to $J^{\prime}=6$ or 7 was obtained in the same way as for E10 by simulating our recorded spectra and merging them with the higher measurable $J^{\prime}$, up to $\sim 10-20$, depending on the isotopologue. Figure A.27 shows the simulated absorption spectra of ${ }^{12} \mathrm{C}^{16} \mathrm{O}$ at $90 \mathrm{~K}$ and at room temperature. Finally, as indicated above, all branches of E30 have well-resolved transitions for all observed 
J. L. Lemaire et al:: Atlas of new and revised high-resolution spectroscopy of six CO isotopologues in the 101-115 nm range

Table 7. References to table and figure numbers for the $E^{1} \Pi$ state.

\begin{tabular}{|c|c|c|c|c|c|}
\hline \multirow[t]{3}{*}{ Band } & \multicolumn{3}{|c|}{$\begin{array}{c}\text { Transition } \\
\text { wavelengths }\end{array}$} & \multirow{3}{*}{$\begin{array}{c}\text { Term } \\
\text { values }\end{array}$} & \multirow{2}{*}{$\begin{array}{c}\text { Reduced } \\
\text { TV } \\
\text { Figure }\end{array}$} \\
\hline & & & Figure & & \\
\hline & ${ }^{12} \mathrm{C}$ & ${ }^{13} \mathrm{C}$ & & & $e$-par. $f$-par. \\
\hline E00 & A.19 & A.20 & A.12 & A.21 & A.13 \\
\hline E10 & A. 22 & A. 23 & A.17 & A. 24 & A.18 \\
\hline E20 & A. 25 & A.26 & A. 25 & A. 29 & A.26 \\
\hline E30 & A. 27 & A. 28 & A. 28 & A. 30 & A. 29 \\
\hline
\end{tabular}

isotopologues. Figures A.30-A.36 show spectra for all five isotopologues; in some cases, the results obtained at $293 \mathrm{~K}$ and $90 \mathrm{~K}$ are compared, which are useful to separate the $R$-branch lines.

In order to verify the quality of our frequency determinations for the $Q$-branch, we use a method similar to the combination differences. We compared the values of the $\Lambda$-type doubling of the upper state obtained through the $R$ - and $P$-branches, $\Lambda_{R}(J)$ and $\Lambda_{P}(J)$ (for $J \geq 1$ ) with

$$
\begin{aligned}
& \Lambda_{R}(J)=[R(J-1)+X(J-1)]-[Q(J)+X(J)] \text { and } \\
& \Lambda_{P}(J)=[P(J+1)+X(J+1)]-[Q(J)+X(J)] .
\end{aligned}
$$

For all isotopologues and all bands (E00, E01, E02, and E03), the results are consistent with the value of $\Lambda_{d}$ provided in the term value tables. The $\Lambda$ doubling of the upper state is graphically represented for all isotopologues in each band, E00, E10, E20, and E30, in Fig. A.37 together with polynomial fits (linear in most cases).

Table 7 lists table and figure numbers associated with the EX bands. Table 8 gives the statistical uncertainty on the $e$-parity term values of the EX bands (see text in Sect. 2.2.2).

\section{Concluding remarks}

Our work presents a comprehensive and homogeneous set of absolutely calibrated line positions from which term values and molecular constants are derived. In most cases, these were obtained from larger sets of data than earlier determinations. Our data complete previous determinations and fill many gaps, particularly concerning the B20, C20, C30, E20, and E30 bands of all isotopologues. We also provide new data, particularly for the ${ }^{12} \mathrm{C}^{17} \mathrm{O}$ and ${ }^{13} \mathrm{C}^{17} \mathrm{O}$ isotopologues.

A final verification of the absolute accuracy of our whole set of results is provided by comparison with the data reported by Daprà et al. (2016). These datasets were not considered as calibrators because they were derived from others cited in Sect. 2.1, but we verified that they are in good agreement (at least for the six $J^{\prime}$ levels included therein) with our own results on B00, C00, and $\mathrm{E} 00$ for ${ }^{12} \mathrm{C}^{16} \mathrm{O}$.

In conclusion, the overall uncertainty of our data is a combination of the relative fitting accuracy in line positions (for a well-resolved typical line $\sim 0.008 \mathrm{~cm}^{-1}$ ) and of the accuracy in the calibrators and in the ground state (up to $\sim 0.003 \mathrm{~cm}^{-1}$ ). Most of the line positions are thus determined to an accuracy of $\sim 0.009 \mathrm{~cm}^{-1}$. For some weak (mainly at high $J^{\prime}$ ) or a few blended lines, the fitting errors are estimated to be as large as $0.10-0.15 \mathrm{~cm}^{-1}$. Uncertainties on term value data are reflected in the $\delta_{P}$ values presented in the term value tables.

Molecular constants are compiled in Table A.31 for all states and bands. In this table the $E$ state $e$ - and $f$-parity are treated independently, and we calculate in Table A.32 $T_{v}(1)$ (average of
Table 8. Statistical uncertainty on the measured term values: $\delta_{P}$ average and std. dev. (at $2 \sigma$ ) (see Sect. 2.2.2) for the $e$-parity levels $(R$ and $P$ ) for the $E^{1} \Pi$ state.

\begin{tabular}{ccccc}
\hline \hline Band & Species & $N$ & $\overline{\delta_{P}}\left(\mathrm{~cm}^{-1}\right)$ & Std. dev. $\left(\mathrm{cm}^{-1}\right)$ \\
\hline E00 & 1216 & 58 & 0.002 & 0.014 \\
& 1217 & 48 & 0.003 & 0.015 \\
& 1218 & 64 & 0.001 & 0.014 \\
& 1316 & 74 & 0.009 & 0.018 \\
& 1317 & 30 & -0.008 & 0.018 \\
& 1318 & 68 & 0.018 & 0.032 \\
\hline E10 & 1216 & 50 & 0.004 & 0.031 \\
& 1217 & 38 & 0.009 & 0.024 \\
& 1218 & 44 & 0.004 & 0.021 \\
& 1316 & 54 & 0.000 & 0.018 \\
& 1317 & 36 & -0.001 & 0.002 \\
& 1318 & 62 & 0.009 & 0.026 \\
\hline E20 & 1216 & 36 & 0.003 & 0.015 \\
& 1217 & 18 & -0.004 & 0.026 \\
& 1218 & 20 & 0.008 & 0.015 \\
& 1316 & 36 & 0.001 & 0.014 \\
& 1317 & & & \\
& 1318 & 48 & -0.003 & 0.027 \\
\hline E30 & 1216 & 30 & -0.001 & 0.046 \\
& 1217 & 16 & -0.002 & 0.037 \\
& 1218 & 18 & -0.005 & 0.030 \\
& 1316 & 18 & 0.003 & 0.019 \\
& 1317 & & & \\
& 1318 & 22 & 0.000 & 0.010 \\
\hline
\end{tabular}

Notes. $N$ : number of rotational transitions $(R$ and $P)$ involved in the statistics.

$T_{v}$ for $e$ - and $f$-parity), $q_{v}=B_{e}-B_{f}$, and $q_{D v}=D_{e}-D_{f}$. These molecular constants are also obtained by a quadratic fit of the $\Lambda$-doubling data shown in Fig. A.37 and reported in Table A.33.

In order to check the consistency of our term values, we compare their trends for the six $\mathrm{CO}$ isotopologues in Fig. A.38. The term value differences between ${ }^{16} \mathrm{O}$ and ${ }^{18} \mathrm{O}$ bearing isotopologues are compared both for ${ }^{12} \mathrm{C}$ and ${ }^{13} \mathrm{C}$ versus the $B, C$, and $E$ states. Term values are also compared as a function of $v^{\prime}$ for each states, and a linear fit is drawn through all isotopologues present in each $\left(T_{V}, v^{\prime}\right)$ data point. Both comparisons show a similar behavior.

The statistical table for the term values (see Tables 4,6 , and 8) can reveal the possible presence of perturbations when there is a large spread in the standard deviation $\left(>0.043 \mathrm{~cm}^{-1}\right.$, namely for ${ }^{12} \mathrm{C}^{16} \mathrm{O}(\mathrm{E} 30)$, for ${ }^{12} \mathrm{C}^{17} \mathrm{O}(\mathrm{C} 30)$, for ${ }^{12} \mathrm{C}^{18} \mathrm{O}(\mathrm{C} 20$ and C30), for ${ }^{13} \mathrm{C}^{16} \mathrm{O}(\mathrm{C} 10, \mathrm{C} 20$ and $\mathrm{C} 30)$, for ${ }^{13} \mathrm{C}^{17} \mathrm{O}(\mathrm{C} 10)$, and for ${ }^{13} \mathrm{C}^{18} \mathrm{O}(\mathrm{C} 30)$. Anomalies in the molecular constants also reveal evidence of perturbations, as shown in Fig. A.39, which illustrates this point more clearly than Table A.31. While $T_{v}$ mainly depends on the absolute calibration, $B_{v}$ and especially $D_{v}$ are very sensitive to perturbations, as shown in Fig. A.39.

Perturbations will be discussed in detail in a subsequent paper. Another forthcoming development of this work will be a comprehensive atlas of oscillator strengths and cross sections for the states, bands, and isotopologues presented here.

Acknowledgements. We acknowledge SOLEIL for providing the synchrotron radiation facilities. All the data have been obtained on beamline DESIRS using the VUV-FTS spectrometer during proposals 20140051, 20120715, 20110121, 20100018, 20090021, and 20080025. We acknowledge assistance from the SOLEIL beamline staff (L. Nahon beamline manager), NdO (VUV-FTS manager and coauthor), and D. Joyeux (designer and builder of the VUV-FTS). This 
Table 9. Rotational energy levels $\left(\mathrm{cm}^{-1}\right)$ of the $X^{1} \Sigma^{+}$ground state for six CO isotopologues (calculated from the Farrenq et al. 1991 Dunham coefficients).

\begin{tabular}{|c|c|c|c|c|c|c|}
\hline$J^{\prime \prime}$ & ${ }^{12} \mathrm{C}^{16} \mathrm{O}$ & ${ }^{12} \mathrm{C}^{17} \mathrm{O}$ & ${ }^{12} \mathrm{C}^{18} \mathrm{O}$ & ${ }^{13} \mathrm{C}^{16} \mathrm{O}$ & ${ }^{13} \mathrm{C}^{17} \mathrm{O}$ & ${ }^{13} \mathrm{C}^{18} \mathrm{O}$ \\
\hline 0 & 0 & 0 & 0 & 0 & 0 & 0 \\
\hline 1 & 3.845 & 3.748 & 3.662 & 3.676 & 3.579 & 3.493 \\
\hline 2 & 11.535 & 11.244 & 10.986 & 11.028 & 10.736 & 10.478 \\
\hline 3 & 23.069 & 22.487 & 21.971 & 22.055 & 21.472 & 20.956 \\
\hline 4 & 38.448 & 37.477 & 36.617 & 36.757 & 35.786 & 34.926 \\
\hline 5 & 57.670 & 56.214 & 54.924 & 55.134 & 53.677 & 52.388 \\
\hline 6 & 80.735 & 78.696 & 76.891 & 77.185 & 75.145 & 73.340 \\
\hline 7 & 107.642 & 104.924 & 102.518 & 102.909 & 100.190 & 97.783 \\
\hline 8 & 138.390 & 134.895 & 131.802 & 132.305 & 128.809 & 125.715 \\
\hline 9 & 172.978 & 168.610 & 164.743 & 165.372 & 161.003 & 157.136 \\
\hline 10 & 211.404 & 206.066 & 201.341 & 202.109 & 196.770 & 192.044 \\
\hline 11 & 253.667 & 247.262 & 241.593 & 242.515 & 236.108 & 230.438 \\
\hline 12 & 299.766 & 292.197 & 285.498 & 286.588 & 279.017 & 272.317 \\
\hline 13 & 349.698 & 340.869 & 333.055 & 334.326 & 325.495 & 317.679 \\
\hline 14 & 403.461 & 393.276 & 384.261 & 385.727 & 375.540 & 366.523 \\
\hline 15 & 461.054 & 449.416 & 439.116 & 440.791 & 429.150 & 418.847 \\
\hline 16 & 522.475 & 509.288 & 497.616 & 499.515 & 486.324 & 474.650 \\
\hline 17 & 587.721 & 572.888 & 559.761 & 561.896 & 547.059 & 533.928 \\
\hline 18 & 656.789 & 640.215 & 625.546 & 627.932 & 611.354 & 596.681 \\
\hline 19 & 729.677 & 711.266 & 694.971 & 697.622 & 679.206 & 662.906 \\
\hline 20 & 806.383 & 786.039 & 768.033 & 770.962 & 750.612 & 732.601 \\
\hline 21 & 886.902 & 864.530 & 844.729 & 847.950 & 825.571 & 805.763 \\
\hline 22 & 971.233 & 946.737 & 925.056 & 928.582 & 904.079 & 882.391 \\
\hline 23 & 1059.372 & 1032.657 & 1009.011 & 1012.857 & 986.133 & 962.480 \\
\hline 24 & 1151.315 & 1122.285 & 1096.591 & 1100.771 & 1071.731 & 1046.028 \\
\hline 25 & 1247.059 & 1215.620 & 1187.794 & 1192.320 & 1160.870 & 1133.034 \\
\hline 26 & 1346.601 & 1312.658 & 1282.615 & 1287.502 & 1253.546 & 1223.492 \\
\hline 27 & 1449.936 & 1413.395 & 1381.051 & 1386.312 & 1349.757 & 1317.401 \\
\hline 28 & 1557.061 & 1517.827 & 1483.099 & 1488.748 & 1449.498 & 1414.757 \\
\hline 29 & 1667.971 & 1625.950 & 1588.755 & 1594.805 & 1552.767 & 1515.557 \\
\hline 30 & 1782.662 & 1737.760 & 1698.015 & 1704.480 & 1659.559 & 1619.797 \\
\hline 31 & 1901.131 & 1853.254 & 1810.876 & 1817.769 & 1769.870 & 1727.473 \\
\hline 32 & 2023.371 & 1972.426 & 1927.332 & 1934.667 & 1883.698 & 1838.582 \\
\hline 33 & 2149.380 & 2095.273 & 2047.380 & 2055.170 & 2001.037 & 1953.120 \\
\hline 34 & 2279.151 & 2221.790 & 2171.015 & 2179.274 & 2121.884 & 2071.084 \\
\hline 35 & 2412.680 & 2351.972 & 2298.233 & 2306.975 & 2246.234 & 2192.468 \\
\hline 36 & 2549.962 & 2485.814 & 2429.030 & 2438.267 & 2374.083 & 2317.268 \\
\hline 37 & 2690.991 & 2623.311 & 2563.400 & 2573.145 & 2505.427 & 2445.482 \\
\hline 38 & 2835.763 & 2764.459 & 2701.339 & 2711.606 & 2640.260 & 2577.102 \\
\hline 39 & 2984.271 & 2909.251 & 2842.841 & 2853.643 & 2778.577 & 2712.127 \\
\hline 40 & 3136.509 & 3057.682 & 2987.901 & 2999.252 & 2920.375 & 2850.549 \\
\hline 41 & 3292.473 & 3209.748 & 3136.515 & 3148.427 & 3065.647 & 2992.366 \\
\hline 42 & 3452.156 & 3365.442 & 3288.676 & 3301.163 & 3214.389 & 3137.572 \\
\hline 43 & 3615.552 & 3524.758 & 3444.380 & 3457.454 & 3366.596 & 3286.161 \\
\hline 44 & 3782.655 & 3687.690 & 3603.619 & 3617.295 & 3522.261 & 3438.129 \\
\hline 45 & 3953.457 & 3854.233 & 3766.390 & 3780.679 & 3681.380 & 3593.470 \\
\hline 46 & 4127.954 & 4024.380 & 3932.685 & 3947.601 & 3843.946 & 3752.179 \\
\hline 47 & 4306.137 & 4198.125 & 4102.499 & 4118.054 & 4009.954 & 3914.251 \\
\hline 48 & 4488.001 & 4375.461 & 4275.825 & 4292.033 & 4179.399 & 4079.679 \\
\hline
\end{tabular}

research was supported by NASA (grants NNG 06-GG70G and NNX10AD80G to the Univ. of Toledo and NNX09AC5GG to Wellesley College). J. R. L. and G. S. thank the NASA Origins of Solar System program (Grant NNX14AD49G) for funding. A. H., while in the Amsterdam team, acknowledges support from the Dutch astrochemistry network (DAN) from the Netherlands Organisation for Scientific Research (NWO) under grant 648.000.002 and the research fellowship program of PSL Research University Paris. J. L. L. thanks the ISMO-CNRS (Institut des Sciences Moléculaires d'Orsay at Université Paris-Sud) for hosting him as visiting researcher.

\section{References}

Baker, J. J. 1994, J. Mol. Spec., 167, 323

Baker, J., \& Launay, F. 1994, J. Mol. Spec., 165, 75

Baker, J., Lemaire, J. L., Couris, S., et al. 1993, Chem. Phys., 178, 569

Baker, J., Lemaire, J. L., Couris, S., et al. 1994, AIP Conf. Proc., 312, 355

Brandi, F., Velchev, I., Hogervorst, W., \& Ubachs, W. 2001, Phys. Rev. A, 64, 032505

Brandi, F., Hogervorst, W., \& Ubachs, W. 2002, J. Phys. B, 35, 1071 
Cacciani, P., \& Ubachs, W. 2004, J. Mol. Spectr., 225, 62

Cacciani, P., Hogervorst, W., \& Ubachs, W. 1995, J. Chem. Phys, 102, 8308

Cacciani, P., Brandi, F., Velchev, I., et al. 2001, Eur. Phys. J. D, 15, 47

Daprà, M., Niu, M. L., Salumbides, E. J., Murphy, T., \& Ubachs, W. 2016, ApJ, 826,192

de Oliveira, N., Joyeux, D., Phalippou, D., et al. 2009, Rev. Sci. Instrum., 80, 043101

de Oliveira, N., Roudjane, M., Joyeux, D., et al. 2011, Nat. Photon., 5, 149

de Oliveira, N., Joyeux, D., Roudjane, M., et al. 2016, J. Synchrotron Radiat, 23 , 887

Drabbels, M., Meerts, W. L., \& ter Meulen, J. J. 1993a, J. Chem. Phys., 99, 2352

Drabbels, M., Heinze, J., ter Meulen, J. J., \& Meerts, W. L. 1993b, J. Chem. Phys., 99, 5701

Eidelsberg, M., \& Rostas, F. 1990, A\&A, 235, 472

Eidelsberg, M., Roncin, J.-Y., Le Floch, A., et al. 1987, J. Mol. Spectr., 121 309

Eidelsberg, M., Benayoun, J. J., Viala, Y. P., \& Rostas, F. 1991, A\&AS, 90, 231

Eidelsberg, M., Benayoun, J. J., Viala, Y. P., et al. 1992, A\&A, 265, 839

Eidelsberg, M., Lemaire, J. L., Federman, S., et al. 2012, A\&A, 543, A69

Eidelsberg, M., Lemaire, J. L., Federman, S. R., et al. 2014, A\&A, 566, A96

Eidelsberg, M., Lemaire, J. L., Federman, S. R., et al. 2017, A\&A, 602, A76

Farrenq, R., Guelachvili, G., Sauval, A. J., Grevesse, N., \& Farmer, C. B. 1991 J. Mol. Spectr., 149, 375

Federman, S. R., Fritts, M., Cheng, S., Menningen, K. M., Knauth, D. C., \& Fulk, K. 2001, ApJS, 134, 133

Gavilan, L., Lemaire, J. L., Eidelsberg, M., et al. 2013, J. Phys. Chem. A, 117 9644

Guelachvili, G., de Villeneuve, D., Farrenq, R., Urban, W., \& Verges, J. 1983, J. Mol. Spectr., 98, 64

Hakalla, R., Niu, M. L., Field, R. W., et al. 2016, RSC Adv., 6, 31588

Hakalla, R., Niu, M. L., Field, R. W., et al. 2017, J. Quant. Spectr. Rad. Transf., 189,312
Haridass, C., Paddy Teddy, S., \& Le Floch, A. C. 1994, J. Mol. Spectr., 168, 429

Heays, A. N., Eidelsberg, M., Stark, G., et al. 2014, J. Chem. Phys., 141, 144311 Herzberg, G. 1950, in Spectra of Diatomic Molecules, Molecular Spectra and Molecular Structure, 2nd ed. (New York: Van Nostrand Reinhold), 1

Ivanov, T. I., Salumbides, E. J., Vieitez, M. O., et al. 2008, MNRAS, 389, 4

Kaufman, V., \& Edlén, B. 1974, J. Phys. Chem. Ref. Data, 3, 825

Lefèbvre-Brion, H., \& Eidelsberg, M. 2012, J. Mol. Spectr., 271, 59

Le Floch, A. 1992, J. Mol. Spectr. 155, 177

Le Floch, A., \& Amiot, C. 1985, Chem. Phys., 97, 379

Lemaire, J. L., Eidelsberg, M., Heays, A. N., et al. 2016, J. Phys. B, 49, 4001

Letzelter, C., Eidelsberg, M., Rostas, F., Breton, J., \& Thieblemont, B. 1987, Chem. Phys., 114, 273

Morton, D. C., \& Noreau, L. 1994, ApJS, 95, 301

Nahon, L., de Oliveira, N., Garcia, G., et al. 2012, J. Synchrotron Radiat., 19 508

Nahon, L., de Oliveira, N., Garcia, G. A., et al. 2013, J. Phys. Conf. Ser., 425, 122004

Niu, M. L., Hakalla, R., Madhu Trivikram, T., et al. 2016, Mol. Phys., 114, 2857

Ogawa, S., \& Ogawa, M. 1974, J. Mol. Spectr., 49, 4540

Philip, J., Sprengers, J. P., Cacciani, P., de Lange, C. A., \& Ubachs, W. 2004, Appl. Phys. B, 78, 737

Stark, G., Lewis, B. R., Gibson, S. T., \& England, J. P. 1999, ApJ, 520, 732

Stark, G., Heays, A. N., Lyons, J. R., et al. 2014, ApJ, 788, 67

Ubachs, W., Eikema, K. S. E., Levelt, P. F., et al. 1994, ApJ, 427, L55

Ubachs, W., Hinnen, P. C., Hansen, P., et al. 1995, J. Mol. Spectr., 174, 388

Ubachs, W., Velchev, I., \& Cacciani, P. 2000, J. Chem. Phys., 113, 547 van Dishoeck, E. F., \& Black, J. H. 1988, ApJ, 334, 771

Viala, Y. P., Letzelter, C., Eidelsberg, M., \& Rostas, F. 1988, A\&A, 193, 265

Visser, R., van Dishoeck, E. F., \& Black, J. H. 2009, A\&A, 503, 323

Yoshino, K., \& Freeman, D. E. 1985, J. Opt. Soc. Am. B, 2, 1268 


\section{Appendix A: Additional figures and tables}

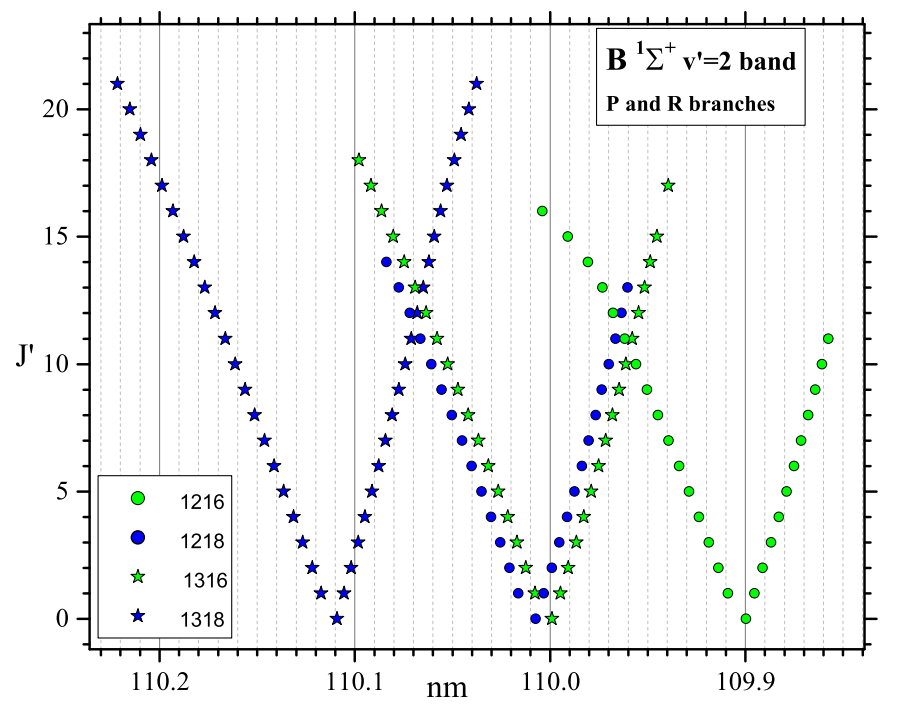

Fig. A.1. Transition wavelengths of the $B^{1} \Sigma^{+}\left(v^{\prime}=2\right)-X^{1} \Sigma^{+}\left(v^{\prime \prime}=0\right)$ band for the four observed CO isotopologues.

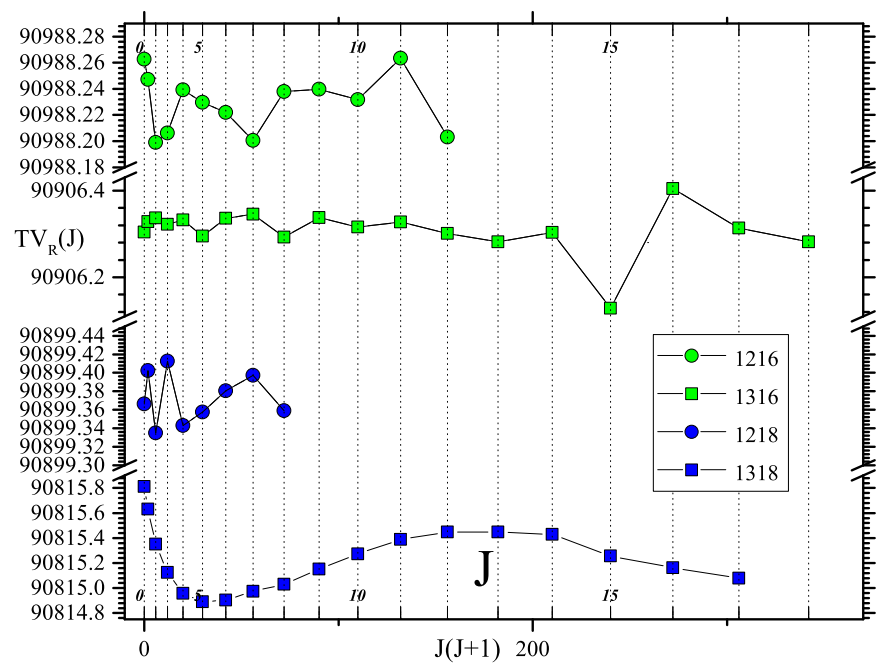

Fig. A.2. Reduced term values $\left(\mathrm{cm}^{-1}\right)$ of the $B^{1} \Sigma^{+}\left(v^{\prime}=2\right)$ levels for the four observed CO isotopologues.

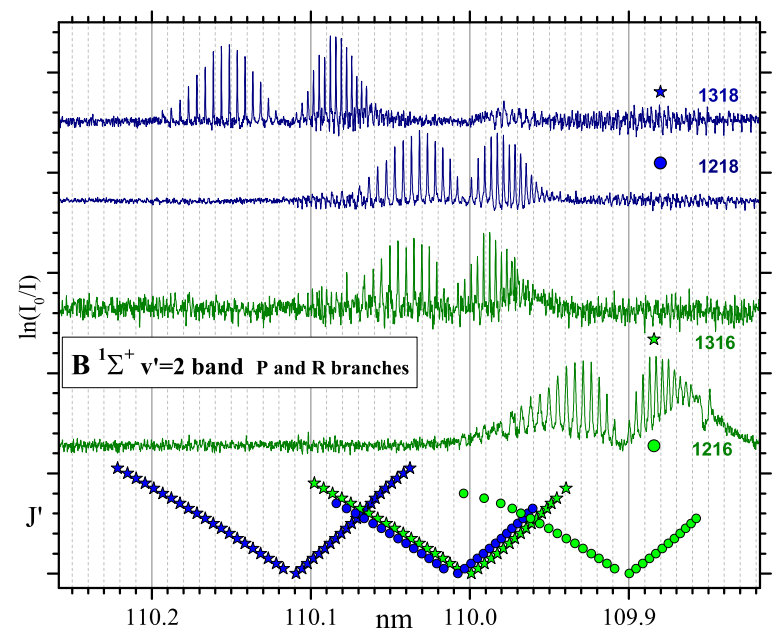

Fig. A.3. Sample of B20 spectra for the four observed isotopologues, in some cases showing perturbations. 
J. L. Lemaire et al.: Atlas of new and revised high-resolution spectroscopy of six CO isotopologues in the 101-115 nm range

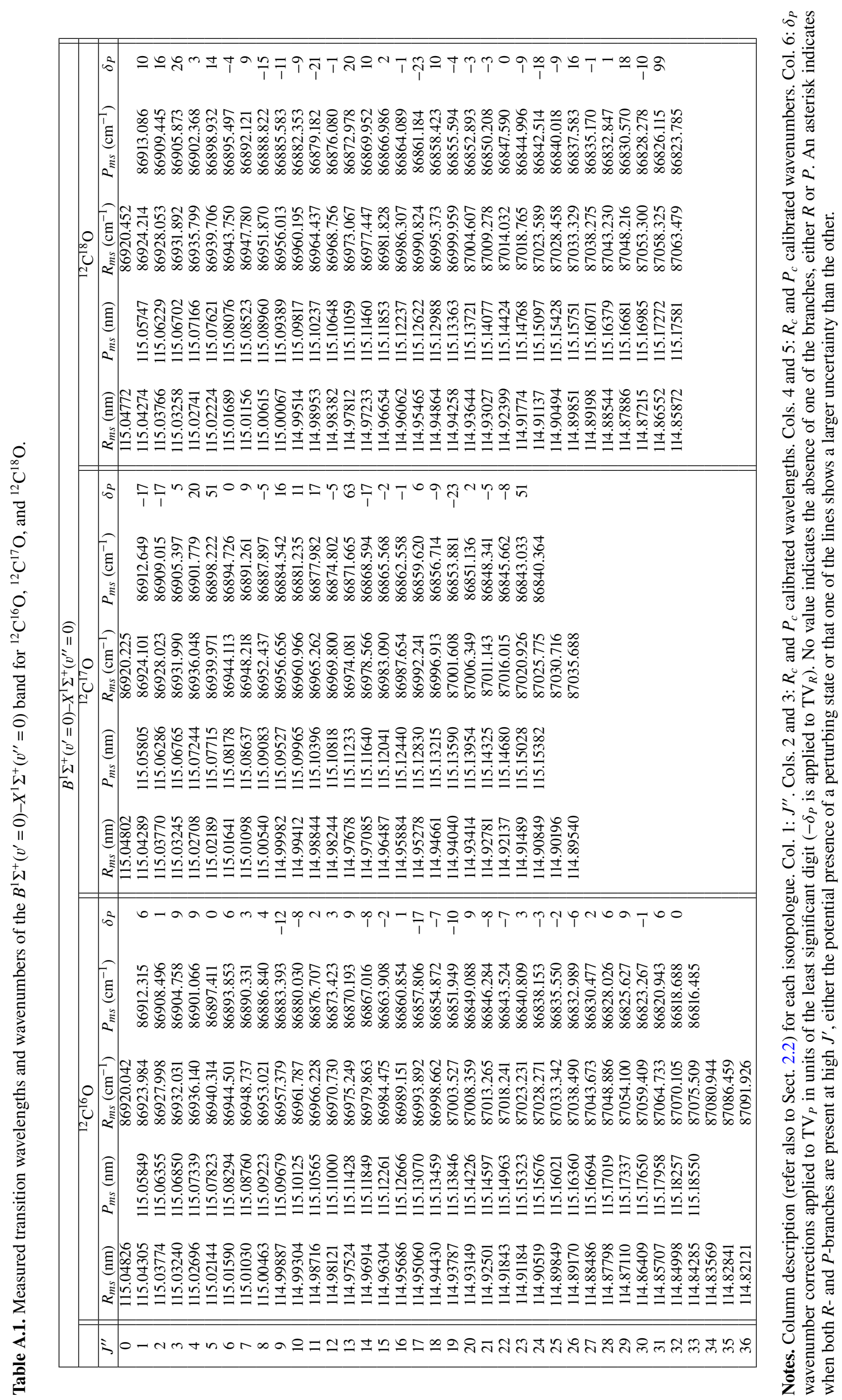




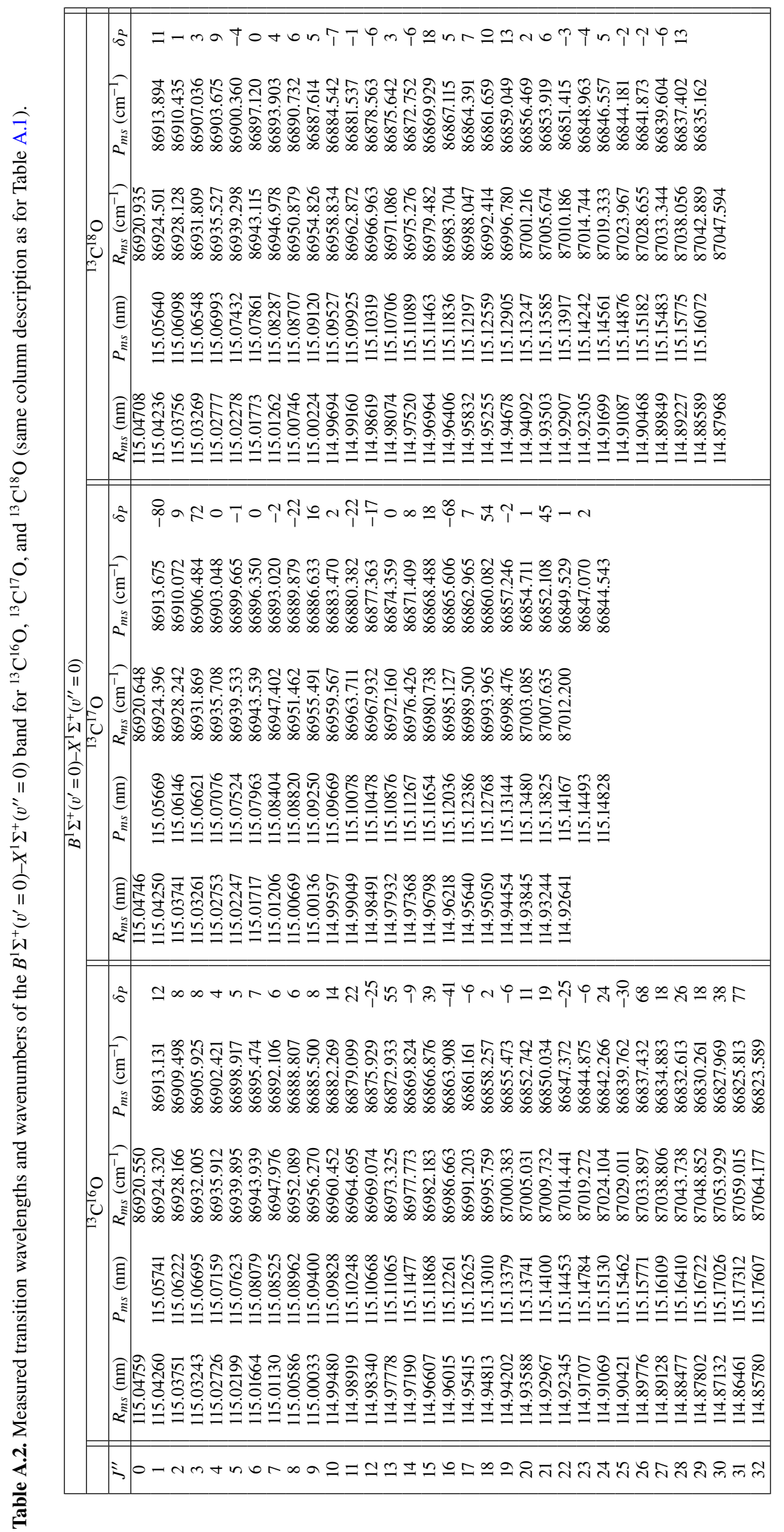

A114, page 16 of 62 
Table A.3. Term values $\left(\mathrm{cm}^{-1}\right)$ of the $B^{1} \Sigma^{+}\left(v^{\prime}=0\right)$ levels for six CO isotopologues.

\begin{tabular}{|c|c|c|c|c|c|c|}
\hline & \multicolumn{6}{|c|}{$B^{1} \Sigma^{+}\left(v^{\prime}=0\right)$} \\
\hline$J^{\prime}$ & ${ }^{12} \mathrm{C}^{16} \mathrm{O}$ & ${ }^{12} \mathrm{C}^{17} \mathrm{O}$ & ${ }^{12} \mathrm{C}^{18} \mathrm{O}$ & ${ }^{13} \mathrm{C}^{16} \mathrm{O}$ & ${ }^{13} \mathrm{C}^{17} \mathrm{O}$ & ${ }^{13} \mathrm{C}^{18} \mathrm{O}$ \\
\hline 0 & 86916.160 & 86916.397 & 86916.748 & 86916.807 & 86917.254 & 86917.387 \\
\hline 1 & $86920.036(6)$ & $86920.242(-17)$ & $86920.441(10)$ & $86920.538(12)$ & $86920.728(-80)$ & $86920.924(11)$ \\
\hline 2 & 86927.828 (1) & $86927.866(-17)$ & $86927.860(16)$ & $86927.988(8)$ & $86927.965(9)$ & $86927.993(1)$ \\
\hline 3 & $86939.524(9)$ & $86939.261(5)$ & $86939.012(26)$ & $86939.186(8)$ & $86938.906(72)$ & $86938.604(3)$ \\
\hline 4 & $86955.091(9)$ & $86954.456(20)$ & $86953.860(3)$ & $86954.056(4)$ & $86953.341(0)$ & $86952.756(9)$ \\
\hline 5 & $86974.588(0)$ & $86973.474(51)$ & $86972.402(14)$ & $86972.664(5)$ & $86971.495(-1)$ & $86970.457(-4)$ \\
\hline 6 & 86997.979 (6) & $86996.185(0)$ & $86994.635(-4)$ & $86995.022(7)$ & $86993.210(0)$ & $86991.686(0)$ \\
\hline 7 & $87025.233(3)$ & $87022.801(9)$ & $87020.633(9)$ & $87021.118(6)$ & $87018.686(-2)$ & $87016.452(4)$ \\
\hline 8 & $87056.375(4)$ & $87053.147(-5)$ & $87050.312(-15)$ & $87050.879(6)$ & $87047.613(-22)$ & $87044.756(6)$ \\
\hline 9 & $87091.422(-12)$ & $87087.316(16)$ & $87083.682(-11)$ & $87084.386(8)$ & $87080.255(16)$ & $87076.590(5)$ \\
\hline 10 & $87130.365(-8)$ & $87125.255(11)$ & $87120.766(-9)$ & $87121.628(14)$ & $87116.492(2)$ & $87111.969(-7)$ \\
\hline 11 & $87173.190(2)$ & 87167.015 (17) & $87161.557(-21)$ & $87162.539(22)$ & $87156.359(-22)$ & $87150.879(-1)$ \\
\hline 12 & $87219.893(3)$ & $87212.529(-5)$ & $87206.032(-1)$ & $87207.234(-25)$ & $87199.837(-17)$ & $87193.316(-6)$ \\
\hline 13 & $87270.486(9)$ & $87261.933(63)$ & $87254.234(20)$ & $87255.606(55)$ & $87246.948(0)$ & $87239.278(3)$ \\
\hline 14 & $87324.954(-8)$ & $87314.967(-17)$ & $87306.112(10)$ & $87307.659(-9)$ & $87297.646(8)$ & $87288.771(-6)$ \\
\hline 15 & $87383.326(-2)$ & $87371.844(-2)$ & 87361.707 (2) & $87363.461(39)$ & $87351.948(18)$ & $87341.782(18)$ \\
\hline 16 & $87445.528(1)$ & $87432.507(-1)$ & $87420.944(-1)$ & $87423.016(-41)$ & $87409.956(-68)$ & $87398.324(5)$ \\
\hline 17 & $87511.644(-17)$ & $87496.935(6)$ & $87483.946(-23)$ & $87486.183(-6)$ & $87471.444(7)$ & $87458.347(7)$ \\
\hline 18 & $87581.619(-7)$ & $87565.139(-9)$ & $87550.575(10)$ & 87553.097 (2) & $87536.506(54)$ & 87521.965 (10) \\
\hline 19 & $87655.461(-10)$ & $87637.152(-23)$ & $87620.923(-4)$ & $87623.698(-6)$ & $87605.321(-2)$ & $87589.082(13)$ \\
\hline 20 & $87733.196(9)$ & $87712.873(2)$ & $87694.934(-3)$ & 87697.994 (11) & $87677.680(1)$ & $87659.685(2)$ \\
\hline 21 & $87814.750(-8)$ & $87792.393(-5)$ & $87772.643(-3)$ & $87775.973(19)$ & $87753.653(45)$ & $87733.811(6)$ \\
\hline 22 & $87900.174(-7)$ & $87875.682(-8)$ & $87854.007(0)$ & $87857.707(-25)$ & $87833.204(1)$ & $87811.440(-3)$ \\
\hline 23 & $87989.471(3)$ & $87962.700(51)$ & $87939.097(-9)$ & $87943.030(-6)$ & 87916.277 (2) & $87892.581(-4)$ \\
\hline 24 & $88082.606(-3)$ & 88053.582 & $88027.794(-18)$ & $88032.105(24)$ & & $87977.219(5)$ \\
\hline 25 & $88179.588(-2)$ & 88148.060 & $88120.189(-9)$ & $88124.904(-30)$ & & $88065.363(-2)$ \\
\hline 26 & $88280.407(-6)$ & 88246.337 & $88216.236(16)$ & $88221.263(68)$ & & $88157.003(-2)$ \\
\hline 27 & 88385.089 (2) & 88348.346 & $88315.945(-1)$ & $88321.380(18)$ & & $88252.153(-6)$ \\
\hline 28 & $88493.603(6)$ & & $88419.326(1)$ & $88425.092(26)$ & & $88350.732(13)$ \\
\hline 29 & $88605.938(9)$ & & $88526.311(18)$ & 88532.467 (18) & & 88452.813 \\
\hline 30 & $88722.072(-1)$ & & $88636.981(-10)$ & $88643.620(38)$ & & 88558.446 \\
\hline 31 & $88842.065(6)$ & & $88751.216(99)$ & $88758.333(77)$ & & 88667.391 \\
\hline 32 & $88965.864(0)$ & & 88869.201 & 88876.784 & & \\
\hline 33 & 89093.476 & & 88990.811 & 88998.843 & & \\
\hline 34 & 89224.889 & & & & & \\
\hline 35 & 89360.095 & & & & & \\
\hline 36 & 89499.139 & & & & & \\
\hline 37 & 89641.888 & & & & & \\
\hline
\end{tabular}

Notes. The $\delta_{P}$ value in parentheses (in units of the least significant digit) corresponds to the wavenumber correction applied to $\mathrm{TV}_{P}$ and $\mathrm{TV}_{R}$. There is no value when the term value is derived from a single transition, either $R$ or $P$. An asterisk indicates when both $R$ - and $P$-branches are present at high $J^{\prime}$, either the potential presence of a perturbing state or that one of the lines shows a larger uncertainty than the other (see also Sect. 2.2.2). 


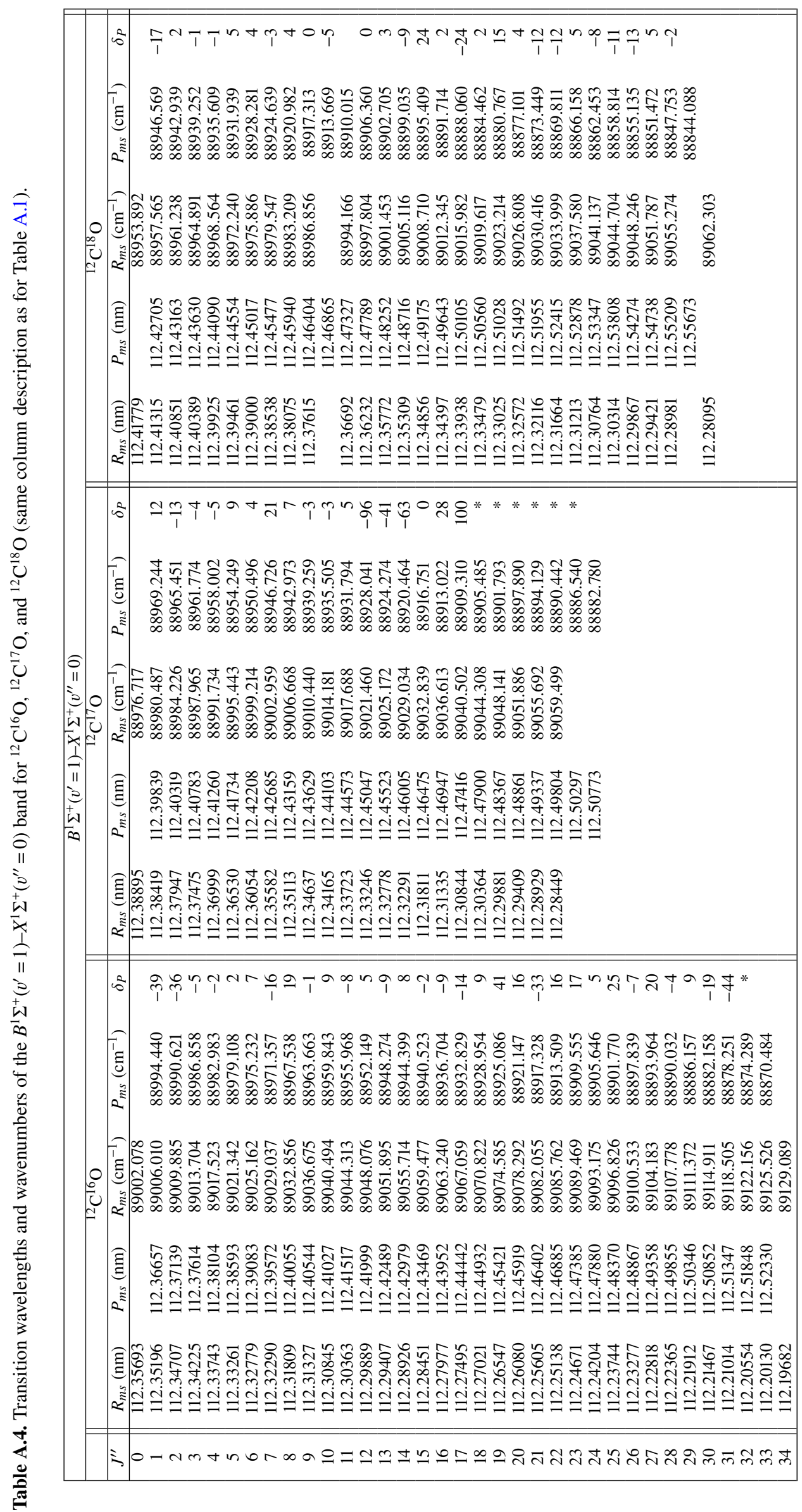

A114, page 18 of 62 
J. L. Lemaire et al.: Atlas of new and revised high-resolution spectroscopy of six CO isotopologues in the 101-115 nm range

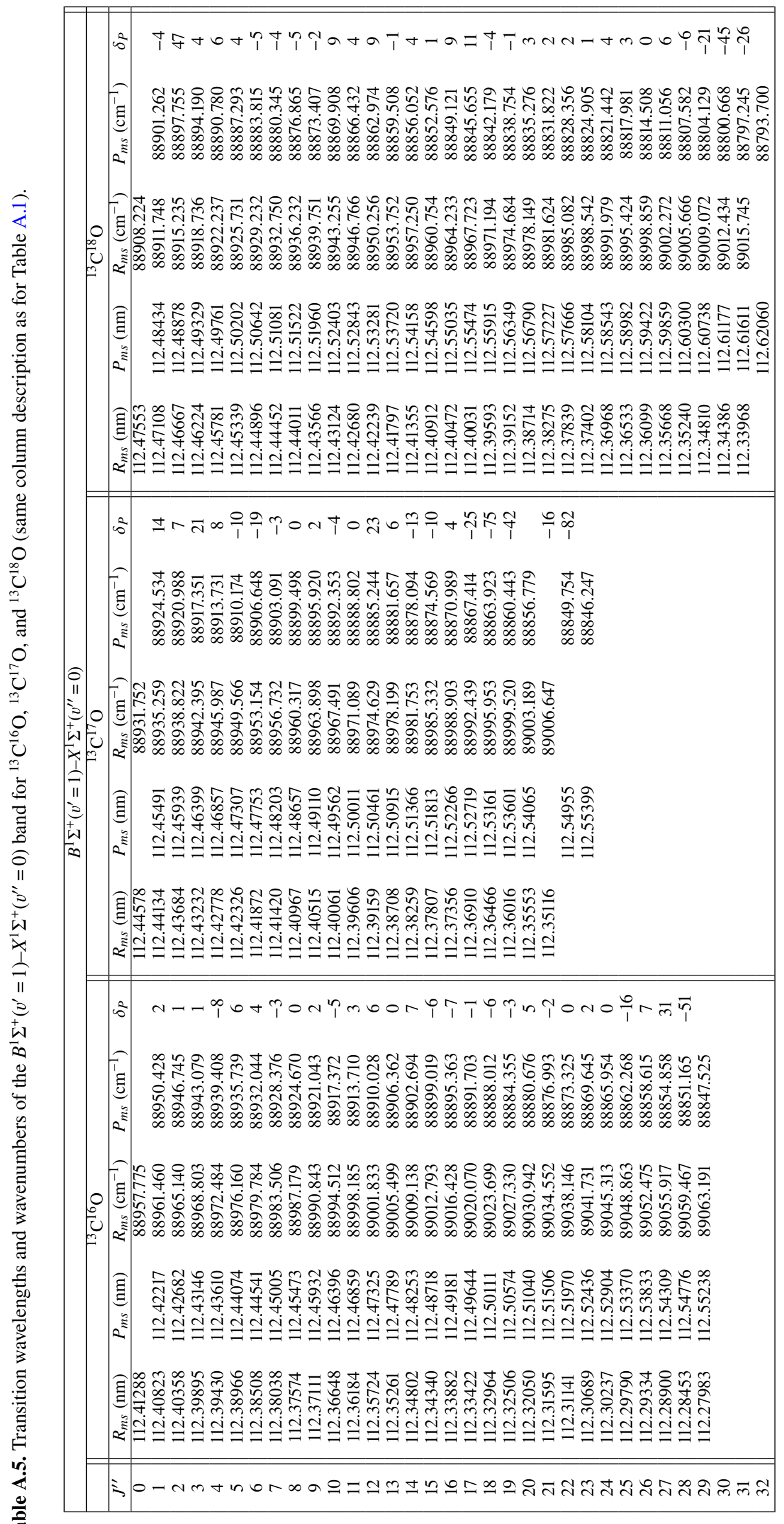


Table A.6. Term values $\left(\mathrm{cm}^{-1}\right)$ of the $B^{1} \Sigma^{+}\left(v^{\prime}=1\right)$ levels for six CO isotopologues.

\begin{tabular}{|c|c|c|c|c|c|c|}
\hline & \multicolumn{6}{|c|}{$B^{1} \Sigma^{+}\left(v^{\prime}=1\right)$} \\
\hline$J^{\prime}$ & ${ }^{12} \mathrm{C}^{16} \mathrm{O}$ & ${ }^{12} \mathrm{C}^{17} \mathrm{O}$ & ${ }^{12} \mathrm{C}^{18} \mathrm{O}$ & ${ }^{13} \mathrm{C}^{16} \mathrm{O}$ & ${ }^{13} \mathrm{C}^{17} \mathrm{O}$ & ${ }^{13} \mathrm{C}^{18} \mathrm{O}$ \\
\hline 0 & 88998.285 & 88972.992 & 88950.231 & 88954.104 & 88928.113 & 88904.754 \\
\hline 1 & $89002.117(-39)$ & 88976.706 (12) & $88953.908(-17)$ & $88957.774(2)$ & 88931.738 (14) & $88908.229(-4)$ \\
\hline 2 & $89009.891(-36)$ & $88984.248(-13)$ & $88961.225(2)$ & 88965.135 (1) & $88938.830(7)$ & 88915.193 (47) \\
\hline 3 & $89021.425(-5)$ & $88995.474(-4)$ & $88972.225(-1)$ & 88976.167 (1) & $88949.538(21)$ & 88925.709 (4) \\
\hline 4 & $89036.776(-2)$ & $89010.457(-5)$ & $88986.863(-1)$ & $88990.866(-8)$ & $88963.859(8)$ & $88939.686(6)$ \\
\hline 5 & $89055.970(2)$ & $89029.202(9)$ & 89005.177 (5) & $89009.235(6)$ & $88981.783(-10)$ & 88957.159 (4) \\
\hline 6 & $89079.006(7)$ & $89051.653(4)$ & $89027.160(4)$ & $89031.290(4)$ & $89003.262(-19)$ & $88978.124(-5)$ \\
\hline 7 & $89105.913(-16)$ & $89077.889(21)$ & $89052.781(-3)$ & $89056.972(-3)$ & $89028.303(-3)$ & $89002.576(-4)$ \\
\hline 8 & $89136.660(19)$ & $89107.875(7)$ & $89082.060(4)$ & $89086.415(0)$ & $89056.922(0)$ & $89030.538(-5)$ \\
\hline 9 & $89171.247(-1)$ & $89141.567(-3)$ & $89115.010(0)$ & $89119.482(2)$ & $89089.125(2)$ & $89061.950(-2)$ \\
\hline 10 & $89209.644(9)$ & $89179.052(-3)$ & $89151.604(-5)$ & $89156.220(-5)$ & $89124.906(-4)$ & $89096.879(9)$ \\
\hline 11 & $89251.906(-8)$ & $89220.242(5)$ & 89191.858 & $89196.619(3)$ & $89164.261(0)$ & 89135.295 (4) \\
\hline 12 & $89297.976(5)$ & $89265.046(-96)$ & $89235.759(0)$ & $89240.694(6)$ & $89207.174(23)$ & 89177.195 (9) \\
\hline 13 & $89347.851(-9)$ & $89313.698(-41)$ & $89283.299(3)$ & $89288.421(0)$ & $89253.640(6)$ & $89222.574(-1)$ \\
\hline 14 & $89401.585(8)$ & $89366.104(-63)$ & $89334.517(-9)$ & $89339.818(7)$ & $89303.706(-13)$ & 89271.427 (4) \\
\hline 15 & $89459.177(-2)$ & $89422.310(0)$ & $89389.354(24)$ & $89394.872(-6)$ & $89357.303(-10)$ & $89323.772(1)$ \\
\hline 16 & $89520.541(-9)$ & $89482.227(28)$ & $89447.823(2)$ & $89453.591(-7)$ & $89414.478(4)$ & $89379.593(9)$ \\
\hline 17 & $89585.729(-14)$ & $89545.800(100)$ & $89509.985(-24)$ & $89515.943(-1)$ & $89475.252(-25)$ & $89438.872(11)$ \\
\hline 18 & $89654.772(9)$ & $89613.225\left(^{*}\right)$ & $89575.740(2)$ & $89581.971(-6)$ & $89539.574(-75)$ & $89501.656(-4)$ \\
\hline 19 & $89727.571(41)$ & $89684.226\left(^{*}\right)$ & $89645.149(15)$ & $89651.635(-3)$ & $89607.349(-42)$ & $89567.876(-1)$ \\
\hline 20 & $89804.246(16)$ & $89759.033\left(^{*}\right)$ & $89718.182(4)$ & $89724.947(5)$ & 89678.726 & $89637.588(3)$ \\
\hline 21 & $89884.708(-33)$ & $89837.552\left(^{*}\right)$ & $89794.854(-12)$ & $89801.906(-2)$ & $89753.817(-16)$ & $89710.749(2)$ \\
\hline 22 & $89968.942(16)$ & $89919.709\left(^{*}\right)$ & $89875.157(-12)$ & $89882.502(0)$ & $89832.299(-82)$ & $89787.386(2)$ \\
\hline 23 & 90056.978 (17) & $90005.651\left(^{*}\right)$ & $89959.050(5)$ & $89966.726(2)$ & & $89867.472(1)$ \\
\hline 24 & $90148.835(5)$ & & $90046.599(-8)$ & $90054.588(0)$ & & 89951.018 (4) \\
\hline 25 & $90244.465(25)$ & & $90137.739(-11)$ & $90146.100(-16)$ & & $90038.004(3)$ \\
\hline 26 & $90343.893(-7)$ & & $90232.510(-13)$ & $90241.177(7)$ & & $90128.457(0)$ \\
\hline 27 & $90447.113(20)$ & & $90330.857(5)$ & $90339.945(31)$ & & $90222.345(6)$ \\
\hline 28 & $90554.124(-4)$ & & $90432.841(-2)$ & $90442.280(-51)$ & & $90319.679(-6)$ \\
\hline 29 & $90664.829(9)$ & & 90538.373 & 90548.215 & & $90420.444(-21)$ \\
\hline 30 & $90779.363(-19)$ & & & 90657.996 & & $90524.674(-45)$ \\
\hline 31 & $90897.617(-44)$ & & 90760.318 & & & $90632.256(-26)$ \\
\hline 32 & 91019.750 (114) & & & & & 90743.218 \\
\hline 33 & 91145.527 & & & & & \\
\hline 34 & 91274.905 & & & & & \\
\hline 35 & 91408.240 & & & & & \\
\hline
\end{tabular}

Notes. See note to Table A.3. 
J. L. Lemaire et al.: Atlas of new and revised high-resolution spectroscopy of six CO isotopologues in the 101-115 nm range

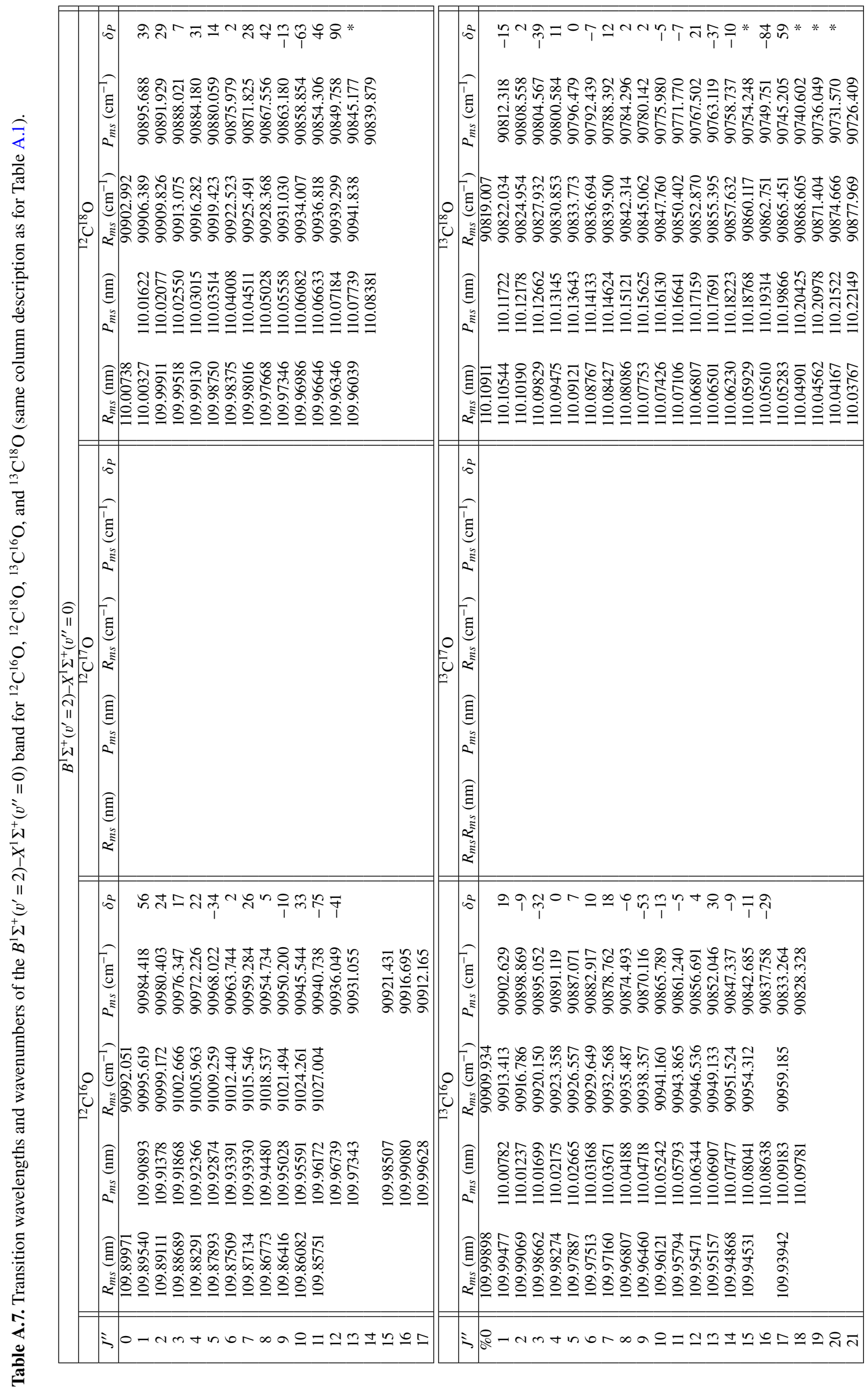


Table A.8. Term values $\left(\mathrm{cm}^{-1}\right)$ of the $B^{1} \Sigma^{+}\left(v^{\prime}=2\right)$ levels for ${ }^{12} \mathrm{C}^{16} \mathrm{O},{ }^{12} \mathrm{C}^{18} \mathrm{O},{ }^{13} \mathrm{C}^{16} \mathrm{O}$, and ${ }^{13} \mathrm{C}^{18} \mathrm{O}$.

\begin{tabular}{|c|c|c|c|c|c|c|}
\hline & \multicolumn{6}{|c|}{$B^{1} \Sigma^{+}\left(v^{\prime}=2\right)$} \\
\hline$J^{\prime}$ & ${ }^{12} \mathrm{C}^{16} \mathrm{O}$ & ${ }^{12} \mathrm{C}^{17} \mathrm{O}$ & ${ }^{12} \mathrm{C}^{18} \mathrm{O}$ & ${ }^{13} \mathrm{C}^{16} \mathrm{O}$ & ${ }^{13} \mathrm{C}^{17} \mathrm{O}$ & ${ }^{13} \mathrm{C}^{18} \mathrm{O}$ \\
\hline 0 & 90988.263 & & 90899.350 & 90906.304 & & 90815.811 \\
\hline 1 & $90991.994(56)$ & & $90902.953(39)$ & 90909.915 (19) & & $90819.021(-15)$ \\
\hline 2 & $90999.441(24)$ & & $90910.021(29)$ & $90917.098(-9)$ & & $90825.525(2)$ \\
\hline 3 & 91010.690 (17) & & $90920.805(7)$ & $90927.845(-32)$ & & $90835.471(-39)$ \\
\hline 4 & $91025.714(22)$ & & $90935.014(31)$ & $90942.205(0)$ & & $90848.877(11)$ \\
\hline 5 & $91044.445(-34)$ & & 90952.885 (14) & $90960.108(7)$ & & $90865.779(0)$ \\
\hline 6 & $91066.928(2)$ & & $90974.345(2)$ & $90981.681(10)$ & & $90886.168(-7)$ \\
\hline 7 & $91093.150(26)$ & & $90999.386(28)$ & $91006.816(18)$ & & $90910.023(12)$ \\
\hline 8 & $91123.183(5)$ & & $91027.966(42)$ & $91035.483(-6)$ & & $90937.280(2)$ \\
\hline 9 & $91156.937(-10)$ & & $91060.182(-13)$ & $91067.845(-53)$ & & $90968.026(2)$ \\
\hline 10 & $91194.439(33)$ & & $91095.836(-63)$ & $91103.742(-13)$ & & $91002.203(-5)$ \\
\hline 11 & $91235.740(-75)$ & & $91135.302(46)$ & $91143.274(-5)$ & & $91039.811(-7)$ \\
\hline 12 & $91280.712(-41)$ & & $91178.322(90)$ & $91186.375(4)$ & & $91080.819(21)$ \\
\hline 13 & & & $91224.469\left(^{*}\right)$ & $91233.094(30)$ & & $91125.223(-37)$ \\
\hline 14 & 91382.486 & & 91274.893 & $91283.468(-9)$ & & $91173.085(-10)$ \\
\hline 15 & 91439.170 & & & $91337.262(-11)$ & & $91224.278(122)$ \\
\hline 16 & 91499.886 & & & $91395.131(-29)$ & & $91279.049(-84)$ \\
\hline 17 & & & & 91456.260 & & $91337.342(59)$ \\
\hline 18 & & & & 91521.080 & & $91399.167\left(^{*}\right)$ \\
\hline 19 & & & & & & $91464.729\left(^{*}\right)$ \\
\hline 20 & & & & & & $91533.242\left(^{*}\right)$ \\
\hline 21 & & & & & & 91607.267 \\
\hline 22 & & & & & & 91683.733 \\
\hline
\end{tabular}

Notes. See note to Table A.3. 
J. L. Lemaire et al.: Atlas of new and revised high-resolution spectroscopy of six CO isotopologues in the 101-115 nm range
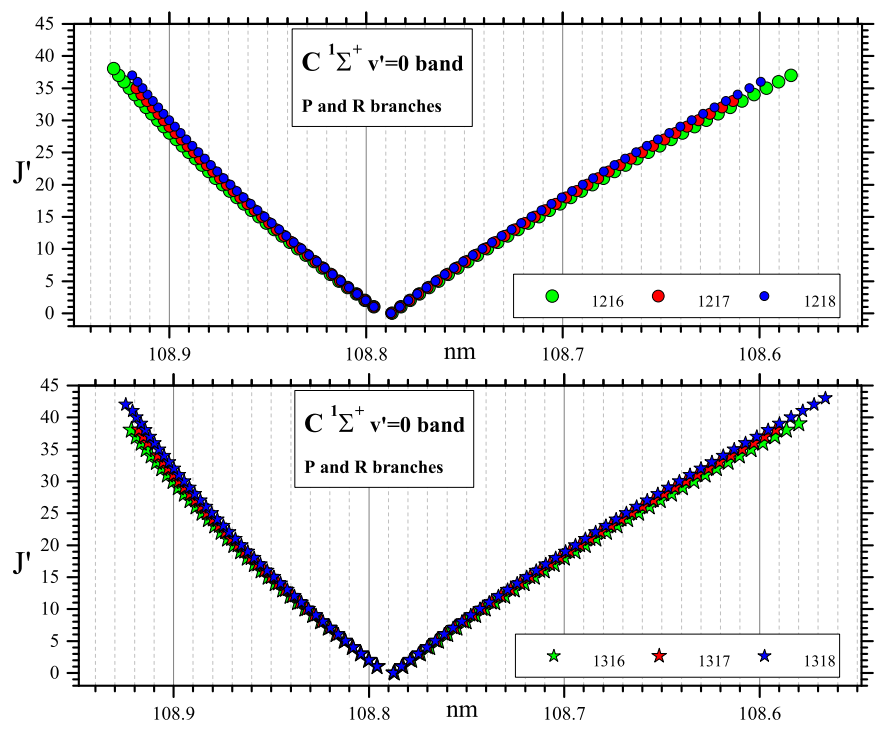

Fig. A.4. Transition wavelengths of the $C^{1} \Sigma^{+}\left(v^{\prime}=0\right)-X^{1} \Sigma^{+}\left(v^{\prime \prime}=0\right)$ band for six CO isotopologues.

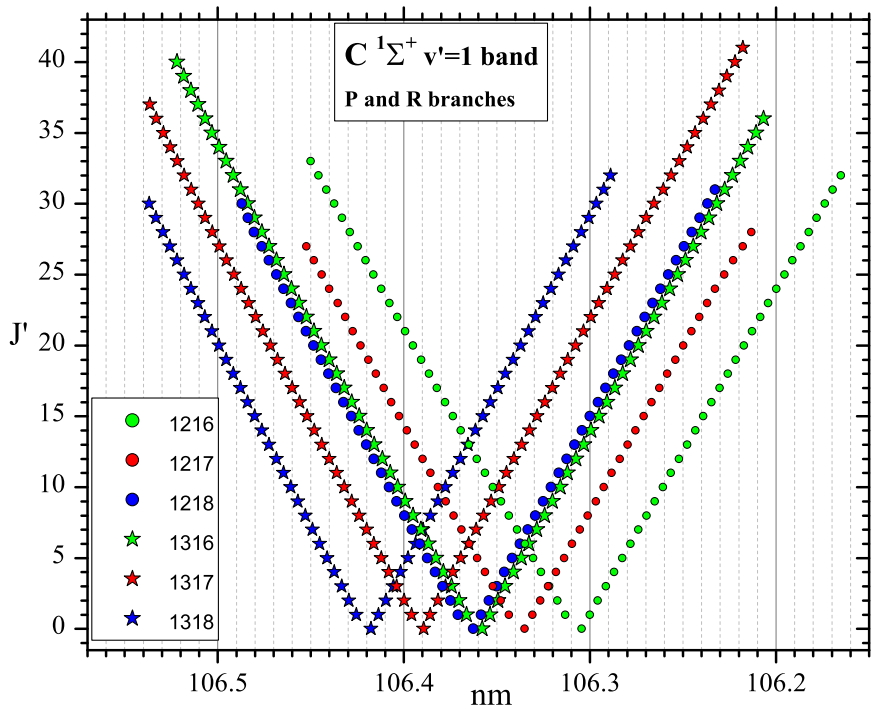

Fig. A.5. Transition wavelengths of the $C^{1} \Sigma^{+}\left(v^{\prime}=1\right)-X^{1} \Sigma^{+}\left(v^{\prime \prime}=0\right)$ band for six CO isotopologues. 

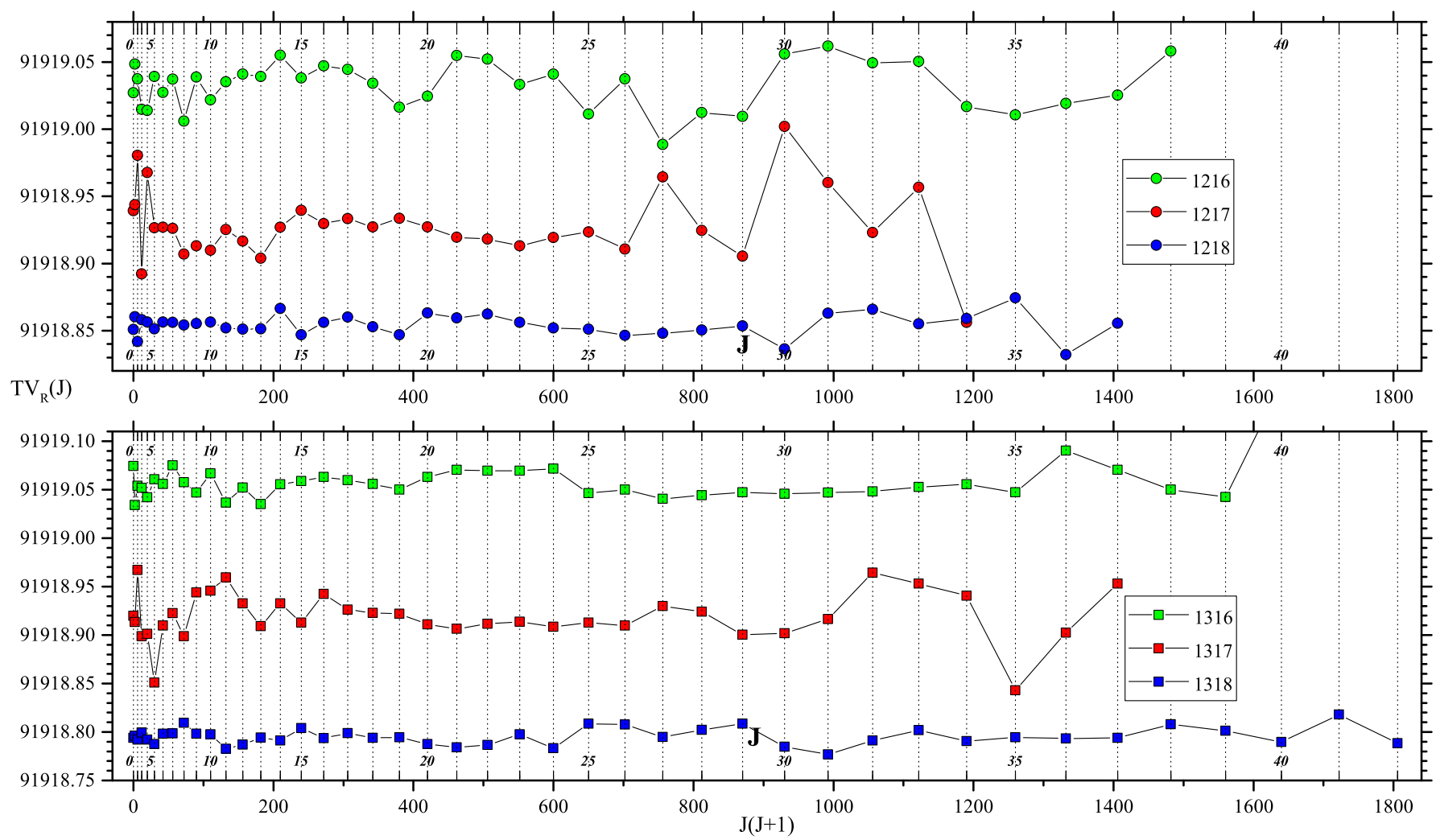

Fig. A.6. Reduced term values $\left(\mathrm{cm}^{-1}\right)$ of the $C^{1} \Sigma^{+}\left(v^{\prime}=0\right)$ levels for six $\mathrm{CO}$ isotopologues.

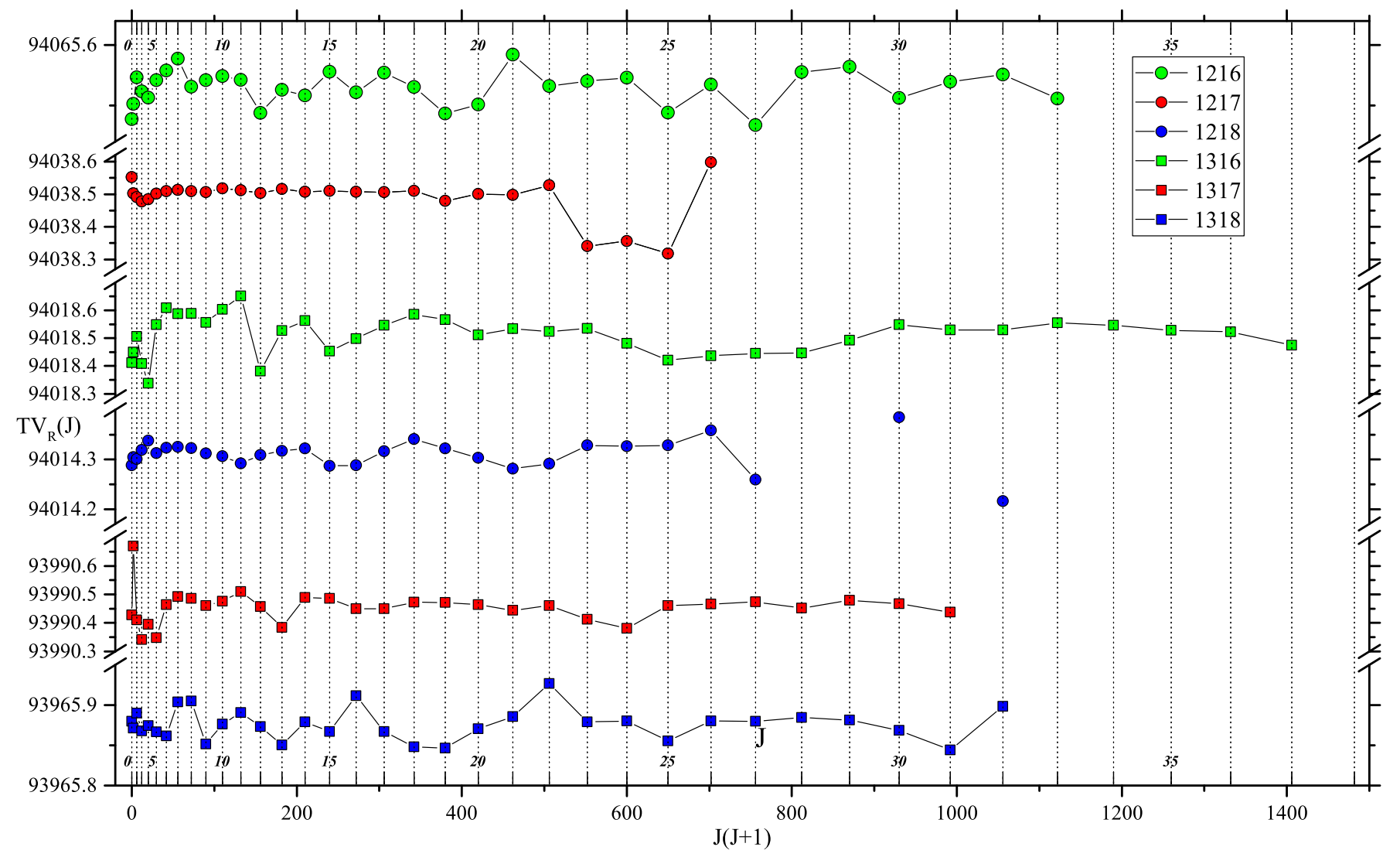

Fig. A.7. Reduced term values $\left(\mathrm{cm}^{-1}\right)$ of the $C^{1} \Sigma^{+}\left(v^{\prime}=1\right)$ levels for six CO isotopologues. 
J. L. Lemaire et al.: Atlas of new and revised high-resolution spectroscopy of six CO isotopologues in the 101-115 nm range

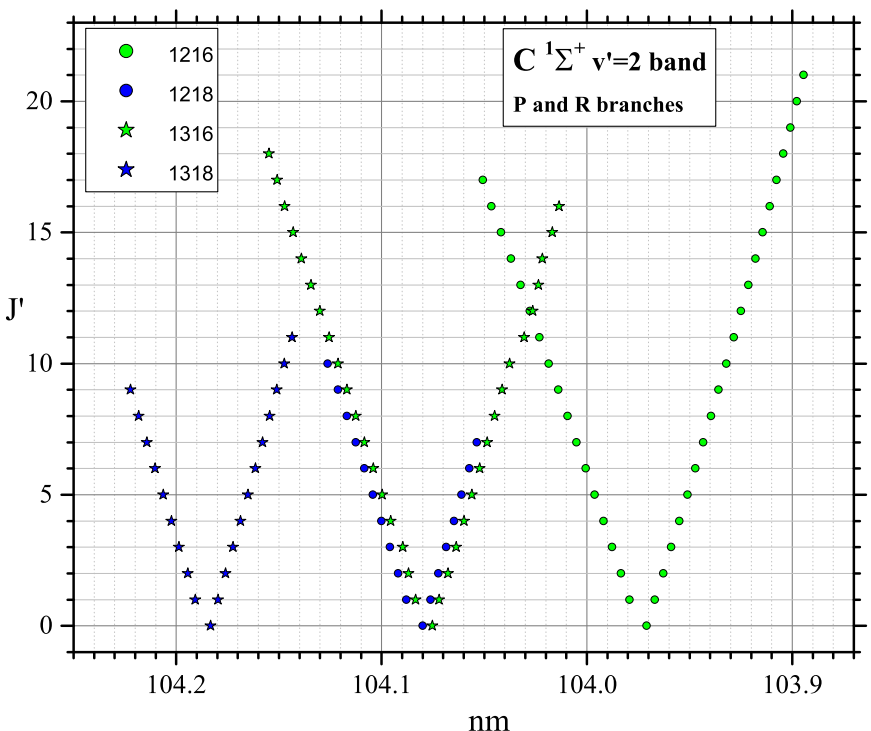

Fig. A.8. Transition wavelengths of the $C^{1} \Sigma^{+}\left(v^{\prime}=2\right)-X^{1} \Sigma^{+}\left(v^{\prime \prime}=0\right)$ band for the four observed $\mathrm{CO}$ isotopologues.

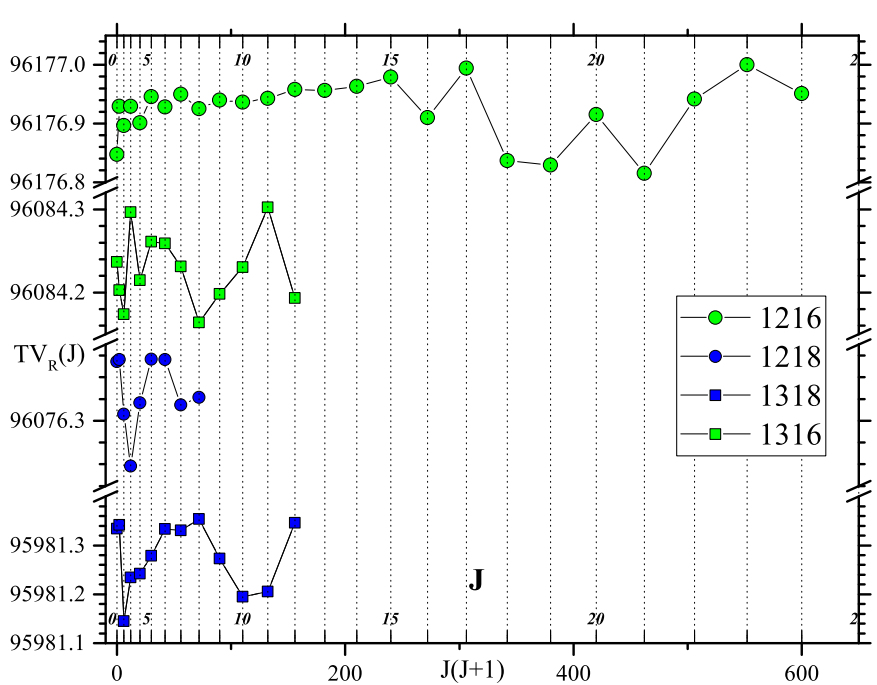

Fig. A.9. Reduced term values $\left(\mathrm{cm}^{-1}\right)$ of the $C^{1} \Sigma^{+}\left(v^{\prime}=2\right)$ levels for the four observed $\mathrm{CO}$ isotopologues.

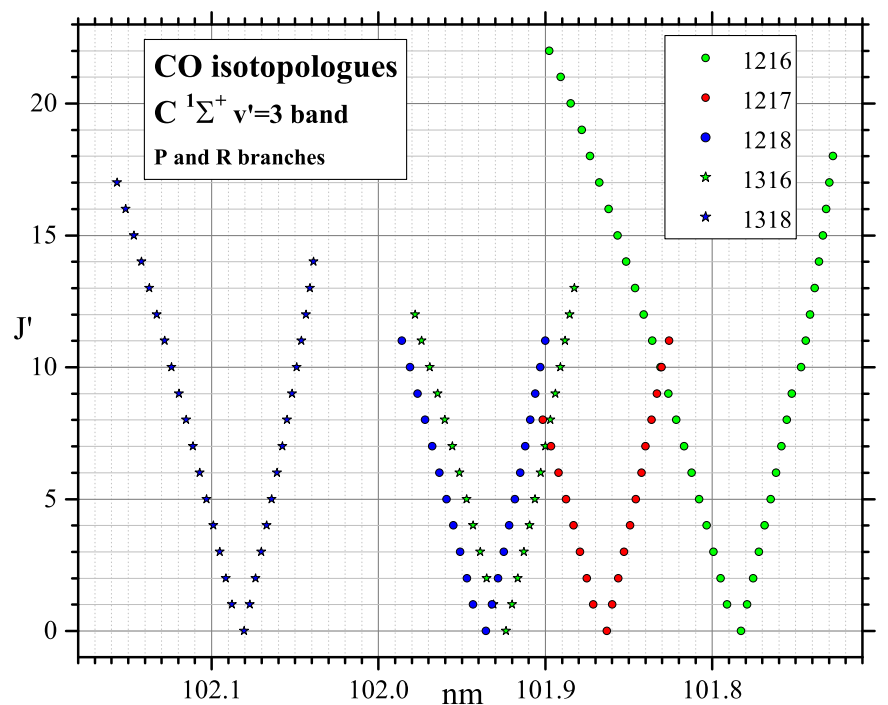

Fig. A.10. Transition wavelengths of the $C^{1} \Sigma^{+}\left(v^{\prime}=3\right)-X^{1} \Sigma^{+}\left(v^{\prime \prime}=0\right)$ band for the four observed $\mathrm{CO}$ isotopologues.

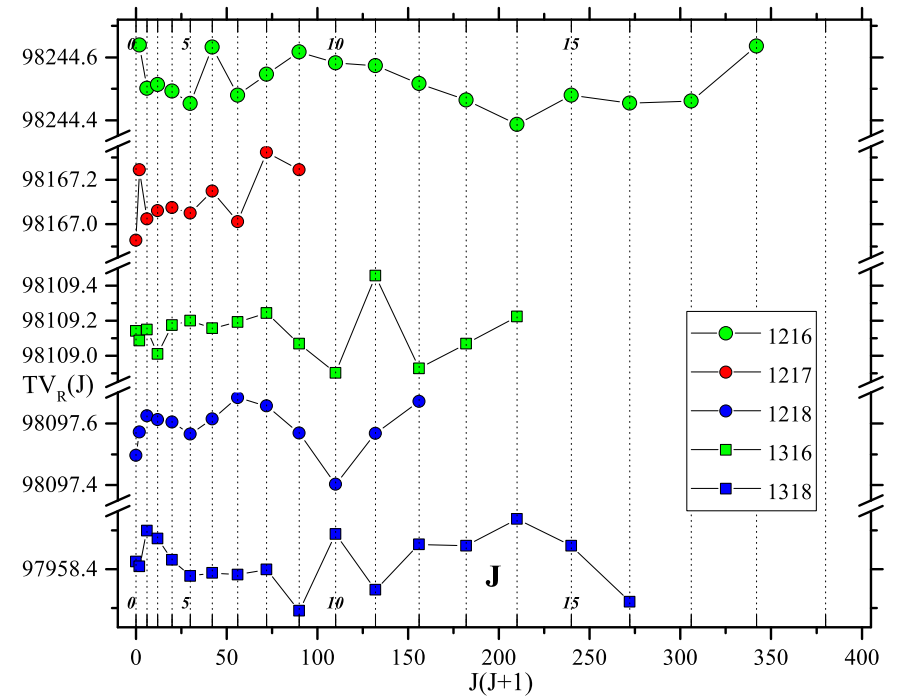

Fig. A.11. Reduced term values $\left(\mathrm{cm}^{-1}\right)$ of the $C^{1} \Sigma^{+}\left(v^{\prime}=3\right)$ levels for the five observed $\mathrm{CO}$ isotopologues. 


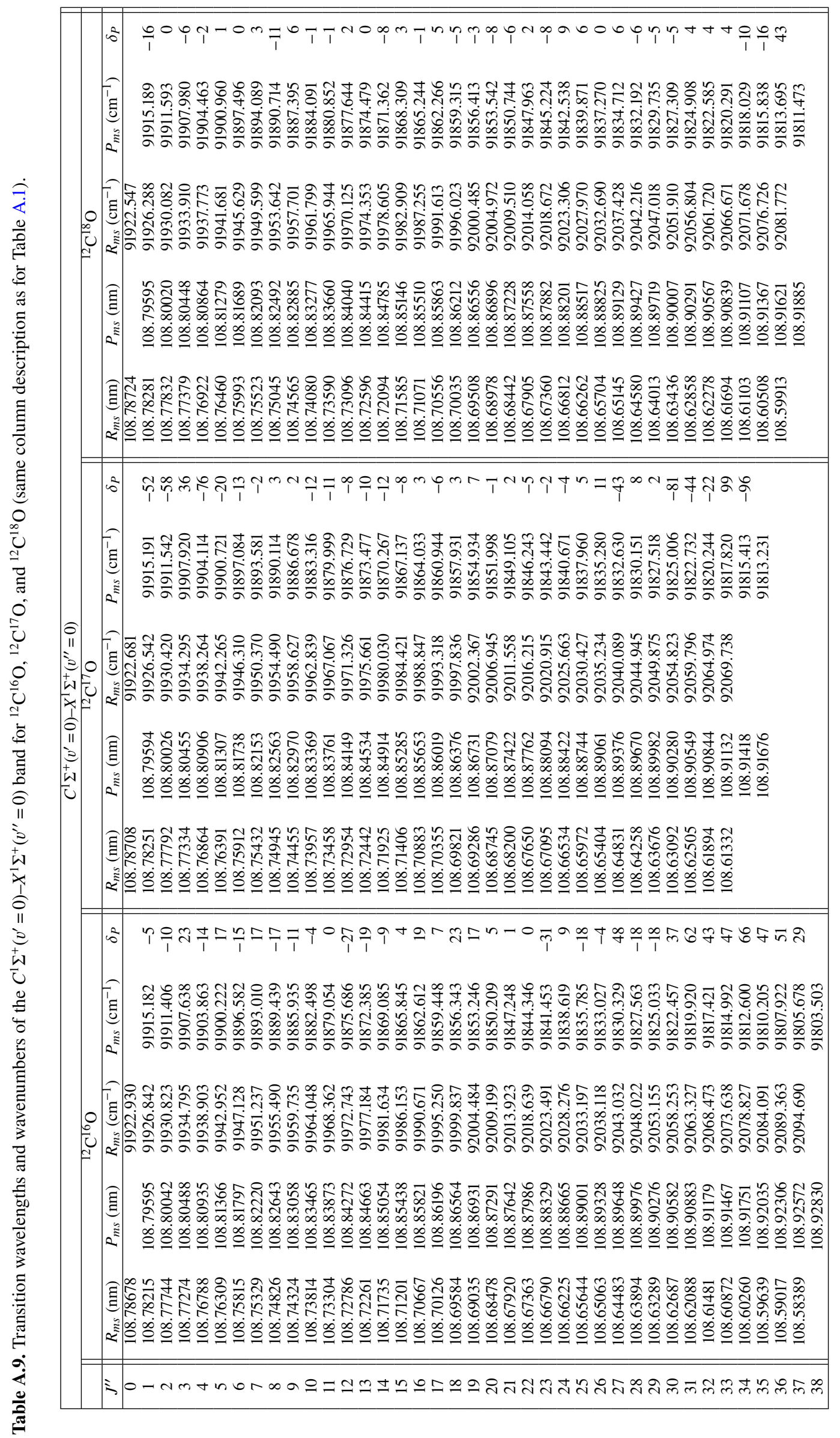

A114, page 26 of 62 
J. L. Lemaire et al.: Atlas of new and revised high-resolution spectroscopy of six CO isotopologues in the 101-115 nm range

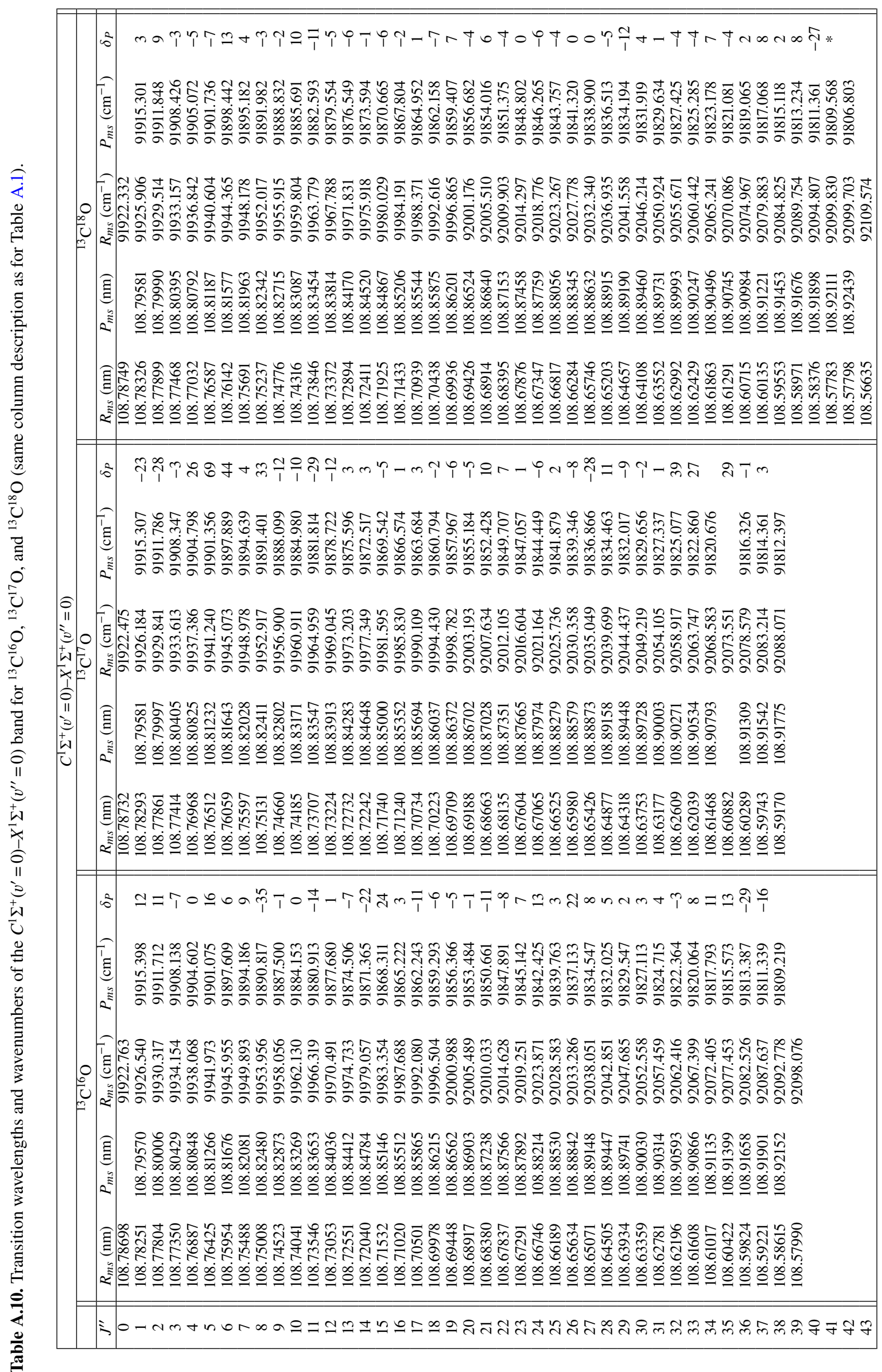


Table A.11. Term values $\left(\mathrm{cm}^{-1}\right)$ of the $C^{1} \Sigma^{+}\left(v^{\prime}=0\right)$ levels for six CO isotopologues.

\begin{tabular}{|c|c|c|c|c|c|c|}
\hline & \multicolumn{6}{|c|}{$C^{I} \Sigma^{+}\left(v^{\prime}=0\right)$} \\
\hline$J^{\prime}$ & ${ }^{12} \mathrm{C}^{16} \mathrm{O}$ & ${ }^{12} \mathrm{C}^{17} \mathrm{O}$ & ${ }^{12} \mathrm{C}^{18} \mathrm{O}$ & ${ }^{13} \mathrm{C}^{16} \mathrm{O}$ & ${ }^{13} \mathrm{C}^{17} \mathrm{O}$ & ${ }^{13} \mathrm{C}^{18} \mathrm{O}$ \\
\hline 0 & 91919.027 & 91918.939 & 91918.851 & 91919.074 & 91918.886 & 91918.794 \\
\hline 1 & $91922.935(-5)$ & $91922.733(-52)$ & $91922.563(-16)$ & $91922.751(12)$ & $91922.499(-23)$ & $91922.329(3)$ \\
\hline 2 & $91930.698(-10)$ & $91930.348(-58)$ & $91929.950(0)$ & 91930.204 (11) & $91929.791(-28)$ & $91929.390(9)$ \\
\hline 3 & $91942.334(23)$ & $91941.627(36)$ & $91941.074(-6)$ & $91941.352(-7)$ & $91940.580(-3)$ & $91939.995(-3)$ \\
\hline 4 & $91957.879(-14)$ & $91956.858(-76)$ & $91955.883(-2)$ & $91956.209(0)$ & $91955.059(26)$ & $91954.118(-5)$ \\
\hline 5 & 91977.334 (17) & $91975.760(-20)$ & 91974.389 (1) & 91974.809 (16) & 91973.103 (69) & $91971.775(-7)$ \\
\hline 6 & $92000.638(-15)$ & $91998.492(-13)$ & $91996.606(0)$ & $91997.101(6)$ & $91994.873(44)$ & 91992.978 (13) \\
\hline 7 & 92027.846 (17) & $92025.008(-2)$ & $92022.518(3)$ & $92023.131(9)$ & $92020.214(4)$ & 92017.701 (4) \\
\hline 8 & $92058.896(-17)$ & $92055.291(3)$ & $92052.127(-11)$ & $92052.837(-35)$ & $92049.134(33)$ & $92045.965(-3)$ \\
\hline 9 & $92093.891(-11)$ & $92089.383(2)$ & $92085.437(6)$ & $92086.262(-1)$ & $92081.738(-12)$ & $92077.734(-2)$ \\
\hline 10 & $92132.717(-4)$ & $92127.249(-12)$ & $92122.444(-1)$ & $92123.428(0)$ & $92117.912(-10)$ & $92113.041(10)$ \\
\hline 11 & $92175.452(0)$ & $92168.915(-11)$ & $92163.141(-1)$ & $92164.253(-14)$ & $92157.710(-29)$ & $92151.859(-11)$ \\
\hline 12 & $92222.056(-27)$ & $92214.337(-8)$ & $92207.535(2)$ & $92208.833(1)$ & $92201.079(-12)$ & $92194.222(-5)$ \\
\hline 13 & $92272.528(-19)$ & $92263.533(-10)$ & $92255.623(0)$ & $92257.085(-7)$ & $92248.060(3)$ & $92240.111(-6)$ \\
\hline 14 & $92326.890(-9)$ & $92316.541(-12)$ & $92307.416(-8)$ & $92309.080(-22)$ & $92298.695(3)$ & $92289.512(-1)$ \\
\hline 15 & $92385.092(4)$ & $92373.313(-8)$ & $92362.863(3)$ & $92364.760(24)$ & $92352.893(-5)$ & $92342.447(-6)$ \\
\hline 16 & 92447.188 (19) & $92433.835(3)$ & $92422.025(-1)$ & $92424.142(3)$ & $92410.744(1)$ & $92398.878(-2)$ \\
\hline 17 & $92513.139(7)$ & $92498.140(-6)$ & $92484.867(5)$ & $92487.214(-11)$ & $92472.151(3)$ & $92458.840(1)$ \\
\hline 18 & $92582.947(23)$ & $92566.203(3)$ & $92551.379(-5)$ & $92553.982(-6)$ & $92537.171(-2)$ & $92522.307(-7)$ \\
\hline 19 & 92656.609 (17) & $92638.044(7)$ & $92621.572(-3)$ & $92624.441(-5)$ & $92605.790(-6)$ & $92589.290(7)$ \\
\hline 20 & $92734.156(5)$ & $92713.634(-1)$ & $92695.465(-8)$ & $92698.610(-1)$ & $92677.993(-5)$ & $92659.775(-4)$ \\
\hline 21 & $92815.581(1)$ & $92792.982(2)$ & $92773.012(-6)$ & $92776.462(-11)$ & $92753.795(10)$ & $92733.771(6)$ \\
\hline 22 & $92900.825(0)$ & $92876.094(-5)$ & $92854.237(2)$ & $92857.991(-8)$ & $92833.197(7)$ & $92811.277(-4)$ \\
\hline 23 & $92989.903(-31)$ & $92962.954(-2)$ & $92939.122(-8)$ & $92943.203(7)$ & $92916.182(1)$ & $92892.294(0)$ \\
\hline 24 & $93082.854(9)$ & $93053.576(-4)$ & $93027.674(9)$ & $93032.096(13)$ & $93002.743(-6)$ & $92976.784(-6)$ \\
\hline 25 & $93179.610(-18)$ & $93147.943(5)$ & $93119.891(6)$ & $93124.638(3)$ & $93092.894(2)$ & $93064.809(-4)$ \\
\hline 26 & $93280.260(-4)$ & $93246.036(11)$ & $93215.764(0)$ & $93220.881(22)$ & $93186.615(-8)$ & $93156.301(0)$ \\
\hline 27 & $93384.671(48)$ & $93347.935(-43)$ & $93315.298(6)$ & $93320.780(8)$ & $93283.933(-28)$ & $93251.270(0)$ \\
\hline 28 & $93492.986(-18)$ & $93453.476(8)$ & $93418.485(-6)$ & $93424.358(5)$ & $93384.795(11)$ & $93349.746(-5)$ \\
\hline 29 & $93605.101(-18)$ & $93562.769(2)$ & $93525.320(-5)$ & $93531.596(2)$ & $93489.206(-9)$ & $93451.704(-12)$ \\
\hline 30 & $93721.089(37)$ & $93675.906(-81)$ & $93635.779(-5)$ & $93642.487(3)$ & $93597.205(-2)$ & $93557.111(4)$ \\
\hline 31 & $93840.854(62)$ & $93792.627(-44)$ & $93749.921(4)$ & $93757.034(4)$ & 93708.777 (1) & $93666.009(1)$ \\
\hline 32 & $93964.415(43)$ & $93913.072(-22)$ & $93867.675(4)$ & $93875.231(-3)$ & $93823.936(39)$ & $93778.401(-4)$ \\
\hline 33 & $94091.798(47)$ & 94037.302 (99) & $93989.048(4)$ & $93997.075(8)$ & $93942.588(27)$ & $93894.258(-4)$ \\
\hline 34 & $94222.951(66)$ & $94165.107(-96)$ & $94114.061(-10)$ & $94122.558(11)$ & 94064.784 & $94013.556(7)$ \\
\hline 35 & $94357.931(47)$ & & $94242.709(-16)$ & $94251.666(13)$ & $94190.438(29)$ & $94136.329(-4)$ \\
\hline 36 & $94496.720(51)$ & & $94374.916(43)$ & $94384.456(-29)$ & $94319.787(-1)$ & $94262.552(2)$ \\
\hline 37 & 94639.295 (29) & & 94510.802 & $94520.809(-16)$ & $94452.659(3)$ & $94392.228(8)$ \\
\hline 38 & 94785.681 & & & 94660.782 & 94588.641 & $94525.363(2)$ \\
\hline 39 & & & & 94804.384 & 94728.331 & $94661.919(8)$ \\
\hline 40 & & & & 94951.719 & & $94801.907(-27)$ \\
\hline 41 & & & & & & $94944.865\left(^{*}\right)$ \\
\hline 42 & & & & & & 95092.196 \\
\hline 43 & & & & & & 95237.275 \\
\hline 44 & & & & & & 95395.735 \\
\hline
\end{tabular}

Notes. The $\delta_{P}$ value in parentheses (in units of the least significant digit) corresponds to the wavenumber correction applied to $\mathrm{TV}_{P}$ and $\mathrm{TV}_{R}$. There is no value when the term value is derived from a single transition, either $R$ or $P$. An asterisk indicates when both $R$ - and $P$-branches are present at high $J^{\prime}$, either the potential presence of a perturbing state or that one of the lines shows a larger uncertainty than the other (see also Sect. 2.2.2). 
J. L. Lemaire et al.: Atlas of new and revised high-resolution spectroscopy of six CO isotopologues in the 101-115 nm range

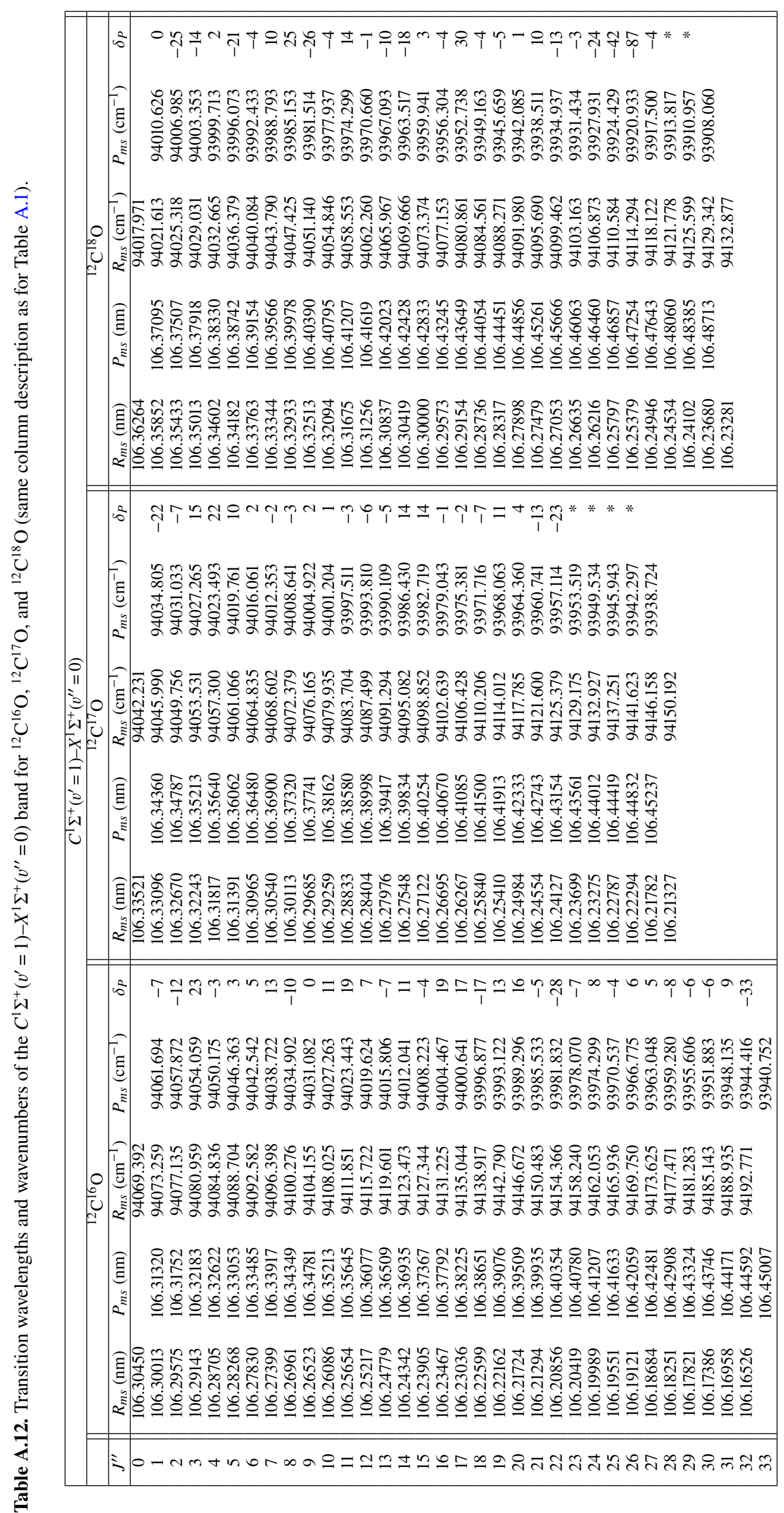




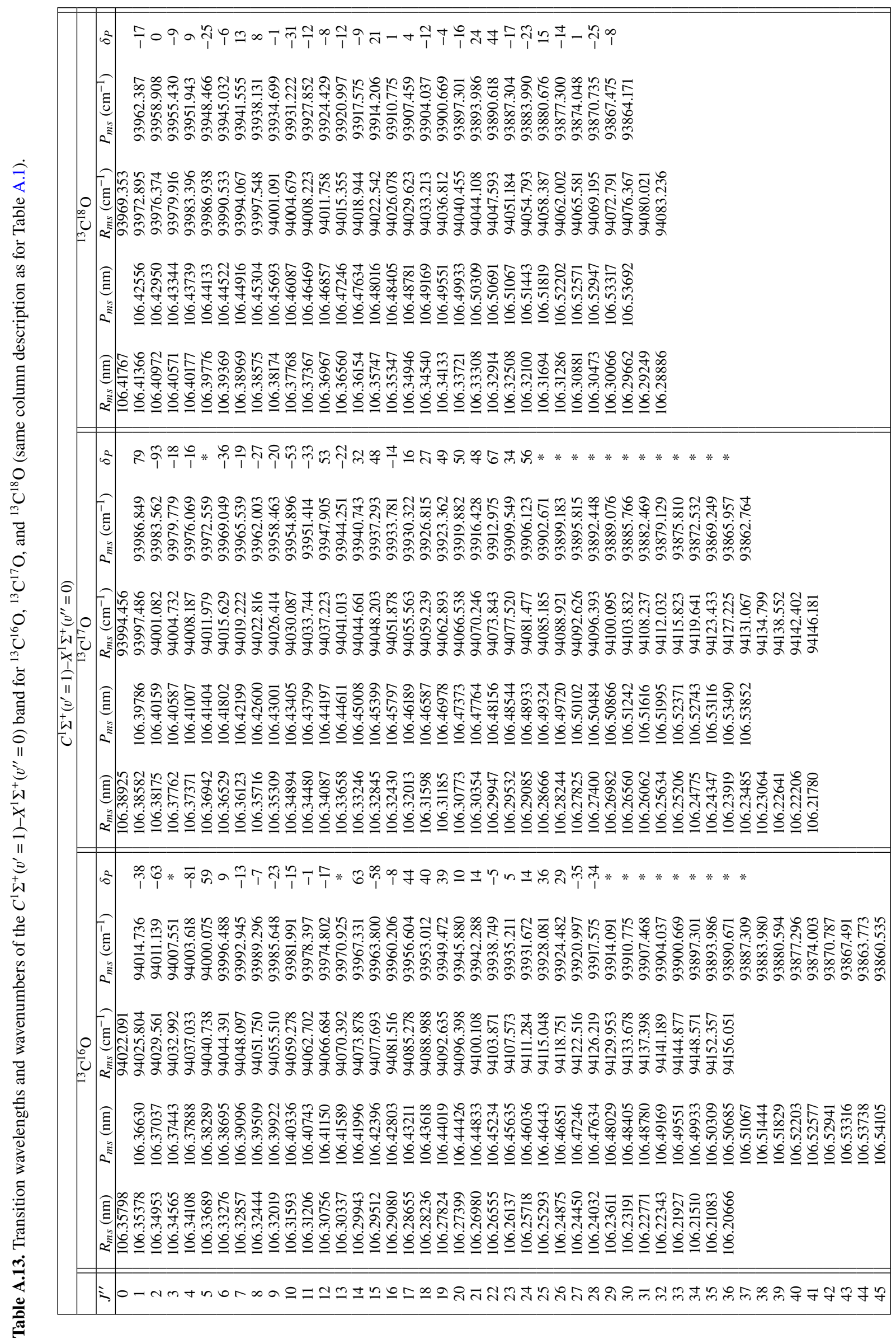

A114, page 30 of 62 
Table A.14. Term values $\left(\mathrm{cm}^{-1}\right)$ of the $C^{1} \Sigma^{+}\left(v^{\prime}=1\right)$ levels for six CO isotopologues.

\begin{tabular}{|c|c|c|c|c|c|c|}
\hline & \multicolumn{6}{|c|}{$C^{1} \Sigma^{+}\left(v^{\prime}=1\right)$} \\
\hline$J^{\prime}$ & ${ }^{12} \mathrm{C}^{16} \mathrm{O}$ & ${ }^{12} \mathrm{C}^{17} \mathrm{O}$ & ${ }^{12} \mathrm{C}^{18} \mathrm{O}$ & ${ }^{13} \mathrm{C}^{16} \mathrm{O}$ & ${ }^{13} \mathrm{C}^{17} \mathrm{O}$ & ${ }^{13} \mathrm{C}^{18} \mathrm{O}$ \\
\hline 0 & 94065.539 & 94038.553 & 94014.288 & 94018.412 & 93990.428 & 93965.880 \\
\hline 1 & $94069.399(-7)$ & $94042.254(-22)$ & $94017.971(0)$ & $94022.129(-38)$ & $93994.252\left(^{*}\right)$ & $93969.370(-17)$ \\
\hline 2 & $94077.116(-12)$ & $94049.745(-7)$ & $94025.300(-25)$ & $94029.543(-63)$ & $94001.158(-93)$ & $93976.387(0)$ \\
\hline 3 & $94088.647(23)$ & $94060.985(15)$ & $94036.317(-14)$ & $94040.482(107)$ & $94011.837(-18)$ & $93986.861(-9)$ \\
\hline 4 & $94104.031(-3)$ & $94075.996(22)$ & 94050.999 (2) & $94055.128(-81)$ & $94026.220(-16)$ & $94000.863(9)$ \\
\hline 5 & $94123.281(3)$ & 94094.767 (10) & $94069.303(-21)$ & $94073.731(59)$ & $94044.084\left({ }^{*}\right)$ & $94018.347(-25)$ \\
\hline 6 & $94146.370(5)$ & $94117.278(2)$ & $94091.307(-4)$ & $94095.863(9)$ & $94065.692(-36)$ & $94039.332(-6)$ \\
\hline 7 & $94173.305(13)$ & $94143.533(-2)$ & 94116.965 (10) & $94121.589(-13)$ & $94090.793(-19)$ & $94063.860(13)$ \\
\hline 8 & $94204.050(-10)$ & $94173.529(-3)$ & $94146.282(25)$ & $94151.013(-7)$ & $94119.439(-27)$ & $94091.842(8)$ \\
\hline 9 & $94238.667(0)$ & $94207.272(2)$ & $94179.252(-26)$ & $94184.078(-23)$ & $94151.645(-20)$ & $94123.265(-1)$ \\
\hline 10 & 94277.122 (11) & $94244.774(1)$ & $94215.887(-4)$ & $94220.897(-15)$ & $94187.469(-53)$ & $94158.259(-31)$ \\
\hline 11 & 94319.409 (19) & $94286.003(-3)$ & $94256.173(14)$ & $94261.389(-1)$ & $94226.890(-33)$ & $94196.734(-12)$ \\
\hline 12 & $94365.511(7)$ & $94330.972(-6)$ & $94300.147(-1)$ & $94305.234(-17)$ & $94269.799(53)$ & $94238.669(-8)$ \\
\hline 13 & $94415.494(-7)$ & $94379.701(-5)$ & $94347.768(-10)$ & $94353.165(106)$ & $94316.262(-22)$ & $94284.086(-12)$ \\
\hline 14 & $94469.288(11)$ & $94432.149(14)$ & $94399.040(-18)$ & $94404.654(63)$ & 94366.475 (32) & $94333.044(-9)$ \\
\hline 15 & $94526.938(-4)$ & $94488.344(14)$ & $94453.924(3)$ & $94459.663(-58)$ & $94420.153(48)$ & $94385.446(21)$ \\
\hline 16 & $94588.380(19)$ & $94548.269(-1)$ & $94512.494(-4)$ & $94518.492(-8)$ & $94477.368(-14)$ & $94441.388(1)$ \\
\hline 17 & $94653.683(17)$ & $94611.929(-2)$ & $94574.739(30)$ & $94580.988(44)$ & $94538.186(16)$ & $94500.723(4)$ \\
\hline 18 & $94722.782(-17)$ & $94679.323(-7)$ & $94640.626(-4)$ & $94647.134(40)$ & 94602.595 (27) & $94563.564(-12)$ \\
\hline 19 & $94795.693(13)$ & $94750.410(11)$ & $94710.113(-5)$ & $94716.881(39)$ & $94670.543(49)$ & $94629.898(-4)$ \\
\hline 20 & $94872.451(16)$ & $94825.275(4)$ & $94783.241(1)$ & 94790.247 (10) & 94742.049 (50) & $94699.734(-16)$ \\
\hline 21 & $94953.060(-5)$ & $94903.838(-13)$ & $94860.003(10)$ & 94867.346 (14) & $94817.102(48)$ & $94773.033(24)$ \\
\hline 22 & $95037.414(-28)$ & $94986.153(-23)$ & $94940.432(-13)$ & $94948.063(-5)$ & 94895.749 (67) & $94849.828(44)$ \\
\hline 23 & $95125.607(-7)$ & $95071.968\left(^{*}\right)$ & $95024.520(-3)$ & $95032.448(5)$ & $94977.888(34)$ & $94930.001(-17)$ \\
\hline 24 & $95217.604(8)$ & $95161.698\left(^{*}\right)$ & $95112.198(-24)$ & $95120.416(14)$ & $95063.597(56)$ & $95013.686(-23)$ \\
\hline 25 & $95313.372(-4)$ & $95255.084\left(^{*}\right)$ & $95203.506(-42)$ & $95212.019(36)$ & $95152.969\left(^{*}\right)$ & $95100.807(15)$ \\
\hline 26 & $95412.990(6)$ & $95352.495\left(^{*}\right)$ & $95298.465(-87)$ & $95307.339(29)$ & $95245.814\left({ }^{*}\right)$ & $95191.435(-14)$ \\
\hline 27 & $95516.346(5)$ & 95454.281 & $95396.912(-4)$ & $95406.288(-35)$ & $95342.207\left(^{*}\right)$ & $95285.493(1)$ \\
\hline 28 & $95623.569(-8)$ & 95559.553 & $95499.443\left(^{*}\right)$ & $95508.862(-34)$ & $95442.113\left(^{*}\right)$ & $95383.007(-25)$ \\
\hline 29 & $95734.539(-6)$ & 95668.018 & $95605.477\left(^{*}\right)$ & $95615.111\left(^{*}\right)$ & $95545.608\left(^{*}\right)$ & $95483.960(-8)$ \\
\hline 30 & $95849.260(-6)$ & & 95714.354 & $95724.997\left(^{*}\right)$ & $95652.600\left(^{*}\right)$ & 95588.347 \\
\hline 31 & $95967.797(9)$ & & 95827.358 & $95838.431\left(^{*}\right)$ & $95763.109\left(^{*}\right)$ & 95696.164 \\
\hline 32 & $96090.099(-33)$ & & 95943.752 & $95955.503\left(^{*}\right)$ & $95877.478\left(^{*}\right)$ & 95807.494 \\
\hline 33 & 96216.142 & & & $96076.216\left(^{*}\right)$ & $95995.073\left(^{*}\right)$ & 95921.819 \\
\hline 34 & & & & $96200.504\left(^{*}\right)$ & $96116.172\left(^{*}\right)$ & \\
\hline 35 & & & & $96328.391\left(^{*}\right)$ & $96240.783\left(^{*}\right)$ & \\
\hline 36 & & & & $96459.893\left(^{*}\right)$ & $96368.929\left(^{*}\right)$ & \\
\hline 37 & & & & $96594.952\left(^{*}\right)$ & 96501.308 & \\
\hline 38 & & & & 96734.237 & 96636.494 & \\
\hline 39 & & & & 96876.548 & 96775.059 & \\
\hline 40 & & & & 97022.430 & 96917.129 & \\
\hline 41 & & & & 97171.950 & 97062.777 & \\
\hline 42 & & & & 97324.945 & 97211.828 & \\
\hline 43 & & & & 97481.067 & & \\
\hline 44 & & & & 97641.214 & & \\
\hline
\end{tabular}

Notes. See note to Table A.11. 


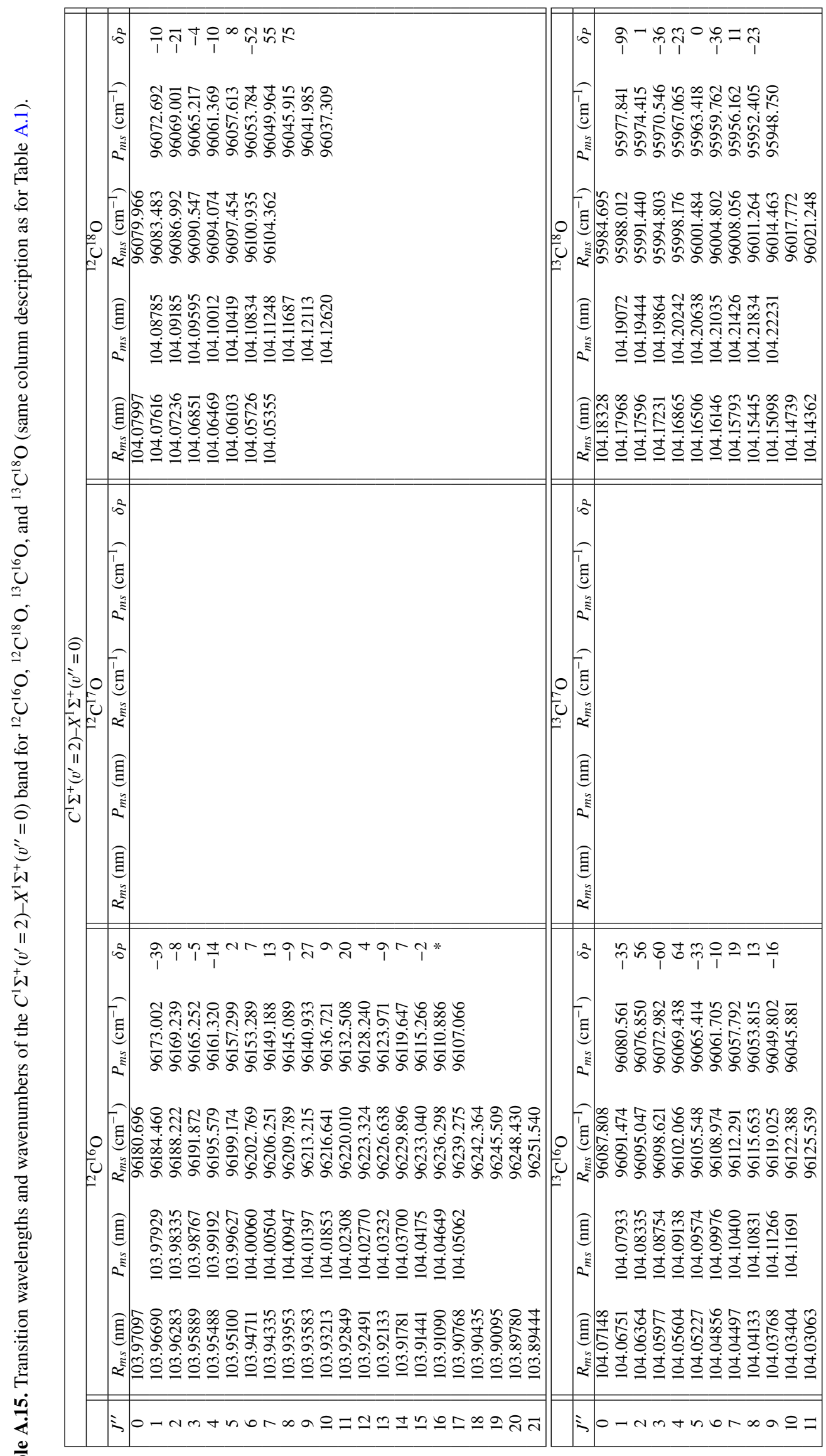


Table A.16. Term values $\left(\mathrm{cm}^{-1}\right)$ of the $C^{1} \Sigma^{+}\left(v^{\prime}=2\right)$ levels for ${ }^{12} \mathrm{C}^{16} \mathrm{O},{ }^{12} \mathrm{C}^{18} \mathrm{O},{ }^{13} \mathrm{C}^{16} \mathrm{O}$ and ${ }^{13} \mathrm{C}^{18} \mathrm{O}$.

\begin{tabular}{|c|c|c|c|c|c|c|}
\hline & \multicolumn{6}{|c|}{$C^{I} \Sigma^{+}\left(v^{\prime}=2\right)$} \\
\hline$J^{\prime}$ & ${ }^{12} \mathrm{C}^{16} \mathrm{O}$ & ${ }^{12} \mathrm{C}^{17} \mathrm{O}$ & ${ }^{12} \mathrm{C}^{18} \mathrm{O}$ & ${ }^{13} \mathrm{C}^{16} \mathrm{O}$ & ${ }^{13} \mathrm{C}^{17} \mathrm{O}$ & ${ }^{13} \mathrm{C}^{18} \mathrm{O}$ \\
\hline 0 & 96176.847 & & 96076.354 & 96084.237 & & 95981.334 \\
\hline 1 & $96180.735(-39)$ & & $96079.976(-10)$ & $96087.843(-35)$ & & $95984.794(-99)$ \\
\hline 2 & $96188.313(-8)$ & & $96087.167(-21)$ & $96095.093(56)$ & & $95991.504(1)$ \\
\hline 3 & $96199.763(-5)$ & & $96097.982(-4)$ & $96106.135(-60)$ & & $96001.954(-36)$ \\
\hline 4 & $96214.956(-14)$ & & $96112.527(-10)$ & $96120.612(64)$ & & $96015.782(-23)$ \\
\hline 5 & $96234.026(2)$ & & $96130.683(8)$ & $96138.856(-33)$ & & $96033.102(0)$ \\
\hline 6 & $96256.838(7)$ & & $96152.430(-52)$ & $96160.691(-10)$ & & $96053.908(-36)$ \\
\hline 7 & $96283.492(13)$ & & $96177.772(55)$ & $96186.140(19)$ & & $96078.132(11)$ \\
\hline 8 & $96313.902(-9)$ & & $96206.804(75)$ & $96215.187(13)$ & & $96105.863(-23)$ \\
\hline 9 & $96348.152(27)$ & & 96238.649 & $96247.974(-16)$ & & 96136.979 \\
\hline 10 & $96386.184(9)$ & & & 96284.397 & & 96171.599 \\
\hline 11 & $96428.026(20)$ & & & 96324.497 & & 96209.816 \\
\hline 12 & $96473.673(4)$ & & & 96368.054 & & 96251.686 \\
\hline 13 & $96523.099(-9)$ & & & & & \\
\hline 14 & $96576.328(7)$ & & & & & \\
\hline 15 & $96633.359(-2)$ & & & & & \\
\hline 16 & $96694.441\left(^{*}\right)$ & & & & & \\
\hline 17 & 96758.774 & & & & & \\
\hline 18 & 96826.996 & & & & & \\
\hline 19 & 96899.153 & & & & & \\
\hline 20 & 96975.186 & & & & & \\
\hline 21 & 97054.812 & & & & & \\
\hline 22 & 97138.442 & & & & & \\
\hline
\end{tabular}

Notes. See note to Table A.11. 


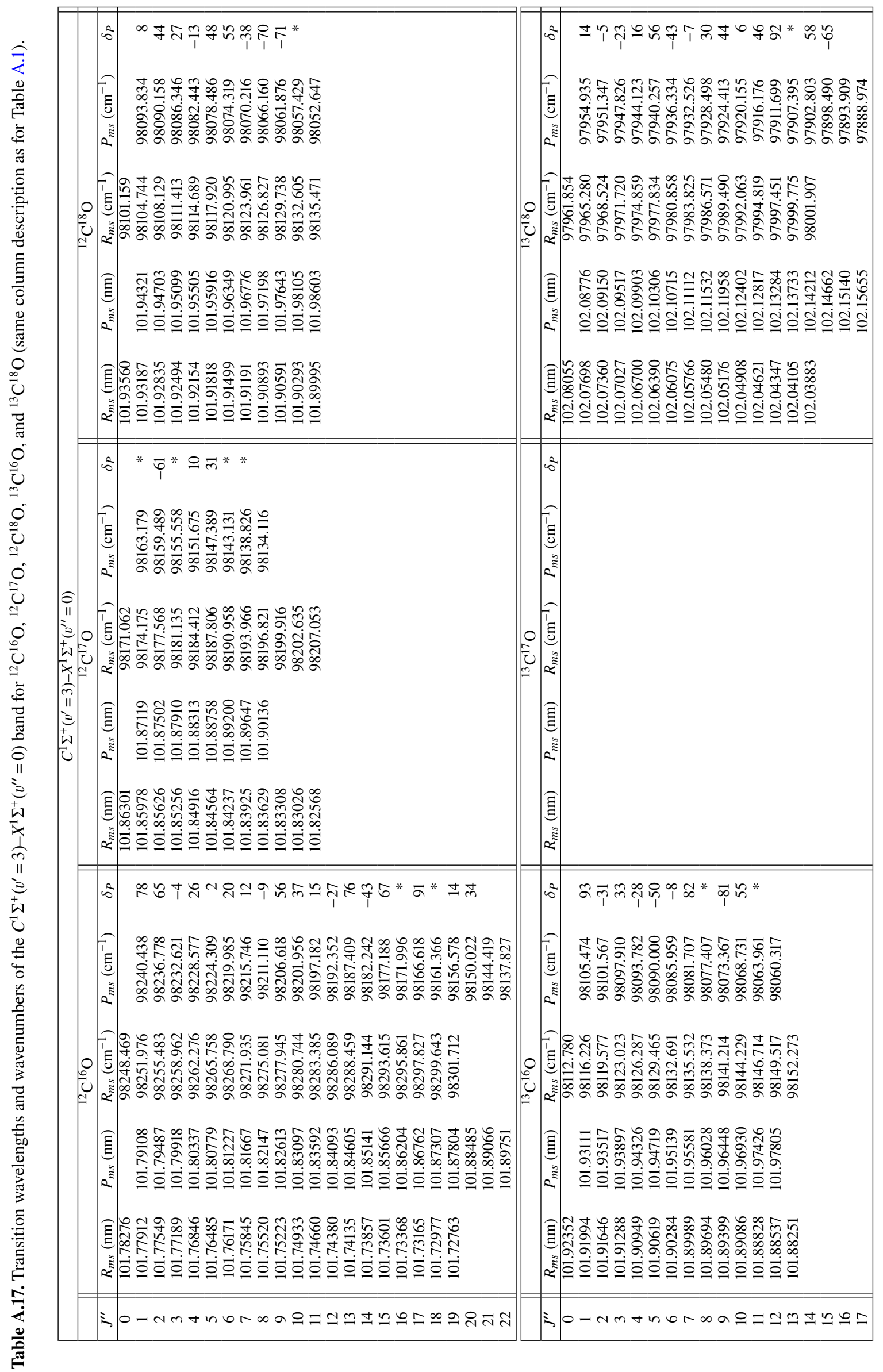


J. L. Lemaire et al.: Atlas of new and revised high-resolution spectroscopy of six CO isotopologues in the 101-115 nm range

Table A.18. Term values $\left(\mathrm{cm}^{-1}\right)$ of the $C^{1} \Sigma^{+}\left(v^{\prime}=3\right)$ levels for ${ }^{12} \mathrm{C}^{16} \mathrm{O},{ }^{12} \mathrm{C}^{17} \mathrm{O},{ }^{12} \mathrm{C}^{18} \mathrm{O},{ }^{13} \mathrm{C}^{16} \mathrm{O}$ and ${ }^{13} \mathrm{C}^{18} \mathrm{O}$.

\begin{tabular}{|c|c|c|c|c|c|c|}
\hline & \multicolumn{6}{|c|}{$C^{1} \Sigma^{+}\left(v^{\prime}=3\right)$} \\
\hline$J^{\prime}$ & ${ }^{12} \mathrm{C}^{16} \mathrm{O}$ & ${ }^{12} \mathrm{C}^{17} \mathrm{O}$ & ${ }^{12} \mathrm{C}^{18} \mathrm{O}$ & ${ }^{13} \mathrm{C}^{16} \mathrm{O}$ & ${ }^{13} \mathrm{C}^{17} \mathrm{O}$ & ${ }^{13} \mathrm{C}^{18} \mathrm{O}$ \\
\hline 0 & 98244.283 & 98166.927 & 98097.496 & 98109.150 & & 97958.428 \\
\hline 1 & $98248.391(78)$ & $98170.897\left(^{*}\right)$ & $98101.151(8)$ & $98112.687(93)$ & & 97961.839 (14) \\
\hline 2 & $98255.756(65)$ & $98177.984(-61)$ & $98108.361(44)$ & $98119.934(-31)$ & & $97968.777(-5)$ \\
\hline 3 & $98267.022(-4)$ & $98188.982\left({ }^{*}\right)$ & $98119.088(27)$ & $98130.572(33)$ & & $97979.025(-23)$ \\
\hline 4 & $98282.005(26)$ & $98203.612(10)$ & $98133.397(-13)$ & $98145.106(-28)$ & & $97992.660(16)$ \\
\hline 5 & $98300.722(2)$ & $98221.858(31)$ & $98151.258(48)$ & $98163.094(-50)$ & & $98009.729(56)$ \\
\hline 6 & $98323.408(20)$ & $98243.884\left(^{*}\right)$ & $98172.789(55)$ & $98184.608(-8)$ & & $98030.266(-43)$ \\
\hline 7 & $98349.513(12)$ & $98269.333\left(^{*}\right)$ & $98197.924(-38)$ & $98209.794(82)$ & & $98054.206(-7)$ \\
\hline 8 & $98379.587(-9)$ & 98298.890 & $98226.549(-70)$ & $98238.590\left(^{*}\right)$ & & $98081.578(30)$ \\
\hline 9 & $98413.415(56)$ & 98331.716 & $98258.699(-71)$ & $98270.759(-81)$ & & $98112.243(44)$ \\
\hline 10 & $98450.886(37)$ & 98368.526 & $98294.361\left(^{*}\right)$ & $98306.531(55)$ & & $98146.620(6)$ \\
\hline 11 & $98492.133(15)$ & 98408.701 & 98333.946 & $98346.621\left(^{*}\right)$ & & $98184.062(46)$ \\
\hline 12 & $98537.080(-27)$ & 98454.314 & 98377.064 & 98389.229 & & $98225.166(92)$ \\
\hline 13 & $98585.779(76)$ & & & 98436.105 & & $98269.547\left(^{*}\right)$ \\
\hline 14 & $98638.200(-43)$ & & & 98486.598 & & $98317.396(58)$ \\
\hline 15 & $98694.538(67)$ & & & & & $98368.494(-65)$ \\
\hline 16 & $98754.504\left(^{*}\right)$ & & & & & 98422.903 \\
\hline 17 & $98818.246(91)$ & & & & & \\
\hline 18 & $98885.902\left({ }^{*}\right)$ & & & & & \\
\hline 19 & $98956.419(14)$ & & & & & \\
\hline 20 & 99031.355 (34) & & & & & \\
\hline 21 & 99109.060 & & & & & \\
\hline
\end{tabular}

Notes. See note to Table A.11. 

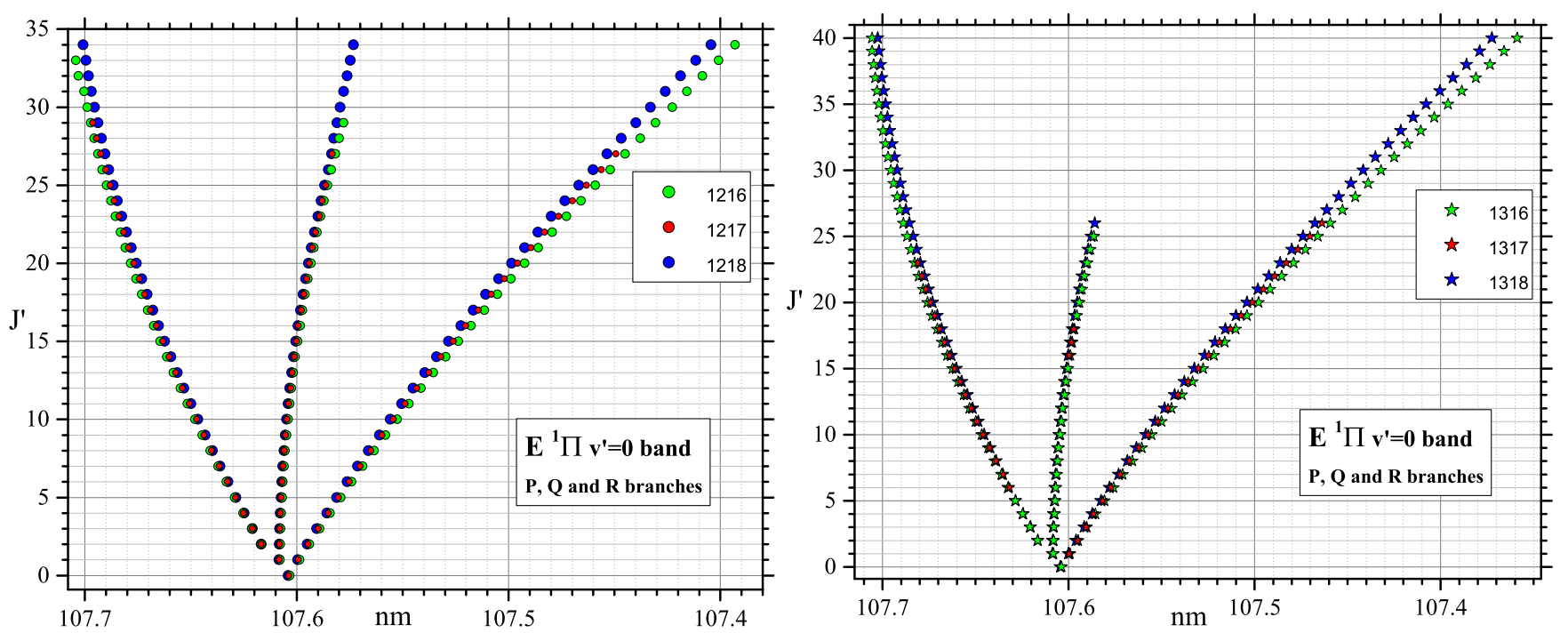

Fig. A.12. Transition wavelengths of the $E^{1} \Pi\left(v^{\prime}=0\right)-X^{1} \Sigma^{+}\left(v^{\prime \prime}=0\right)$ band for six CO isotopologues.

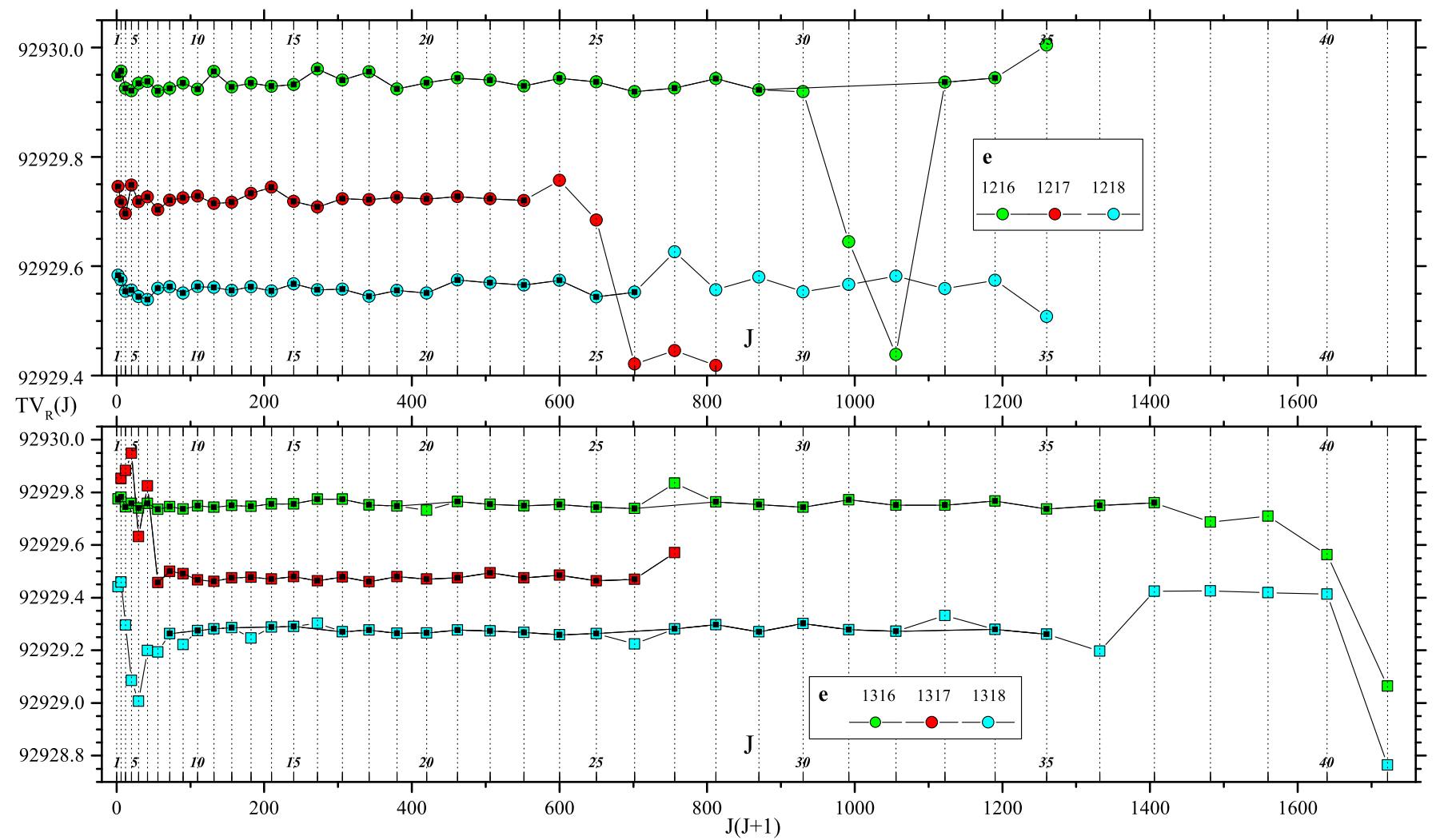

Fig. A.13. e-parity reduced term values $\left(\mathrm{cm}^{-1}\right)$ of the $E^{1} \Pi\left(v^{\prime}=0\right)$ levels for six CO isotopologues. Data marked with a black center are kept to calculate molecular constants. 
J. L. Lemaire et al.: Atlas of new and revised high-resolution spectroscopy of six CO isotopologues in the 101-115 nm range
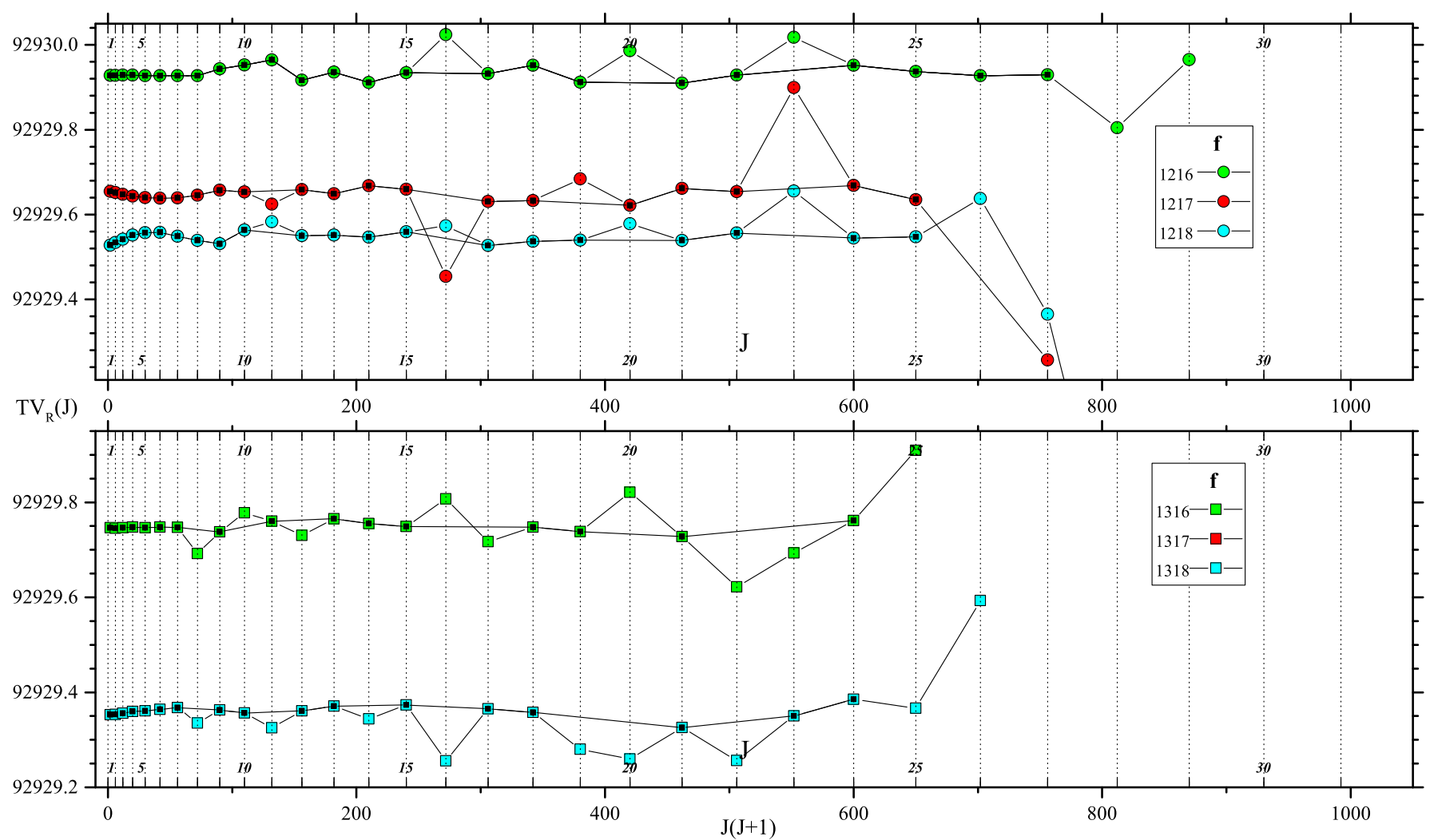

Fig. A.14. $f$-parity reduced term values $\left(\mathrm{cm}^{-1}\right)$ of the $E^{1} \Pi\left(v^{\prime}=0\right)$ levels for six CO isotopologues (data marked with a black center are kept to calculate molecular constants).
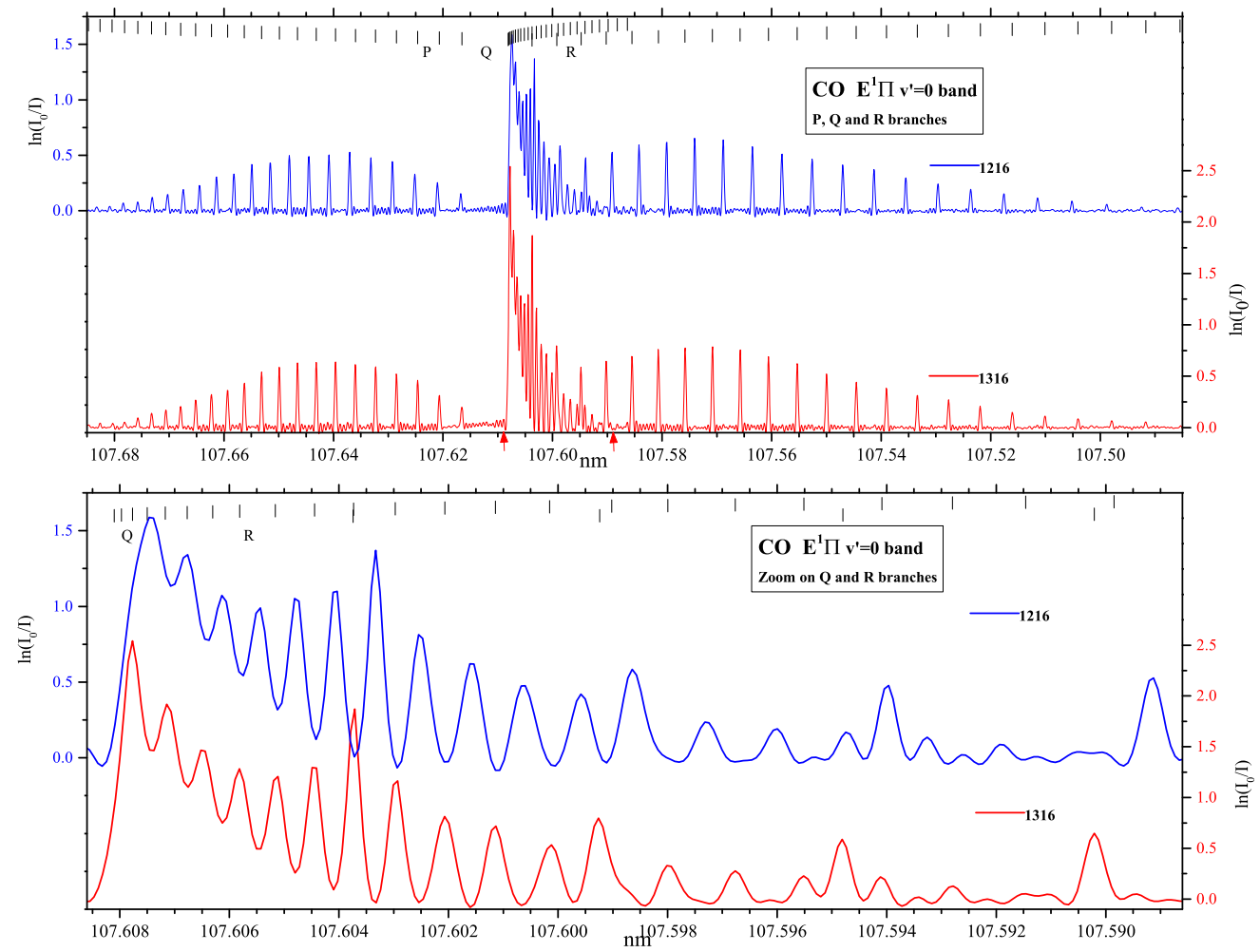

Fig. A.15. Spectra of the $E^{1} \Pi\left(v^{\prime}=0\right)-X^{1} \Sigma^{+}\left(v^{\prime \prime}=0\right)$ band for ${ }^{13} \mathrm{C}^{16} \mathrm{O}$ and ${ }^{12} \mathrm{C}^{16} \mathrm{O}$. The lower graph shows a $\times 10$ expanded scale on the $Q$-branch between the red arrows). 
A\&A 614, A114 (2018)
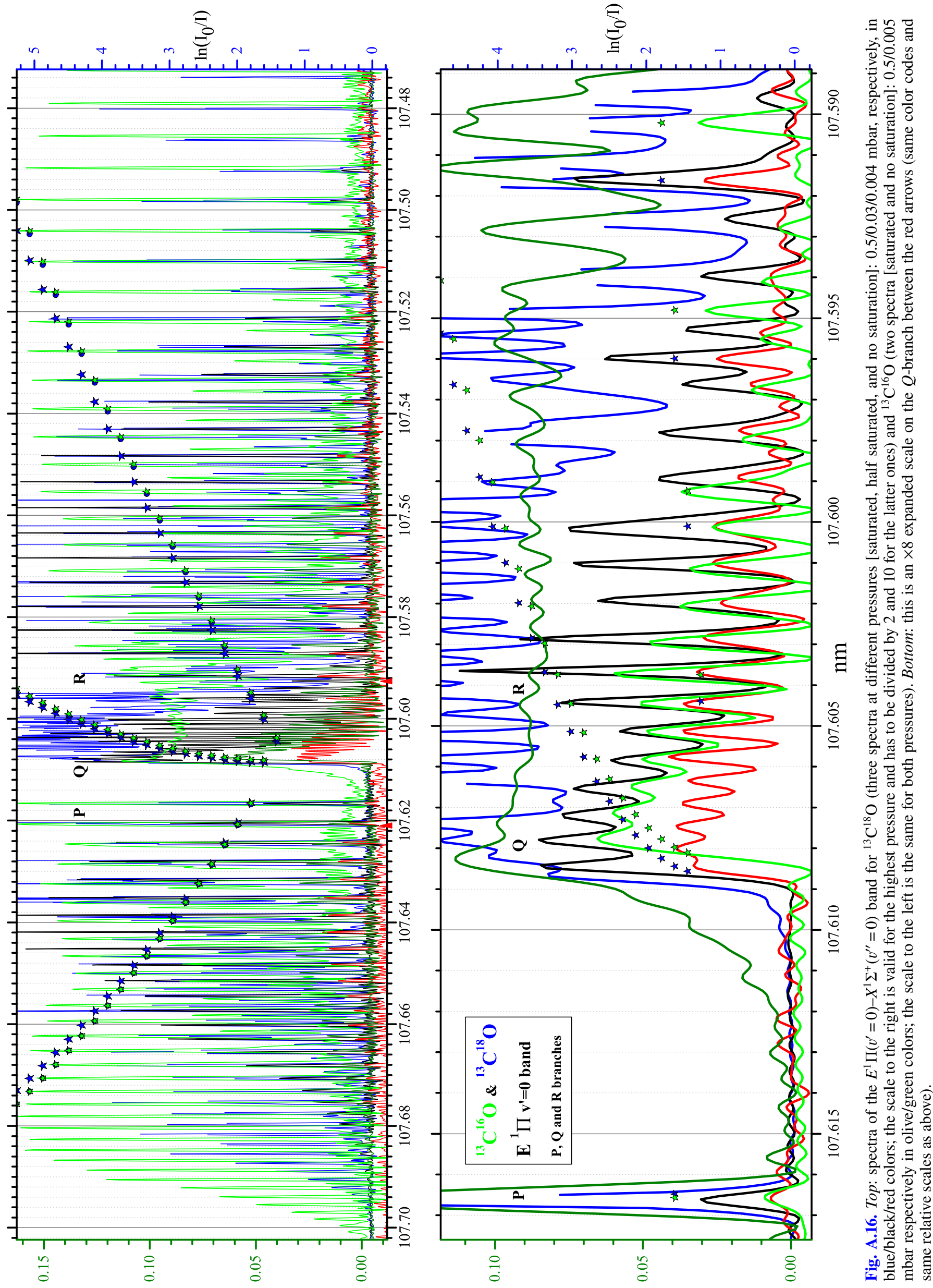

A114, page 38 of 62 
J. L. Lemaire et al.: Atlas of new and revised high-resolution spectroscopy of six CO isotopologues in the 101-115 nm range
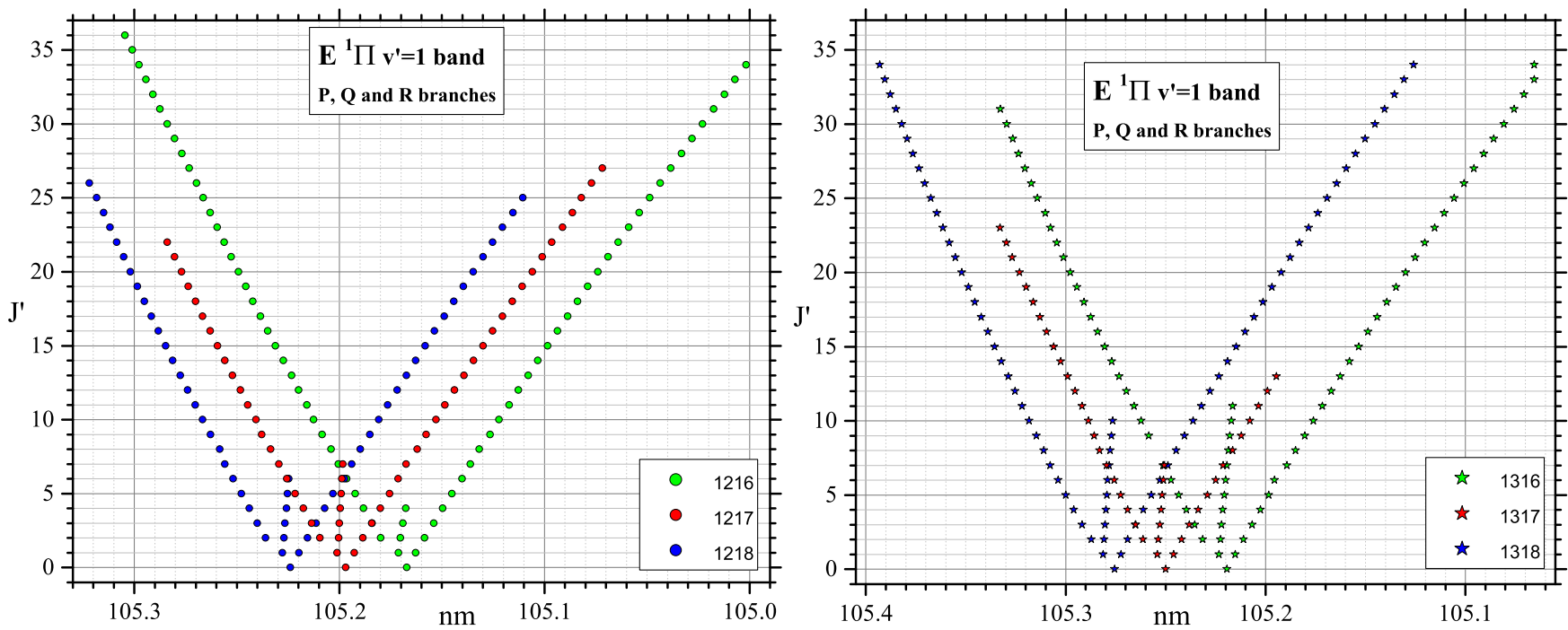

Fig. A.17. Transition wavelengths of the $E^{1} \Pi\left(v^{\prime}=1\right)-X^{1} \Sigma^{+}\left(v^{\prime \prime}=0\right)$ band for six CO isotopologues.

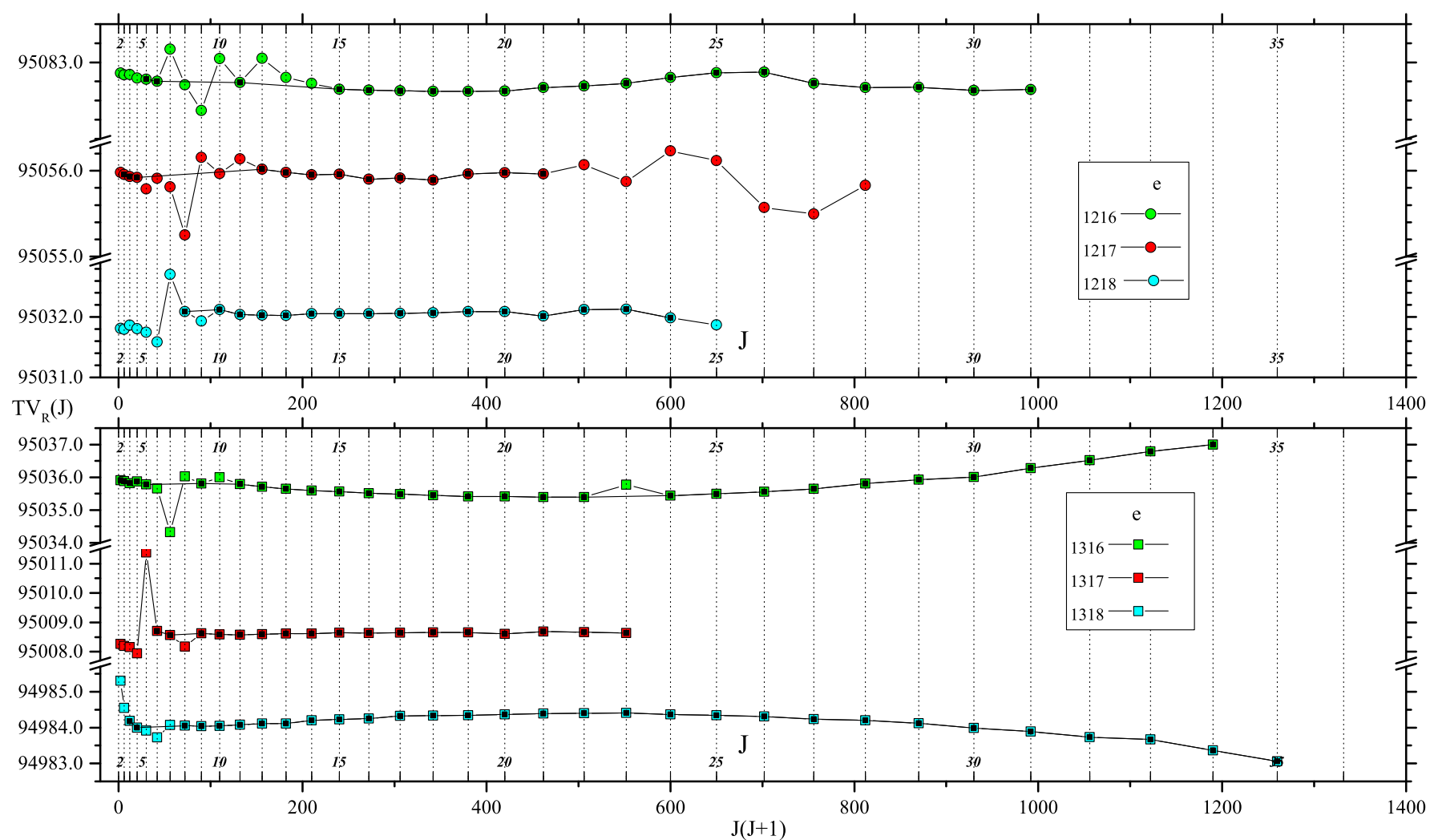

Fig. A.18. $e$-parity reduced term values $\left(\mathrm{cm}^{-1}\right)$ of the $E^{1} \Pi\left(v^{\prime}=1\right)$ levels for six $C O$ isotopologues (left). Data marked with a black center are kept to calculate molecular constants. 

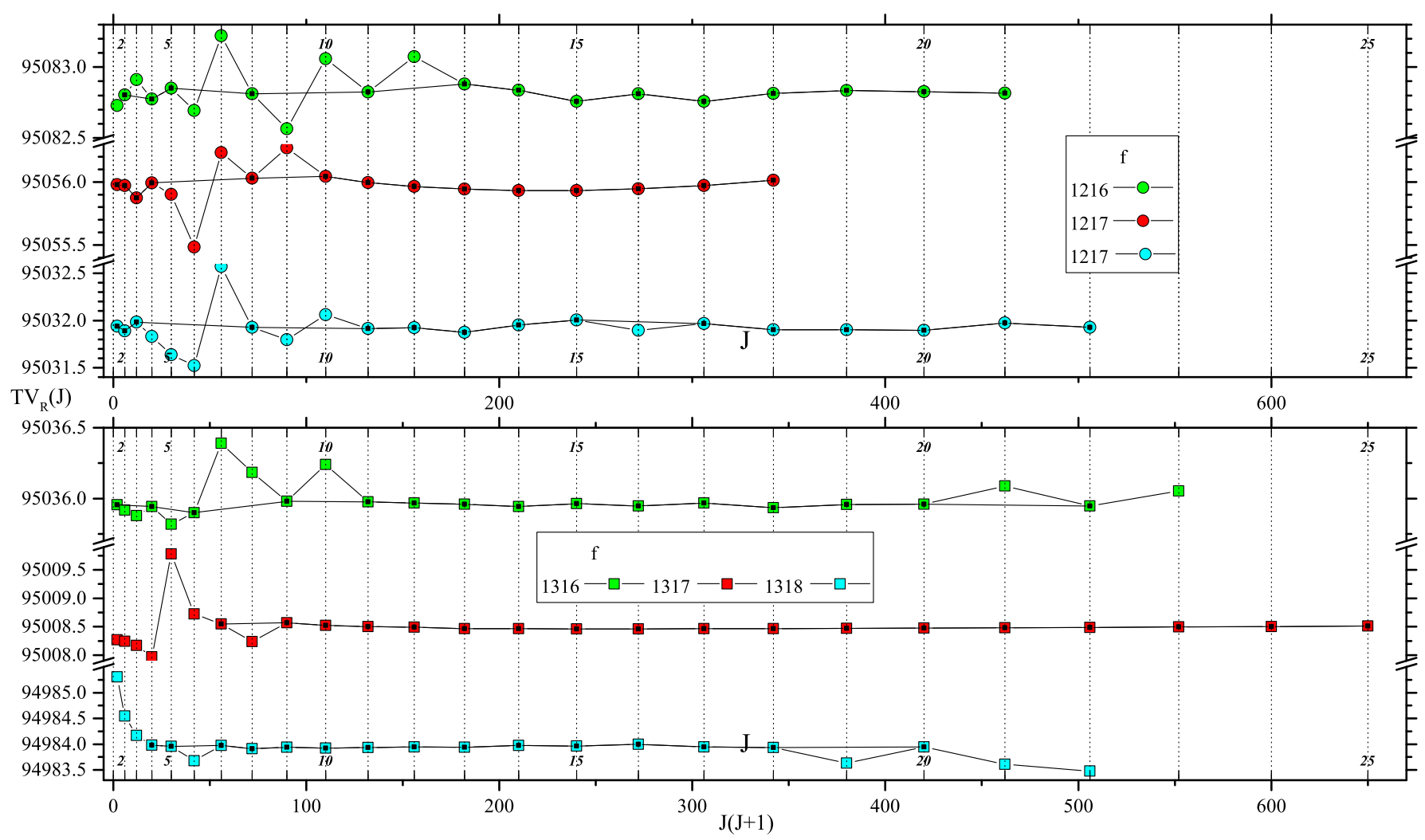

Fig. A.19. $f$-parity reduced term values $\left(\mathrm{cm}^{-1}\right)$ of the $E^{1} \Pi\left(v^{\prime}=1\right)$ levels for six CO isotopologues (data marked with a black center are kept to calculate molecular constants). 
J. L. Lemaire et al.: Atlas of new and revised high-resolution spectroscopy of six CO isotopologues in the 101-115 nm range
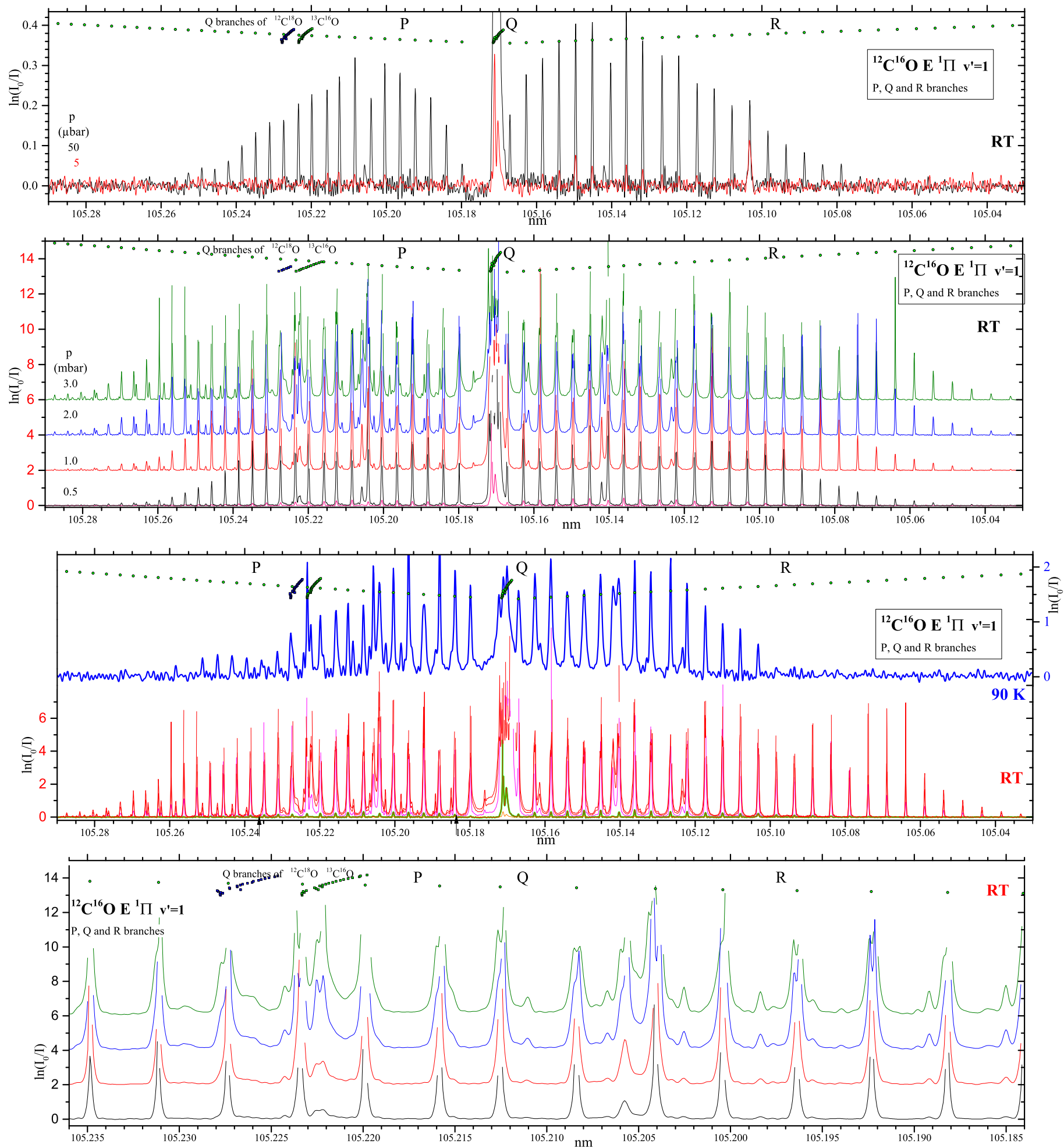

Fig. A.20. Spectra of the $E^{1} \Pi\left(v^{\prime}=1\right)-X^{1} \Sigma^{+}\left(v^{\prime \prime}=0\right)$ band for ${ }^{12} \mathrm{C}^{16} \mathrm{O}$. Two upper panels: RT spectra taken at different pressures. Third panel: comparison between $90 \mathrm{~K}$ ( 1 pressure) and room-temperature spectra (all pressures). Lower panel: $\times 5$ expanded scale on the region indicated by black arrows on the above panel. This region contains among other lines those of the $k^{3} \Pi\left(v^{\prime}=5\right)$ perturbing band (around $\left.105.205 \mathrm{~nm}\right)$, while $k^{3} \Pi\left(v^{\prime}=6\right)$ appears around $105.14 \mathrm{~nm}$. 

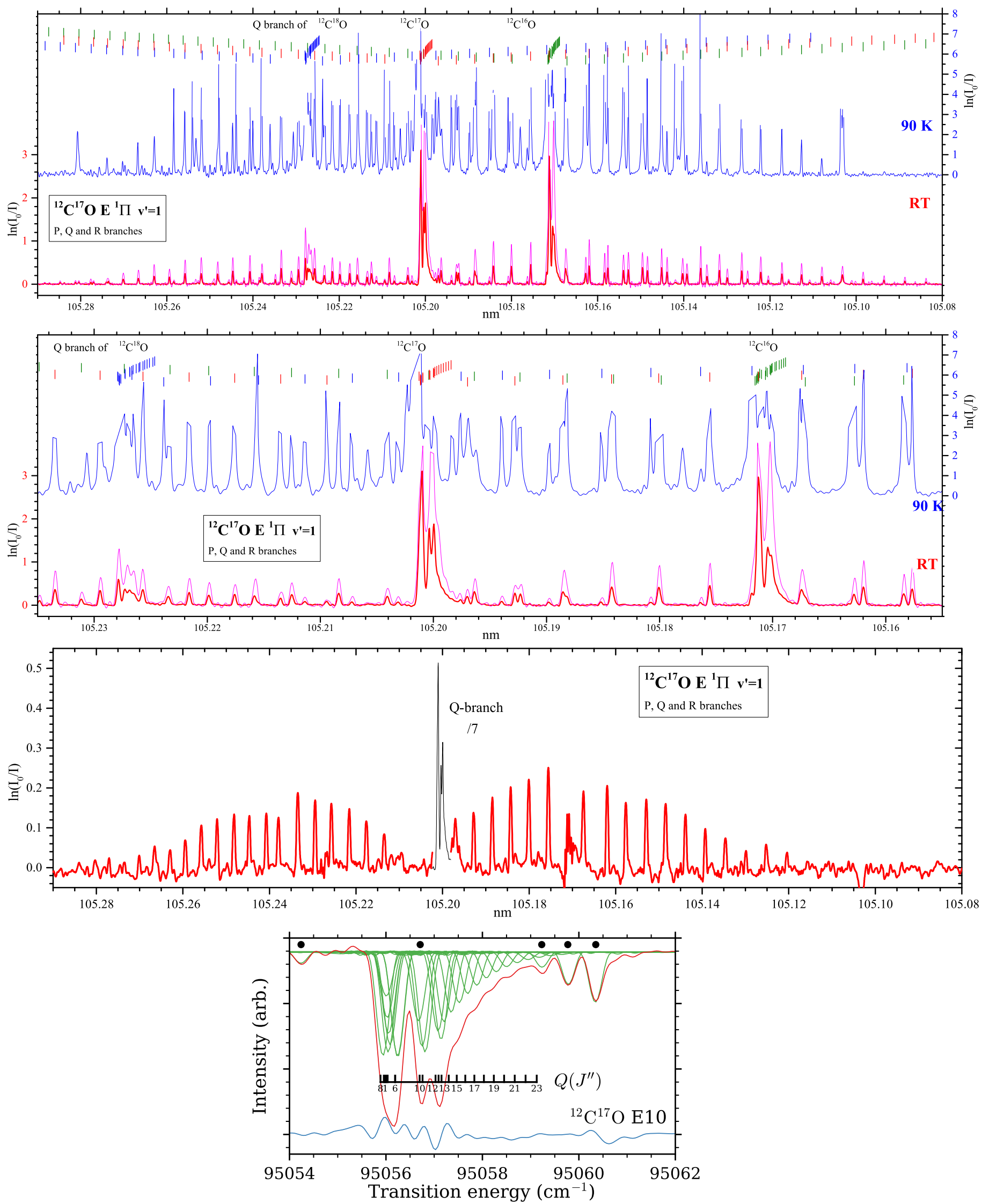

Fig. A.21. Spectra of the $E^{1} \Pi\left(v^{\prime}=1\right)-X^{1} \Sigma^{+}\left(v^{\prime \prime}=0\right)$ band for ${ }^{12} \mathrm{C}^{17} \mathrm{O}$ at $90 \mathrm{~K}$ and at room temperature (two pressures for the latter). Second panel: zoom of the central part of the upper panel $\left(\times 3\right.$ zoom). Third panel: RT spectrum after weighted subtraction of ${ }^{12} \mathrm{C}^{16} \mathrm{O}$ and ${ }^{12} \mathrm{C}^{18} \mathrm{O}$ spectra $($ the signal in the $Q$-branch, in black, is divided by 7). Lower panel: simulated absorption spectrum of the $Q$-branch at room temperature. 
J. L. Lemaire et al.: Atlas of new and revised high-resolution spectroscopy of six CO isotopologues in the 101-115 nm range

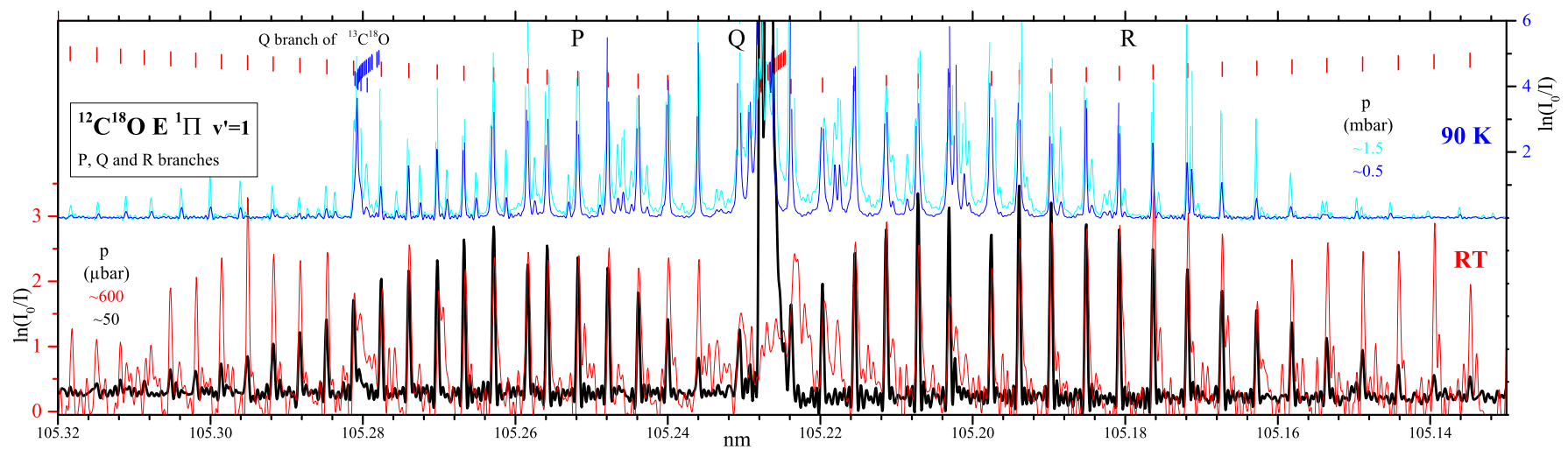

Fig. A.22. Spectra of the $E^{1} \Pi\left(v^{\prime}=1\right)-X^{1} \Sigma^{+}\left(v^{\prime \prime}=0\right)$ band for ${ }^{12} \mathrm{C}^{18} \mathrm{O}$ at $90 \mathrm{~K}$ and room temperature (both at two pressures).

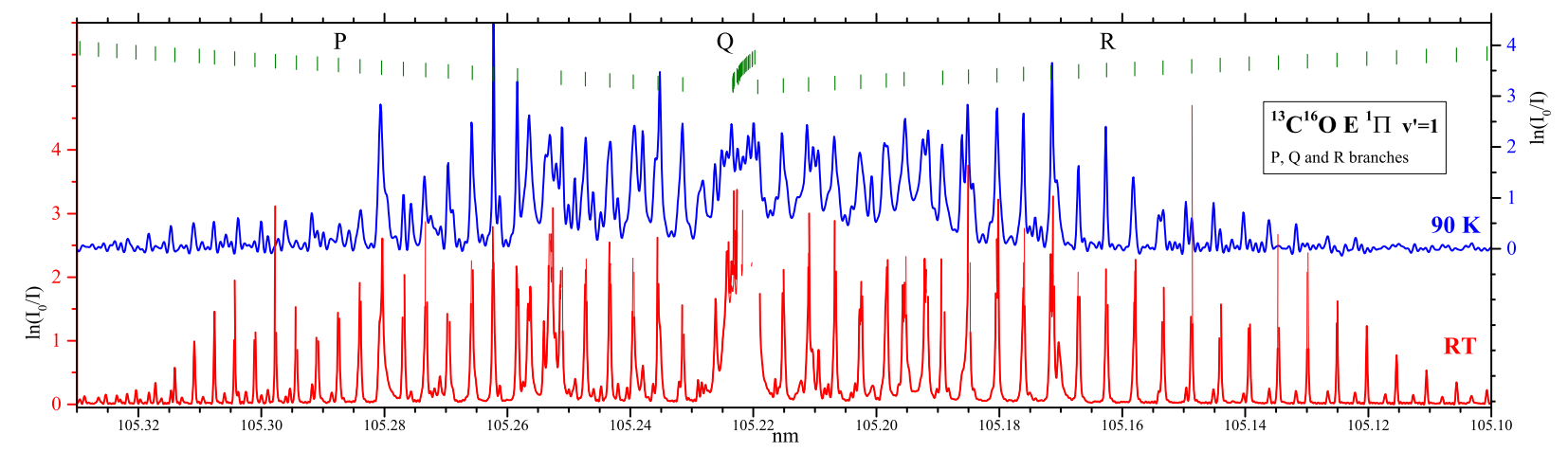

Fig. A.23. Spectra of the $E^{1} \Pi\left(v^{\prime}=1\right)-X^{1} \Sigma^{+}\left(v^{\prime \prime}=0\right)$ band for ${ }^{13} \mathrm{C}^{16} \mathrm{O}$ at $90 \mathrm{~K}$ and room temperature.

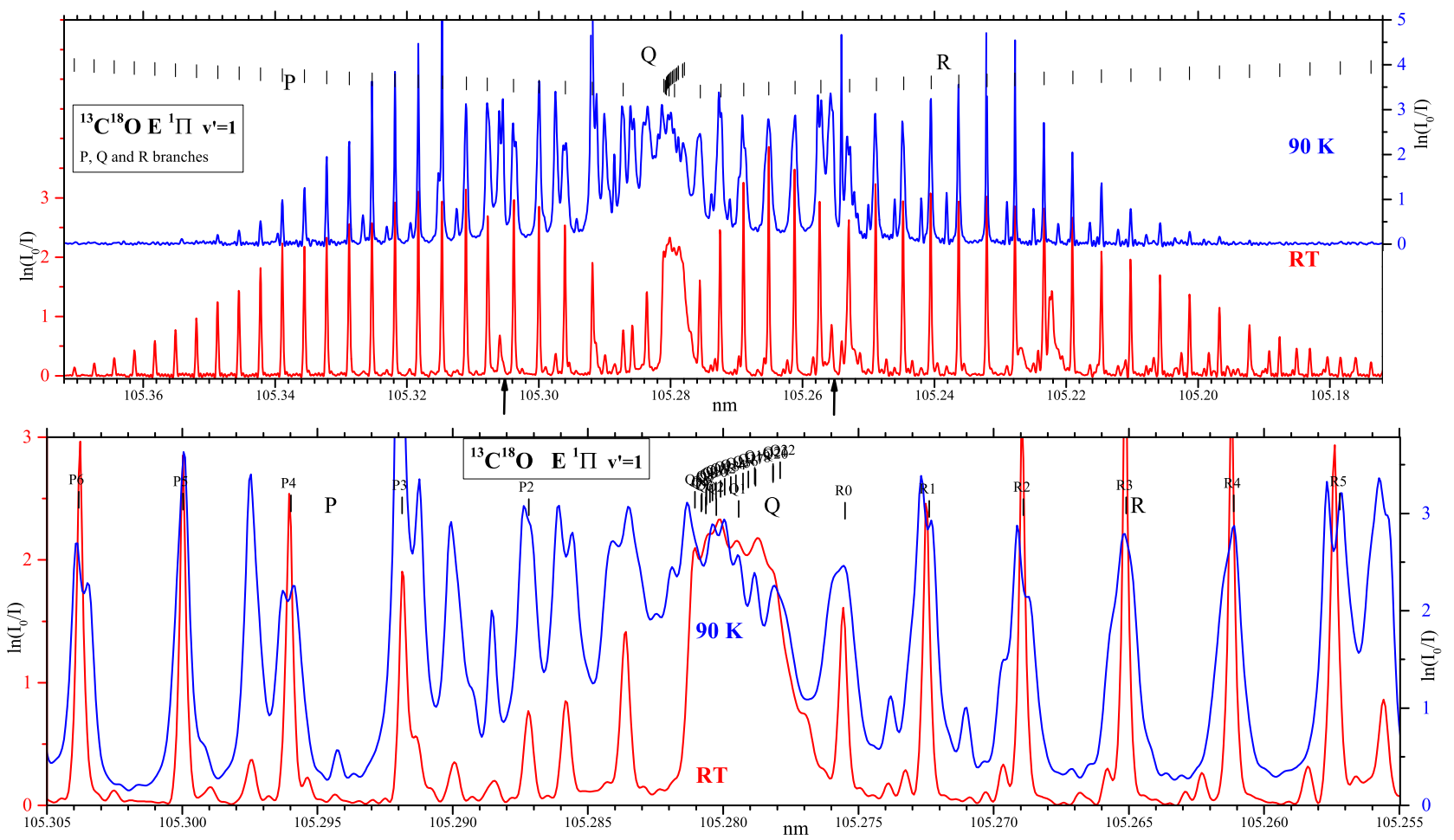

Fig. A.24. Upper panel: spectra of the $E^{1} \Pi\left(v^{\prime}=1\right)-X^{1} \Sigma^{+}\left(v^{\prime \prime}=0\right)$ band for ${ }^{13} \mathrm{C}^{18} \mathrm{O}$ at $90 \mathrm{~K}$ and room temperature. Lower panel: $\times 4$ expanded scale on the $Q$-branch between the black arrows. 


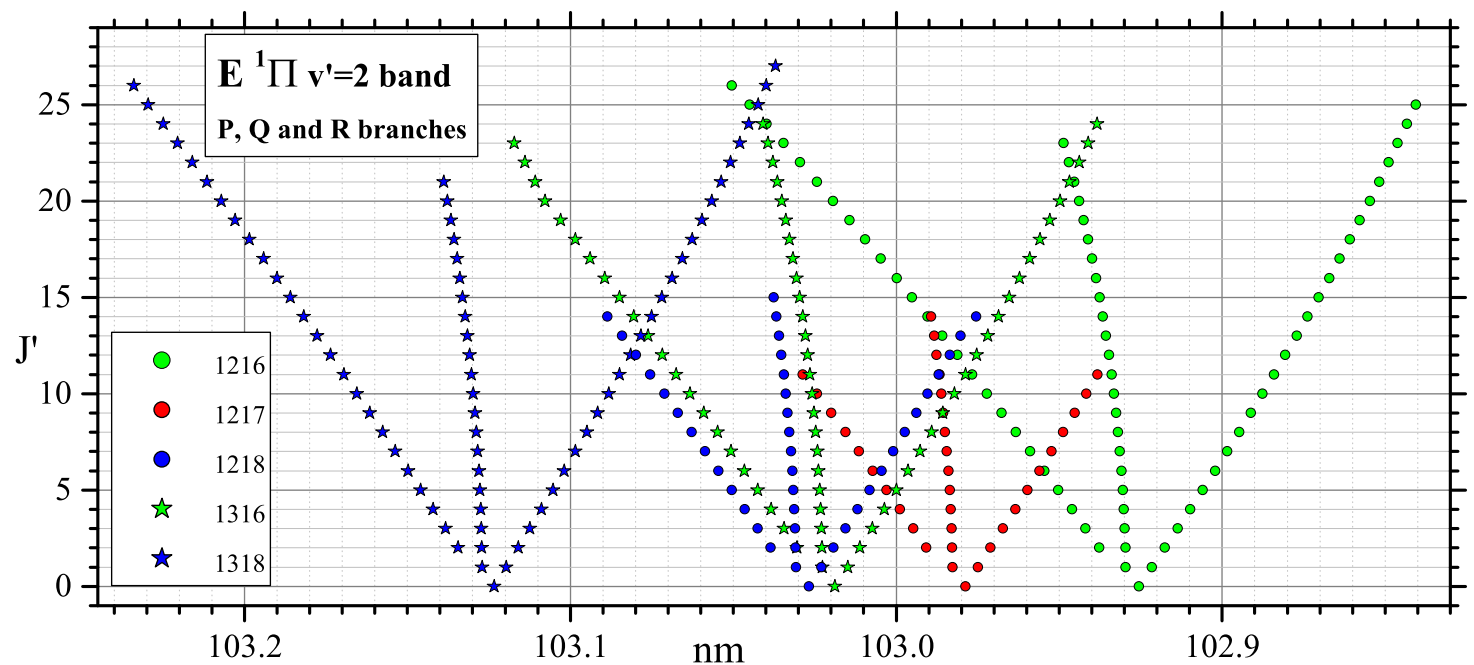

Fig. A.25. Transition wavelengths of the $E^{1} \Pi\left(v^{\prime}=2\right)-X^{1} \Sigma^{+}\left(v^{\prime \prime}=0\right)$ band for five CO isotopologues.

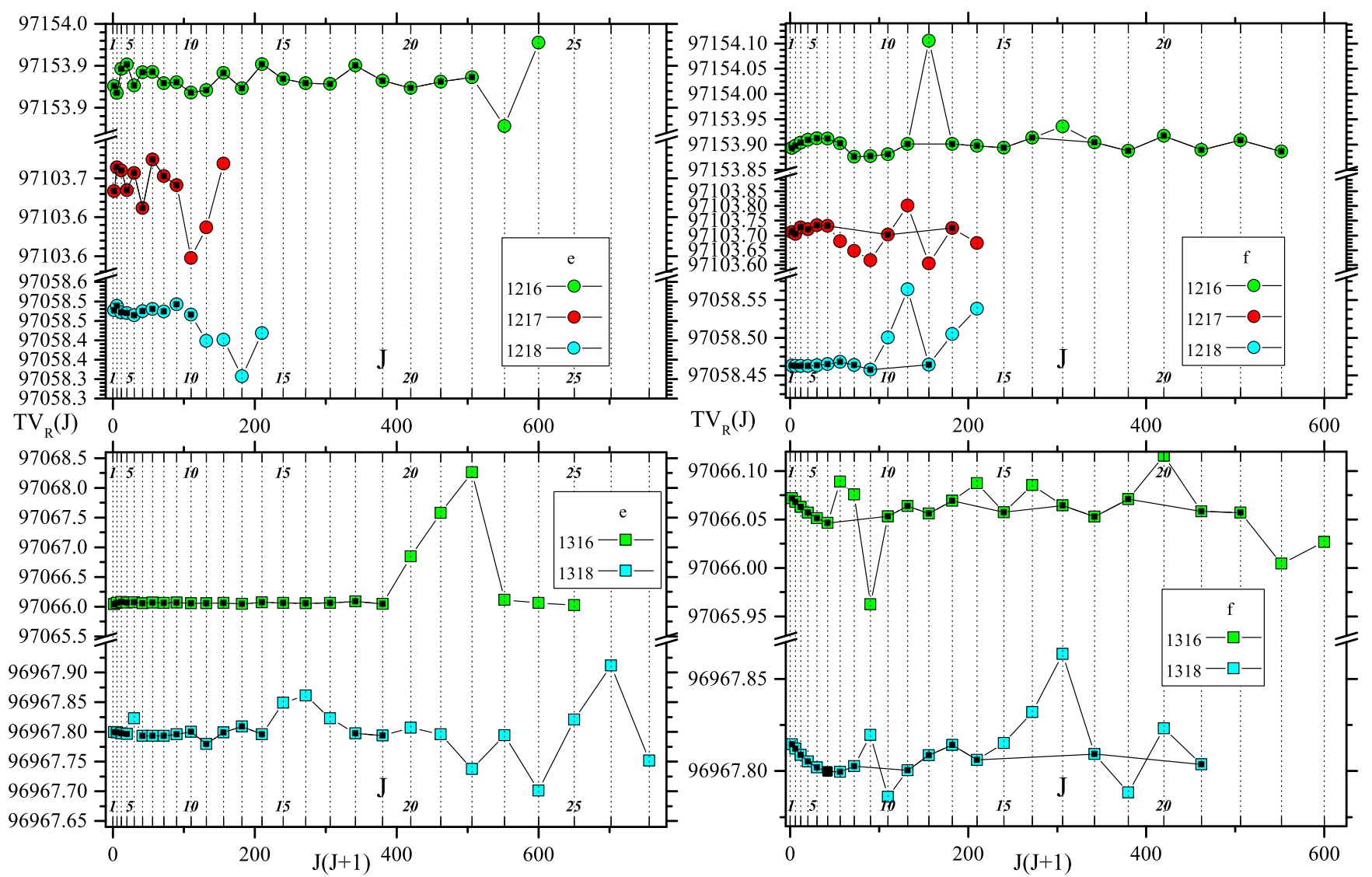

Fig. A.26. Reduced term values $\left(\mathrm{cm}^{-1}\right)$ of the $E^{1} \Pi\left(v^{\prime}=2\right)$ levels for five $\mathrm{CO}$ isotopologues (left: $e$-parity and right: $f$-parity). Data marked with a black center are kept to calculate molecular constants. 
J. L. Lemaire et al.: Atlas of new and revised high-resolution spectroscopy of six CO isotopologues in the 101-115 nm range
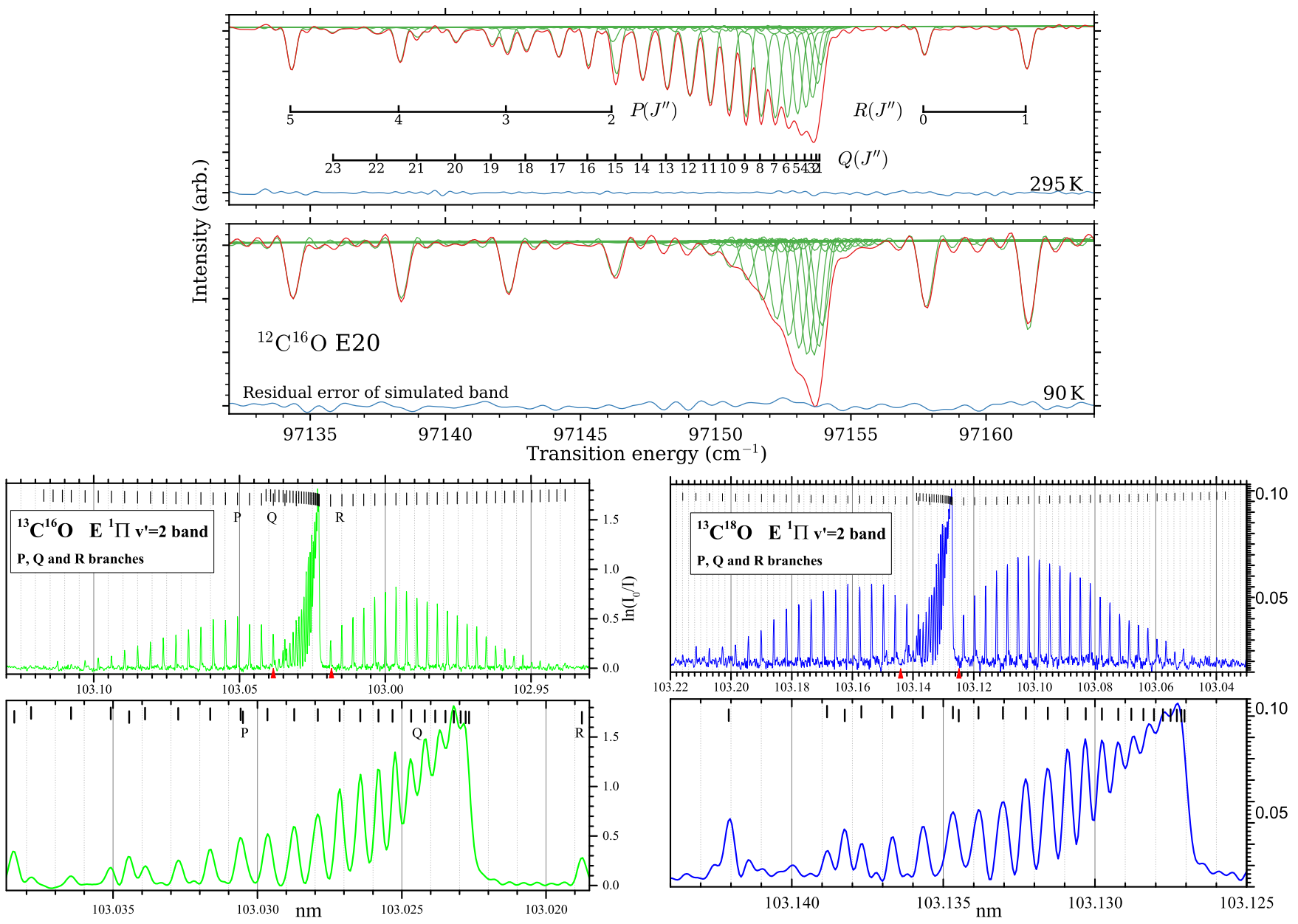

Fig. A.27. Spectra of the $E^{1} \Pi\left(v^{\prime}=2\right)-X^{1} \Sigma^{+}\left(v^{\prime \prime}=0\right)$ band. Upper panel: Simulated absorption spectra of the $Q$-branch of the for ${ }^{12} \mathrm{C}^{16} \mathrm{O}$ at $90 \mathrm{~K}$ and at room temperature. Lower panels: spectra of ${ }^{13} \mathrm{C}^{16} \mathrm{O}($ left $)$ and ${ }^{13} \mathrm{C}^{18} \mathrm{O}($ right $)$. Lowest panel: $\times 10$ expanded scale on the $Q$-branch between the red arrows).

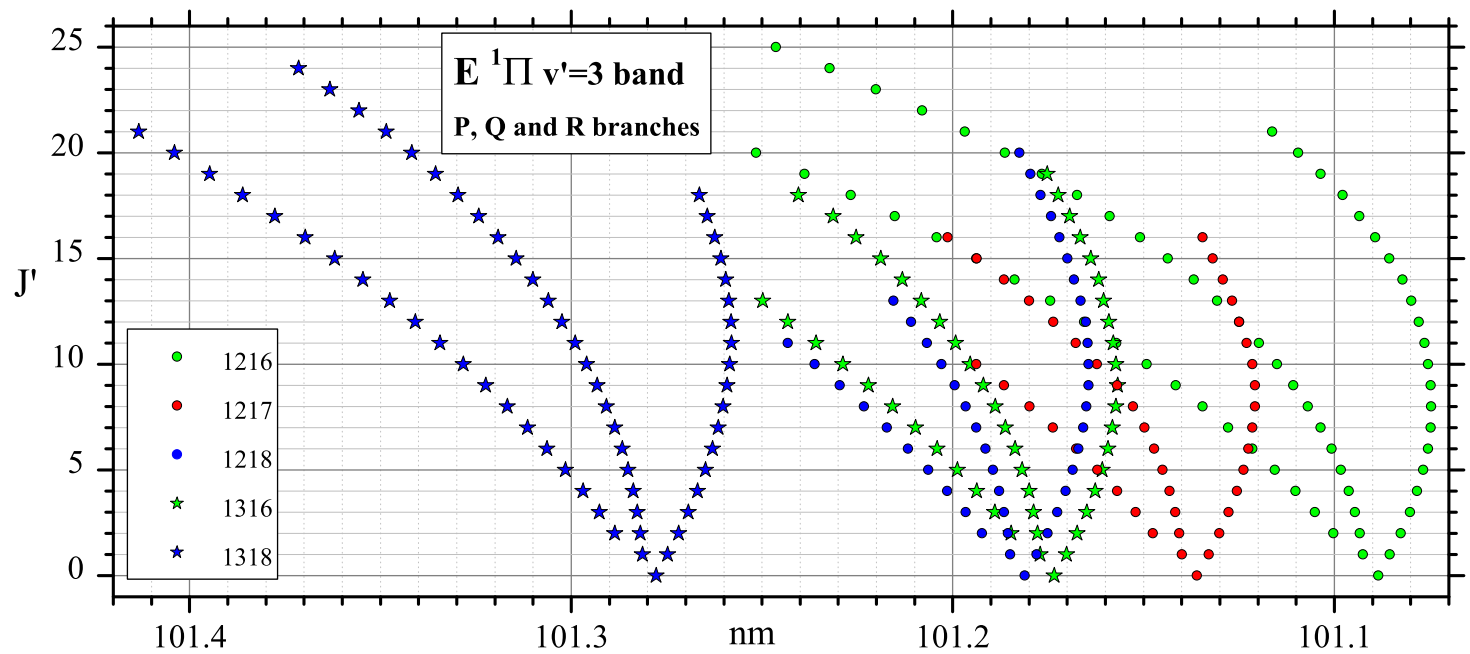

Fig. A.28. Transition wavelengths of the $E^{1} \Pi\left(v^{\prime}=3\right)-X^{1} \Sigma^{+}\left(v^{\prime \prime}=0\right)$ band for the five observed CO isotopologues. 


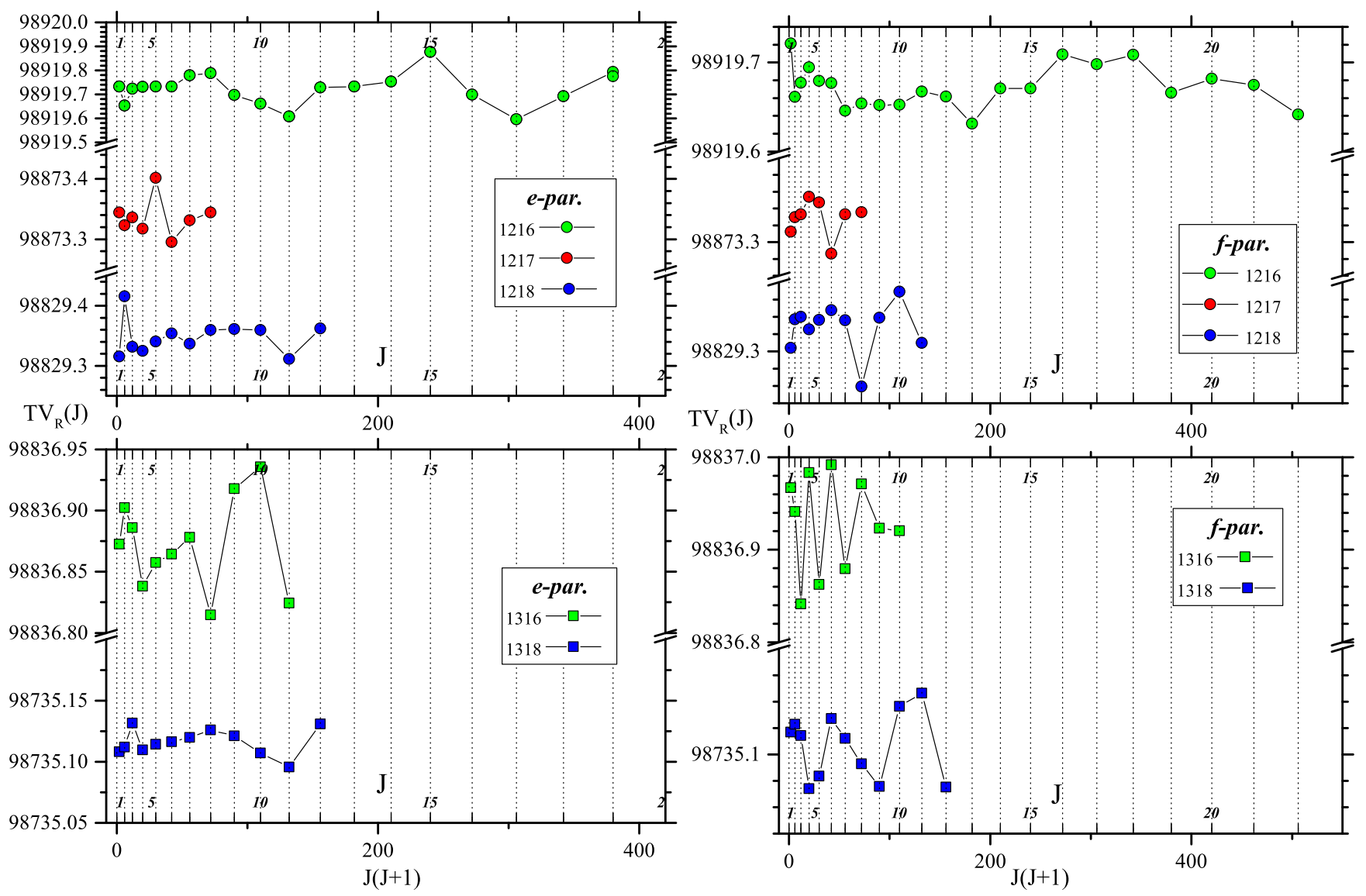

Fig. A.29. Reduced term values $\left(\mathrm{cm}^{-1}\right)$ of the $E^{1} \Pi\left(v^{\prime}=3\right)$ levels for the five observed CO isotopologues (left: $e$-parity, and right: $f$-parity). 
J. L. Lemaire et al.: Atlas of new and revised high-resolution spectroscopy of six CO isotopologues in the 101-115 nm range
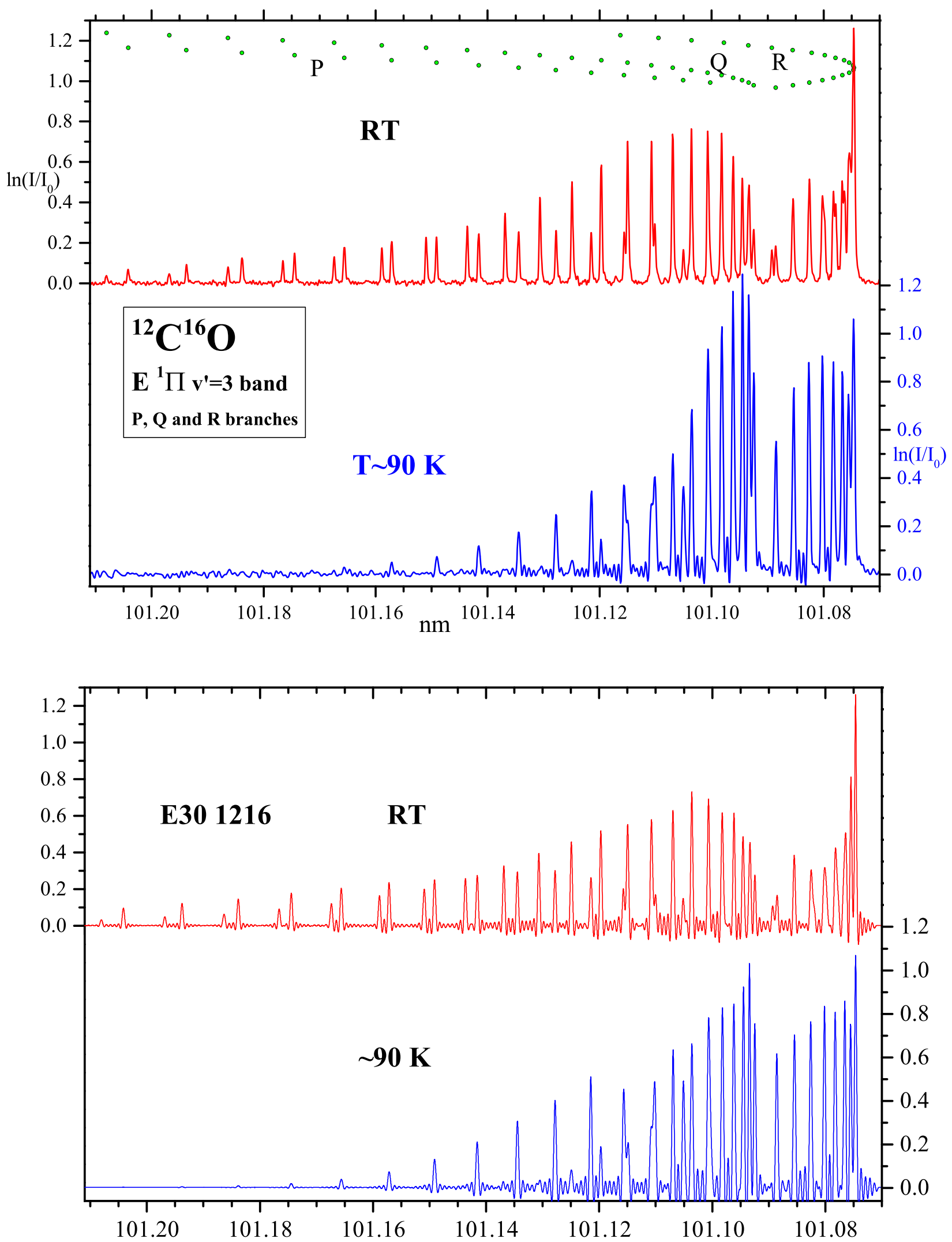

Fig. A.30. Spectra of the $E^{1} \Pi\left(v^{\prime}=3\right)-X^{1} \Sigma^{+}\left(v^{\prime \prime}=0\right)$ band for ${ }^{12} \mathrm{C}^{16} \mathrm{O}$ at room temperature (RT) and at $\sim 90 \mathrm{~K}$. Simulations below, in emission, of the upper experimental spectra (using classical Hönl-London factors). 


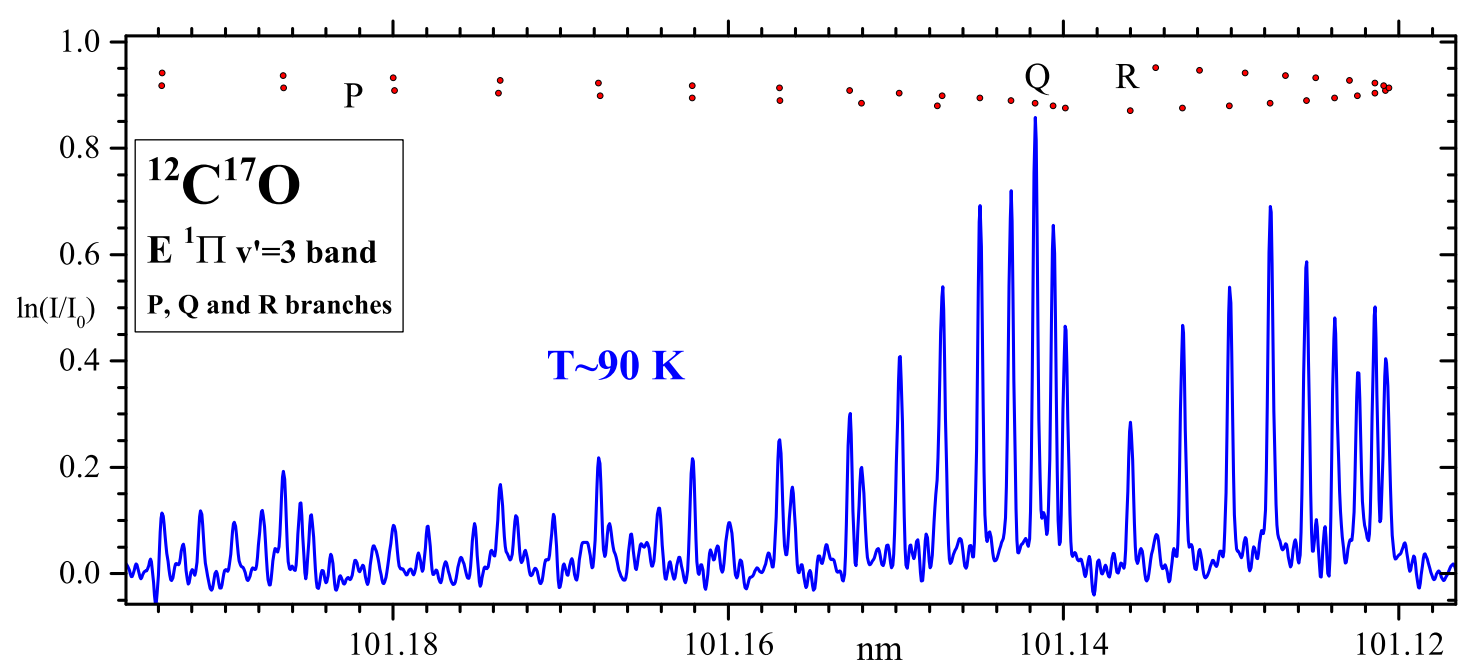

Fig. A.31. Spectra of the $E^{1} \Pi\left(v^{\prime}=3\right)-X^{1} \Sigma^{+}\left(v^{\prime \prime}=0\right)$ band for ${ }^{12} \mathrm{C}^{17} \mathrm{O}$ at $\sim 90 \mathrm{~K}$. Traces of ${ }^{12} \mathrm{C}^{18} \mathrm{O}$ are present around $101.185 \mathrm{~nm}$.

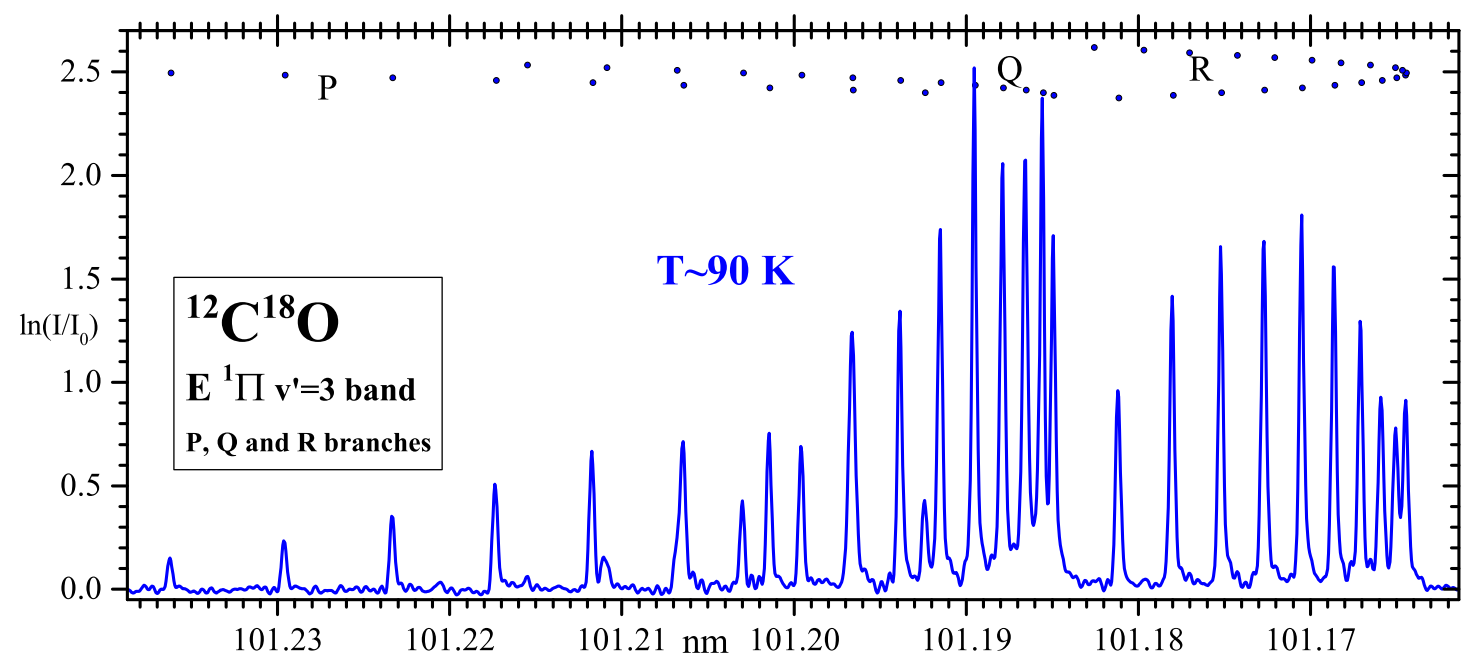

Fig. A.32. Spectra of the $E^{1} \Pi\left(v^{\prime}=3\right)-X^{1} \Sigma^{+}\left(v^{\prime \prime}=0\right)$ band for ${ }^{12} \mathrm{C}^{18} \mathrm{O}$ at $\sim 90 \mathrm{~K}$. 
J. L. Lemaire et al.: Atlas of new and revised high-resolution spectroscopy of six CO isotopologues in the 101-115 nm range

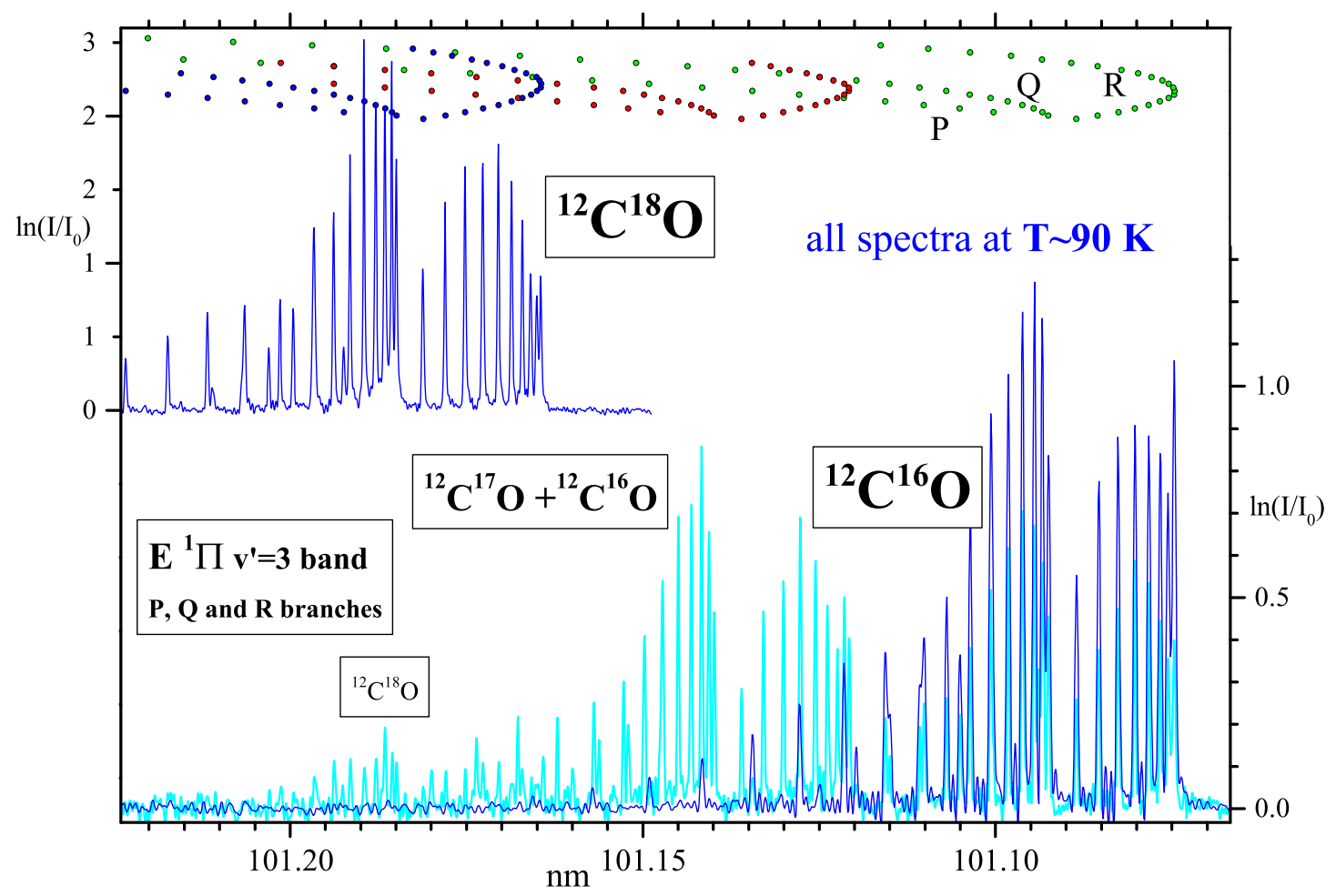

Fig. A.33. Spectra of the $E^{1} \Pi\left(v^{\prime}=3\right)-X^{1} \Sigma^{+}\left(v^{\prime \prime}=0\right)$ band for ${ }^{12} \mathrm{C}^{16} \mathrm{O},{ }^{12} \mathrm{C}^{17} \mathrm{O}$, and ${ }^{12} \mathrm{C}^{18} \mathrm{O}$ at $\sim 90 \mathrm{~K} .{ }^{12} \mathrm{C}^{17} \mathrm{O}$ is about equally mixed with ${ }^{12} \mathrm{C}^{16} \mathrm{O}$, and traces of ${ }^{12} \mathrm{C}^{18} \mathrm{O}$ are present.

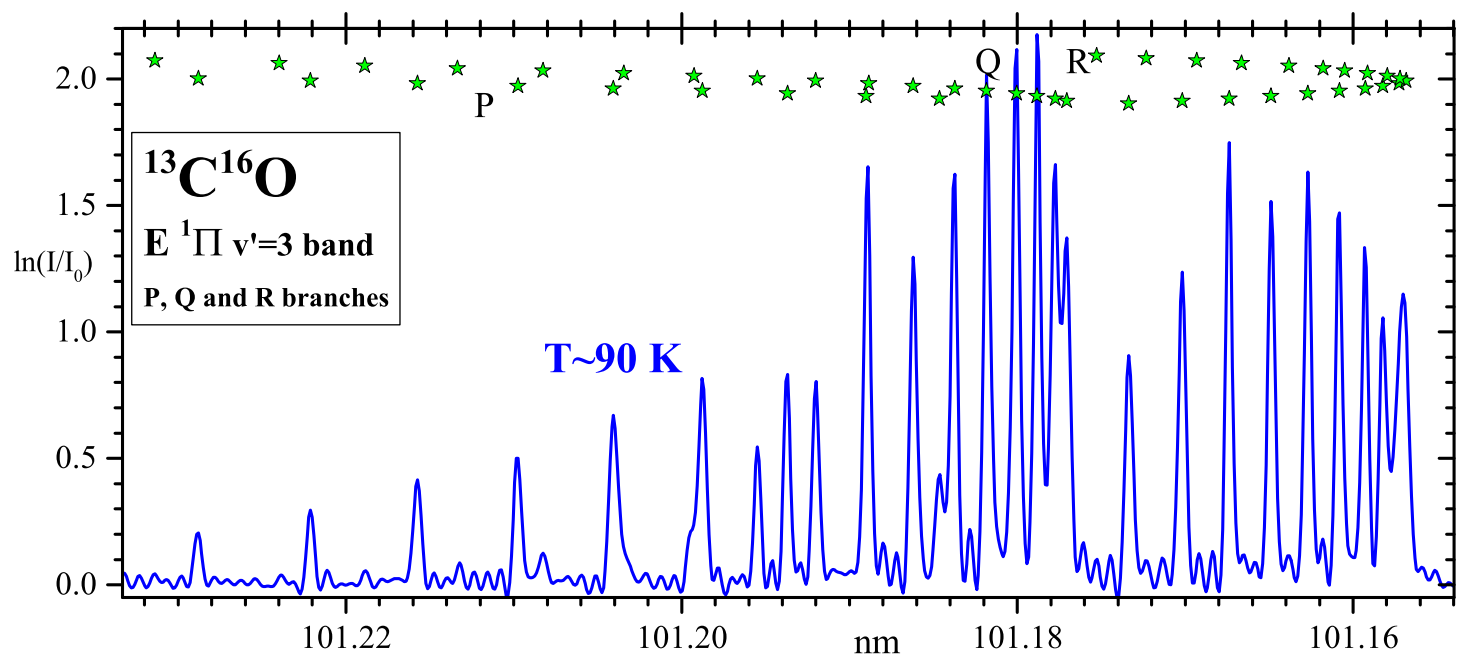

Fig. A.34. Spectrum of the $E^{1} \Pi\left(v^{\prime}=3\right)-X^{1} \Sigma^{+}\left(v^{\prime \prime}=0\right)$ band for ${ }^{13} \mathrm{C}^{16} \mathrm{O}$ at $\sim 90 \mathrm{~K}$. 


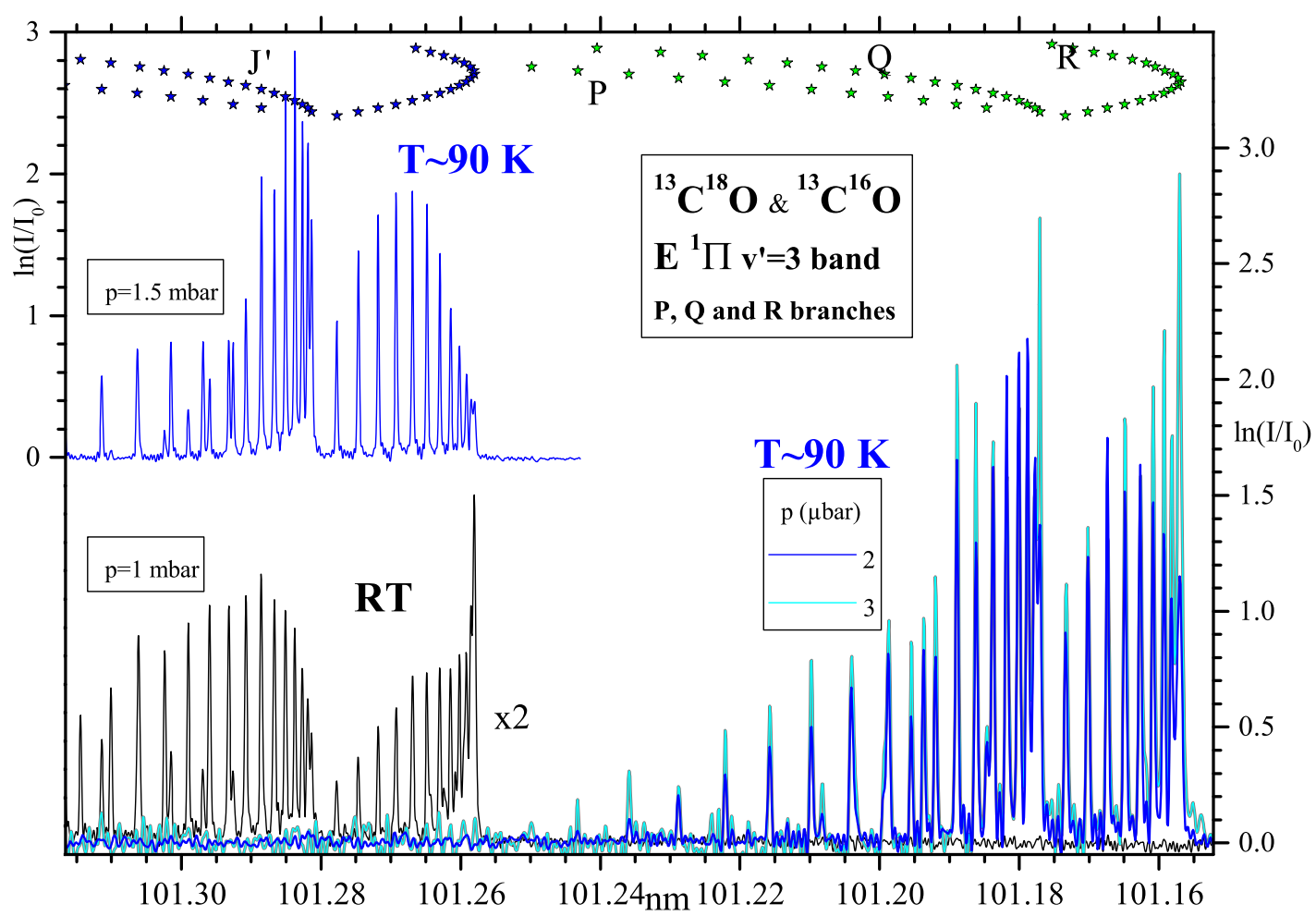

Fig. A.35. Spectra of the $E^{1} \Pi\left(v^{\prime}=3\right)-X^{1} \Sigma^{+}\left(v^{\prime \prime}=0\right)$ band for ${ }^{13} \mathrm{C}^{16} \mathrm{O}$ at $\sim 90 \mathrm{~K}$ (at two pressures) and ${ }^{13} \mathrm{C}^{18} \mathrm{O}$ at room temperature (in black) and $\sim 90 \mathrm{~K}$ (with two different blues).

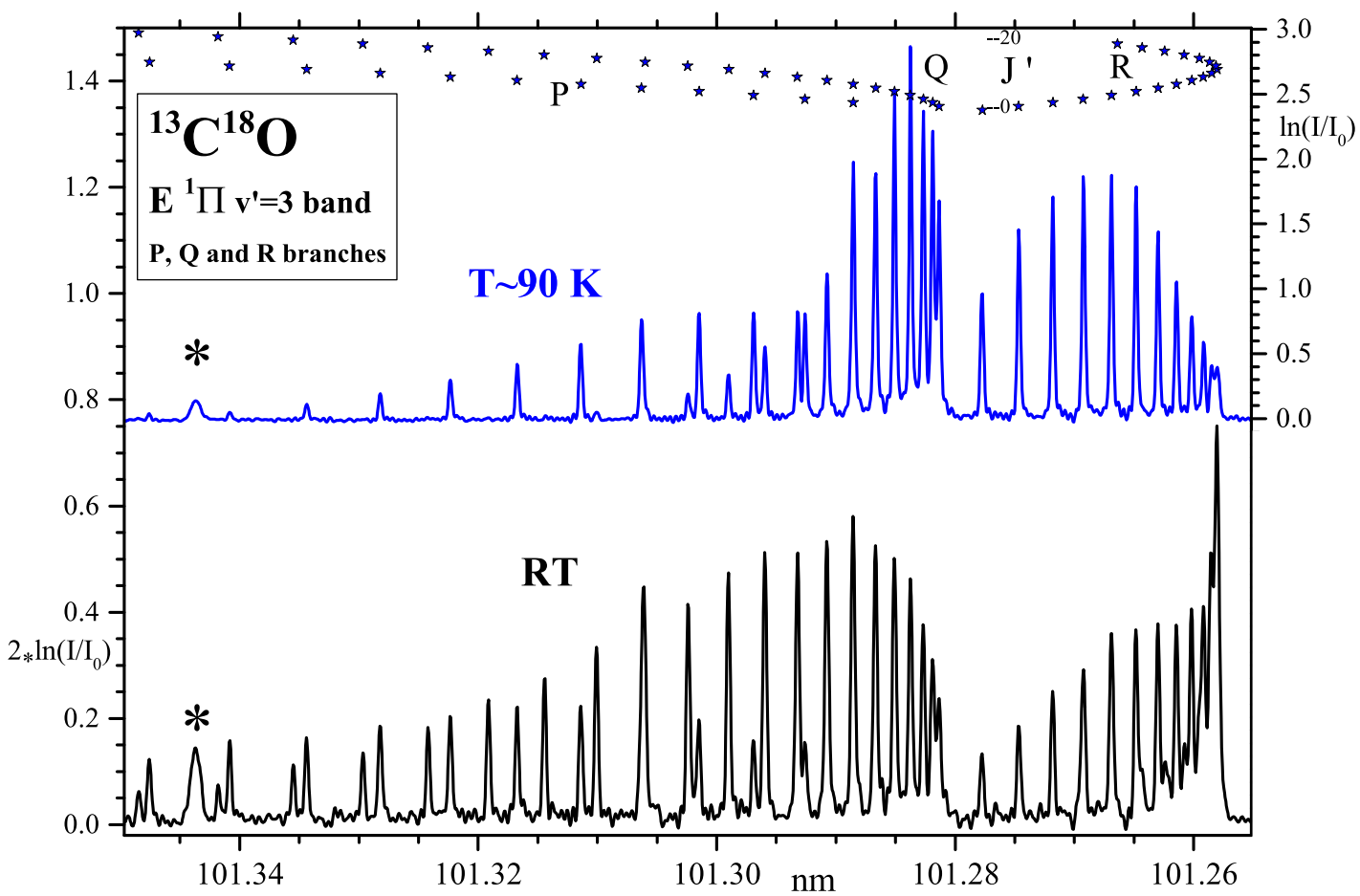

Fig. A.36. Spectra of the $E^{1} \Pi\left(v^{\prime}=3\right)-X^{1} \Sigma^{+}\left(v^{\prime \prime}=0\right)$ band for ${ }^{13} \mathrm{C}^{18} \mathrm{O}$ at room temperature (RT) and at $\sim 90 \mathrm{~K}$. The asterisk shows an impurity line in the gas filter. 
J. L. Lemaire et al.: Atlas of new and revised high-resolution spectroscopy of six CO isotopologues in the 101-115 nm range

Table A.19. Measured transition wavelengths and wavenumbers of the $E^{1} \Pi\left(v^{\prime}=0\right)-X^{1} \Sigma^{+}\left(v^{\prime \prime}=0\right)$ band for ${ }^{12} \mathrm{C}^{16} \mathrm{O},{ }^{12} \mathrm{C}^{17} \mathrm{O}$, and ${ }^{12} \mathrm{C}^{18} \mathrm{O}$.

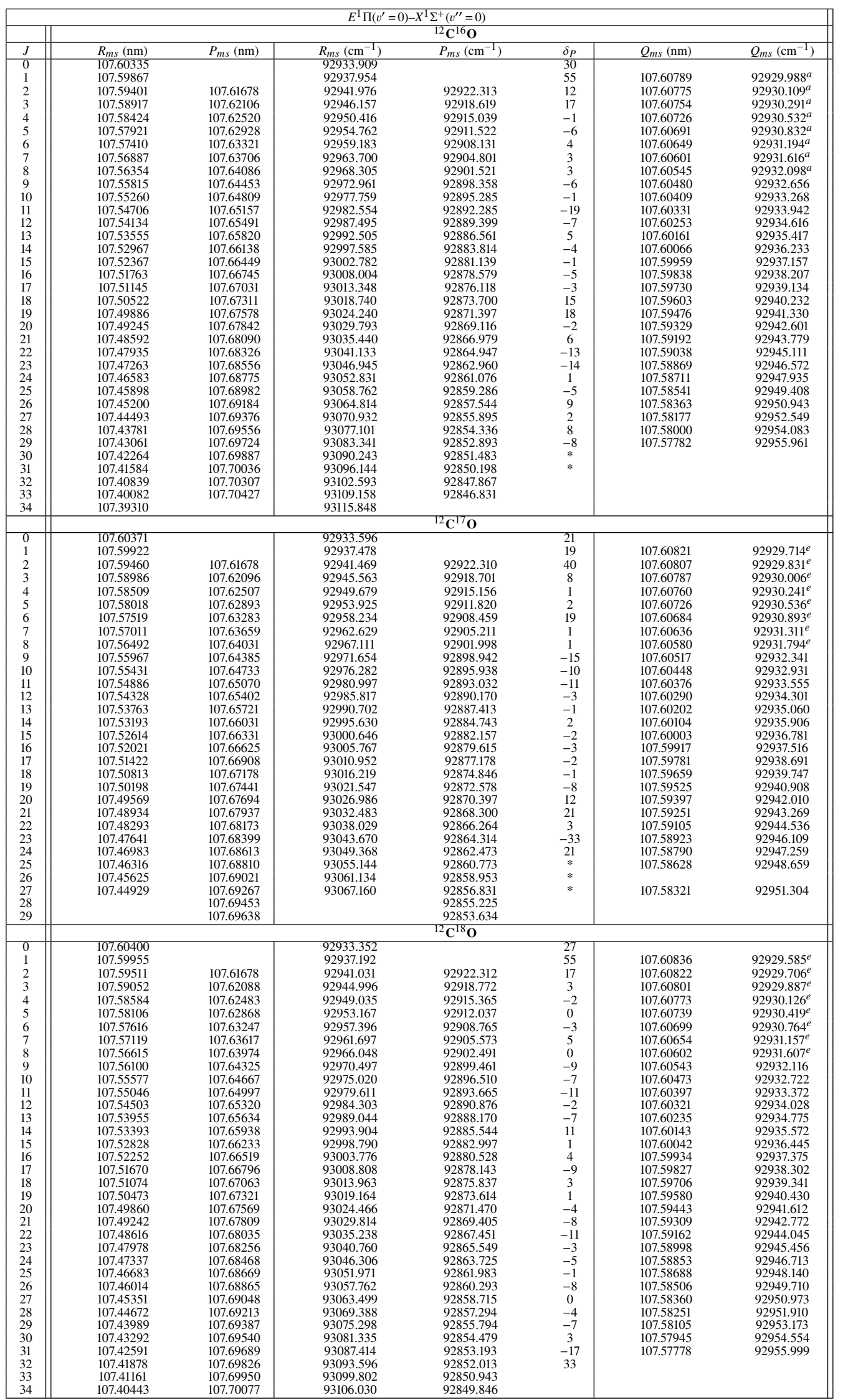

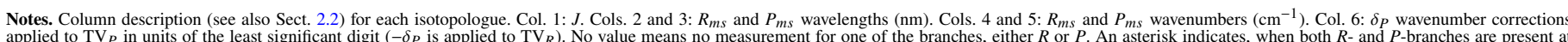
applied to $T V_{P}$ in units or the least significant digit $\left(-\delta_{P}\right.$ is applied to $T V_{R}$ ). No value means no measurement for one of the banches, either $R$, os $P$. high $J^{\prime}$, either the potential presence of a perturbing state or that one of the lines shows a larger uncertainty than the other. Cols. 7 and 8: $Q_{m s} Q$-branch wavelengths and wavenumbers. ${ }^{(a)}$ Data from Cacciani \& Ubachs (2004). ${ }^{(e)}$ Data calculated from the e-parity levels. 
A\&A 614, A114 (2018)

Table A.20. Measured transition wavelengths and wavenumbers of the $E^{1} \Pi\left(v^{\prime}=0\right)-X^{1} \Sigma^{+}\left(v^{\prime \prime}=0\right)$ band for ${ }^{13} \mathrm{C}^{16} \mathrm{O},{ }^{13} \mathrm{C}^{17} \mathrm{O}$, and ${ }^{13} \mathrm{C}^{18} \mathrm{O}(\mathrm{same}$ column description as for Table A.19).

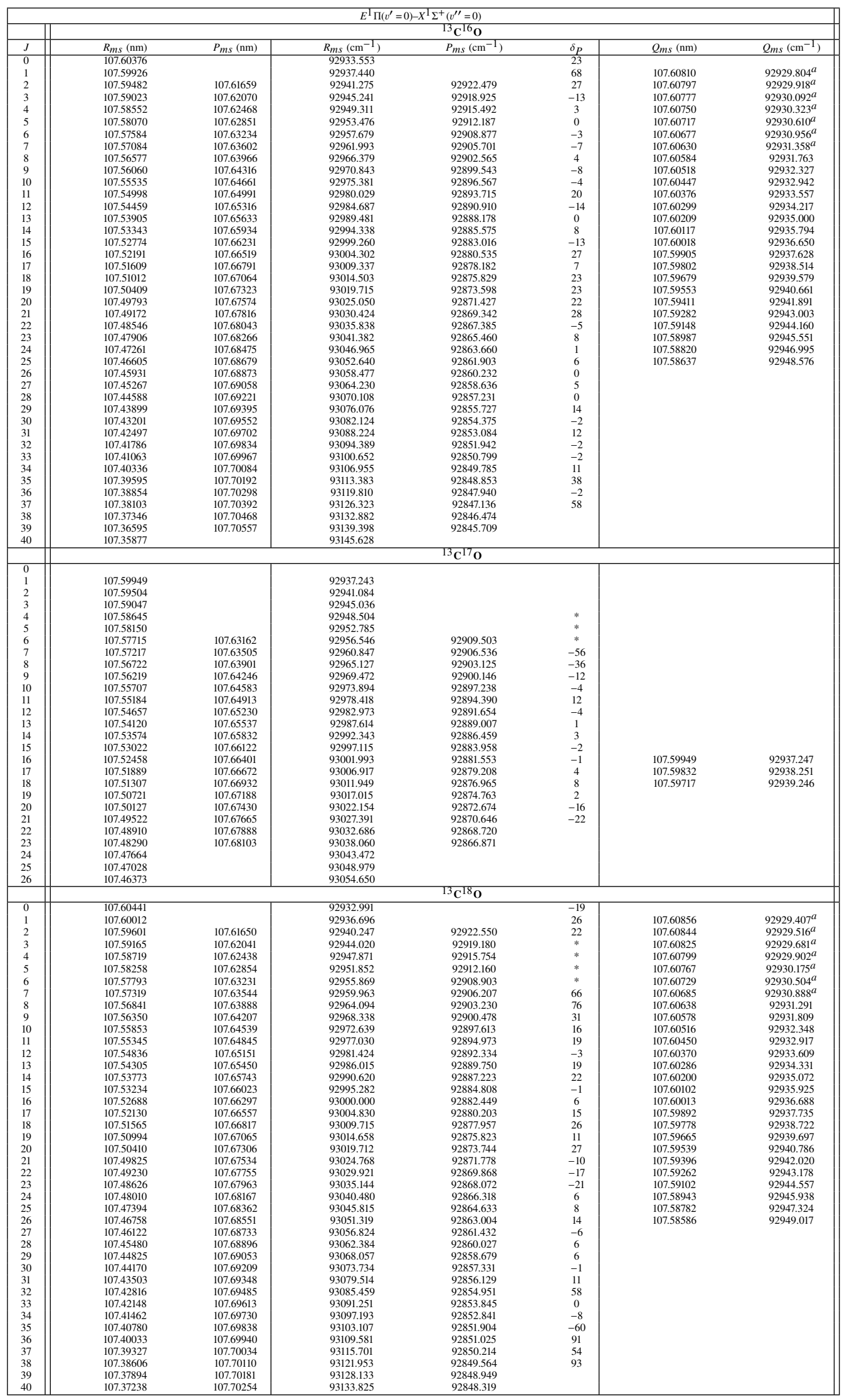

Notes. ${ }^{(a)}$ Data from Cacciani \& Ubachs (2004) (same column description as for Table A.19). 
J. L. Lemaire et al.: Atlas of new and revised high-resolution spectroscopy of six CO isotopologues in the 101-115 nm range

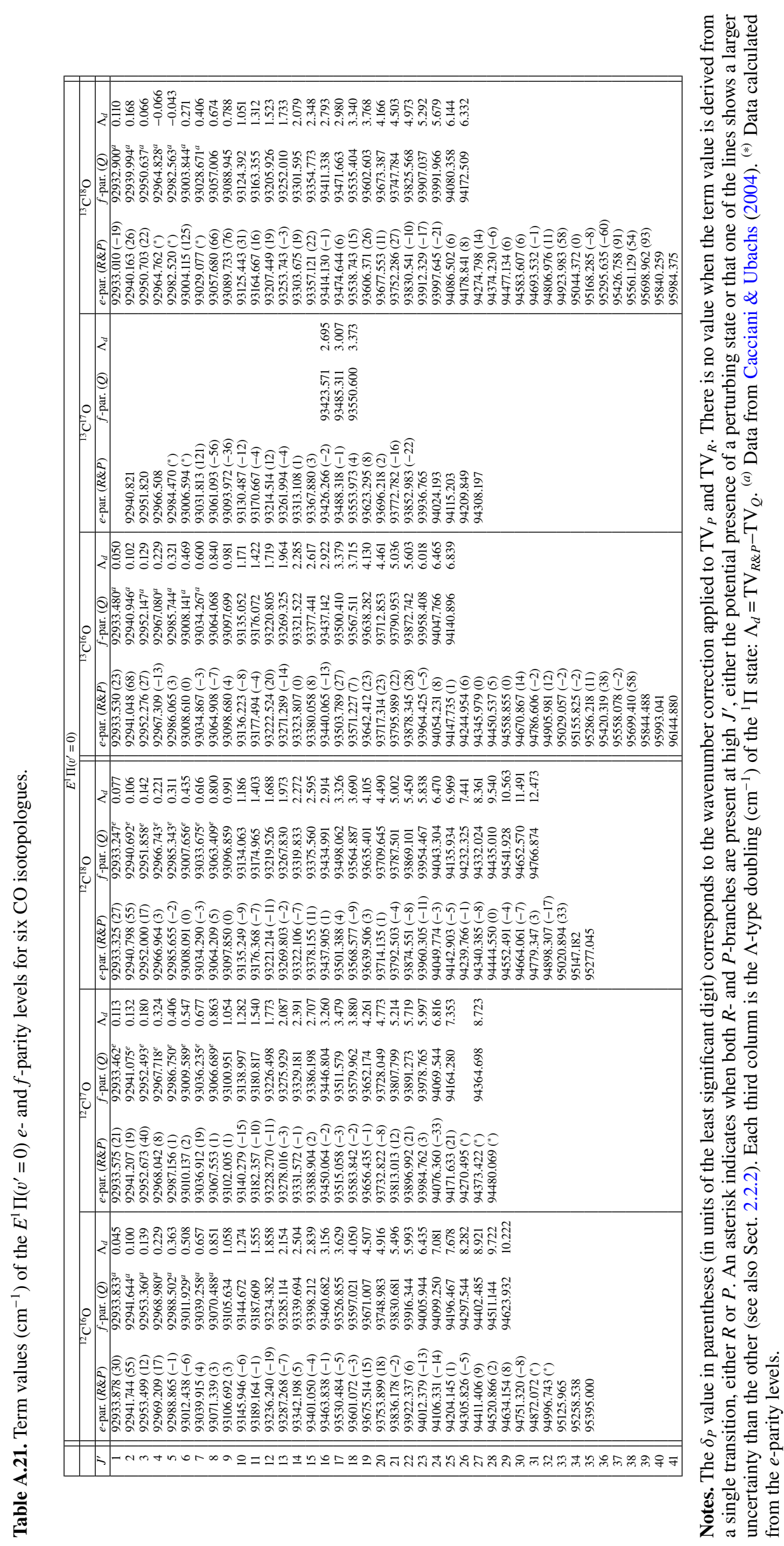


Table A.22. Measured transition wavelengths and wavenumbers of the $E^{1} \Pi\left(v^{\prime}=1\right)-X^{1} \Sigma^{+}\left(v^{\prime \prime}=0\right)$ band for ${ }^{12} \mathrm{C}^{16} \mathrm{O},{ }^{12} \mathrm{C}^{17} \mathrm{O}$, and ${ }^{12} \mathrm{C}^{18} \mathrm{O}$ (same column description as for Table A.19).
Table A.23. Measured transition wavelengths and wavenumbers of the $E^{1} \Pi\left(v^{\prime}=1\right)-X^{1} \Sigma^{+}\left(v^{\prime \prime}=0\right)$ band for ${ }^{13} \mathrm{C}^{16} \mathrm{O},{ }^{13} \mathrm{C}^{17} \mathrm{O}$, and ${ }^{13} \mathrm{C}^{18} \mathrm{O}$ (same column description as for Table A.19).

\begin{tabular}{|c|c|c|c|c|c|c|c|}
\hline \multicolumn{8}{|c|}{$E^{1} \Pi\left(v^{\prime}=\right.$} \\
\hline$J$ & $R_{m s}(\mathrm{~nm})$ & $P_{m s}(\mathrm{~nm})$ & $R_{m s}\left(\mathrm{~cm}^{-1}\right)$ & $P_{m s}\left(\mathrm{~cm}^{-1}\right)$ & $\delta_{P}$ & $Q_{m s}(\mathrm{~nm})$ & $Q_{m s}\left(\mathrm{~cm}^{-1}\right)$ \\
\hline 0 & $\begin{array}{l}105.16712 \\
50.6727\end{array}$ & & & & -11 & & \\
\hline 1 & 105.16277 & & 95090.688 & & 20 & 105.17156 & \\
\hline 2 & 105.15842 & 105.17985 & 95094.620 & 95075.244 & -5 & 105.17145 & $95082.841^{b}$ \\
\hline & 105.15401 & 105.18408 & 95098.607 & 95071.424 & 26 & 105.17129 & $95082.987^{b}$ \\
\hline 5 & $\begin{array}{l}105.14960 \\
0.14513\end{array}$ & 105.18818 & 95102.595 & 95067.718 & 2 & 105.17138 & $95082.898^{b}$ \\
\hline 6 & 105.14513 & 105.19234 & 95106.639 & 95063.954 & 6 & 105.17123 & $95083.036^{b}$ \\
\hline 6 & $\begin{array}{l}105.14016 \\
1013607\end{array}$ & $\begin{array}{l}105.19638 \\
05\end{array}$ & $\begin{array}{l}95111.132 \\
\end{array}$ & $\begin{array}{l}95060.305 \\
050566\end{array}$ & 69 & $\begin{array}{l}105.17133 \\
10517065\end{array}$ & 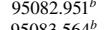 \\
\hline $\begin{array}{l}7 \\
8\end{array}$ & $\begin{array}{l}150.13607 \\
105.13178\end{array}$ & $\begin{array}{l}105.20042 \\
10520409\end{array}$ & $\begin{array}{l}55114.8399 \\
95118.714\end{array}$ & $\begin{array}{l}95056.654 \\
95053.340\end{array}$ & $\begin{array}{l}19 \\
-1\end{array}$ & $\begin{array}{l}105.577065 \\
105.17100\end{array}$ & $\begin{array}{c}95083.564^{b} \\
95083.244^{b, u}\end{array}$ \\
\hline & $\begin{array}{l}105.12651 \\
1\end{array}$ & $\begin{array}{l}105.20409 \\
105.20838\end{array}$ & 95123.488 & 95049.465 & 37 & $\begin{array}{l}105.1711115 \\
105\end{array}$ & $95083.244^{9}$ \\
\hline 10 & 105.12216 & 105.21254 & 95127.420 & 95045.702 & -8 & 105.17048 & $\begin{array}{l}950803.7108^{b, u} \\
9.4\end{array}$ \\
\hline 11 & 105.11726 & 105.21584 & 95131.857 & 95042.726 & -80 & 105.17060 & $95083.607^{b, u}$ \\
\hline & & 105.21988 & 95136.013 & 95039.074 & -9 & 105.17018 & $95083.991^{b}$ \\
\hline 13 & 105.10795 & 105.22330 & 95140.281 & 95035.985 & 8 & 105.17023 & $95083.938^{b, u}$ \\
\hline 14 & 105.10324 & 105.22734 & 95144.549 & 95032.335 & -2 & 105.17012 & $95084.042^{b, u}$ \\
\hline 15 & 105.09840 & 105.23114 & 95148.930 & 95028.909 & 19 & 105.17004 & $95084.116^{b, u}$ \\
\hline 16 & 105.09356 & 105.23487 & 95153.311 & 95025.540 & 14 & 105.16980 & $95084.331^{b, u}$ \\
\hline 17 & 105.08872 & 105.23854 & 95157.692 & 95022.226 & -16 & 105.16968 & $95084.442^{b, u}$ \\
\hline 18 & 105.08382 & 105.24214 & 95162.129 & 95018.968 & -15 & 105.16943 & $95084.664^{b, u}$ \\
\hline & 105.07886 & 105.24569 & 95166.622 & 95015.767 & 16 & 105.16922 & $95084.853^{b, u}$ \\
\hline 20 & $\begin{array}{l}105.07390 \\
10506984\end{array}$ & $\begin{array}{l}105.24924 \\
1052524\end{array}$ & $\begin{array}{l}95171.1115 \\
9917568\end{array}$ & $\begin{array}{r}95012.565 \\
05093\end{array}$ & -5 & 105.16904 & $\begin{array}{l}95085.018^{b, u} \\
0.4\end{array}$ \\
\hline $\begin{array}{l}21 \\
22\end{array}$ & $\begin{array}{l}105.06694 \\
105.06392\end{array}$ & $\begin{array}{l}105.25278 \\
1052521\end{array}$ & $\begin{array}{l}551515.608 .15 \\
9515\end{array}$ & $\begin{array}{l}95009.364 \\
9506.275\end{array}$ & $\begin{array}{l}-24 \\
-11\end{array}$ & & $95085.176^{b, u}$ \\
\hline 23 & 105.05883 & $\begin{array}{l}105.25021 \\
105963\end{array}$ & 95184.762 & 95003.186 & 5 & & \\
\hline 24 & 105.05381 & 105.26305 & 95189.311 & 95000.097 & -31 & & \\
\hline 25 & 105.04867 & 105.26641 & 95193.973 & 94997.064 & 77 & & \\
\hline 26 & 105.04358 & 105.26971 & 95198.579 & 94994.087 & * & & \\
\hline 27 & 105.03844 & 105.27319 & 95203.240 & 94990.942 & * & & \\
\hline 28 & 105.03317 & 105.27687 & 95208.014 & 94987.628 & * & & \\
\hline & 105.02804 & 105.28042 & $\begin{array}{l}95212.665 \\
\end{array}$ & 94984.427 & * & & \\
\hline $\begin{array}{l}30 \\
31\end{array}$ & 105.02280 & $\begin{array}{l}105.28396 \\
105.28745\end{array}$ & 95217.416 & $\begin{array}{l}94981.2262 \\
94978.081\end{array}$ & & & \\
\hline 32 & & 105.29094 & & 94974.936 & & & \\
\hline & & 105.29437 & & 94971.836 & & & \\
\hline 34 & & $\begin{array}{l}105.29780 \\
105.3108\end{array}$ & & $\begin{array}{l}94968.743 \\
94965.793\end{array}$ & & & \\
\hline $\begin{array}{l}35 \\
36\end{array}$ & & $\begin{array}{l}105.30108 \\
105.30449\end{array}$ & & $\begin{array}{l}94965.7919 \\
94962.708\end{array}$ & & & \\
\hline 0 & 105 & & & ${ }^{{ }^{1} \mathbf{C}^{1 / 1} \mathbf{O}}$ & & & \\
\hline 1 & 1051079 & & $\begin{array}{l}95059.162 \\
9506354\end{array}$ & & -1 & & \\
\hline 1 & $\begin{array}{l}101.18855 \\
10855\end{array}$ & 105,20942 & 95067381 & 95048.522 & -2 & $\begin{array}{l}1052011 \\
1025\end{array}$ & ${ }_{95050030}$ \\
\hline 3 & 105.18425 & 105.21351 & 95071.271 & 95044.828 & 13 & 105.20116 & $95055.989^{\circ}$ \\
\hline 4 & 105.18008 & 105.21758 & 95075.037 & 95041.151 & -4 & 105.20094 & $95056.184^{e}$ \\
\hline & 105.17557 & 105.22160 & 95079.115 & 95037.518 & -1 & 105.20094 & $95056.188^{e}$ \\
\hline 6 & 105.17126 & 105.22569 & $\begin{array}{l}95083.007 \\
05006\end{array}$ & 95033.825 & 2 & 105.20128 & $95055.882^{e}$ \\
\hline 8 & $\begin{array}{l}150.161444 \\
10516108\end{array}$ & 105.22948 & $\begin{array}{l}95086.466 \\
05001\end{array}$ & $\begin{array}{r}95030.408 \\
95026\end{array}$ & 4 & $\begin{array}{l}105.20031 \\
1052038\end{array}$ & $\begin{array}{l}95056.754^{e} \\
05055690\end{array}$ \\
\hline 9 & $\begin{array}{l}10.1015786 \\
101575\end{array}$ & $\begin{array}{l}105.23344 \\
105.23793\end{array}$ & $\begin{array}{l}55099.405 \\
9509.312\end{array}$ & $\begin{array}{l}95026.804 \\
9502270\end{array}$ & $\begin{array}{l}-7 \\
7\end{array}$ & $\begin{array}{l}100.20038 \\
10510994\end{array}$ & $\begin{array}{l}950506.693^{\circ} \\
950507086\end{array}$ \\
\hline 10 & 105.15291 & $\begin{array}{l}105.24073\end{array}$ & 95099.999 & 95020248 & 10 & 1050001 & $\begin{array}{l}95057.023^{\circ} \\
9\end{array}$ \\
\hline 11 & 105.14848 & 10524472 & 95103611 & 95016645 & 3 & 10519988 & $95057.147^{\circ}$ \\
\hline 12 & 105.14389 & 105.24826 & 95107.760 & 95013.447 & 17 & 105.19971 & $95057.297^{\mathrm{e}}$ \\
\hline 13 & 105.13929 & 105.25208 & 95111.926 & 95009.998 & 13 & 105.19953 & $95057.463^{e}$ \\
\hline 14 & 105.13464 & 105.25579 & 95116.128 & 95006.647 & -19 & 105.19933 & $95057.640^{\circ}$ \\
\hline 10 & 105.12994 & 105.25944 & 95120.384 & 95003.353 & 40 & 105.19912 & $95057.828^{e}$ \\
\hline 16 & $\begin{array}{l}105.12522 \\
10.12228\end{array}$ & $\begin{array}{l}105.26299 \\
\end{array}$ & $\begin{array}{l}95124.654 \\
0\end{array}$ & 95000.155 & 15 & $\begin{array}{l}105.19890 \\
10.1067\end{array}$ & $\begin{array}{l}95058.026^{e} \\
0\end{array}$ \\
\hline 18 & $\begin{array}{l}150.121238 \\
105.11566\end{array}$ & $\begin{array}{l}105.26667 \\
10527014\end{array}$ & $\begin{array}{l}55129.031 \\
9513.302\end{array}$ & $\begin{array}{l}94996-833 \\
94993.69\end{array}$ & $=0$ & $\begin{array}{l}105.19867 \\
10519844\end{array}$ & $\begin{array}{l}95050.232^{e} \\
0505844 e^{e}\end{array}$ \\
\hline 10 & $\begin{array}{l}105.1506 \\
105.11079\end{array}$ & 105.273746 & $\begin{array}{l}95135.302 \\
05137.713\end{array}$ & 9499.6912 & 25 & 100.15044 & \\
\hline 20 & 105.10590 & $\begin{array}{l}105.27699 \\
\end{array}$ & 95142.141 & 94987.519 & 90 & & \\
\hline 21 & 105.10102 & 105.28045 & 95146.554 & 94984.400 & & & \\
\hline 22 & 105.09636 & 105.28392 & 95150.777 & 94981.263 & & & \\
\hline 23 & 105.09106 & & 95155.568 & & & & \\
\hline 24 & 105.08627 & & 95159.911 & & & & \\
\hline & $\begin{array}{l}105.0889494 \\
10797\end{array}$ & & 95163.833 & & & & \\
\hline 27 & $\begin{array}{l}105.07 / 177 \\
105774\end{array}$ & & $\begin{array}{l}551616.244 \\
95173073\end{array}$ & & & & \\
\hline & & & & ${ }^{2} \mathbf{C}^{1 / 8}$ & & & \\
\hline 0 & 105.22385 & & 95035.489 & & -15 & & \\
\hline & 105.21971 & & 95039.225 & & 12 & 105.22776 & $95031.953^{b}$ \\
\hline 2 & 105.21546 & 105.23598 & 95043.067 & 95024.533 & 24 & 105.22779 & $95031.929^{b}$ \\
\hline & & 105.2 & 95046 & & 2 & 105.22764 & $95032.064^{\circ}$ \\
\hline 4 & 1053.20718 & 105.24389 & 95050.548 & 95017.388 & 15 & 105.22775 & $95031.968^{8}$ \\
\hline & 105.20308 & $105.24 / 85$ & 95054.234 & 95013.817 & 28 & 105.22789 & $95031.841^{\circ}$ \\
\hline 7 & 105.19390 & $\begin{array}{l}105.25584 \\
\end{array}$ & 95062.545 & 95006.605 & 25 & 105.22666 & ${ }_{95032.947}^{b}$ \\
\hline 0 & 105 & 105.25840 & 95066.319 & 95004.297 & 8 & 105.22726 & $95032.407^{b, u}$ \\
\hline & 105.18510 & 105.26286 & 950 & 95000.270 & 25 & 105.22728 & $95032.392^{b, u}$ \\
\hline 10 & 105.18078 & 105.26674 & 95074.406 & 94996.765 & 11 & 105.22684 & 95032.784 \\
\hline & $\begin{array}{l}105.17638 \\
10171703\end{array}$ & 105.27025 & 95078 & 94993.597 & -36 & 105.22685 & \\
\hline 12 & $\begin{array}{l}105.17183 \\
10167278\end{array}$ & 105.27399 & $\begin{array}{l}95082.494 \\
9508605\end{array}$ & $\begin{array}{l}94990.227 \\
9496.99\end{array}$ & 20 & 105.22668 & $95032.932^{b, u}$ \\
\hline 10 & $\begin{array}{l}100.161 / 28 \\
10516274\end{array}$ & $\begin{array}{l}105.28123 \\
105.2812\end{array}$ & $\begin{array}{l}95086.0600 \\
95090.717\end{array}$ & 1988.992 & $\begin{array}{l}11 \\
4\end{array}$ & $\begin{array}{l}105.22656 \\
1020200\end{array}$ & $95033.041^{b, u}$ \\
\hline 15 & 10 & 110 & 5 & 94980523 & 32 & $\begin{array}{l}150.222629 \\
10522604\end{array}$ & $\begin{array}{l}95035.284^{b} \\
9503500^{b}\end{array}$ \\
\hline 16 & & & & & -39 & 105 & 958 \\
\hline 17 & 10514 & 1052 & 95103 & & -6 & & \\
\hline 18 & 105 & 105.2 & 95107 & & -11 & 105.22554 & $95033.959^{b}$ \\
\hline 1 & 105 & 10. & 95111 & 968.054 & -41 & 105.22533 & 95034.1 \\
\hline 20 & 10 & 10 & 4 & 3 & 15 & 105.22512 & 95034 \\
\hline 21 & 10 & 10 & 66 & 55 & -14 & 105.22482 & 95034.616 \\
\hline 22 & 105 & 7 & 95 & 12 & * & 105.22465 & $95034.766^{b}$ \\
\hline 23 & 105.12047 & 105.3 & 95128.953 & 94956.132 & -8 & & \\
\hline 24 & & & 133.534 & 95 & & & \\
\hline . & 105.11054 & $\begin{array}{l}105.31838 \\
105.32201\end{array}$ & 95137.938 & 9495 & * & & \\
\hline 27 & & 105.32201 & & 94946.914 & & & \\
\hline
\end{tabular}

Notes. ${ }^{(b)}$ Data from Baker et al. (1993). ${ }^{(u)}$ Data from Ubachs et al. (2000). ${ }^{(e)}$ Data calculated from the $e$-parity levels.

\begin{tabular}{|c|c|c|c|c|c|c|c|}
\hline \multicolumn{8}{|c|}{$\frac{E^{1} \Pi\left(v^{\prime}=1\right)-X^{1} \Sigma^{+}\left(v^{\prime \prime}=0\right)}{{ }^{13} \mathrm{C}^{16} \mathrm{O}}$} \\
\hline & & $P_{m s}(\mathrm{~nm})$ & & & & $O_{m s(n m)}$ & $O_{m s}\left(\mathrm{~cm}^{-1}\right)$ \\
\hline 0 & $\frac{K m s}{105.21928}$ & Tims mim & $\frac{A_{m s}}{95039.616}$ & Tms toul te & $\frac{\partial p}{-2}$ & Qms (min) & mis toni \\
\hline 1 & 105.21515 & & 95043.351 & & 5 & 105.22332 & 955035.969 b \\
\hline 2 & 105.21101 & 105.23149 & 95047.086 & 95028.592 & 12 & 105.22333 & $95035.958^{b}$ \\
\hline 3 & 105.20672 & 105.23551 & 95050.961 & 95024.962 & 2 & 105.22333 & $95035.961^{b}$ \\
\hline 4 & 105.20255 & 105.23953 & 95054.730 & 95021.333 & 1 & 105.22320 & $95036.078^{b}$ \\
\hline 5 & 105.19838 & 105.24335 & 95058.502 & 95017.877 & -2 & 105.22326 & $95036.021^{b}$ \\
\hline 6 & 105.19549 & 105.24732 & 95061.111 & 95014.300 & & 105.22308 & $95036.180^{b}$ \\
\hline & 105.18922 & 105.25127 & 95066.774 & 95010.732 & -9 & 105.22244 & $95036.763^{, b u}$ \\
\hline 8 & 105.18501 & & 95070.579 & & & 105.22255 & $95036.662^{b, u}$ \\
\hline 9 & 105.18037 & 105.25836 & 95074.771 & 95004.330 & -28 & 105.22265 & $95036.575^{b, u}$ \\
\hline 10 & 105.17608 & 105.26233 & 95078.656 & 95000.745 & -2 & 105.22222 & $95036.962^{b, u}$ \\
\hline 111 & 105.1776 & 105.26572 & 95082.692 & 94997.685 & 16 & 105.22236 & $95036.836^{p, u}$ \\
\hline 12 & 105.16712 & 105.2696 & 95086.751 & 94994.181 & 8 & 105.22220 & $95036.978^{b, u}$ \\
\hline 13 & 105.16257 & 105.27330 & 95090.869 & 94990.850 & 20 & 105.22204 & 95037.126, \\
\hline 14 & 105.15799 & 105.27690 & 95095.006 & 94987.595 & -4 & 105.22187 & $95037.276^{, 0 u}$ \\
\hline 15 & 105.15340 & 105.28049 & 95099.162 & 94984.363 & -6 & 105.22165 & $95037.472^{2, u}$ \\
\hline 16 & 105.14874 & 1055.28396 & 95103.377 & 94981.227 & -2 & 105.22147 & $95037.640^{\circ, u}$ \\
\hline 17 & 105.14408 & 105.28746 & 95107.593 & 94978.069 & -6 & 105.22124 & $95037.849^{\circ, u}$ \\
\hline 18 & 105.13937 & 105.29091 & 95111.847 & 94974.964 & -1 & 105.22106 & $95038.011^{b, u}$ \\
\hline 19 & 105.13463 & 105.29433 & 95116.141 & 94971.878 & 1 & 105.22081 & $95038.235^{\text {bu }}$ \\
\hline 20 & 105.12988 & 105.29772 & 95120.433 & 94968.820 & -7 & 105.22058 & $95038.44^{b, u}$ \\
\hline${ }^{21}$ & 105.12510 & $\begin{array}{l}105.30105 \\
10530436\end{array}$ & $\begin{array}{l}95124.765 \\
05512013\end{array}$ & 94965.811 & -6 & 105.22021 & $95038.775^{\circ, u}$ \\
\hline $\begin{array}{l}22 \\
23\end{array}$ & $\begin{array}{l}105.1212027 \\
105.1542\end{array}$ & $\begin{array}{l}105.30436 \\
10530764\end{array}$ & $\begin{array}{l}95129.135 \\
95133.520\end{array}$ & $\begin{array}{l}94962.826 \\
9495868\end{array}$ & $\begin{array}{l}* \\
5\end{array}$ & $\begin{array}{l}105.2221014 \\
105.21979\end{array}$ & 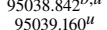 \\
\hline 24 & $\begin{array}{l}10.111058 \\
1051058 \\
10.51068\end{array}$ & 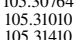 & 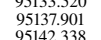 & $\begin{array}{l}944959.78568 \\
9905.656\end{array}$ & $\begin{array}{c}-23 \\
-18\end{array}$ & & \\
\hline & $\begin{array}{l}105.10508 \\
105.10072\end{array}$ & $\begin{array}{l}1055.341710 \\
105.3724\end{array}$ & 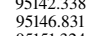 & $\begin{array}{l}44955.048 \\
94951.216\end{array}$ & $\begin{array}{c}-18 \\
8\end{array}$ & & \\
\hline $\begin{array}{l}27 \\
28\end{array}$ & $\begin{array}{l}105.09975 \\
1050.09078\end{array}$ & $\begin{array}{l}105.322038 \\
105332350\end{array}$ & $\begin{array}{l}95151.32424 \\
95158.823\end{array}$ & $\begin{array}{l}94448.381 \\
99445.569\end{array}$ & $\begin{array}{l}-26 \\
-16\end{array}$ & & \\
\hline $\begin{array}{l}29 \\
30\end{array}$ & $\begin{array}{l}105.08578 \\
1.55 .00874\end{array}$ & $\begin{array}{l}105.32648 \\
10532958 \\
10535\end{array}$ & $\begin{array}{l}95160.0353 \\
9551694920\end{array}$ & $\begin{array}{l}94942.884 \\
94940122\end{array}$ & & & \\
\hline $\begin{array}{l}31 \\
32\end{array}$ & $\begin{array}{l}105.00767 \\
10507759\end{array}$ & & $\begin{array}{l}95169.508 \\
95151714\end{array}$ & $\begin{array}{l}94937.264 \\
\end{array}$ & & & \\
\hline $\begin{array}{l}33 \\
34\end{array}$ & $\begin{array}{l}105.06558 \\
10505589\end{array}$ & & 955178.646 & & & & \\
\hline & & & & ${ }^{13} \mathbf{C}^{17} \mathbf{O}$ & & & \\
\hline & 105.25000 & & 95011.872 & & -2 & & \\
\hline & $\begin{array}{l}105.24604 \\
10520203\end{array}$ & & $\begin{array}{l}95015.447 \\
0500067\end{array}$ & & 3 & $\begin{array}{l}105.25399 \\
010252509\end{array}$ & 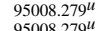 \\
\hline 3 & 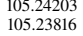 & $\begin{array}{l}105.26189 \\
105.26587\end{array}$ & $\begin{array}{l}950019.067 \\
95022.562\end{array}$ & $\begin{array}{l}950001.140 \\
9497.548\end{array}$ & -1 & $\begin{array}{l}150.253999 \\
105.25402\end{array}$ & $\begin{array}{l}95000.277^{a l u} \\
95008.26^{u}\end{array}$ \\
\hline 5 & 010522003 & 105.26978 & & $\begin{array}{r}94994.020 \\
\end{array}$ & & 105.25419 & ${ }_{95008.095^{u}}$ \\
\hline & $\begin{array}{l}105.22903 \\
1052209\end{array}$ & 10527384 & $\begin{array}{l}9303030.800 \\
9_{95034}\end{array}$ & & 1 & 105.25212 & $\begin{array}{l}95009.966^{u} \\
\end{array}$ \\
\hline 7 & 105.22120 & 10528056 & 95037.878 & 94984.293 & -1 & 10525310 & 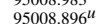 \\
\hline 8 & 105.21645 & 105.28444 & 95042.168 & 94980.792 & 0 & 105.25354 & $95008.681^{u}$ \\
\hline 9 & 105.21220 & 105.28857 & 95046.007 & 94977.067 & -2 & 105.25305 & $\begin{array}{l}95009.127^{u} \\
u^{u}\end{array}$ \\
\hline 10 & 100.402891 & $\begin{array}{l}1050.29174 \\
0.5954\end{array}$ & $\begin{array}{l}950499.901 \\
050505\end{array}$ & $\begin{array}{r}49974.201 \\
\end{array}$ & & 105.25296 & $\begin{aligned} 95009 \cdot 2033^{u} & \end{aligned}$ \\
\hline $\begin{array}{l}11 \\
12\end{array}$ & $\begin{array}{l}105.19510 \\
10.1910\end{array}$ & $\begin{array}{l}105.29900 \\
105\end{array}$ & $\begin{array}{l}95057.853 \\
5057\end{array}$ & $\begin{array}{l}94967.659 \\
946\end{array}$ & $\begin{array}{l}-2 \\
-4\end{array}$ & $\begin{array}{l}105.25269 \\
105269\end{array}$ & $\begin{array}{l}950009.447^{u} \\
9\end{array}$ \\
\hline 13 & 105.19468 & 105.30253 & 95061.837 & 94964.476 & -4 & 105.25254 & $95009.581^{x}$ \\
\hline 14 & 105.19019 & 105.30602 & 95065.895 & 94961.328 & 2 & 105.25236 & $95009.746^{x}$ \\
\hline 15 & $\begin{array}{l}150.158727 \\
15.510\end{array}$ & $\begin{array}{l}1055.390550 \\
0.5321002\end{array}$ & $\begin{array}{l}950069.935 \\
9057907\end{array}$ & $\begin{array}{l}94959.1900 \\
\text { 94955 }\end{array}$ & -3 & $\begin{array}{l}150.25216 \\
1025105\end{array}$ & $\begin{array}{l}95009.924^{x} \\
0.501014^{x}\end{array}$ \\
\hline 17 & 10.17662 & 10531633 & 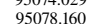 & 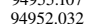 & -2 & 1025573 & $\begin{array}{l}9550101.11_{11}^{* x} \\
950016^{x}\end{array}$ \\
\hline 18 & 105.17204 & 105.31969 & 95082.301 & 94949.003 & -1 & 105.25149 & $95010.52^{x}$ \\
\hline 19 & 105.16747 & 105.32300 & 95086.432 & 94946.019 & -1 & 105.25125 & $95010.75^{x}$ \\
\hline & $\begin{array}{l}105.1627272 \\
1.1527\end{array}$ & $\begin{array}{l}105.3263030 \\
0.0530\end{array}$ & $\begin{array}{l}950000.727 \\
5097\end{array}$ & 99443.044 & & $\begin{array}{l}105.25098 \\
10525071\end{array}$ & $\begin{array}{l}95010.988 x \\
0.051232 x\end{array}$ \\
\hline $\begin{array}{l}21 \\
22 \\
22\end{array}$ & $\begin{array}{l}150.18506 \\
105.15337\end{array}$ & $\begin{array}{l}1055.32960 \\
10533272\end{array}$ & $\begin{array}{l}95599.4941 \\
95099.183\end{array}$ & $\begin{array}{l}944440.069 \\
94937.257\end{array}$ & & $\begin{array}{l}150.25571 \\
105.25043\end{array}$ & $\begin{array}{l}95011.23^{3} x^{x} \\
950011.48^{x}\end{array}$ \\
\hline $\begin{array}{l}23 \\
24\end{array}$ & & & & & & $\begin{array}{l}105.25014 \\
10529083\end{array}$ & $\begin{array}{l}95011.754^{x} \\
90902002\end{array}$ \\
\hline 25 & & & & & & $\begin{array}{l}105.24952 \\
0\end{array}$ & $95012.313^{x}$ \\
\hline & & & & ${ }^{13} \mathbf{C}^{18} \mathbf{O}$ & & & \\
\hline $\begin{array}{l}0 \\
1\end{array}$ & $\begin{array}{l}150.277550 \\
105.27239\end{array}$ & & $\begin{array}{l}949988.861 \\
94991.669\end{array}$ & & $\begin{array}{l}35 \\
58\end{array}$ & 43 & 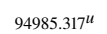 \\
\hline 2 & 105.26890 & 105.28719 & 94994.815 & 94978.312 & -8 & 105.28026 & $94984.570^{b, u}$ \\
\hline 3 & 105.26511 & 105.29187 & 10 & 94974.090 & 10 & 105.28065 & $94984.220^{b, u}$ \\
\hline 4 & 105.26112 & 105.29598 & 95001.835 & 94970.383 & 57 & 105.28082 & $94984.067^{b, u}$ \\
\hline 5 & 105.25720 & 105.29997 & 95005.373 & 94966.789 & * & 105.28079 & $94984.086^{b, u}$ \\
\hline 6 & 105.25285 & 105.30383 & 95009.305 & 94963.307 & 41 & 105.28104 & $94983.860^{b, u}$ \\
\hline & 105.24880 & 105.30782 & 95012.955 & 94959.712 & 6 & 105.28064 & 94984.227 \\
\hline 8 & 105.24464 & 105.31099 & 95016.718 & 94956.848 & 56 & 105.28062 & $94984.240^{b, u}$ \\
\hline & 105.24047 & 105.31461 & 95020.481 & 94953.590 & 52 & 105.28049 & $94984.358^{b, u}$ \\
\hline 10 & 105.23630 & 105.31828 & 95024.246 & 94950.277 & -7 & 105.28040 & $94984.441^{b, u}$ \\
\hline 11 & 105.23201 & 105.32183 & 95028.119 & 94947.075 & 19 & 105.28026 & $94984.564^{b, u}$ \\
\hline 12 & 105.22778 & 105.32526 & 95031.938 & 94943.986 & -10 & 105.28010 & $94984.710^{0, u}$ \\
\hline 13 & 105.22337 & 105.32875 & 950 & 94940.841 & 19 & 105.27994 & 94984 \\
\hline 14 & 105.21901 & 105.33218 & 95039.858 & 94937.752 & 22 & 105.27973 & $94985.049^{b, u}$ \\
\hline 15 & 105.21466 & 105.33554 & 950 & 94934.719 & -1 & 105.27953 & $94985.2255^{,, u}$ \\
\hline 16 & 105.21018 & 105.33891 & 95047.832 & 94931.687 & 6 & 105.27927 & 94985. \\
\hline 17 & 105.20577 & 105.34221 & 95055.820 & 94928.710 & -14 & 105.27908 & $94985.634^{4, u}$ \\
\hline 18 & 105.20129 & 105.34545 & 95055.864 & 94925.789 & -2 & 105.27881 & $874^{, b u}$ \\
\hline 19 & 105.19676 & 105.34869 & 95059.964 & 94922.869 & 11 & 105.27884 & $94985.849^{b}$ \\
\hline 20 & 105.19222 & 105.3 & 95064.0 & & -1 & 105.27816 & $94986.464^{b}$ \\
\hline 11 & 105.18762 & 105.35511 & 95068.2 & 9491 & 18 & 5.27816 & $94986.462^{b}$ \\
\hline & 105.18302 & 105.35823 & 95072.376 & 94914.276 & 11 & 105.27790 & $94986.695^{b}$ \\
\hline 23 & 105.17843 & 105.36135 & 95076.5322 & 94911.468 & 7 & & \\
\hline & $\begin{array}{l}1055.169717 \\
105911\end{array}$ & $\begin{array}{l}1053.36440 \\
105.3746\end{array}$ & 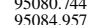 & $\begin{array}{l}94908.176 \\
9490564\end{array}$ & 量o & & \\
\hline & 5.16439 & 105.37045 & 95089.225 & 94903.268 & 14 & & \\
\hline & 55.15960 & 105.377338 & 95093.550 & $\begin{array}{l}94900.0629 \\
\end{array}$ & 23 & & \\
\hline & 80 & 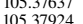 & $\begin{array}{l}939017.818 \\
09513\end{array}$ & $\begin{array}{r}948989.932 \\
04853\end{array}$ & & & \\
\hline & $\begin{array}{l}105.14526 \\
155262\end{array}$ & 105.38205 & 95106.522 & $\begin{array}{l}94892.822 \\
\end{array}$ & 2 & & \\
\hline 31 & 105.14043 & 105.38493 & 95110.887 & 94890.225 & 0 & & \\
\hline 33 & & $\begin{array}{l}105 . \\
105 .\end{array}$ & & $\begin{array}{l}94888.7 .1252 \\
94885.239\end{array}$ & & & \\
\hline 34 & 105.12588 & 105.39301 & 5124.053 & 94882.956 & & & \\
\hline
\end{tabular}

Notes. ${ }^{(b)}$ Data from Baker et al. (1993). ${ }^{\left({ }^{u}\right)}$ Data from Ubachs et al. (2000). ${ }^{(e)}$ Data calculated from the $e$-parity levels. ${ }^{(x)}$ Data calculated from the $e$-parity levels using the deperturbation described in Ubachs et al. (2000). 


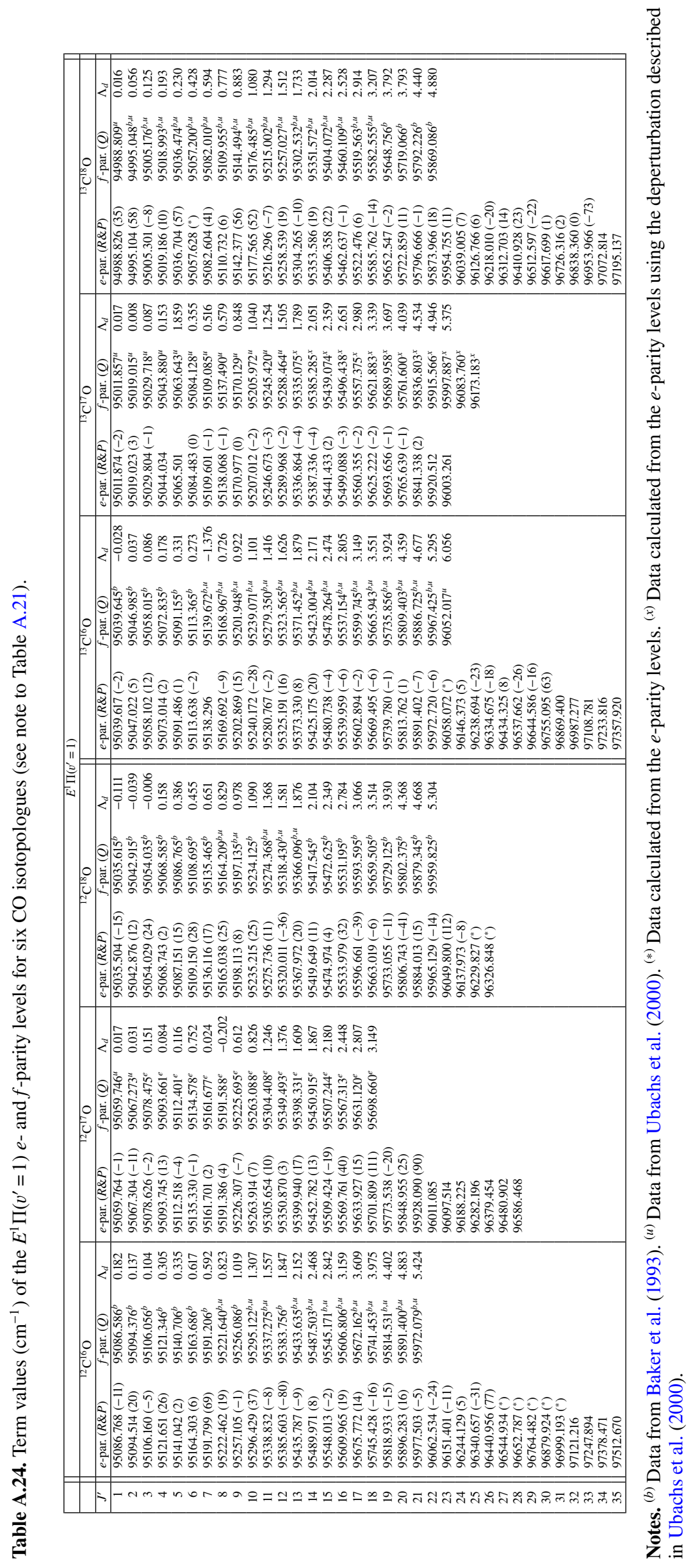


Table A.25. Measured transition wavelengths and wavenumbers of the $E^{1} \Pi\left(v^{\prime}=2\right)-X^{1} \Sigma^{+}\left(v^{\prime \prime}=0\right)$ band for ${ }^{12} \mathrm{C}^{16} \mathrm{O},{ }^{12} \mathrm{C}^{17} \mathrm{O}$, and ${ }^{12} \mathrm{C}^{18} \mathrm{O}$ (same column description as for Table A.19).

\begin{tabular}{|c|c|c|c|c|c|c|c|}
\hline \multirow{2}{*}{\multicolumn{8}{|c|}{$E^{1} \Pi\left(v^{\prime}=2\right)-X^{1} \Sigma^{+}\left(v^{\prime \prime}=0\right)$}} \\
\hline & \multicolumn{2}{|c|}{${ }^{12} \mathbf{C}^{16} \mathbf{O}$} & & & & & \\
\hline$J$ & $R_{m s}(\mathrm{~nm})$ & $P_{m s}(\mathrm{~nm})$ & $R_{m s}\left(\mathrm{~cm}^{-1}\right)$ & $P_{m s}\left(\mathrm{~cm}^{-1}\right)$ & $\delta_{P}$ & $Q_{m s}(\mathrm{~nm})$ & $Q_{m s}\left(\mathrm{~cm}^{-1}\right)$ \\
\hline 0 & 102.92548 & & 97157.676 & & -6 & & \\
\hline 1 & 102.92149 & & 97161.438 & & 0 & 102.92955 & 97153.831 \\
\hline 2 & 102.91750 & 102.93769 & 97165.201 & 97146.152 & 9 & 102.92968 & 97153.712 \\
\hline 3 & 102.91364 & 102.94186 & 97168.852 & 97142.214 & -30 & 102.92987 & 97153.531 \\
\hline 4 & 102.90977 & 102.94604 & 97172.503 & 97138.271 & 2 & 102.93012 & 97153.288 \\
\hline 5 & 102.90596 & 102.95023 & 97176.098 & 97134.311 & -21 & 102.93045 & 97152.979 \\
\hline 6 & 102.90216 & 102.95458 & 97179.692 & 97130.212 & 13 & 102.93085 & 97152.604 \\
\hline 7 & 102.89847 & 102.95887 & 97183.174 & 97126.168 & -9 & 102.93132 & 97152.156 \\
\hline 8 & 102.89478 & 102.96327 & 97186.656 & 97122.012 & -1 & 102.93189 & 97151.626 \\
\hline 9 & 102.89116 & 102.96768 & 97190.082 & 97117.856 & 9 & 102.93249 & 97151.060 \\
\hline 10 & 102.88759 & 102.97214 & 97193.452 & 97113.644 & -8 & 102.93315 & 97150.430 \\
\hline 11 & 102.88402 & 102.97667 & 97196.821 & 97109.375 & 4 & 102.93387 & 97149.752 \\
\hline 12 & 102.88058 & 102.98120 & 97200.079 & 97105.106 & -9 & 102.93447 & 97149.189 \\
\hline 13 & 102.87707 & 102.98578 & 97203.392 & 97100.782 & 35 & 102.93557 & 97148.150 \\
\hline 14 & 102.87374 & 102.99043 & 97206.538 & 97096.401 & 8 & 102.93653 & 97147.243 \\
\hline 15 & 102.87041 & 102.99514 & 97209.684 & 97091.965 & 20 & 102.93757 & 97146.265 \\
\hline 16 & 102.86714 & 102.99986 & 97212.772 & 97087.508 & 23 & 102.93865 & 97145.240 \\
\hline 17 & 102.86394 & 103.00467 & 97215.802 & 97082.977 & -1 & 102.93981 & 97144.145 \\
\hline 18 & 102.86080 & 103.00951 & 97218.770 & 97078.413 & 9 & 102.94111 & 97142.922 \\
\hline 19 & 102.85773 & 103.01436 & 97221.671 & 97073.848 & & 102.94247 & 97141.638 \\
\hline 20 & 102.85469 & 103.01933 & 97224.538 & 97069.158 & & 102.94386 & 97140.325 \\
\hline 21 & 102.85173 & & 97227.342 & & & 102.94540 & 97138.875 \\
\hline 22 & 102.84890 & & 97230.019 & & & 102.94697 & 97137.393 \\
\hline \multirow[t]{2}{*}{23} & 102.84597 & & 97232.789 & & & 102.94867 & 97135.788 \\
\hline & \multicolumn{7}{|c|}{${ }^{2} \mathrm{C}^{1 / 2} \mathbf{O}$} \\
\hline 0 & 102.97878 & & 97107.382 & & 35 & & \\
\hline 1 & 102.97490 & & 97111.046 & & -8 & 102.98274 & 97103.654 \\
\hline 2 & 102.97105 & 102.99078 & 97114.672 & 97096.067 & -20 & 102.98287 & 97103.531 \\
\hline 3 & 102.96724 & 102.99475 & 97118.266 & 97092.324 & -5 & 102.98303 & 97103.379 \\
\hline 4 & 102.96340 & 102.99883 & 97121.892 & 97088.479 & 30 & 102.98328 & 97103.140 \\
\hline 5 & 102.95975 & 103.00300 & 97125.334 & 97084.550 & -12 & 102.98358 & 97102.863 \\
\hline 6 & 102.95602 & 103.00718 & 97128.850 & 97080.612 & -48 & 102.98395 & 97102.511 \\
\hline 7 & 102.95236 & 103.01139 & 97132.309 & 97076.647 & -17 & 102.98444 & 97102.052 \\
\hline 8 & 102.94873 & 103.01553 & 97135.732 & 97072.747 & 11 & 102.98497 & 97101.553 \\
\hline 9 & 102.94524 & 103.01987 & 97139.025 & 97068.657 & 36 & 102.98556 & 97100.995 \\
\hline 10 & 102.94172 & 103.02424 & 97142.346 & 97064.539 & & 102.98608 & 97100.498 \\
\hline 11 & 102.93817 & 103.02873 & 97145.697 & 97060.302 & & 102.98666 & 97099.952 \\
\hline 12 & & & & & & 102.98762 & 97099.053 \\
\hline 13 & & & & & & 102.98830 & 97098.409 \\
\hline \multirow[t]{2}{*}{14} & & & & & & 102.98923 & 97097.534 \\
\hline & \multicolumn{7}{|c|}{${ }^{12} \mathbf{C}^{18} \mathbf{O}$} \\
\hline 0 & 103.02681 & & 97062.114 & & 8 & & \\
\hline 1 & 103.02299 & & 97065.713 & & 2 & 103.03074 & 97058.409 \\
\hline 2 & 103.01924 & 103.03849 & 97069.246 & 97051.112 & -9 & 103.03086 & 97058.302 \\
\hline 3 & 103.01548 & 103.04243 & 97072.789 & 97047.401 & 8 & 103.03103 & 97058.141 \\
\hline 4 & 103.01179 & 103.04643 & 97076.267 & 97043.634 & -2 & 103.03126 & 97057.927 \\
\hline 5 & 103.00809 & 103.05048 & 97079.754 & 97039.820 & 17 & 103.03154 & 97057.658 \\
\hline 6 & 103.00446 & 103.05454 & 97083.175 & 97035.997 & 8 & 103.03188 & 97057.336 \\
\hline 7 & 103.00088 & 103.05865 & 97086.549 & 97032.127 & 1 & 103.03228 & 97056.959 \\
\hline 8 & 102.99731 & 103.06277 & 97089.914 & 97028.248 & -6 & 103.03275 & 97056.518 \\
\hline 9 & 102.99379 & 103.06694 & 97093.233 & 97024.322 & 21 & 103.03328 & 97056.019 \\
\hline 10 & 102.99036 & 103.07112 & 97096.466 & 97020.387 & 41 & 103.03382 & 97055.511 \\
\hline 11 & 102.98695 & 103.07542 & 97099.677 & 97016.340 & 3 & 103.03440 & 97054.964 \\
\hline 12 & 102.98357 & 103.07979 & 97102.866 & 97012.227 & 78 & 103.03522 & 97054.194 \\
\hline 13 & 102.98017 & 103.08406 & 97106.070 & 97008.209 & & 103.03595 & 97053.502 \\
\hline 14 & 102.97550 & 103.08859 & 97110.479 & 97003.946 & & 103.03676 & 97052.741 \\
\hline & & & & & & 103.03759 & \\
\hline
\end{tabular}

Table A.26. Measured transition wavelengths and wavenumbers of the $E^{1} \Pi\left(v^{\prime}=2\right)-X^{1} \Sigma^{+}\left(v^{\prime \prime}=0\right)$ band for ${ }^{13} \mathrm{C}^{16} \mathrm{O},{ }^{13} \mathrm{C}^{17} \mathrm{O}$, and ${ }^{13} \mathrm{C}^{18} \mathrm{O}$ (same column description as for Table A.19).

\begin{tabular}{|c|c|c|c|c|c|c|c|}
\hline \multirow{2}{*}{\multicolumn{8}{|c|}{$E^{1} \Pi\left(v^{\prime}=2\right)-X^{1} \Sigma^{+}\left(v^{\prime \prime}=0\right)$}} \\
\hline & & & & & & & \\
\hline$J$ & $\begin{array}{l}R_{m s}(\mathrm{~nm}) \\
\end{array}$ & $P_{m s}(\mathrm{~nm})$ & $R_{m s}\left(\mathrm{~cm}^{-1}\right)$ & $P_{m s}\left(\mathrm{~cm}^{-1}\right)$ & $\begin{array}{ll}\delta_{P} \\
\end{array}$ & $Q_{m s}(\mathrm{~nm})$ & $Q_{m s}\left(\mathrm{~cm}^{-1}\right)$ \\
\hline 0 & 103.01876 & & 97069.703 & & 22 & & \\
\hline 1 & 103.01491 & & 97073.325 & & 13 & 103.02267 & 97066.018 \\
\hline 2 & 103.01111 & 103.03051 & 97076.906 & 97058.631 & 3 & 103.02278 & 97065.907 \\
\hline 3 & 103.00738 & 103.03445 & 97080.427 & 97054.919 & -6 & 103.02296 & 97065.740 \\
\hline 4 & 103.00364 & 103.03843 & 97083.951 & 97051.171 & 10 & 103.02320 & 97065.518 \\
\hline 5 & 102.99998 & 103.04248 & 97087.394 & 97047.358 & -1 & 103.02349 & 97065.241 \\
\hline 6 & 102.99633 & 103.04657 & 97090.837 & 97043.502 & -3 & 103.02384 & 97064.911 \\
\hline 7 & 102.99272 & 103.05069 & 97094.242 & 97039.620 & 6 & 103.02420 & 97064.573 \\
\hline 8 & 102.98915 & 103.05483 & 97097.605 & 97035.724 & 4 & 103.02468 & 97064.124 \\
\hline 9 & 102.98565 & 103.05903 & 97100.908 & 97031.767 & -6 & 103.02532 & 97063.518 \\
\hline 10 & 102.98217 & 103.06325 & 97104.192 & 97027.792 & -4 & 103.02581 & 97063.059 \\
\hline 11 & 102.97870 & 103.06752 & 97107.459 & 97023.776 & 10 & 103.02644 & 97062.463 \\
\hline 12 & 102.97533 & 103.07183 & 97110.642 & 97019.722 & 3 & 103.02715 & 97061.790 \\
\hline 13 & 102.97195 & 103.07618 & 97113.828 & 97015.629 & -1 & 103.02791 & 97061.079 \\
\hline 14 & 102.96865 & 103.08057 & 97116.936 & 97011.496 & -1 & 103.02872 & 97060.313 \\
\hline 15 & 102.96538 & 103.08496 & 97120.023 & 97007.364 & 11 & 103.02965 & 97059.438 \\
\hline 16 & 102.96217 & 103.08943 & 97123.050 & 97003.152 & 1 & 103.03058 & 97058.559 \\
\hline 17 & 102.95903 & 103.09396 & 97126.017 & 96998.896 & -49 & 103.03164 & 97057.568 \\
\hline 18 & 102.95588 & 103.09849 & 97128.985 & 96994.630 & 21 & 103.03275 & 97056.522 \\
\hline 19 & 102.95282 & 103.10300 & 97131.871 & 96990.389 & * & 103.03389 & 97055.441 \\
\hline 20 & 102.94978 & 103.10776 & 97134.739 & 96985.913 & * & 103.03508 & 97054.320 \\
\hline 21 & 102.94691 & 103.11073 & 97137.450 & 96983.118 & * & 103.03646 & 97053.028 \\
\hline 22 & 102.94389 & 103.11393 & 97140.297 & 96980.108 & & 103.03784 & 97051.724 \\
\hline 23 & 102.94110 & 103.11717 & 97142.928 & 96977.056 & & 103.03936 & 97050.297 \\
\hline \multirow[t]{2}{*}{24} & 102.93836 & & 97145.520 & & & 103.04087 & 97048.873 \\
\hline & & & & ${ }^{15} \mathbf{C}^{17} \mathbf{O}$ & & & \\
\hline 0 & 103.07389 & & 97017.780 & & $*$ & & \\
\hline 1 & 103.06991 & & 97021.526 & & * & 103.07767 & 97014.220 \\
\hline 2 & & 103.08426 & & 97008.020 & & & \\
\hline 3 & & 103.08762 & & 97004.859 & & & \\
\hline 4 & & 103.09098 & & 97001.697 & & & \\
\hline 5 & & 103.09442 & & 96998.460 & & & \\
\hline 6 & & 103.09783 & & 96995.252 & & & \\
\hline 7 & & 103.10130 & & 96991.987 & & & \\
\hline 8 & & 103.10479 & & 96988.704 & & & \\
\hline 9 & & 103.10830 & & 96985.403 & & & \\
\hline 10 & & 103.11187 & & 96982.045 & & & \\
\hline 11 & & 103.11544 & & 96978.687 & & & \\
\hline \multirow{2}{*}{12} & & 103.11906 & & 96975.283 & & & \\
\hline & & & & ${ }^{15} \mathrm{C}^{18} \mathrm{O}$ & & & \\
\hline 0 & 103.12332 & & 96971.277 & & 12 & & \\
\hline 1 & 103.11968 & & 96974.703 & & 2 & 103.12705 & 96967.768 \\
\hline 2 & 103.11603 & 103.13449 & 96978.129 & 96960.774 & 20 & 103.12715 & 96967.673 \\
\hline 3 & 103.11245 & 103.13825 & 96981.499 & 96957.237 & 10 & 103.12730 & 96967.530 \\
\hline 4 & 103.10887 & 103.14208 & 96984.868 & 96953.642 & 1 & 103.12751 & 96967.341 \\
\hline 5 & 103.10535 & 103.14590 & 96988.182 & 96950.047 & 21 & 103.12776 & 96967.104 \\
\hline 6 & 103.10188 & 103.14973 & 96991.440 & 96946.453 & -15 & 103.12806 & 96966.822 \\
\hline 7 & 103.09842 & 103.15367 & 96994.697 & 96942.746 & -22 & 103.12841 & 96966.495 \\
\hline 8 & 103.09496 & 103.15755 & 96997.955 & 96939.096 & 0 & 103.12880 & 96966.123 \\
\hline 9 & 103.09156 & 103.16150 & 97001.156 & 96935.389 & -4 & 103.12923 & 96965.717 \\
\hline 10 & 103.08821 & 103.16550 & 97004.302 & 96931.626 & -8 & 103.12977 & 96965.212 \\
\hline 11 & 103.08487 & 103.16951 & 97007.446 & 96927.863 & -19 & 103.13031 & 96964.706 \\
\hline 12 & 103.08153 & 103.17357 & 97010.591 & 96924.044 & 14 & 103.13091 & 96964.145 \\
\hline 13 & 103.07831 & 103.17762 & 97013.625 & 96920.243 & -8 & 103.13156 & 96963.531 \\
\hline 14 & 103.07506 & 103.18176 & 97016.679 & 96916.358 & -40 & 103.13228 & 96962.853 \\
\hline 15 & 103.07188 & 103.18589 & 97019.671 & 96912.473 & -56 & 103.13304 & 96962.141 \\
\hline 16 & 103.06875 & 103.18998 & 97022.617 & 96908.632 & -30 & 103.13384 & 96961.385 \\
\hline 17 & 103.06568 & 103.19417 & 97025.511 & 96904.702 & -30 & 103.13468 & 96960.592 \\
\hline 18 & 103.06260 & 103.19849 & 97028.409 & 96900.645 & -9 & 103.13568 & 96959.659 \\
\hline 19 & 103.05955 & 103.20280 & 97031.282 & 96896.593 & 13 & 103.13669 & 96958.706 \\
\hline 20 & 103.05660 & 103.20716 & 97034.059 & 96892.506 & 5 & 103.13770 & 96957.754 \\
\hline 21 & 103.05368 & 103.21153 & 97036.804 & 96888.399 & 56 & 103.13883 & 96956.691 \\
\hline 22 & 103.05083 & 103.21594 & 97039.488 & 96884.260 & -23 & & \\
\hline 23 & 103.04801 & 103.22051 & 97042.147 & 96879.976 & 68 & & \\
\hline 24 & 103.04519 & 103.22485 & 97044.804 & 96875.897 & -5 & & \\
\hline 25 & 103.04237 & 103.22958 & 97047.462 & 96871.456 & & & \\
\hline 26 & 103.03987 & 103.23396 & 97049.812 & 96867.351 & & & \\
\hline & & & & & & & \\
\hline
\end{tabular}


J. L. Lemaire et al.: Atlas of new and revised high-resolution spectroscopy of six CO isotopologues in the 101-115 nm range

Table A.27. Measured transition wavelengths and wavenumbers of the $E^{1} \Pi\left(v^{\prime}=3\right)-X^{1} \Sigma^{+}\left(v^{\prime \prime}=0\right)$ band for ${ }^{12} \mathrm{C}^{16} \mathrm{O},{ }^{12} \mathrm{C}^{17} \mathrm{O}$, and ${ }^{12} \mathrm{C}^{18} \mathrm{O}$ (same column description as for Table A.19).

\begin{tabular}{|c|c|c|c|c|c|c|c|}
\hline \multicolumn{8}{|c|}{$E^{1} \Pi\left(v^{\prime}=3\right)-X^{1} \Sigma^{+}\left(v^{\prime \prime}=0\right)$} \\
\hline & \multicolumn{7}{|c|}{${ }^{12} \mathbf{C}^{16} \mathbf{O}$} \\
\hline$J$ & $R_{m s}(\mathrm{~nm})$ & $P_{m s}(\mathrm{~nm})$ & $R_{m s}\left(\mathrm{~cm}^{-1}\right)$ & $P_{m s}\left(\mathrm{~cm}^{-1}\right)$ & $\delta_{P}$ & $Q_{m s}(\mathrm{~nm})$ & $Q_{m s}\left(\mathrm{~cm}^{-1}\right)$ \\
\hline 0 & 101.08858 & & 98923.141 & & -59 & & \\
\hline 1 & 101.08548 & & 98926.174 & & -34 & 101.09248 & 98919.326 \\
\hline 2 & 101.08256 & 101.10025 & 98929.039 & 98911.724 & 53 & 101.09335 & 98918.475 \\
\hline 3 & 101.08020 & 101.10506 & 98931.341 & 98907.018 & 26 & 101.09455 & 98917.301 \\
\hline 4 & 101.07825 & 101.11017 & 98933.250 & 98902.019 & 3 & 101.09616 & 98915.725 \\
\hline 5 & 101.07665 & 101.11562 & 98934.815 & 98896.689 & 33 & 101.09822 & 98913.710 \\
\hline 6 & 101.07544 & 101.12148 & 98936.003 & 98890.958 & 41 & 101.10069 & 98911.293 \\
\hline 7 & 101.07469 & 101.12780 & 98936.739 & 98884.777 & 49 & 101.10362 & 98908.427 \\
\hline 8 & 101.07459 & 101.13446 & 98936.838 & 98878.266 & -60 & 101.10695 & 98905.169 \\
\hline 9 & 101.07475 & 101.14158 & 98936.679 & 98871.305 & -48 & 101.11074 & 98901.462 \\
\hline 10 & 101.07544 & 101.14911 & 98936.003 & 98863.945 & -94 & 101.11499 & 98897.305 \\
\hline 11 & 101.07630 & 101.15715 & 98935.160 & 98856.087 & -22 & 101.11970 & 98892.698 \\
\hline 12 & 101.07785 & 101.16560 & 98933.644 & 98847.830 & -36 & 101.12492 & 98887.594 \\
\hline 13 & 101.07978 & 101.17446 & 98931.754 & 98839.173 & 47 & 101.13067 & 98881.971 \\
\hline 14 & 101.08211 & 101.18383 & 98929.473 & 98830.021 & * & 101.13687 & 98875.909 \\
\hline 15 & 101.08552 & 101.19378 & 98926.134 & 98820.303 & 0 & 101.14365 & 98869.281 \\
\hline 16 & 101.08923 & 101.20415 & 98922.503 & 98810.177 & 31 & 101.15095 & 98862.146 \\
\hline 17 & 101.09327 & 101.21512 & 98918.550 & 98799.468 & $*$ & 101.15888 & 98854.396 \\
\hline 18 & 101.09779 & 101.22674 & 98914.131 & 98788.127 & * & 101.16739 & 98846.081 \\
\hline 19 & 101.10357 & 101.23877 & 98908.472 & 98776.388 & & 101.17658 & 98837.102 \\
\hline 20 & 101.10950 & 101.25154 & 98902.677 & 98763.930 & & 101.18636 & 98827.549 \\
\hline 21 & 101.11626 & & 98896.065 & & & 101.19684 & 98817.315 \\
\hline 22 & & & & & & 101.20805 & 98806.370 \\
\hline 23 & & & & & & 101.22003 & 98794.674 \\
\hline 24 & & & & & & 101.23283 & 98782.180 \\
\hline \multirow[t]{2}{*}{25} & & & & & & 101.24633 & 98769.012 \\
\hline & \multicolumn{7}{|c|}{${ }^{{ }^{12}} \mathbf{C}^{1 / 2} \mathbf{O}$} \\
\hline 0 & 101.13600 & & 98876.756 & & 2 & & \\
\hline 1 & 101.13290 & & 98879.787 & & -16 & 101.13989 & 98872.957 \\
\hline 2 & 101.13009 & 101.14751 & 98882.538 & 98865.508 & -8 & 101.14060 & 98872.263 \\
\hline 3 & 101.12768 & 101.15204 & 98884.898 & 98861.081 & -20 & 101.14169 & 98871.197 \\
\hline 4 & 101.12550 & 101.15691 & 98887.031 & 98856.321 & -17 & 101.14313 & 98869.790 \\
\hline 5 & 101.12383 & 101.16214 & 98888.661 & 98851.211 & 17 & 101.14497 & 98867.991 \\
\hline 6 & 101.12245 & 101.16763 & 98890.008 & 98845.846 & -25 & 101.14724 & 98865.772 \\
\hline 7 & 101.12142 & 101.17370 & 98891.019 & 98839.916 & -30 & 101.14978 & 98863.290 \\
\hline 8 & 101.12078 & 101.17990 & 98891.639 & 98833.859 & 83 & 101.15275 & 98860.387 \\
\hline 9 & 101.12077 & 101.18652 & 98891.648 & 98827.393 & & 101.15692 & 98856.312 \\
\hline 10 & 101.12142 & 101.19378 & 98891.019 & 98820.303 & & 101.16215 & 98851.201 \\
\hline 11 & 101.12294 & & 98889.535 & & & 101.16773 & 98845.749 \\
\hline 12 & 101.12494 & & 98887.576 & & & 101.17359 & 98840.023 \\
\hline 13 & 101.12675 & & 98885.803 & & & 101.17997 & 98833.791 \\
\hline 14 & 101.12915 & & 98883.455 & & & 101.18654 & 98827.374 \\
\hline 15 & 101.13187 & & 98880.802 & & & 101.19376 & 98820.323 \\
\hline \multirow[t]{2}{*}{16} & 101.13448 & & 98878.242 & & & 101.20130 & 98812.960 \\
\hline & \multicolumn{7}{|c|}{${ }^{12} \mathbf{C}^{18} \mathbf{O}$} \\
\hline 0 & 101.18111 & & 98832.677 & & 1 & & \\
\hline 1 & 101.17796 & & 98835.754 & & -81 & 101.18489 & 98828.985 \\
\hline 2 & 101.17514 & 101.19236 & 98838.509 & 98821.690 & 3 & 101.18551 & 98828.380 \\
\hline 3 & 101.17264 & 101.19654 & 98840.951 & 98817.608 & 4 & 101.18649 & 98827.423 \\
\hline 4 & 101.17044 & 101.20139 & 98843.101 & 98812.872 & 0 & 101.18782 & 98826.124 \\
\hline 5 & 101.16857 & 101.20639 & 98844.928 & 98807.990 & -8 & 101.18946 & 98824.522 \\
\hline 6 & 101.16702 & 101.21168 & 98846.442 & 98802.826 & 24 & 101.19144 & 98822.588 \\
\hline 7 & 101.16582 & 101.21729 & 98847.615 & 98797.350 & 2 & 101.19379 & 98820.293 \\
\hline 8 & 101.16497 & 101.22330 & 98848.445 & 98791.484 & -4 & 101.19656 & 98817.588 \\
\hline 9 & 101.16445 & 101.22955 & 98848.953 & 98785.384 & 14 & 101.19953 & 98814.688 \\
\hline 10 & 101.16440 & 101.23618 & 98849.002 & 98778.915 & -25 & 101.20292 & 98811.378 \\
\hline 11 & 101.16463 & 101.24319 & 98848.777 & 98772.075 & -73 & 101.20678 & 98807.610 \\
\hline 12 & 101.16505 & 101.25055 & 98848.367 & 98764.896 & & 101.21085 & 98803.636 \\
\hline 13 & 101.16650 & 101.25817 & 98846.950 & 98757.462 & & 101.21547 & 98799.126 \\
\hline 14 & 101.16820 & & 98845.289 & & & 101.22059 & 98794.127 \\
\hline 15 & 101.16989 & & 98843.638 & & & & \\
\hline 16 & 101.17207 & & 98841.508 & & & & \\
\hline 17 & 101.17424 & & 98839.388 & & & & \\
\hline 18 & 101.17702 & & 98836.673 & & & & \\
\hline 19 & 101.17967 & & 98834.084 & & & & \\
\hline 20 & 101.18946 & & 98824.522 & & & & \\
\hline 21 & 101.18255 & & 98831.271 & & & & \\
\hline
\end{tabular}

Table A.28. Measured transition wavelengths and wavenumbers of the $E^{1} \Pi\left(v^{\prime}=3\right)-X^{1} \Sigma^{+}\left(v^{\prime \prime}=0\right)$ band for ${ }^{13} \mathrm{C}^{16} \mathrm{O},{ }^{13} \mathrm{C}^{17} \mathrm{O}$, and ${ }^{13} \mathrm{C}^{18} \mathrm{O}$ (same column description as for Table A.19).

\begin{tabular}{|c|c|c|c|c|c|c|c|}
\hline \multicolumn{8}{|c|}{$E^{1} \Pi\left(v^{\prime}=3\right)-X^{1} \Sigma^{+}\left(v^{\prime \prime}=0\right)$} \\
\hline & & & & & & & \\
\hline$J$ & $R_{m s}(\mathrm{~nm})$ & $P_{m s}(\mathrm{~nm})$ & $R_{m s}\left(\mathrm{~cm}^{-1}\right)$ & $P_{m s}\left(\mathrm{~cm}^{-1}\right)$ & $\delta_{P}$ & $Q_{m s}(\mathrm{~nm})$ & $Q_{m s}\left(\mathrm{~cm}^{-1}\right)$ \\
\hline 0 & $\begin{array}{l}m s \\
101.17336\end{array}$ & & 98840.250 & & 1 & & \\
\hline 1 & 101.17017 & & 98843.366 & & 13 & 101.17705 & 98836.643 \\
\hline 2 & 101.16738 & 101.18465 & 98846.091 & 98829.220 & -14 & 101.17774 & 98835.969 \\
\hline 3 & 101.16489 & 101.18901 & 98848.525 & 98824.961 & 8 & 101.17884 & 98834.895 \\
\hline 4 & 101.16270 & 101.19369 & 98850.667 & 98820.391 & -13 & 101.18003 & 98833.732 \\
\hline 5 & 101.16080 & 101.19877 & 98852.516 & 98815.430 & 11 & 101.18183 & 98831.974 \\
\hline 6 & 101.15927 & 101.20406 & 98854.014 & 98810.265 & 11 & 101.18372 & 98830.128 \\
\hline 7 & 101.15821 & 101.20974 & 98855.048 & 98804.720 & -30 & 101.18621 & 98827.696 \\
\hline 8 & 101.15725 & 101.21573 & 98855.992 & 98798.872 & 31 & 101.18885 & 98825.118 \\
\hline 9 & 101.15683 & 101.22211 & 98856.401 & 98792.645 & 16 & 101.19200 & 98822.041 \\
\hline 10 & 101.15720 & 101.22879 & 98856.039 & 98786.126 & $*$ & 101.19548 & 98818.643 \\
\hline 11 & 101.15795 & 101.23586 & 98855.302 & 98779.227 & $*$ & 101.19927 & 98814.942 \\
\hline 12 & 101.15914 & 101.24320 & 98854.145 & 98772.066 & & 101.20345 & 98810.861 \\
\hline 13 & 101.16051 & 101.24981 & 98852.807 & 98765.617 & & 101.20825 & 98806.174 \\
\hline 14 & 101.16179 & & 98851.554 & & & 101.21322 & 98801.323 \\
\hline 15 & 101.16382 & & 98849.572 & & & 101.21881 & 98795.866 \\
\hline 16 & 101.16664 & & 98846.813 & & & 101.22533 & 98789.503 \\
\hline 17 & 101.16932 & & 98844.197 & & & 101.23138 & 98783.599 \\
\hline 18 & 101.17231 & & 98841.274 & & & 101.24046 & 98774.739 \\
\hline $\begin{array}{l}10 \\
19\end{array}$ & 101.17528 & & 98838.371 & & & & \\
\hline & & & & ${ }^{13} \mathbf{C}^{17} \mathbf{O}$ & & & \\
\hline 0 & & & & & & & \\
\hline 1 & & & & & & 101.13448 & $98878.242^{t}$ \\
\hline & & & & ${ }^{13} \mathbf{C}^{18} \mathbf{O}$ & & & \\
\hline 0 & 101.27772 & & 98738.403 & & 41 & & \\
\hline 1 & 101.27466 & & 98741.379 & & 1 & 101.28135 & 98734.861 \\
\hline 2 & 101.27178 & 101.28855 & 98744.187 & 98727.842 & 18 & 101.28187 & 98734.354 \\
\hline 3 & $\begin{array}{l}101.26925 \\
\end{array}$ & 101.29258 & 98746.658 & 98723.914 & $\begin{array}{l}10 \\
-17\end{array}$ & 101.28267 & 98733.574 \\
\hline 4 & 101.26689 & 101.29690 & 98748.961 & 98719.704 & 1 & 101.28377 & 98732.502 \\
\hline 5 & 101.26482 & 101.30146 & 98750.983 & 98715.260 & -8 & 101.28509 & 98731.215 \\
\hline 6 & 101.26297 & 101.30630 & 98752.780 & 98710.544 & 11 & 101.28665 & 98729.694 \\
\hline 7 & 101.26142 & 101.31137 & 98754.297 & 98705.604 & 8 & 101.28855 & 98727.842 \\
\hline 8 & 101.26015 & 101.31673 & 98755.532 & 98700.382 & 2 & 101.29074 & 98725.708 \\
\hline 9 & 101.25917 & 101.32233 & 98756.487 & 98694.927 & -3 & 101.29322 & 98723.291 \\
\hline 10 & 101.25848 & 101.32821 & 98757.161 & 98689.200 & -11 & $\begin{array}{l}101.29592 \\
\end{array}$ & 98720.659 \\
\hline 11 & 101.25801 & 101.33438 & 98757.615 & 98683.191 & 3 & 101.29898 & 98717.677 \\
\hline 12 & 101.25813 & $\begin{array}{l}101.34083 \\
\end{array}$ & 98757.499 & 98676.910 & $*$ & 101.30244 & 98714.305 \\
\hline 13 & 101.25864 & 101.34755 & 98757.004 & 98670.367 & * & 101.30596 & 98710.875 \\
\hline 14 & 101.25951 & 101.35460 & 98756.160 & 98663.504 & * & 101.31006 & 98706.881 \\
\hline $\begin{array}{l}14 \\
15\end{array}$ & $\begin{array}{l}101.26078 \\
\end{array}$ & $\begin{array}{l}101.36193 \\
\end{array}$ & 98754.922 & 98656.369 & * & 101.31444 & 98702.613 \\
\hline 16 & 101.26242 & 101.36964 & 98753.321 & 98648.866 & $*$ & 101.31912 & 98698.054 \\
\hline 17 & 101.26433 & 101.37766 & 98751.456 & 98641.062 & * & 101.32420 & 98693.106 \\
\hline 18 & 101.26639 & 101.38603 & 98749.448 & 98632.918 & $*$ & 101.32965 & 98687.798 \\
\hline $\begin{array}{l}10 \\
19\end{array}$ & & 101.39478 & & 98624.407 & & 101.33550 & 98682.101 \\
\hline 20 & & 101.40394 & & 98615.498 & & 101.34180 & 98675.966 \\
\hline 21 & & 101.41328 & & 98606.415 & & 101.34846 & 98669.482 \\
\hline $\begin{array}{l}21 \\
22\end{array}$ & & & & & & $\begin{array}{l}101.355610 \\
101\end{array}$ & 98662.521 \\
\hline 23 & & & & & & 101.36318 & 98655.153 \\
\hline 24 & & & & & & 101.37144 & 98647.114 \\
\hline
\end{tabular}

Notes. ${ }^{(t)}$ A small signal for ${ }^{13} \mathrm{C}^{17} \mathrm{O}$ may be indicative of the $Q$-branch position. 
A\&A 614, A114 (2018)
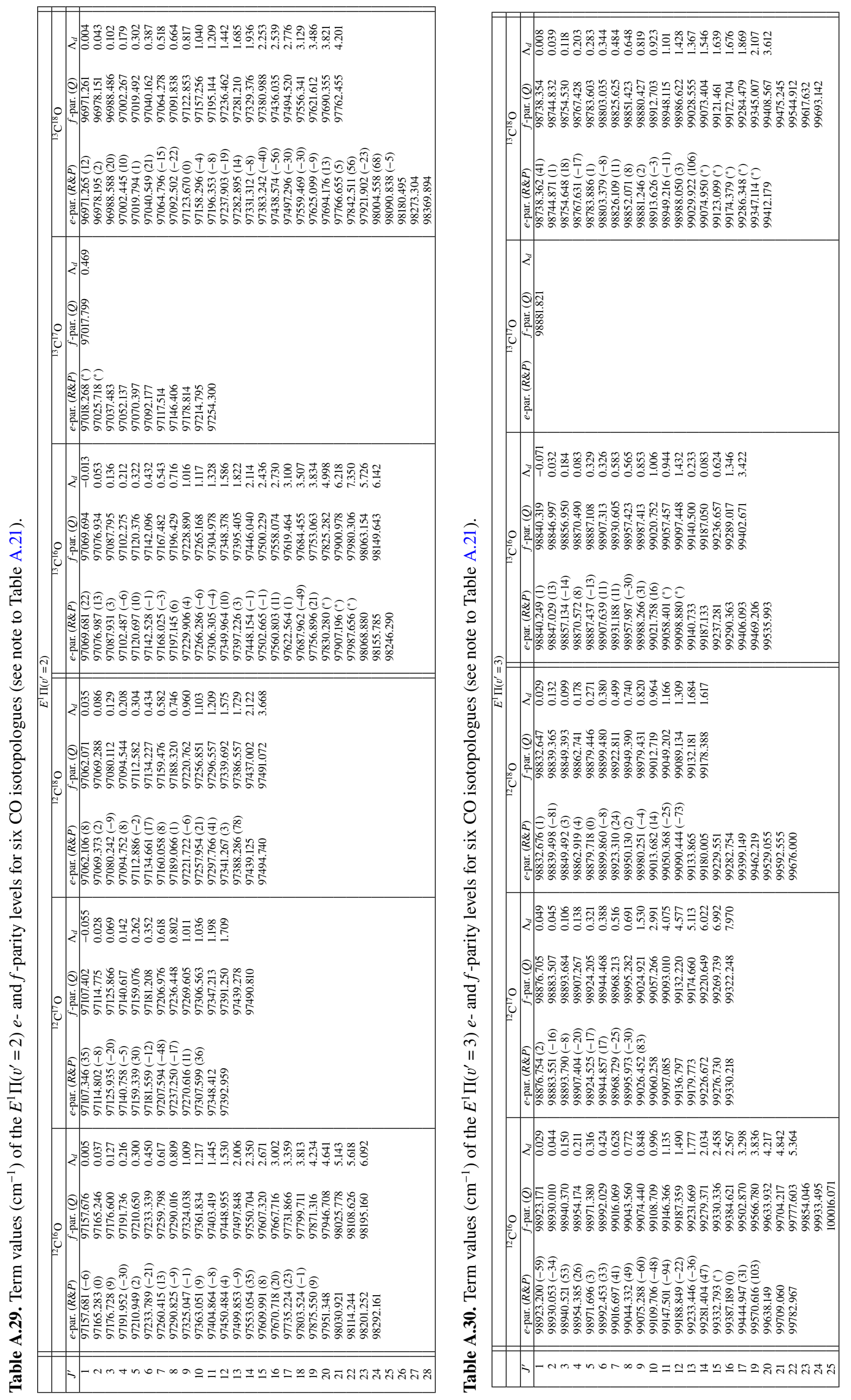

A114, page 58 of 62 
J. L. Lemaire et al.: Atlas of new and revised high-resolution spectroscopy of six CO isotopologues in the 101-115 nm range

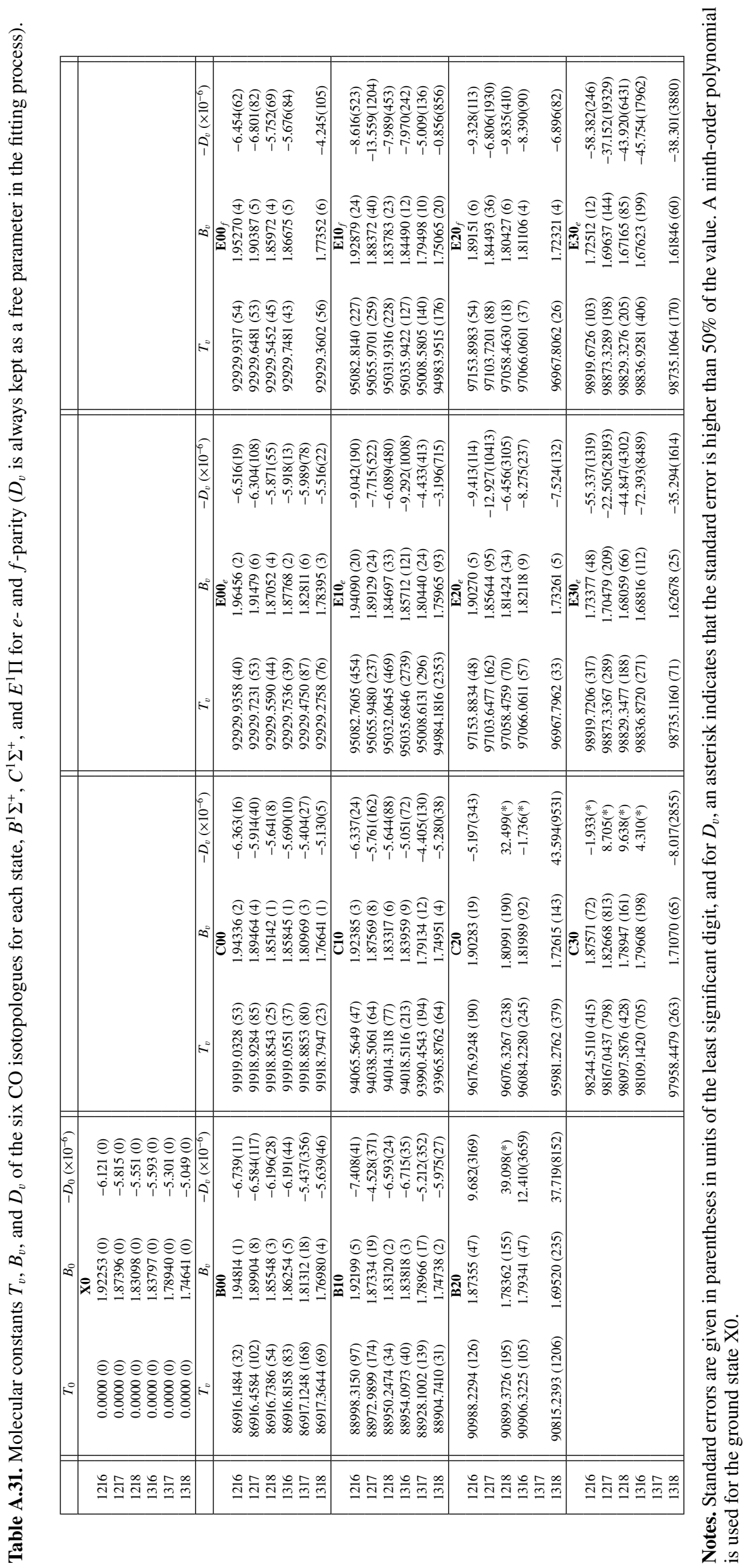


Table A.32. Molecular constants $T_{v}(1), q_{v}$, and $q_{D v}$ of the six CO isotopologues for the $E^{1} \Pi$ state, calculated from the previous table: $T_{v}(J=1)$ is the average of $T_{v}$ for $e$ - and $f$-parity, $q_{v}=B_{e}-B_{f}$, and $q_{D v}=D_{e}-D_{f}$.

\begin{tabular}{|l||ccc||}
\hline Species & $T_{v}(1)$ & $q_{v}$ & $q_{D v}\left(\times 10^{-6}\right)$ \\
\hline & & $\mathbf{E 0 0}$ & \\
1216 & $92929.9338(47)$ & $0.01186(3)$ & $-0.06(4)$ \\
1217 & $92929.6856(53)$ & $0.01092(5)$ & $0.50(10)$ \\
1218 & $92929.5521(44)$ & $0.01080(4)$ & $-0.12(6)$ \\
1316 & $92929.7509(41)$ & $0.01093(3)$ & $-0.24(5)$ \\
1317 & $92929.4750(87)$ & & \\
1318 & $92929.3180(66)$ & $0.01043(4)$ & $-1.27(6)$ \\
\hline & & $\mathbf{E 1 0}$ & \\
1216 & $95082.7873(341)$ & $0.01211(22)$ & $-0.43(36)$ \\
1217 & $95055.9591(248)$ & $0.00757(32)$ & $5.84(86)$ \\
1218 & $95031.9981(348)$ & $0.00914(28)$ & $1.90(47)$ \\
1316 & $95035.8134(1433)$ & $0.01222(67)$ & $-1.32(63)$ \\
1317 & $95008.5968(218)$ & $0.00942(17)$ & $0.58(27)$ \\
1318 & $94984.0666(1264)$ & $0.00900(57)$ & $-2.34(79)$ \\
\hline & & $\mathbf{E 2 0}$ & \\
1216 & $97153.8909(51)$ & $0.01119(6)$ & $-0.09(11)$ \\
1217 & $97103.6839(125)$ & $0.01151(65)$ & $-6.12(617)$ \\
1218 & $97058.4695(44)$ & $0.00997(20)$ & $3.38(176)$ \\
1316 & $97066.0606(47)$ & $0.01012(6)$ & $0.12(16)$ \\
1317 & & & \\
1318 & $96967.8012(29)$ & $0.00940(4)$ & $-0.63(11)$ \\
\hline & & $\mathbf{E 3 0}$ & \\
1216 & $98919.6966(210)$ & $0.00865(30)$ & $3.04(78)$ \\
1217 & $98873.3328(243)$ & $0.00842(177)$ & $14.65(2376)$ \\
1218 & $98829.3377(197)$ & $0.00894(75)$ & $-0.93(537)$ \\
1316 & $98836.9001(338)$ & $0.01193(156)$ & $-26.64(1323)$ \\
1317 & & & \\
1318 & $98735.1112(120)$ & $0.00832(42)$ & $3.01(275)$ \\
\hline
\end{tabular}

Notes. The standard errors, in parentheses, are expressed in units of the least significant digit.
Table A.33. Molecular constants $q_{v}$ and $q_{D v}$ of the six CO isotopologues for the $E^{1} \Pi$ state, obtained from a second-order regression through the data.

\begin{tabular}{|c|c|c|c|}
\hline Species & $N$ & $q_{v}$ & $q_{D v}\left(\times 10^{-6}\right)$ \\
\hline & \multicolumn{3}{|c|}{ E00 } \\
\hline 1216 & 29 & $0.01173(9)$ & $0.10(12)$ \\
\hline 1217 & 26 & $0.01082(21)$ & $0.61(31)$ \\
\hline 1218 & 26 & $0.01084(10)$ & $-0.27(15)$ \\
\hline 1316 & 25 & $0.01107(19)$ & $-0.54(32)$ \\
\hline 1317 & & & \\
\hline 1318 & 26 & $0.01112(35)$ & $-2.41(53)$ \\
\hline & \multicolumn{3}{|c|}{ E10 } \\
\hline 1216 & 21 & $0.01133(29)$ & $0.55(67)$ \\
\hline 1217 & 18 & $0.00848(60)$ & $2.75(183)$ \\
\hline 1218 & 22 & $0.01025(37)$ & $0.23(76)$ \\
\hline 1316 & 22 & $0.01140(208)$ & $-1.13(434)$ \\
\hline 1317 & 22 & $0.00996(15)$ & $-0.21(32)$ \\
\hline 1318 & 22 & $0.00943(36)$ & $0.13(74)$ \\
\hline & \multicolumn{3}{|c|}{ E20 } \\
\hline 1216 & 23 & $0.01108(20)$ & $0.09(38)$ \\
\hline 1217 & 12 & $0.01128(185)$ & $-4.08(1198)$ \\
\hline 1218 & 14 & $0.00967(67)$ & $0.33(328)$ \\
\hline 1316 & 21 & $0.00998(14)$ & $0.51(25)$ \\
\hline 1317 & & & \\
\hline 1318 & 21 & $0.00947(10)$ & $-0.80(23)$ \\
\hline & \multicolumn{3}{|c|}{ E30 } \\
\hline 1216 & 22 & $0.00832(38)$ & $4.11(79)$ \\
\hline 1217 & 8 & $0.00842(183)$ & $14.69(2463)$ \\
\hline 1218 & 11 & $0.00958(104)$ & $-6.38(793)$ \\
\hline 1316 & 13 & $0.00792(96)$ & $5.96(279)$ \\
\hline 1317 & & & \\
\hline 1318 & 12 & $0.00832(76)$ & $3.05(494)$ \\
\hline
\end{tabular}

Notes. The standard errors, in parentheses, are expressed in units of the least significant digit. $N$ is the number of data. 
J. L. Lemaire et al.: Atlas of new and revised high-resolution spectroscopy of six CO isotopologues in the 101-115 nm range
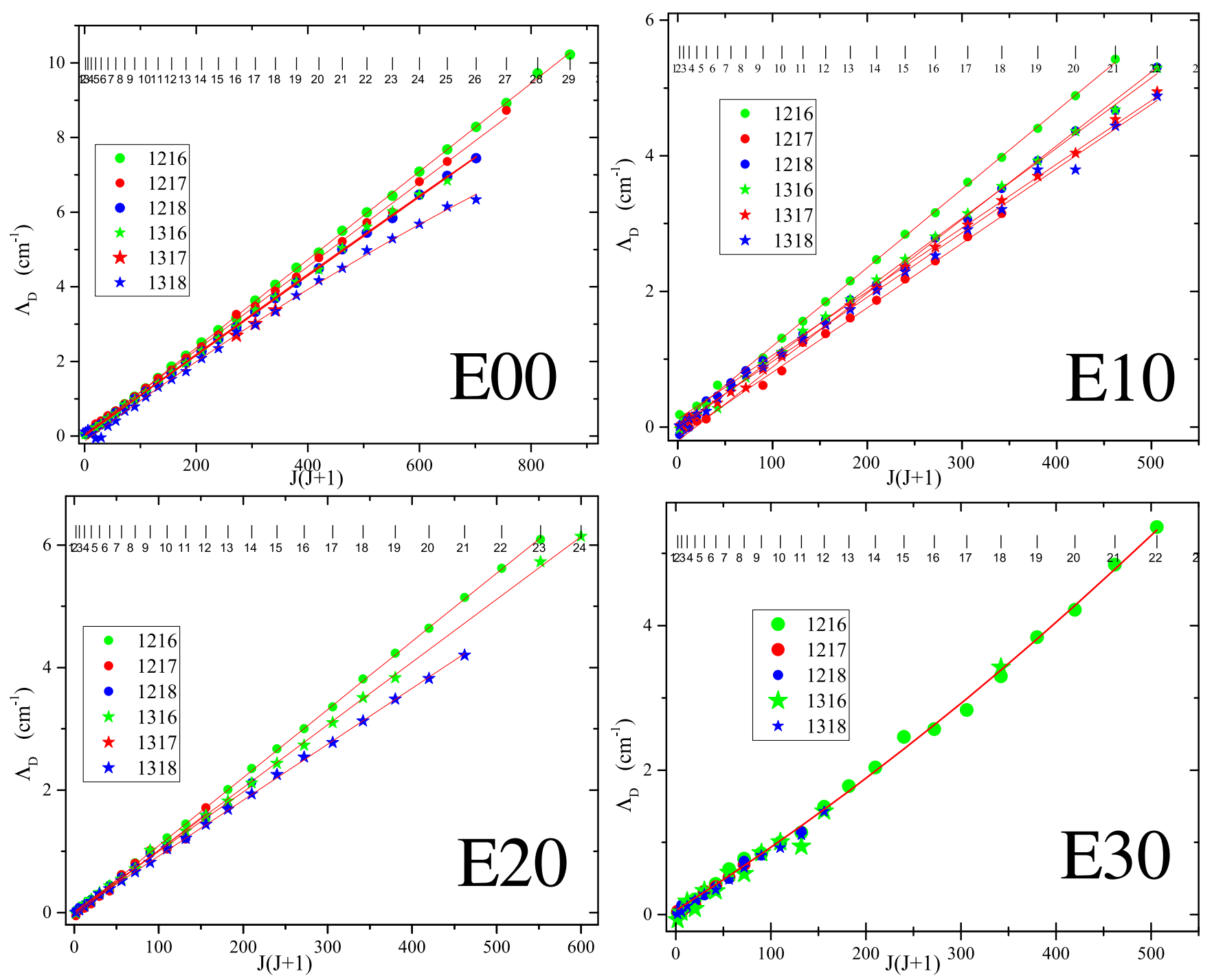

Fig. A.37. $\Lambda$-type doubling (in $\left.\mathrm{cm}^{-1}\right)$ vs. $J \times(J+1)$ of E00, E10, and E20 for the six isotopologues and of E30 for five isotopologues. For E10, we combined our dataset for the $R$ - and $P$-branches and the $Q$-branch of Ubachs et al. (2000). A polynomial fit is also drawn; it is linear in most cases.
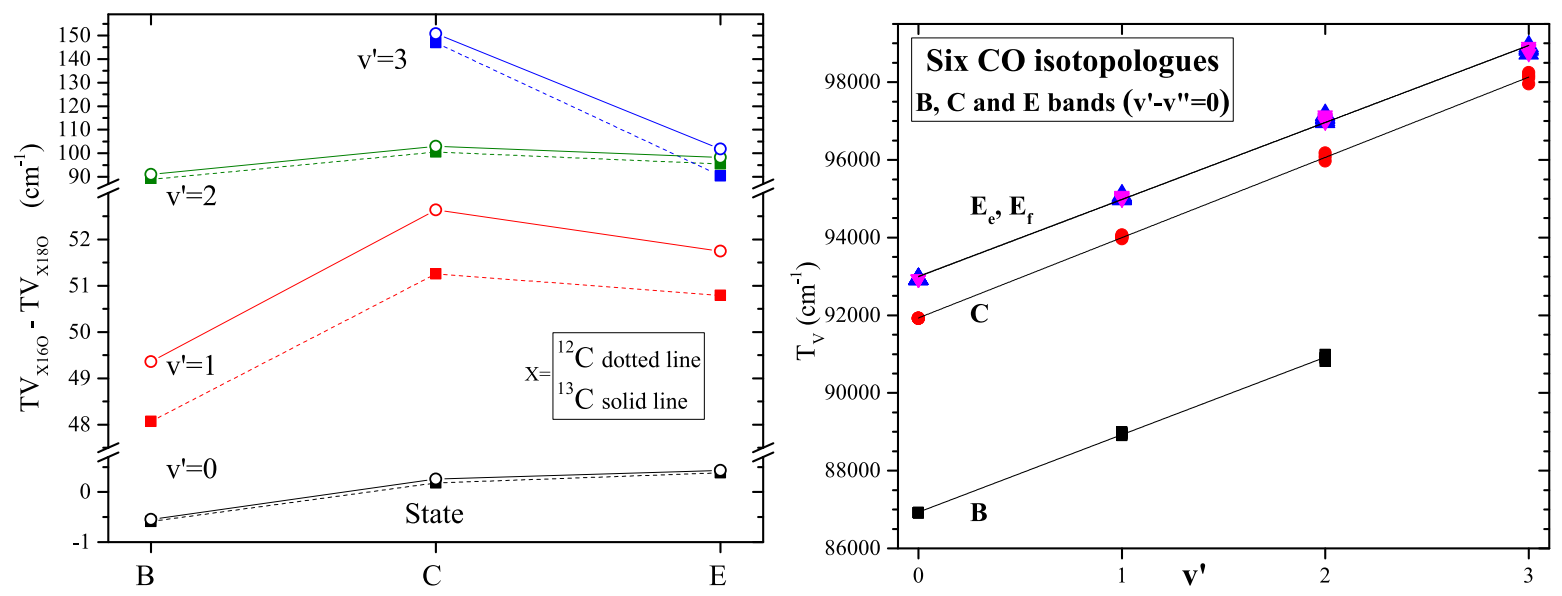

Fig. A.38. Trend comparison for the six CO isotopologues. Left: term value differences between ${ }^{16} \mathrm{O}$ - and ${ }^{18} \mathrm{O}$-bearing isotopologues for ${ }^{12} \mathrm{C}$ and ${ }^{13} \mathrm{C}$ (dotted and solid lines, respectively) versus the $B, C$, and $E$ states. Right: $T_{v}$ versus $v^{\prime}$ for the $B, C$, and $E$ states (each datapoint contains up to six isotopologues). For each state, a linear fit is drawn through all isotopologues. 

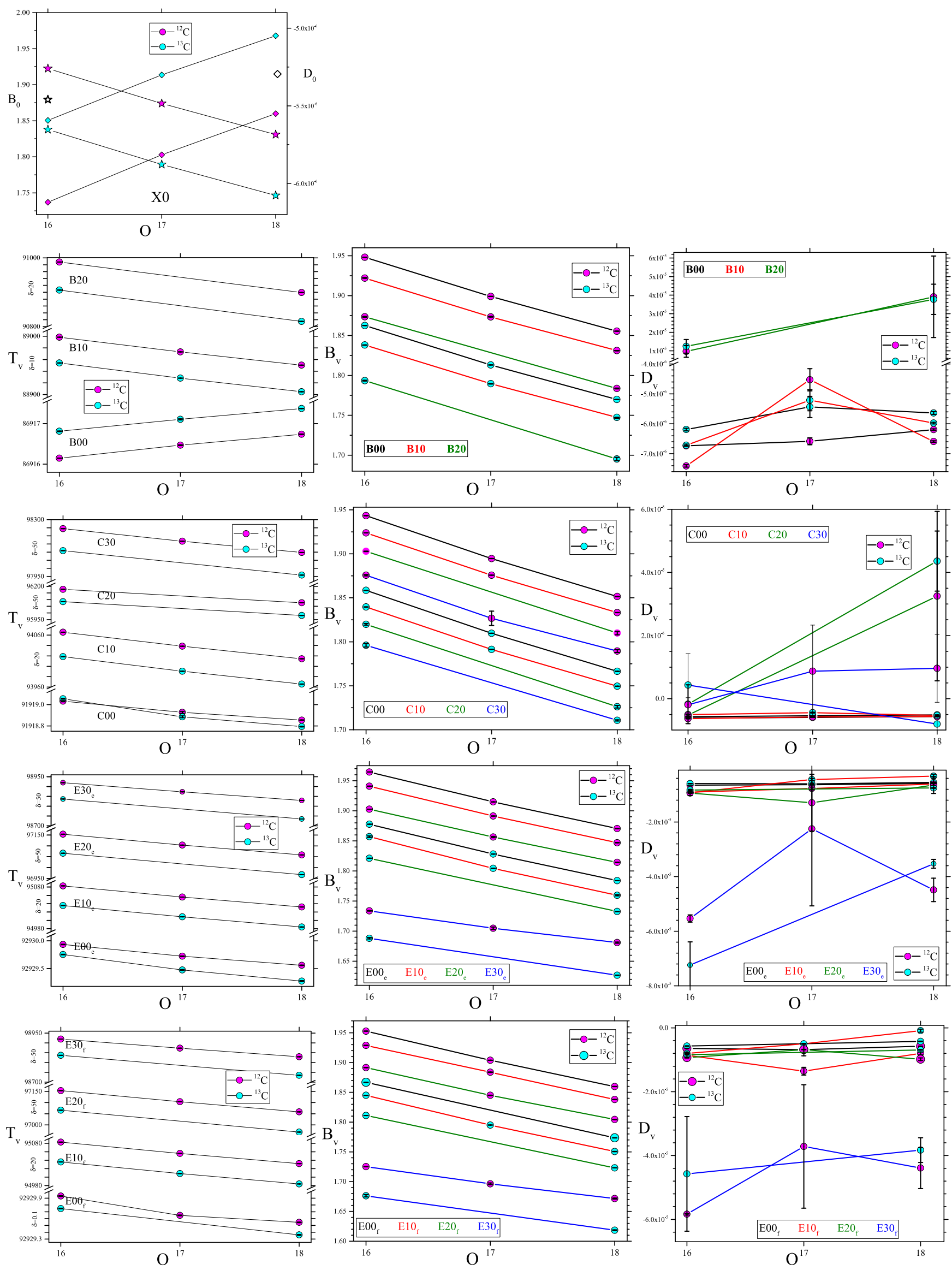

Fig. A.39. Molecular constants for the six CO isotopologues. Top row: $B_{0}$ and $D_{0}$ for $v^{\prime \prime}=0$ of the $X^{1} \Sigma^{+}$ground state $\left(T_{0}=0\right.$ for all). The standard deviation (at $2 \sigma$ ) is shown between two short horizontal bars. For $T_{V}$, all values are in $\mathrm{cm}^{-1}$, with $\delta$ values indicating the local spacing between ticks. 